\title{
ULTRASONIC SPOT WELDING OF SIMILAR AND DISSIMILAR ALLOYS FOR AUTOMOTIVE APPLICATIONS
}

\author{
by \\ ANDREW MACWAN \\ Bachelor of Engineering in Mechanical Engineering \\ Sardar Patel University, Anand, GJ, India, 2003
}
Master of Applied Science in Mechanical Engineering
Ryerson University, Toronto, Canada, 2012

A dissertation

presented to Ryerson University

in partial fulfillment of the

requirements for the degree of

Doctor of Philosophy

in the Program of

Mechanical and Industrial Engineering

Toronto, Ontario, Canada, 2016

(C)Andrew Macwan, 2016 


\section{AUTHOR'S DECLARATION}

I hereby declare that I am the sole author of this dissertation. This is a true copy of the dissertation, including any required final revisions, as accepted by my examiners.

I authorize Ryerson University to lend this dissertation to other institutions or individuals for the purpose of scholarly research.

I further authorize Ryerson University to reproduce this dissertation by photocopying or by other means, in total or in part, at the request of other institutions or individuals for the purpose of scholarly research.

I understand that my dissertation may be made electronically available to the public. 


\title{
ULTRASONIC SPOT WELDING OF SIMILAR AND DISSIMILAR ALLOYS FOR AUTOMOTIVE APPLICATIONS
}

\author{
Andrew Macwan, 2016 \\ Doctor of Philosophy \\ Department of Mechanical and Industrial Engineering \\ Ryerson University
}

\begin{abstract}
Lightweighting has been regarded as a key strategy in the automotive industry to improve fuel efficiency and reduce anthropogenic environment-damaging, climate-changing, and costly emissions. Magnesium ( $\mathrm{Mg}$ ) alloys and Aluminum $(\mathrm{Al})$ alloys are progressively more used in the transportation industries to reduce the weight of vehicles due to their high strength-toweight ratio. Similarly, high strength low alloy (HSLA) steel is widely used to reduce gauge thickness and still maintain the same strength, and thereby reduce vehicle weight as well. A multi-material design of automotive structures and parts inevitably involve similar Mg-to-Mg and dissimilar Mg-to-Al, Al-to-steel, and Mg-to-Cu joints. Ultrasonic spot welding (USW) a solid-state joining technique has recently received significant attention due to its higher efficiency in comparison with conventional fusion welding techniques. In this study, USW was used to generate similar joints of low rare-earth containing ZEK100 Mg alloy sheets and dissimilar ZEK100-to-A15754, Al6111-to-HSLA steel, and Mg-to-Cu joints at different levels of welding energy or welding time. To optimize welding process and identify key factors affecting the weld strength, microstructural evolution, microhardness test, tensile lap shear test,
\end{abstract}


fatigue test, and fracture analysis were performed on similar and dissimilar ultrasonic spot welded (USWed) joints.

Dynamic recrystallization and grain coarsening were observed during $\mathrm{Mg}$-to-Mg similar welding while rapid formation and growth of interface diffusion layer were observed in all dissimilar joints in the present study. It was due to significantly high strain rate $\left(\sim 10^{3} \mathrm{~s}^{-1}\right)$ and high temperature generated via frictional heating during USW. The interface diffusion layer was analyzed by SEM, EDS and XRD phase identification techniques which showed the presence of eutectic structure containing intermetallic compounds (IMCs). As a result, brittleness at the interface increased. The Zn coating in dissimilar USWed Al-to-steel joints eliminated the formation of brittle IMCs of Al-F, which were replaced by relatively ductile AlZn eutectic. The optimum welding energy or welding time during similar and dissimilar USW of lightweight alloys with a sheet thickness of 1-2 mm was in the range of $\sim 500 \mathrm{~J}$ to $2000 \mathrm{~J}$ $(\sim 0.25 \mathrm{~s}$ to $1 \mathrm{~s})$. 


\section{ACKNOWLEDGEMENTS}

First of all, I wish to praise and thank God for all his/her blessings. I would not have made any progress without his/her providence.

Several people should be acknowledged for their part in contributing to the work of this thesis. On the technical side of things, first is my supervisor: Dr. Daolun Chen, to whom I am of course forever grateful for insightful discussions, guidance, support, and encouragement during my studies at Ryerson University. He continuously encouraged and supported me through my research program and enabled me to know many things. I will be eternally grateful to my supervisor for transforming my mechanical engineering background to material science and engineering. Undoubtedly, he is instrumental in shaping my knowledge and my abilities as a researcher.

I would also like to thank the Natural Sciences and Engineering Research Council of Canada (NSERC) for PGS-D scholarship, Government of Ontario for Ontario Graduate Scholarship, AUTO21 Network of Centers of Excellence, Premier's Research Excellence Award (PREA), NSERC-Discovery Accelerator Supplement (DAS) Award, Canada Foundation for Innovation (CFI), and Ryerson Research Chair (RRC) for providing financial support. This investigation involves part of the Canada-China-USA Collaborative Research Project on the Magnesium

Front End Research and Development (MFERD). The authors thank Professor A.A. Luo (Ohio State University), Dr. T. Skszek and Dr. X.P. Niu (Magna International Inc.) and Professor M. Worswick (University of Waterloo) for supplying test materials. 
I am grateful to my committee members for their precious time in evaluating and subsequently raising several valuable points during this work. I would like to extend my thanks to all my friends and colleagues at Ryerson University for helping me and keeping my spirits up. Special thanks are owed to A. Machin, J. Amankrah, Q. Li, and R. Churaman for their strong support in providing easy access to the facilities.

Finally, while I offer everything, I do in life up to God, I dedicate this particular piece of work to four people: Ayana, my beautiful and loving daughter who changed my life, Sweta, who I cannot imagine myself without. She provided me with love, encouragement, and support, without which this wouldn't be possible for me. Moreover, my parents, John and Pushpa Macwan, who are the rocks upon which all of my current and future success has been and will be built. 
To

\section{My loving daughter}

\section{Ayana}




\section{TABLE OF CONTENTS}

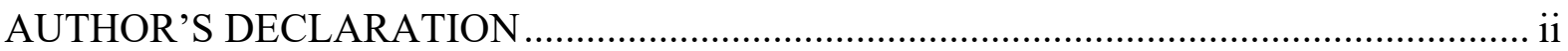

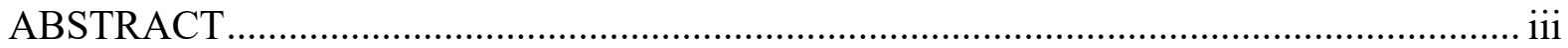

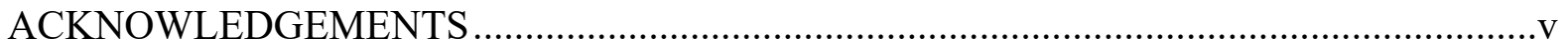

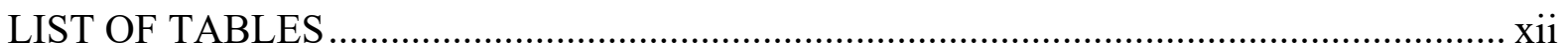

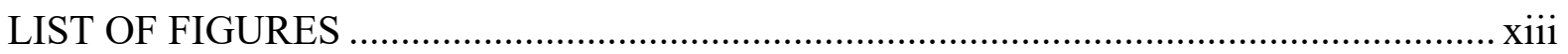

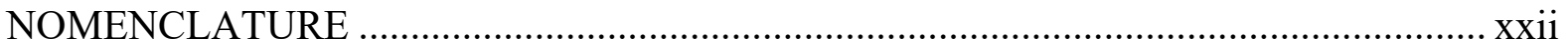

Chapter 1. Introduction and Motivation .........................................................................................1

1.1 Motivation for ultrasonic spot welding ............................................................... 3

1.2 Objective and scope of the dissertation ................................................................. 5

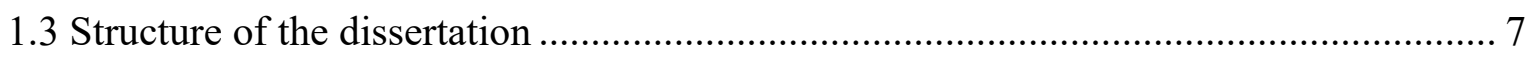

Chapter 2. Literature Review ...............................................................................................8

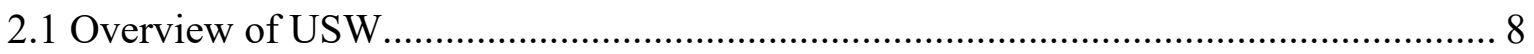

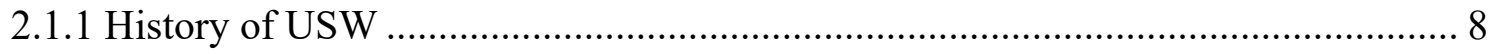

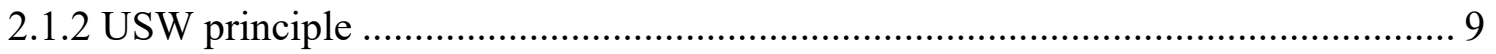

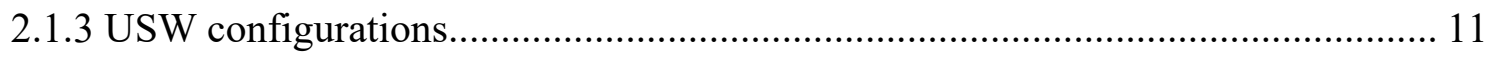

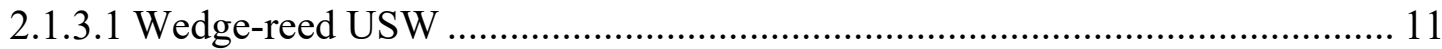

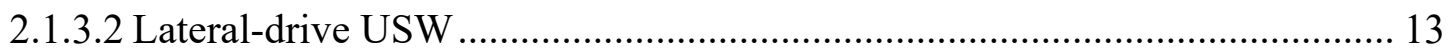

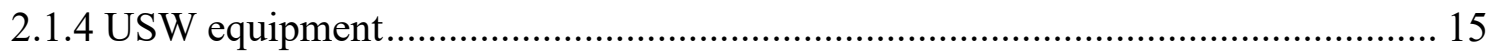

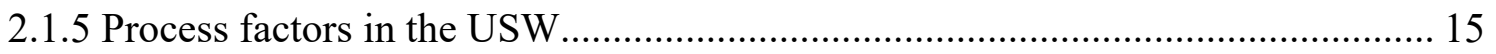

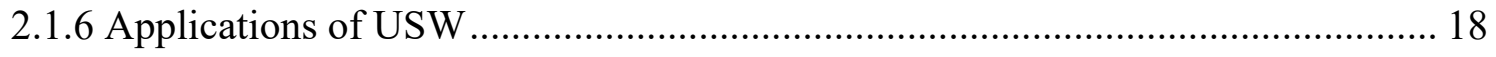

2.1.7 Advantages and disadvantages of USW system ............................................... 20

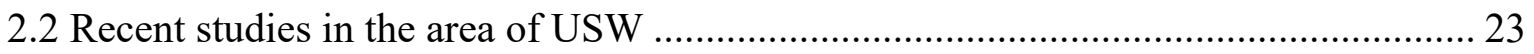




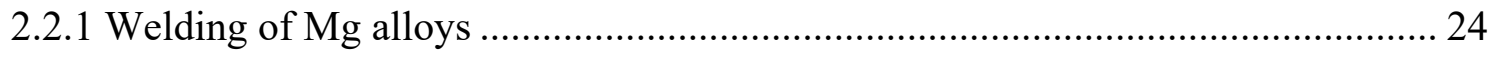

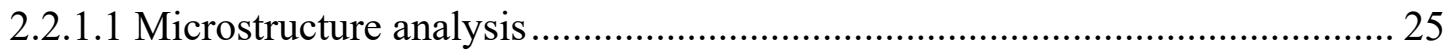

2.2.1.2 Mechanical properties ............................................................................. 30

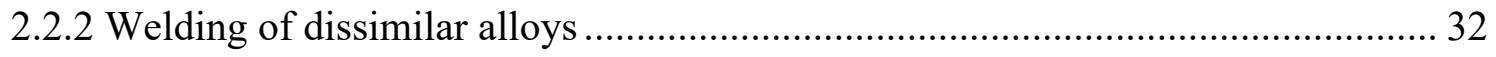

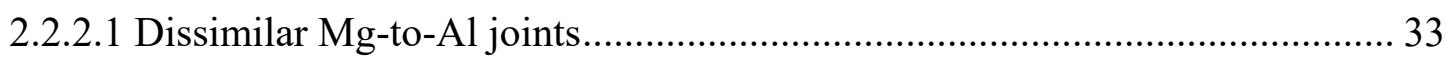

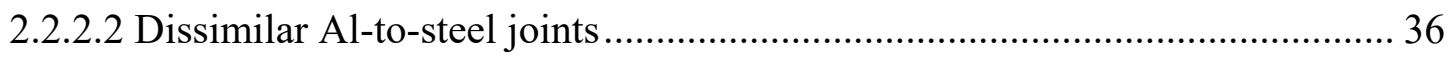

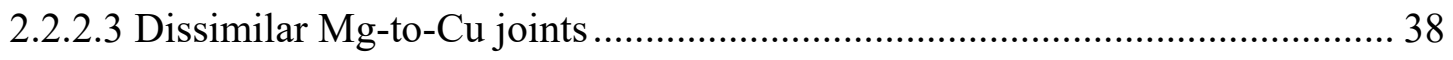

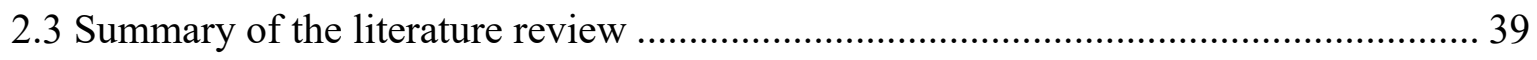

Chapter 3. Materials and Experimental Procedure .....................................................................41

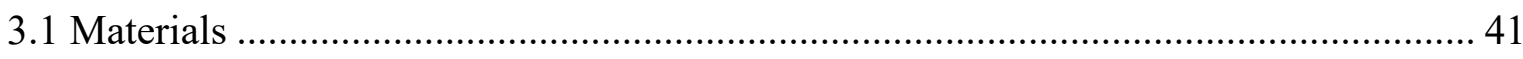

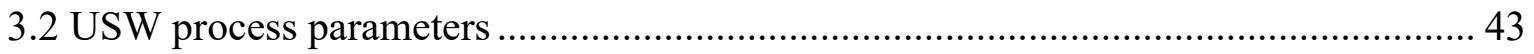

3.3 Temperature profile during USW ....................................................................... 44

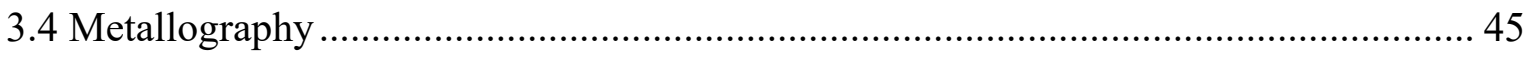

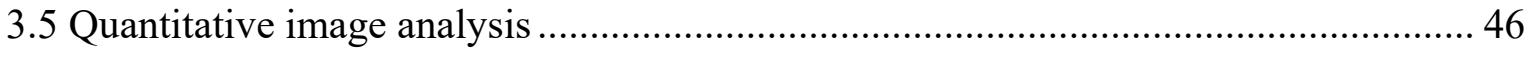

3.6 Phase identification by X-ray diffraction................................................................. 46

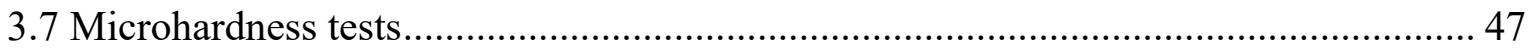

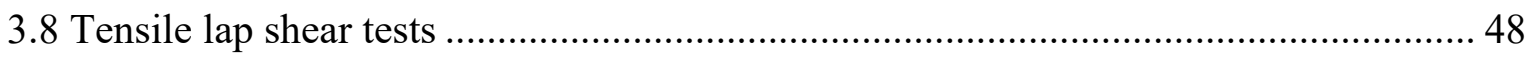

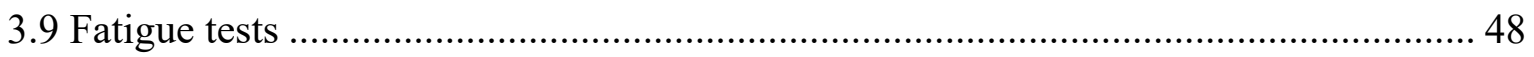

Chapter 4. Ultrasonic Spot Welding of a Rare-Earth Containing ZEK100 Magnesium

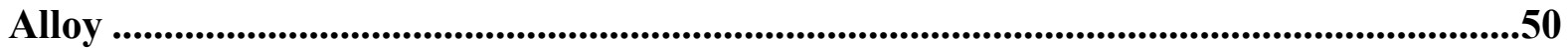

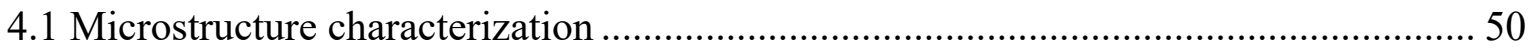

4.2 Zener-Hollomon parameter and grain size …………………….......................... 53

4.2.1 Shear strain rate during USW .......................................................................... 53 


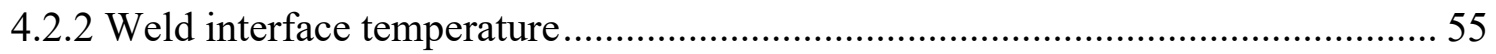

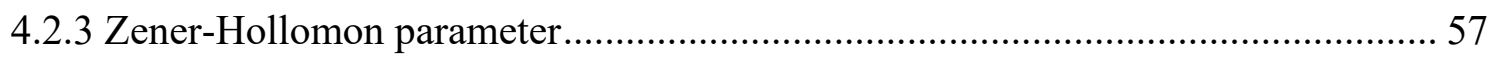

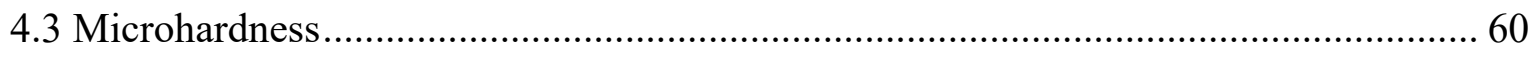

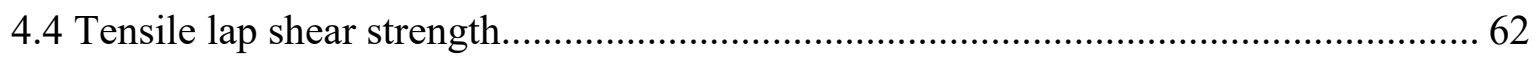

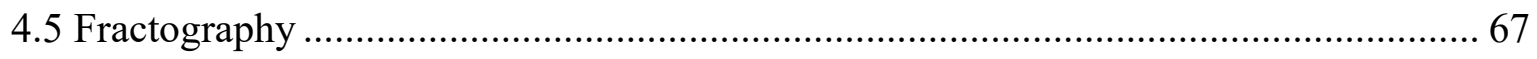

4.6 Effect of test temperature on the tensile lap shear strength ................................... 68

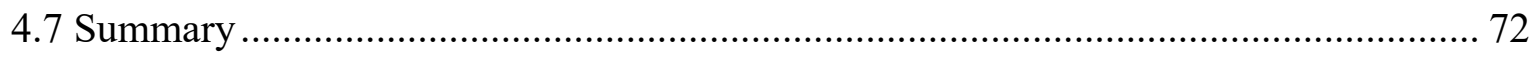

Chapter 5. Ultrasonic Spot Welding of Magnesium Alloy-to-Aluminum Alloys..............75

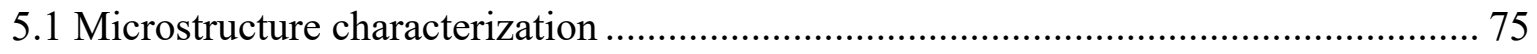

5.1.1 Energy-dispersive X-ray spectroscopy analysis ...................................... 76

5.1.2 X-ray diffraction phase identification........................................................ 77

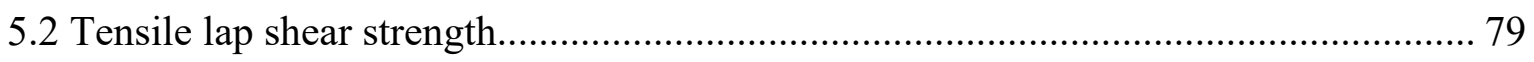

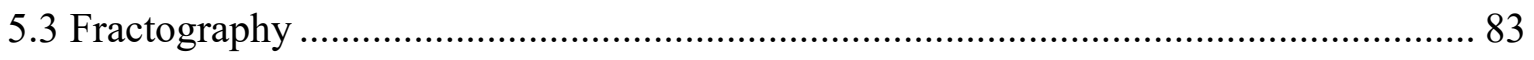

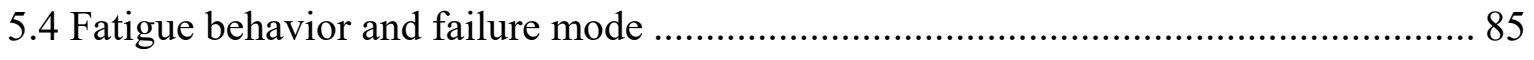

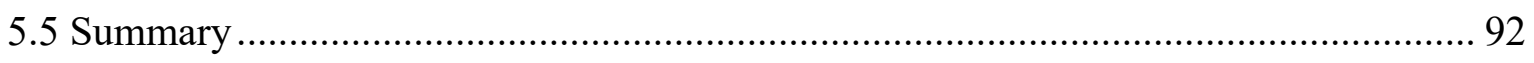

Chapter 6. Ultrasonic Spot Welding of Aluminum Alloy-to-HSLA Steel ........................94

6.1 Microstructure characterization ................................................................... 94

6.1.1 Energy-dispersive X-ray spectroscopy analysis ........................................ 99

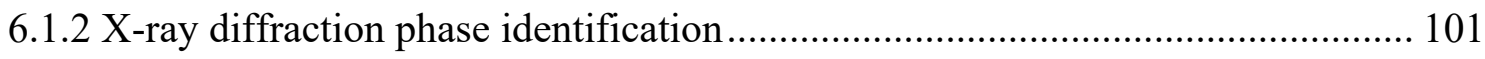

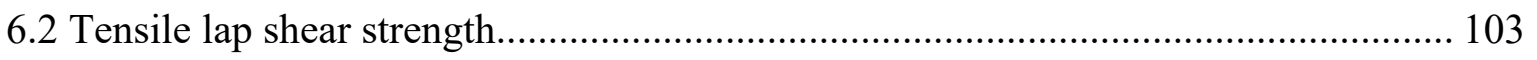

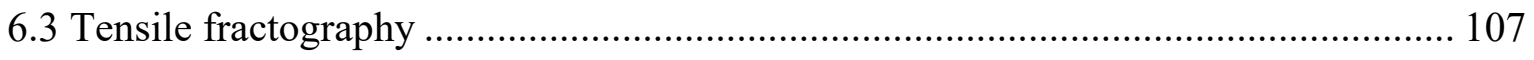

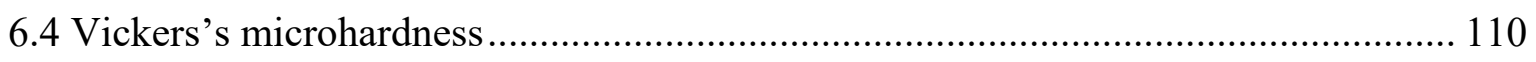

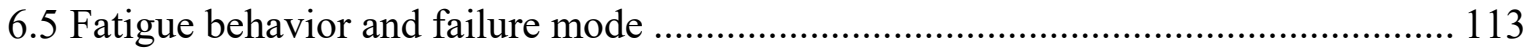


6.6 Fatigue fractography ……………………………....................................... 117

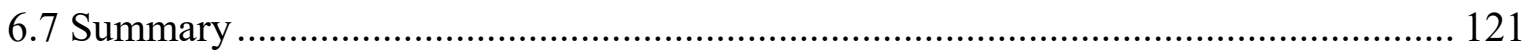

Chapter 7. Ultrasonic Spot Welding of Magnesium Alloy-to-Copper ...............................124

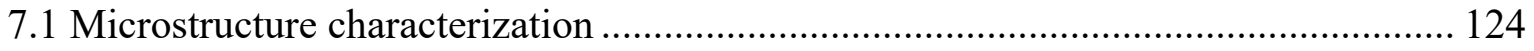

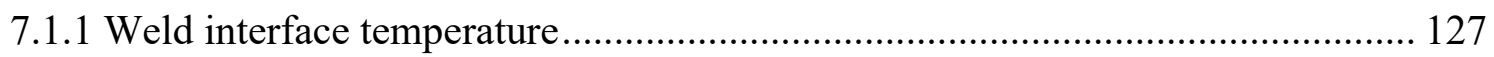

7.1.2 Energy-dispersive X-ray spectroscopy analysis ................................................. 129

7.1.3 X-ray diffraction phase identification............................................................... 130

7.1.4 Diffusion pattern ............................................................................................ 131

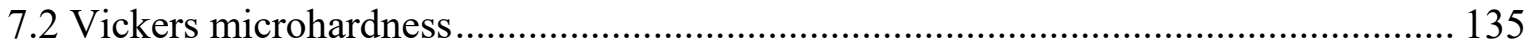

7.3 Tensile lap shear strength.................................................................................... 137

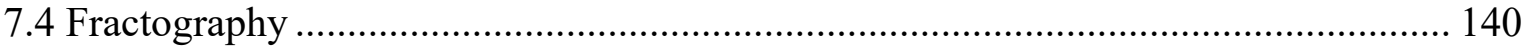

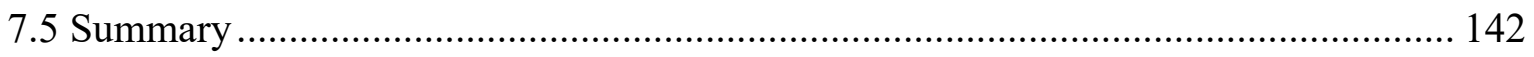

Chapter 8. Conclusions and Future Work .................................................................................143

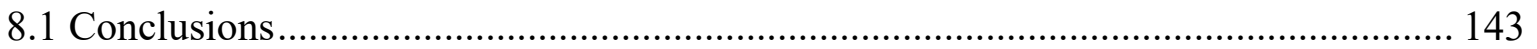

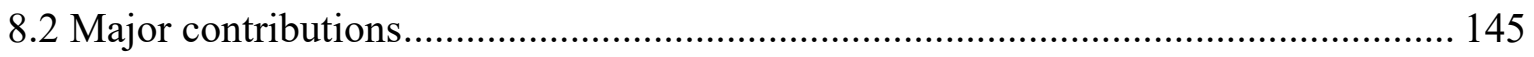

8.3 Recommendations for future work ................................................................... 146

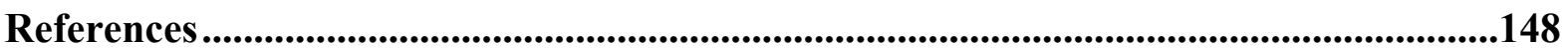




\section{LIST OF TABLES}

Table 2.1: Comparison of the range of welding energy and welding time required for different spot joining process in $1 \mathrm{~mm}$ aluminum sheet [45].

Table 2.2: Cost comparison of different joining techniques [57] .................................. 23

Table 3.1: Chemical composition of the ZEK100-O Mg alloy [44] ................................ 41

Table 3.2: Chemical composition of the A15754-O Al alloy [117]. ................................ 41

Table 3.3: Chemical composition of the Al6111-T4 Al alloy........................................ 42

Table 3.4: Chemical composition of the HSLA 340 steel............................................. 42

Table 3.5: Chemical composition of the AZ31B-H24 Mg alloy ..................................... 42

Table 3.6: Physical properties of the common materials used in this study $[27,44] \ldots \ldots \ldots \ldots . .42$

Table 4.1: A summary of the calculated strain rate and Zener-Hollomon parameter at different levels of welding energy. ........................................................... 58 


\section{LIST OF FIGURES}

Figure 1.1: Super light car; materials and weight distribution [33] ................................. 3

Figure 2.1: Schematic diagram illustrating USW principle with four stage interface

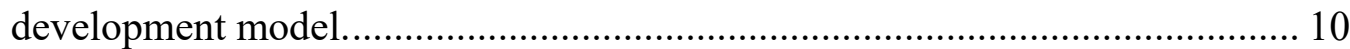

Figure 2.2: USW systems with transverse vibration pattern (a) wedge-reed and (b)

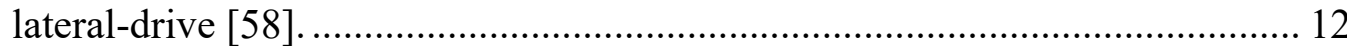

Figure 2.3: Different parts of USW machine ............................................................ 16

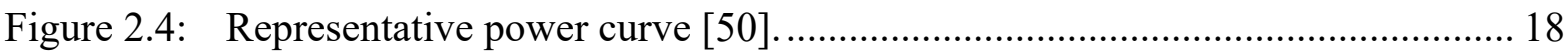

Figure 2.5: (a) Electrical wire harnesses, (b) C-Frame robotic weld gun with clamping system and (c) automotive closure panel [65].

Figure 2.6: Optical micrograph of AZ31 BM and welded samples at different energy levels. (a) AZ31 BM, (b) $500 \mathrm{~J}$, (c) $1500 \mathrm{~J}$, (d) $2500 \mathrm{~J}$ [80]. 26

Figure 2.7: Representative microstructure of the friction stir spot welded (FSSWed) lap-shear coupons in the stir zone (SZ) at (a) $1500 \mathrm{rpm}$, (b) $2250 \mathrm{rpm}$, thermo-mechanically affected zone (TMAZ) at (c) $1500 \mathrm{rpm}$, (d) $2250 \mathrm{rpm}$, and (e) base material (BM) [25].

Figure 2.8: Tensile lap shear strength of USWed AZ31-to-AZ31 Mg alloy joints at varying energy inputs [82]

Figure 2.9: Lap shear strength of FSSWed ZEK100 Mg alloy as a function of (a) tool shoulder plunge depth, (b) effective sheet thickness, (c) hook width, and (d) tool rotation rate [25]. 
Figure 2.10: SEM images of the joint interface at weld center showing IMC growth at different welding time of (a) $0.24 \mathrm{~s}$, (b) $0.40 \mathrm{~s}$, (c) $0.70 \mathrm{~s}$, and (d) Electron backscatter diffraction (EBSD) phase map [52] .................................... 35

Figure 2.11: Lap shear strength as a function of welding energy for $\mathrm{Mg}$-Al joints with

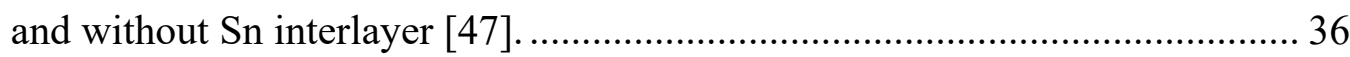

Figure 3.1: Schematic diagram of the lap joint........................................................ 43

Figure 3.2: Images of the welding tip with its knurl pattern..................................... 44

Figure 3.3: Schematic diagram showing the positioning of thermocouple during temperature measurement.............................................................. 45

Figure 3.4: Microhardness indentation made diagonally across the welded joints............. 47

Figure 3.5: Schematic of specimen used for tensile lap shear and fatigue tests. ............... 48

Figure 4.1: Optical micrographs of (a) ZEK100-O base metal, and samples welded at a welding energy of (b) $500 \mathrm{~J}$, (c) $1000 \mathrm{~J}$, (d) $1500 \mathrm{~J}$, and (e, f) $2000 \mathrm{~J}$ ((e) $1000 \times$ and (f) $400 \times$ ), respectively. 52

Figure 4.2: Average grain size in NZ as a function of welding energy where error bar indicates standard deviation for 15 repeats 53

Figure 4.3: (a) Temperature profiles and (b) peak temperatures, measured at the center of the weld during USW at a welding energy of $500 \mathrm{~J}, 750 \mathrm{~J}, 1000 \mathrm{~J}$ and $1500 \mathrm{~J}$, respectively.

Figure 4.4: Relationship between DRX grain size and Zener-Hollomon parameter for the samples welded at different levels of welding energy. 59

Figure 4.5: (a) Vickers microhardness in the nugget zone as a function of welding energy, and (b) Hall-Petch type relationship between the microhardness and 
grain size in the USWed ZEK100 Mg alloy. Error bar indicates standard deviation for 15 repeats of grain size and 25 repeats of hardness

Figure 4.6: (a) The maximum tensile shear load, (b) The tensile lap shear strength, and (c) total failure energy as a function of welding energy (or welding time), at a welding power of $2 \mathrm{~kW}$ and a clamping pressure of $0.4 \mathrm{MPa}$

Figure 4.7: The change of weld thickness with welding energy (or welding time) 65

Figure 4.8: Macroscopic images of the failed tensile lap shear samples welded at different levels of welding energy.

Figure 4.9: Typical fracture surface SEM images of tensile lap shear failed samples welded at a welding energy of (a,c,d) $1000 \mathrm{~J}$ and (b,d,f) $1500 \mathrm{~J} .(\mathrm{a}, \mathrm{b})$ Overall view of the entire fracture surfaces, $(\mathrm{c}, \mathrm{d}, \mathrm{e}, \mathrm{f})$ higher magnification images of the fracture surfaces.

Figure 4.10: (a) Typical tensile lap shear test curves of the samples welded at an optimal welding energy of $1500 \mathrm{~J}$, and (b) variation of the tensile lap shear failure load and total failure energy with test temperatures. Error bars indicates range for 2 repeats.

Figure 4.11: Macroscopic images of the failed tensile lap shear samples welded at an optimal welding energy of $1500 \mathrm{~J}$ and tested at (a) LT and (b) HT. 72

Figure 5.1: Typical SEM images at the interface of ZEK100-A15754 joints at a welding energy of (a) $250 \mathrm{~J}$, (b) $500 \mathrm{~J}$, and (c) $1000 \mathrm{~J}$. 76

Figure 5.2: SEM micrographs showing the positions of EDS line scan and the relevant EDS line scan results at a welding energy of (a) $250 \mathrm{~J}$, (b) $500 \mathrm{~J}$, and (c) $1000 \mathrm{~J}$ along with the EDS point analysis results. 78 
Figure 5.3: XRD patterns obtained on both matching surfaces of $\mathrm{Mg}$ side and $\mathrm{Al}$ side after the tensile lap shear test of a sample welded at a welding energy of $1000 \mathrm{~J}$

Figure 5.4: The maximum tensile shear load as a function of welding energy at a constant welding power of $2 \mathrm{~kW}$ and a constant pressure of $0.4 \mathrm{MPa}$ for (a) ZEK100-A15754, (b) AZ31-A15754 [41], and (d) AZ31-A15754 with Sn interlayer [47].

Figure 5.5: (a) tensile lap shear strength comparison of $\mathrm{Mg}-\mathrm{Al}$ dissimilar joints with the Mg-Mg and Al-Al similar joints. (b) Comparison of the tensile lap shear strengths of the $\mathrm{Mg}-\mathrm{Al}$ joints made with different $\mathrm{Mg}$ and $\mathrm{Al}$ alloys and different joining techniques. 84

Figure 5.6: SEM images showing the typical fracture surface of a tensile lap shear failed sample welded at a welding energy of $1000 \mathrm{~J}$, (a) overall view on the Mg side, (b) overall view on the $\mathrm{Al}$ side, (c, d, e) higher magnification images in region $\mathrm{A}, \mathrm{B}$, and $\mathrm{C}$ on the $\mathrm{Mg}$ side, $(\mathrm{f}, \mathrm{g}$ ) higher magnification images in region $\mathrm{D}$ and $\mathrm{E}$ on the $\mathrm{Al}$ side. 86

Figure 5.7: (a) S-N curves and (b) the stress amplitude vs. the number of reversals to failure on a log-log scale for the USWed ZEK100-A15754 dissimilar joints made at a welding energy of $500 \mathrm{~J}$ and $1000 \mathrm{~J}$, tested at RT, R=0.2, and a frequency of $50 \mathrm{~Hz}$. 88

Figure 5.8: Macroscopic images showing fatigue failed samples of the USWed ZEK100-A15754 dissimilar joints tested in the condition of (a) $500 \mathrm{~J}-0.5$ 
kN, (b) $500 \mathrm{~J}-1.0 \mathrm{kN}$, (c) $500 \mathrm{~J}-1.5 \mathrm{kN}$, (d) $1000 \mathrm{~J}-0.5 \mathrm{kN}$, (e) $1000 \mathrm{~J}-1.0$

$\mathrm{kN}$, and (f) $1000 \mathrm{~J}-1.5 \mathrm{kN}$

90

Figure 5.9: SEM images of a fatigue failed sample made at a welding energy of $500 \mathrm{~J}$ and tested at a maximum load of $0.5 \mathrm{kN}$. $(\mathrm{a}, \mathrm{b})$ Overall view of the entire fracture surfaces on the $\mathrm{Mg}$ side and $\mathrm{Al}$ side, respectively, and (c,d,e,f) magnified view of the regions of interest indicated in (a) and (b).

Figure 6.1: Typical SEM images showing the nugget interface microstructure of the USWed Al6111-HSLA steel joint at a welding energy of (a) $500 \mathrm{~J}$, (b) 1000 $\mathrm{J}$, (c) $1500 \mathrm{~J}$, (d) $2000 \mathrm{~J}$, (e) $2500 \mathrm{~J}$, and (f) $3000 \mathrm{~J}$, respectively (composition in at.\%).

Figure 6.2: SEM micrographs showing characteristic diffusion patterns of Al-Zn eutectoid at the nugget edge in the Al6111-HSLA steel dissimilar joints made at a welding energy of (a) $1500 \mathrm{~J}$, (b) $2000 \mathrm{~J}$, and (c) $2500 \mathrm{~J}$, and (d) magnified view of the squeezed-out diffusion layer outside the nugget edge at a weld energy of $1500 \mathrm{~J}$ (composition in at.\%).

Figure 6.3: Results of EDS line scan analyses at the nugget interface of the USWed A16111-HSLA steel dissimilar joints made at a welding energy of (a) 500 $\mathrm{J}$, (b) $1000 \mathrm{~J}$, (c) $2000 \mathrm{~J}$, and (d) $3000 \mathrm{~J}$, respectively. 100

Figure 6.4: XRD patterns obtained from the fracture surface of the tensile failed samples welded at a welding energy of (a) $1000 \mathrm{~J}, \mathrm{Al}$ side, (b) $1000 \mathrm{~J}$, steel side, (c) $1500 \mathrm{~J}$, Al side, and (d) $1500 \mathrm{~J}$, steel side 102 
Figure 6.5: Maximum tensile lap shear load of USWed Al6111-HSLA steel joints as a function of welding energy at a constant power of $2000 \mathrm{~W}$ and clamping pressure of $0.4 \mathrm{MPa}$

Figure 6.6: Macroscopic images of tensile failed samples welded at a welding energy of (a) $1000 \mathrm{~J}$, (b) $2000 \mathrm{~J}$, and (c) $3000 \mathrm{~J}$, respectively

Figure 6.7: (a) Comparison of average maximum tensile lap shear failure load of USWed Al-Al, steel-steel, and Al-steel joints (b) Comparison of the average maximum tensile strength of Al-Steel using FSSW and USW techniques. 106

Figure 6.8: SEM images of a tensile failed sample made at a welding energy of $1500 \mathrm{~J}$, (a) overall view of Al side, (b) 900 clockwise rotated and magnified image of box in (a), and (c) the results of EDS line scan in (b); (d) overall view of steel side, (e) 900 clockwise rotated and magnified image of box in (d), and (f) the results of EDS line scan in (e) (composition in at.\%) 108

Figure 6.9: (a) Schematic diagram illustrating the hardness measurement procedure, (b) hardness profile across transverse cross-section measured after $3 \mathrm{hrs}, 3$ days and 2 weeks of welding (c) hardness profile across longitudinal crosssection measured after 3 hrs and 2 weeks of welding, for an Al6111-HSLA steel weld made at a welding energy of $2000 \mathrm{~J}$.

Figure 6.10: S-N curves of the USWed Al-HSLA steel joints tested at room temperature, $\mathrm{R}=0.2$, and a frequency of $50 \mathrm{~Hz}$ 
Figure 6.11: Macroscopic images of fatigue failed samples made and tested at (a) 1000 J-1 kN, (b) $1000 \mathrm{~J}-2 \mathrm{kN}$, (c) $1000 \mathrm{~J}-3 \mathrm{kN}$, (d) $2000 \mathrm{~J}-1 \mathrm{kN}$, (e) $2000 \mathrm{~J}-2 \mathrm{kN}$, and (f) $2000 \mathrm{~J}-3 \mathrm{kN}$.

Figure 6.12: Schematic diagrams of (a) side (cross-section) view and (b) top view showing a comparison of bonding areas at a welding energy of $1000 \mathrm{~J}$ and $2000 \mathrm{~J}$, respectively. 116

Figure 6.13: Stress amplitude vs. the number of reversals to failure (2Nf) in the double$\log$ scale for the USWed Al-HSLA steel joint at a welding energy of 1000 $\mathrm{J}$ and $2000 \mathrm{~J}$.

Figure 6.14: Typical SEM images showing Al base metal failed fatigue fracture surface of USWed Al6111-HSLA steel joint made at a welding energy of $2000 \mathrm{~J}$ and tested at a maximum cyclic load of $P_{\max }=1 \mathrm{kN}$. (a) Overall view, (b) crack initiation area, (c) magnified image of (b), (d) magnified image of a crack propagation area, and (e) magnified image of fast crack propagation area.

Figure 6.15: Typical SEM images showing interfacial failed fatigue fracture surface of USWed Al6111-HSLA steel made at a welding energy of $2000 \mathrm{~J}$ and tested at a maximum cyclic load of $P_{\max }=2.5 \mathrm{kN}$. (a) Overall view of $\mathrm{Al}$ fracture surface, (b) overall view of the steel fracture surface, (c) magnified and 900 clockwise rotated image of nugget edge in (a), and (d) magnified and 900 anticlockwise rotated image of the nugget edge in (b) (composition in at.\%). 
Figure 7.1: Typical SEM images are showing the joint interface of the USWed Cu-toAZ31-H24 joint at a welding energy of (a) $1000 \mathrm{~J}$, (b) $1500 \mathrm{~J}$, (c) $2000 \mathrm{~J}$, and (d) $2500 \mathrm{~J}$

Figure 7.2: (a) Joint interface temperature profiles and (b) peak temperatures, measured at the center of the nugget during USW at a welding energy of $1000 \mathrm{~J}, 1500$ $\mathrm{J}, 2000 \mathrm{~J}$ and $2500 \mathrm{~J}$. 128

Figure 7.3: (a), (c) and (e) SEM micrographs showing the positions of EDS line scan, and (b), (d) and (f) the results of EDS line scan at a welding energy of 1000 $\mathrm{J}, 1500 \mathrm{~J}$ and $2000 \mathrm{~J}$, respectively. 130

Figure 7.4: XRD patterns obtained on both matching surfaces of $\mathrm{Mg}$ side and $\mathrm{Cu}$ side after the lap shear tensile test of samples joined at a welding energy of (a) $1000 \mathrm{~J}$, (b) $1500 \mathrm{~J}$, (c) $2000 \mathrm{~J}$, and (d) $2500 \mathrm{~J}$.

Figure 7.5: (a) SEM micrograph of an outburst-like pattern of diffusion layer at the interface of $2500 \mathrm{~J}$ welding energy sample, (b) a view of the boxed region in (a) at a higher magnification, and (c) schematic diagram showing the formation of outburst-like patterns in four stages.....

Figure 7.6: Microhardness profile diagonally measured across the joint interface for the samples joined at a welding energy of $2000 \mathrm{~J}$ and $2500 \mathrm{~J}$

Figure 7.7: (a) Tensile lap shear strength and (b) total failure energy, as a function of welding energy at a constant power of $2000 \mathrm{~W}$ and a clamping pressure of $0.4 \mathrm{MPa}$ 139

Figure 7.8: SEM images of fracture surfaces joined at a welding energy of $1500 \mathrm{~J}$, (a) overall view on the $\mathrm{Mg}$ side, (b) overall view on the $\mathrm{Cu}$ side, (c) $\mathrm{Mg}$ side 
at a higher magnification, (d) $\mathrm{Cu}$ side at a higher magnification, (e) EDS line scan on the fracture surface of Mg side, and (f) EDS line scan on the

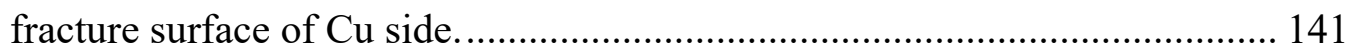




\section{NOMENCLATURE}

\begin{tabular}{|c|c|}
\hline Acronym & Definition \\
\hline ASTM & American Society for Testing of Materials \\
\hline AWS & American Welding Society \\
\hline $\mathrm{BM}$ & Base Metal \\
\hline DRX & Dynamic Recrystallization \\
\hline EBSD & Electron Backscatter Diffraction \\
\hline EDS & Energy Dispersive X-ray Spectroscopy \\
\hline FSW & Friction Stir Welding \\
\hline FSP & Friction Stir Processing \\
\hline FSSW & Friction Stir Spot Welding \\
\hline FSSWed & Friction Stir Spot Welded \\
\hline HAZ & Heat Affected Zone \\
\hline HSLA & High Strength Low Alloy \\
\hline HT & High Temperature \\
\hline HV & Vickers Hardness \\
\hline IMC & Intermetallics Compound \\
\hline LFW & Linear Friction Welding \\
\hline LSW & Laser Spot Welding \\
\hline LT & Low Temperature \\
\hline NZ & Nugget Zone \\
\hline $\mathrm{OM}$ & Optical Microscopy \\
\hline
\end{tabular}




$\begin{array}{ll}\text { RSW } & \text { Resistance Spot Welding } \\ \text { RT } & \text { Room Temperature } \\ \text { RE } & \text { Rare Earth } \\ \text { SEM } & \text { Scanning Electron Microscope } \\ \text { SZ } & \text { Stir Zone } \\ \text { TMAZ } & \text { Thermo-mechanically affected zone } \\ \text { TTT } & \text { Transverse Through Thickness } \\ \text { USW } & \text { Ultrasonic Spot Welding } \\ \text { USWed } & \text { Ultrasonic Spot Welded } \\ \text { XRD } & \text { X-ray Diffraction }\end{array}$

Symbol

Z

$\dot{\varepsilon}$

$Q$

$R$

$T$

$\dot{\gamma}$

f

A

$h_{o}$

\section{Definition}

Zener-Holloman parameter

Strain rate

Activation energy

Gas constant

Temperature

Shear strain rate

Frequency of vibration

Amplitude of vibration

Slit thickness/ thickness of the melt layer/reduced thickness of weld sheet 


$\begin{array}{ll}\varnothing & \text { Outputting coefficient } \\ \rho & \text { Density } \\ c & \text { Ultrasonic velocity } \\ E & \text { Energy } \\ n & \text { Power law exponent } \\ D & \text { Grain Size } \\ t & \text { Welding time } \\ N_{f} & \text { Fatigue life } \\ R & \text { Loading ratio } \\ P & \text { Welding power }\end{array}$




\section{Chapter 1. Introduction and Motivation}

The mounting environmental concern to diminish anthropogenic climate-changing, environment-damaging, costly and human death-causing* emissions along with unstable energy prices has driven the transportation industry to improve fuel efficiency [1-7]. Researchers have developed various strategies to improve fuel efficiency including lightweighting, powertrain improvements, aerodynamic (drag reducing) enhancements, and the use of alternative/renewable energy sources. Out of which, lightweighting has been regarded as a key strategy in the global transportation industry. Additionally, it has recently been portrayed as the "storm" of lightweighting - a revolution in materials, processes, and business models - which is brewing on the horizon of the transportation industry [8-11]. Magnesium $(\mathrm{Mg})$ alloys are attractive for the transportation industries to achieve vehicle lightweighting due to their low density, high strength-to-weight ratio, and superior damping capacity. Although the wrought (extruded, rolled) Mg alloys show better mechanical properties than the cast counterparts, their applications are limited by the strong deformation texture, which leads to the tensioncompression yield asymmetry and mechanical anisotropy [12,13]. It is associated with the hexagonal close-packed crystal structure of $\mathrm{Mg}$ alloys with a nearly ideal $c / a$ ratio (1.624), which results in limited deformation modes (i.e., basal slip and twinning) and strong textures at room temperature $[12,14]$. Also, Mg alloys also have a poor corrosion resistance compared with Al alloys [15-17]. In recent years, it has been realized that the addition of rare-earth (RE)

\footnotetext{
* According to Science News entitled "Air pollution kills 7 million people a year" on March 25, 2014 at http://www.sciencemag.org/news/sifter/air-pollution-kills-7-million-people-year: "Air pollution is not just harming Earth; it's hurting us, too. Startling new numbers released by the World Health Organization today reveal that one in eight deaths are a result of exposure to air pollution. The data reveal a strong link between the tiny particles that we breathe into our lungs and the illnesses they can lead to, including stroke, heart attack, lung cancer, and chronic obstructive pulmonary disease."
} 
elements to $\mathrm{Mg}$ alloys along with $\mathrm{Zn}$ can soften or randomize the texture and improve their room temperature formability $[11,12,18-20]$, and also improve the corrosion resistance of $\mathrm{Mg}$ alloys [21,22]. Therefore, some new Mg alloys are being developed by adding RE elements. While, Mg alloys with high RE elements, e.g., Mg-10Gd-3Y-0.5Zr [12,23], or with intermediate RE elements, e.g., Mg-3Nd-0.2Zn-0.5Zr [24], have been developed for some special applications, more efforts are being made to develop Mg alloys with the minimum RE elements to be price competitive and also achieve better mechanical properties for the automotive applications. One such Mg alloy is ZEK100, which contains only $0.2 \mathrm{wt} \% \mathrm{Nd}$. Several recent studies showed that ZEK100 Mg alloy exhibited superior room temperature formability $[8,25,26]$, and as a result, it is being considered as an excellent candidate for the transportation applications.

Similarly, the use of lightweight aluminum (Al) alloys has become increasingly popular due to its high strength to weight ratio, environment friendliness, good formability, machinability, and recyclability [27,28]. The "storm" of lightweighting also hit steel industry, which led to unprecedented steel innovation to produce alloys with high strength and good cold formability to the development of high-strength steel alloys. Today, the main material used in the body of a passenger car is high-strength steel, such as traditional (ferritic, ferritic-pearlitic or bainitic) galvanized high strength low alloy (HSLA) steel. Copper $(\mathrm{Cu})$ is also used in automotive, electronics and electrical power industry due to its high electrical conductivity, thermal conductivity, and machinability. Today's automotive production is based on a multi-material design approach to achieve lightweighting without excessively increasing cost or compromising performance [29-32]. The European project SuperLIGHT-CAR (SLC) resulted in a multi- 
material car design (Figure 1.1) that was 37\% lighter than traditional body-in-white (BIW) of a compact class passenger car while maintaining the same performance as the reference [32,33]. It can be seen that major structural materials were $\mathrm{Al}, \mathrm{Mg}$, and steel, and dissimilar Al-to-Mg and Al-to-steel joints were required to achieve this structure. Also, it has been reported that Mg$\mathrm{Cu}$ bimetals are widely used in the electronic and electrical industries, electrical appliances, machinery and automotive industries. The research and application of $\mathrm{Mg}-\mathrm{Cu}$ bimetals have been extended from navigation and military fields to civil products of additional high value such as an automobile, computer and communication equipment [34]. These applications involve joining of two dissimilar materials: $\mathrm{Cu}$ and $\mathrm{Mg}$ alloy. It is understood that dissimilar metals are very difficult to join due to variation in their chemical and physical properties. Therefore, researchers are trying to develop efficient and reliable joining technique to join these materials. The remainder of this chapter establishes the motivation for selecting ultrasonic spot welding (USW) for similar and dissimilar joining in automotive applications, followed by an overview.

\begin{tabular}{|c|c|c|c|c|}
\hline \multirow[t]{9}{*}{ Weight SLC BIW: 180 kg } & \multirow{9}{*}{$\begin{array}{ll} & \text { Materials } \\
& \text { Aluminium sheet } \\
& \text { Aluminium die-casting } \\
& \text { Aluminium extrusion } \\
& \text { Steel } \\
& \text { Hot-formed steel } \\
& \text { Magnesium sheet } \\
& \text { Magnesium die-casting } \\
& \text { Fiberglas thermoplastic }\end{array}$} & \multicolumn{3}{|c|}{ Weight distribution } \\
\hline & & Aluminium & $96 \mathrm{~kg}$ & $(53 \%)$ \\
\hline & & Steel & $66 \mathrm{~kg}$ & $(36 \%)$ \\
\hline & & Magnesium & $11 \mathrm{~kg}$ & $(7 \%)$ \\
\hline & & Plastic & $7 \mathrm{~kg}$ & $(4 \%)$ \\
\hline & & & & \\
\hline & & & & \\
\hline & & & & \\
\hline & & & & \\
\hline
\end{tabular}

Figure 1.1: Super light car; materials and weight distribution [33].

\subsection{Motivation for ultrasonic spot welding}


The vision of welding by American Society of Welding [35] indicated welding as a critical technique during the assembly process which has significant effects on the integrity and reliability of the structural body and parts. Welding especially spot welding is considered as an efficient, fast, reliable and cost effective joining technique compared to others. A single car has greater than 5000 spot weld on its body. Thus, researchers are trying to develop an efficient and a reliable spot welding technique for lightweight alloys. Conventional fusion welding techniques produce large grains, porosity, voids and other defects in the weld zone that seriously degrades mechanical properties of joints. Currently, resistance spot welding (RSW) is a principal spot welding technique for sheet metal joining in the automotive industry [36]. It is due to simplicity, speed, and low operational cost, however; problems like high energy costs, unstable weld quality, short electrode life, and large residual stress limit their applications, specifically for similar and dissimilar $\mathrm{Mg}$ and $\mathrm{Al}$ joints [37,38]. Similarly, laser welding is contactless, high precision, and high speed joining technique, however, disadvantages such as the need for shielding gas, high initial cost and higher energy consumption limit their applications [32]. Since both are a fusion joining processes, high rate of intermetallic reaction occurs in the liquid phase, which degrades the joints quality [36,39]. Hence, solid-state spot joining processes like USW and friction stir spot welding (FSSW) could potentially be used to substitute RSW and laser welding, which can diminish the tendency for intermetallic compounds (IMCs) formation because no liquid phase is produced [38,40-42]. However, in the solid state spot welding techniques USW and FSSW, the later imposes challenges such as high energy consumption, longer cycle time, and reduction of top sheet thickness due to keyhole left by tool probe [43]. On the other hand, USW is an emerging joining process with low energy consumption, shorter weld time, no shrinkage and distortion problems $[9,38,44]$, and higher 
efficiency, since heat generation is at the weld interface $[9,38,44]$ rather than on the top surface as in FSSW $[27,42,43]$. For instance, it was reported during welding of aluminum alloys; the USW process uses only about $0.3 \mathrm{kWh}$ energy for 1000 joints [45,46] compared to $2 \mathrm{kWh}$ with FSSW and $20 \mathrm{kWh}$ with RSW [46]. Several studies have reported that joints prepared with USW have higher strength than FSSW when compared on the basis of bonding area $[47,48]$. In USW, shear vibrations typically $20 \mathrm{kHz}$ are applied to the specimens clamped under moderate pressures leading to shear plastic deformation and breaking of oxide films. It produces frictional heat and softens the materials due to dominant effect of temperature rise, which lowers the yield strength of the material. Finally, joining takes place by the formation and growth of microwelds at the surfaces due to nascent metal-to-metal contact, creating metallurgical adhesion and interdiffusion across the interface $[27,38,44,49]$.

\subsection{Objective and scope of the dissertation}

This dissertation represents a contribution towards the development and optimization of USW techniques for joining newly developed Mg alloys in similar Mg-to-Mg \& dissimilar Mg-to-Al, dissimilar Al-to-HSLA steel, and dissimilar Mg-to-Cu joints for their applications in the automotive structural body and parts. For a wide range of materials and conditions a welldeveloped welding procedure is not available for USW process (as they do, e.g., for RSW), thus each material combinations are usually approached in an exploratory manner [50]. There are a few studies on the USW of AZ 31-H24 Mg alloy in similar configurations and with automotive grade, $\mathrm{Al}$ alloys (A15754, A16111) in dissimilar configurations [41,47,51-53]. However, to the author's knowledge, there are no such studies on similar (ZEK100-ZEK100) and dissimilar 
(ZEK100-Al alloy) joints of a recently developed high performance low rare earth containing ZEK100 Mg alloy. Similarly, there are no studies on ultrasonic spot welded (USWed) Mg alloys to $\mathrm{Cu}$ joints. Moreover, there are very limited studies on dissimilar USW of HSLA steel with automotive grade $\mathrm{Al}$ alloys [27]. Thus, critical information regarding these important USWed joints is still not available in the open literature, such as the optimum welding parameters, microstructural studies, mechanical properties like tensile, fatigue and hardness, and thermal profile. Therefore, this dissertation specifically focuses on the development and optimization of USWed ZEK100-to-ZEK100, ZEK100-to-A15754, A16111-to-HSLA steel, and AZ31-to-Cu joints by analyzing their thermal profile, microstructure and mechanical properties such as hardness, tensile and fatigue to ensure the reliability and safety of the joints and structures.

The specific objectives include the following:

- $\quad$ Evaluate feasibility of joining rare earth containing ZEK100 Mg alloy using USW and to identify the effect of a key welding parameter (i.e., welding energy) on the microstructure, hardness, and tensile properties, thereby to develop a relationship between grain sizes and the Zener-Holloman parameter as well as Hall-Petch type relationship of USWed ZEK100 Mg alloy. Also, the effect of test temperature on the tensile lap shear strength was evaluated.

- $\quad$ To study the feasibility of joining ZEK100 Mg alloy to $5754 \mathrm{Al}$ alloy via USW and identify the effect of a key welding parameter (i.e., welding energy) on the microstructure, tensile properties and fatigue life of the dissimilar joints. 
- To investigate interface microstructure, tensile lap shear strength, hardness and fatigue properties of USWed automotive heat-treatable Al 6111-T4 alloy to galvanized HSLA steel joints and to study effects of nature aging of $\mathrm{Al}$ alloys on joint properties.

- To understand diffusion kinetics at the joint interface of AZ31 Mg alloy-to-Cu joints and to identify the effect of welding energy on the interface diffusion layer and strength of the joints.

\subsection{Structure of the dissertation}

This dissertation has been structured as follows:

Chapter 2 - the principle and fundamental study of USW, and some prior work on the welding of similar and dissimilar joints of lightweight materials.

Chapter 3 - the experimental procedures used in this study.

Chapter 4 - USW of similar Mg alloy, where microstructure evolution, the relationship between Zener-Hollomon parameter and grain size, microhardness profile, lap shear tensile and high and low-temperature strength of USW joints are discussed.

Chapters 5, 6, 7 - USW of challenging dissimilar Mg-to-Al, Al-to-steel, and Mg-to-Cu, respectively, where all dissimilar combinations of USW joints were characterized in terms of their microstructure evolution and mechanical properties.

Chapter 8 - conclusions, major contribution and future scope of the present study. 


\section{Chapter 2. Literature Review}

This chapter comprises a review of the literature pertinent to the current study. The chapter is divided into two sections: the principle and fundamentals of USW process and previous studies on the similar and dissimilar joining of $\mathrm{Mg}$ alloys, $\mathrm{Al}$ alloys, steel, and $\mathrm{Cu}$.

\subsection{Overview of USW}

USW is emerging and promising solid-state spot welding technique and is extensively used in applications ranging from plastic industries, tube sealing, welding microscopic connections on microchips to, including electrical interconnections, however, the focus of this work is limited to the sheet metal welding, where the welding mechanism is thought to be different from that for thin foils, wires, and plastics.

\subsubsection{History of USW}

Since many decades, ultrasonic vibrations have been used to join materials. In the 1930s, it was initially applied to refine grains in molten metal, in 1940s for soldering, and with arc and resistance welding to join plastics in 1950s. In the late 1940s, the Aeroprojects Company of West Chester, Pennsylvania (the forerunner of the current Sonobond Corporation) used ultrasonic vibrations to decrease surface resistance in spot welding of aluminum with conventional resistance welding equipment [54]. During this research, it was realized that metal parts could be welded without melting the metals using ultrasonic vibrations [54,55]. A piece 
of work on welding by mechanical vibration was also reported by Willrich in 1950, who obtained cold weld in the region of resistance welding by applying low-frequency vibration to the welding tool [56]. The first independent ultrasonic metal welding equipment was patented in 1960 [57].

\subsubsection{USW principle}

The USW is considered as a solid-state joining process where joint takes place without any melting of base metals, however melting occurs when low melting point interlayers/coatings are present. It is important to understand the principle of USW and difference from other process used in the conventional welding. Figure 2.1 shows the general schematic of USW process. For ease of understanding, the principle of USW of metals could be divided into four main stages [55].

a) Clamping force (normal force) and mechanical vibration (shear forces) are applied to both workpiece sheets by sonotrode welding tool. The relative motion between intimate surfaces begins to remove and clean asperities.

b) The effects of interfacial slip and plastic deformation will increase the temperature of the scrubbing area and therefore diffusion across the interface, which creates localized microwelds at many points between the adjacent surfaces.

c) With an increase in the shear strain rate and temperature, the bonding area starts to increase through a spreading of the microwelds.

d) Finally, microwelds are combined to from continuous layer and welds are complete when the power received by deforming area of intimate surfaces is sufficient. 


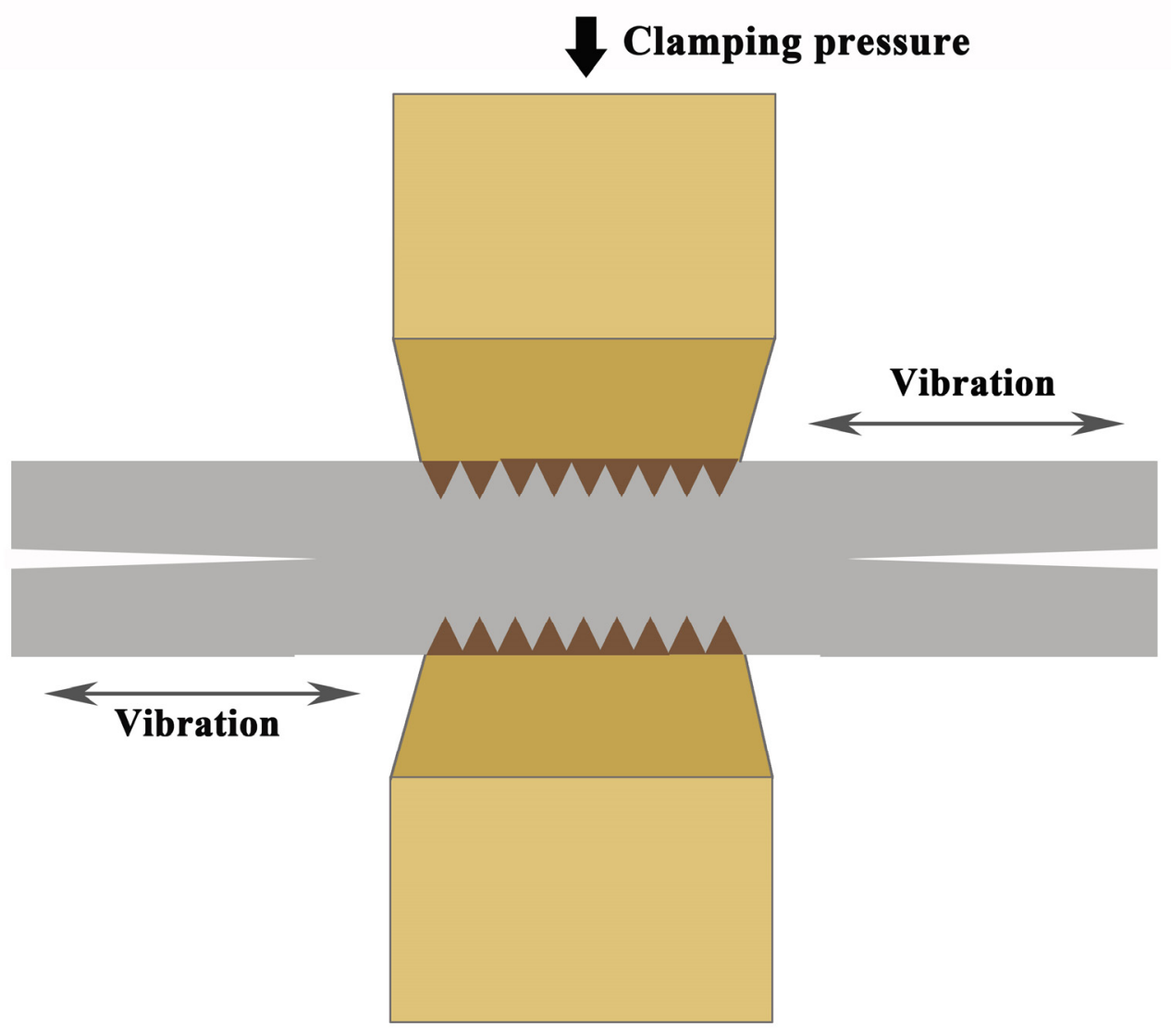

Clamping pressure
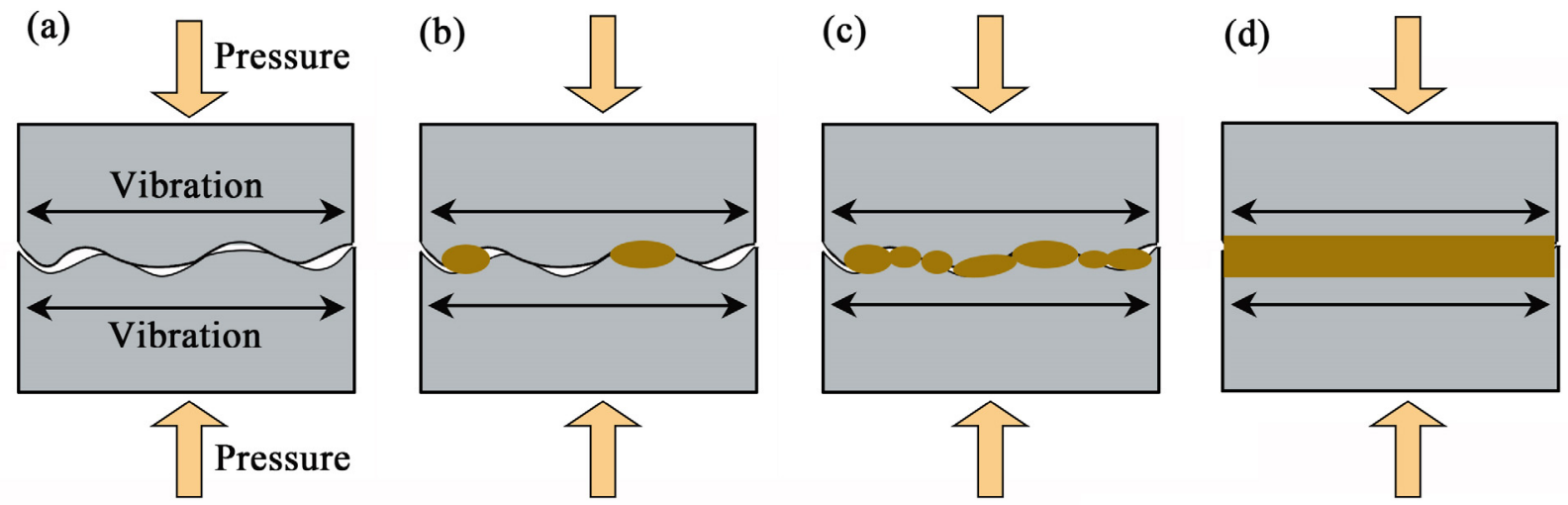

Figure 2.1: Schematic diagram illustrating USW principle with four stage interface development model. 


\subsubsection{USW configurations}

In USW, there are several variants of the process which can be adopted, based on the type of the weld, geometry, and the materials to be joined. The USW of metals is then obtained using transverse ultrasonic vibration to create scrubbing action between the specimens. Ultrasonic welding has many variants including line, ring, torsion, and seam [58], e.g., circular closure welds and stud welds are prepared by ultrasonic torsion welding, and continuous welds in thin gauge materials have been achieved by ultrasonic seam welding. The present research is focused on sheet metal welding, which is the most common approach for fabricating structural body parts and components for their applications in the automotive industry and also used in many industrial assembly lines. Furthermore, bonding area covers only a small area of the sample, typically up to around $40 \mathrm{~mm}^{2}$ [59]. In general, USW system can be divided into two categories for sheet metal welding, wedge-reed system or a lateral-drive system, as shown in Figure 2.2. Although, both systems are different in shape and application, the vibration mechanism at weld interface is the same $[59,60]$. Both systems are discussed briefly in the following section.

\subsubsection{Wedge-reed USW}

Figure 2.2(a) shows a wedge-reed system which consists of a generator, transducer, and the wedge-reed-welding tip assembly, used to produce and transmit the ultrasonic vibration energy to the specimens clamped between sonotrode welding tip and anvil [50]. In the present study, 
USW machine had a dual wedge-reed system, where instead of the anvil, both sides have a wedge and reed series components that transfer vibration to both surfaces of the workpiece. It increases the capacity of this machine to use for traditionally unsuitable or high-strength alloys.
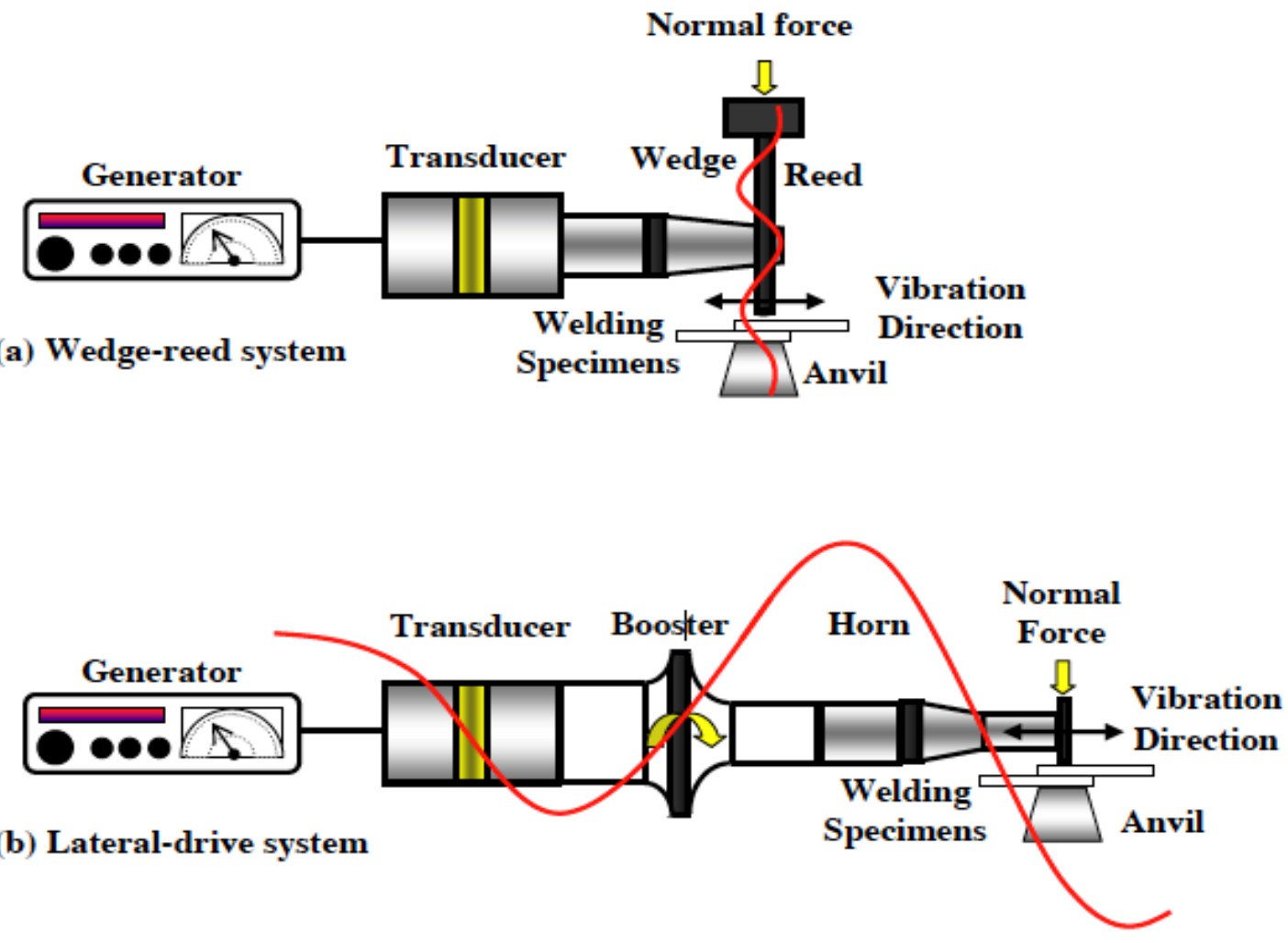

Figure 2.2: USW systems with transverse vibration pattern (a) wedge-reed and (b) lateral-drive [58].

The normal clamping force is applied using a pneumatic cylinder placed onto the mass at the top of the upper reed, so that can easily control the upward and downward movement of the welding tip. The magnitude of force ranges from a few Newton to several kilo-Newton [54]. The transducer converts the electrical energy into mechanical vibration which is amplified by a wedge. During welding, the vibration amplitude may vary according to the tool design and input power for a given application. Normally, the amplitude varies from 10 to $100 \mu \mathrm{m}$ peakpeak [58]. It is necessary to mention here that 'wedge' amplifies the vibration amplitude which 
is transferred through the reed to the workpiece. Wedge are normally welded or brazed to the vertical reed to prevent any losses.

\subsubsection{Lateral-drive USW}

For this kind of USW, the system mainly consists of a generator, transducer, booster and horn with welding tip as shown in Figure 2.2(b). Sometimes the horn and booster assembly are referred as a 'welding stack', which is connected to the transducer. The transducer produces a vibration of the piezoelectric disks as also in the case of wedge-reed system. The booster serves as a mounting for the welding stack as well as acts as a clamp of the joint specimens. Furthermore, it increases the transducer amplitude depending on the gain value. The welding horn can further amplify amplitude in the welding area. In this type of system, the horn is placed parallel to the welding tool vibration direction. Hence, ultrasonic welding energy is transferred to the specimens in a transverse manner. The specimens such as thin films or metal sheets are firmly clamped under welding horn tip and stationary anvil, where the upper specimen is gripped against the knurled pattern on the horn tip surface. Similarly, the lower specimen is gripped against the anvil with knurled surface. The ultrasonic vibration of the welding horn is in the parallel direction to the specimen surface, creating a scrubbing motion at the interface. It leads to the friction, causing shear, deformation, and a flattening of the surface asperities and then subsequent weld formation. Unlike wedge-reed system, this system is suitable for joining thin gauges. This system can allow for the measurement of process parameters, such as actual welding energy, mechanical amplitude and clamping force more accurately than the wedge- 
reed system. These accurate values help to correlate the weld strength to the different welding conditions [58].

It can be seen that wedge-reed system or a lateral-drive system results in the same kind of transverse vibration of the workpiece from the weld tip, as shown in Figure 2.2. The top and bottom samples move in accord with the welding tip. This sticking of the samples to the welding tips is usually attained by a roughened or knurled surface of the tip, to engage better with the surface. As a result, relative motion between the samples at a contact surface is produced by welding tip. This relative and transverse motion between the two opposing surfaces of the samples results in the scrubbing action, causing shearing and plastic deformation between asperities of the opposing surfaces, getting around growing areas of metal-to-metal contact, and results in a solid-state bonding between the samples. The two unique differences of ultrasonic metal welding system worth emphasizing are as follows [50]:

1. The type of the motion is the transverse oscillations between the samples, where the samples move parallel to each another during the metal welding process, whereas opposing surfaces move at perpendicular to one another in ultrasonic plastic welding.

2. Usually, no melting of the metals happens during welding (except during some dissimilar joints with low melting point interlayer), and the weld is via solid-state welding. In contrast, a fusion weld occurs via melting in the weld nugget of the RSW or other fusion-based processes such as the arc or laser welding. 


\subsubsection{USW equipment}

Figure 2.3 shows the dual wedge-reed ultrasonic welding equipment used in the present study. It has six major parts as indicated in Figure 2.3 including, (1) power supply and controller, (2) piezoelectric transducer (3) wedge and reed assembly, (4) welding tip, (5) clamping system, and (6) air cooling system. The power supply provides driving power to the USW system by converting line frequency to the ultrasonic frequency required by the transducer. It also provides additional control and operating function. The ultrasonic transducer converts this electrical power into mechanical vibratory power at $20 \mathrm{kHz}$. The vibration amplitude at the front end of the ultrasonic transducer is very small, usually in the range of 30-to-60 $\mu \mathrm{m}$, peak-to-peak which is invisible to the unaided eye. The very small vibration amplitude and operating frequencies above the audible limit cause little visible or audible action during a welding cycle. A wedge amplifies the vibration amplitude and transmits it to the reed. The wedge is solidly attached to the vertical reed by welding or brazing. A reed transfers this vibratory power to the contact parts to be welded via welding tip. The welding tips are detachable and connected to the reed via a threaded connection. A pneumatic system that uses compressed air to provide pressure to a cylinder which in turn provides a clamping force to the wedge-reed/tip assembly. In a dual reed system, two transducers/wedge-reed/tip assembly are used as discussed earlier. Air cooling system is used to avoid overheating of the welding tips during the welding.

\subsubsection{Process factors in the USW}




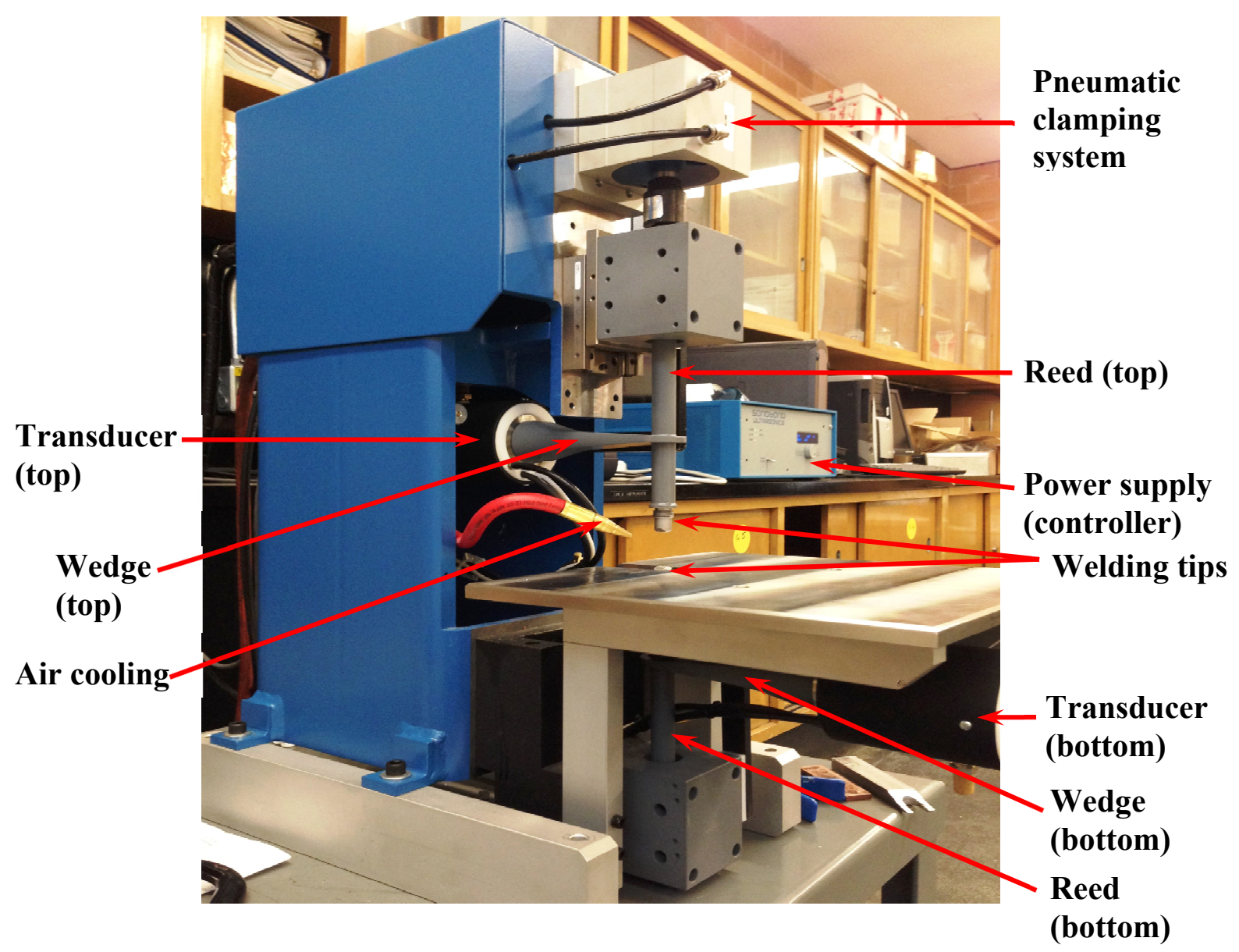

Figure 2.3: Different parts of USW machine

There are some USW process parameters that greatly influence the microstructure and properties of the welds. These parameters can be divided into two groups; process parameters and metal parameters. Process parameters include welding energy, welding time, electric power, clamping pressure (static load), the amplitude of vibration, and resonance frequency. Metal parameters include the characteristics of the specimens being welded, i.e., hardness, surface roughness, oxides and contaminants [54,60]. The ultrasonic welding transducers are designed to operate at a specific frequency ranging from 15 to $300 \mathrm{kHz}$. However, most metal welding systems operate at 20,30 , and $40 \mathrm{kHz}$ [50]. The present study was performed using a system 
(Figure 2.3) operated at a frequency of $20 \mathrm{kHz}$. Ultrasonic vibration amplitude is one of the key parameters affecting the welding. It has been identified earlier that the amplitude generated during USW varies from 30 to $60 \mu \mathrm{m}$ [44]. For welding system used in present study, the amplitude is a dependent variable and is related to the power applied. For some welding system, it can also be an independent variable, capable of being set and controlled at the power supply because of added features of the feedback control system. Clamping pressure is also a parameter, where force is applied to the samples via welding tip to bring them together firmly. The magnitude of the force depends on the material being welded and its thickness. It has been reported that the low clamping pressure leads to weak or nonexistent bonding while higher clamping pressure may lead to excessive deformation and interlocking of the parts being welded.

The welding energy, power, and time are most important parameters in the USW process. Figure 2.4 (a) shows the representative power curve ( $P$ vs. $t$ ), where the area under the curve is welding energy in Joule (more specifically electrical energy supplied to the transducer) [50]. It is evident that all three cannot be independent. Welding energy and welding time are often used interchangeably to represent the power introduced to the workpiece, as:

$$
E=P \times t
$$

where, $E$ is welding energy $(\mathrm{J}), P$ is welding power (W) and $t$ is welding time (s). If power is constant, then the energy is proportional to time. Often, a machine will include an impedance matching setting to optimize the phase match between the current and voltage and hence maximize the power for a given combination of settings [32]. There are two kinds of input mode available, energy mode and time mode. In the energy mode one can set energy at some constant power, and weld would run until such time where set energy level is reached. In the time mode, 
one can fix time at some constant power, and weld would run for the set time period. Powertime curve depends on many parameters including material, sample dimensions, surface finish, amplitude, and clamping pressure. There are other variations occurring in practice. The power supplied to the transducer is converted and transmitted as an ultrasonic power at the weld. However, there are many intermediate conversion and transmission stages which affect the efficiency of the system. This includes the efficiency of transducer, losses in the bulk material and at the interfaces of transducer, wedge, reed system, and losses at the weld tip to sample interface.

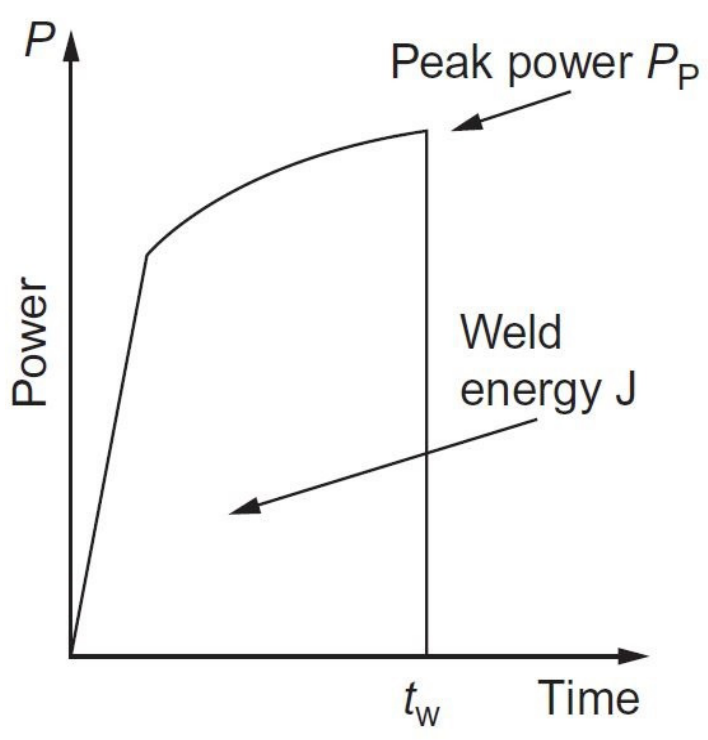

Figure 2.4: Representative power curve [50].

\subsubsection{Applications of USW}

The applications of USW for metal welding are widespread, in the electrical/electronic, automotive, aerospace, appliance, and medical products industries. The parts of metal plates, sheets, foils, wires, ribbons, and opposing flat surfaces are joined using USW. Many types of 
dissimilar metal combinations (e.g., Al-Mg) are readily welded with USW. Several examples of automotive and electrical applications are shown in Figure 2.5. One of the most common use is for automotive wire "harnesses" (Figure 2.5(a)), where many stranded copper cables are joined into a single junction. Also, it is used in the joining of multiple foils for electric vehicle and other battery applications. With the availability of high power, it is increasingly used for structural components in the automotive and aerospace industries such as closure panel in both helicopter and aircraft uses (Figure 2.5 (b and c)). Assemblies of transformers, capacitors, field coils and electric motors are other examples where ultrasonic welding is used. Another application is for encapsulating temperature-sensitive chemical or pyrotechnic materials. Furthermore, a variant of ultrasonic micro bonding is most widely used in the semiconductor and microelectronics industries. Battery and fuel cell manufacturer use ultrasonic welding to create various joints in these products, including thin gauge copper, nickel, or aluminum tabs; foil layers; or metal meshes and foams [50]. Thus, ultrasonic metal welding is well suited for the multilayer foil-to-tab joints made up of copper or aluminum foils found inside of a typical prismatic lithium-ion battery that is finding wide use in the electrical and hybrid vehicle market [61]. USW can also be used in water or a vacuum for various applications $[58,62]$. USW technique has been used to join material like alloys of copper, magnesium, aluminum, silver, titanium, nickel, and gold. USW systems can be used successfully in different welding applications, such as ring welding, line welding, continuous seam welding and spot welding [63,64], e.g., ultrasonic seam welding is used to merge foil rolls during continuous manufacturing and seam foil food and cooking pouches. Cylindrical containers with highly reactive or heat sensitive (e.g., airbag igniters) are sealed using ultrasonic torsion welding, also used to make stud weld attachments. Ultrasonic welding also used in air conditioning and 
refrigerating industries to seal a tube containing refrigerant. Recently, there is an increasing trend in the application of USW in structural automotive and aerospace applications, joining thin gauge sheet of lightweight metals such as magnesium, aluminum, and advanced steel alloys.
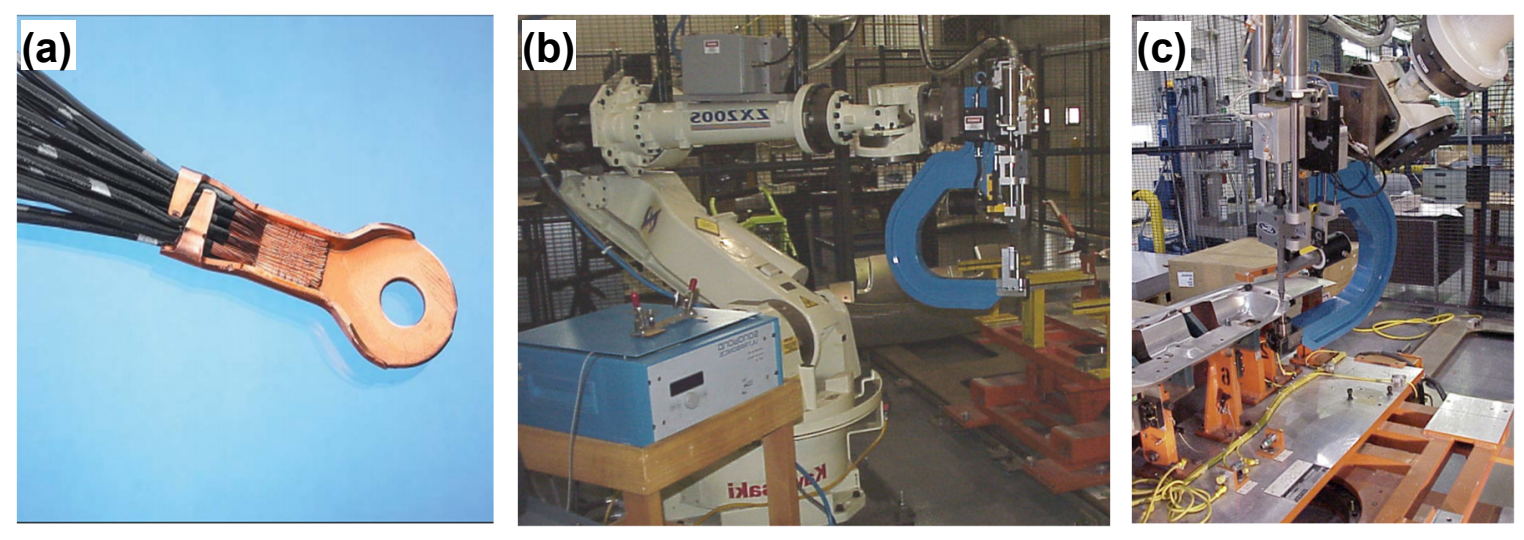

Figure 2.5: (a) Electrical wire harnesses, (b) C-Frame robotic weld gun with clamping system and (c) automotive closure panel [65].

\subsubsection{Advantages and disadvantages of USW system}

Like every other joining technique, USW process also has their advantages and disadvantages compared with other joining techniques. The major advantages and disadvantages are as follows [50]:

\section{$\underline{\text { Advantages }}$}

- A solid-state welding process, hence low heat generation

- Require low energy

- High efficiency and shorter weld time, easily automated

- Shielding gas or filler not required 
- Used to join a wide range of similar and dissimilar material combinations

- Good for high thermal conductivity materials such as $\mathrm{Al}, \mathrm{Cu}$, etc.

- Can weld combination of thin-thick sheets

- Welds through oxides and contaminants

\section{$\underline{\text { Disadvantages }}$}

- Can weld limited thickness sheets $(\leq 3 \mathrm{~mm})$

- Material with high strength and hardness are difficult to weld

- Material deformation may occur

- Noise from part resonance may occur

Many of the advantages of USW come from the solid state nature of the process. In the absence of melting and fusion, the heat generation is localized at the weld interface, and little deformation is seen away from the interface. This localized heat generation reduces heat affected zone (HAZ) during USW [66], which is detrimental to the strength of the joint. Furthermore, defects related to melting such as porosity are absent from the weld interface, unlike in RSW and laser spot welding processes. It is difficult to weld Al alloys using RSW because of their tendency to degrade electrode and high energy cost due to their higher thermal conductivity $[57,66,67]$. In contrast, most material combinations are welded using USW, even softer $\mathrm{Al}$ and $\mathrm{Mg}$ alloys. During dissimilar joining, a high rate of intermetallic reactions occurs in the liquid phase during RSW and laser welding, which degrades the joint quality $[36,68]$. USW can lessen the tendency for the IMCs formation because no liquid phase is generated $[44,69]$. Another advantage is the ability to join thin-to-thick sheets combinations. Oxides and 
contaminants are fractured, disrupted, and dispersed during USW due to friction at weld interface, e.g., oil on the surface is vaporized, and oxides are either dispersed into weld nugget edge or the turbulent micro-volume of plastically deformed material at the weld interface. However, variation in the surface condition will yield variation in the process and therefore, the strength. Hence, USW may not need any special cleaning methods, but, due consideration must be given to the consistency of surface conditions. Filler metals or shielding gases are not required during USW. However, interlayers and coatings have been used during joining difficult dissimilar material combinations, e.g., Mg-to-steel. In addition, an inert gas-filled enclosure can be used under hazardous conditions (e.g., closure of explosive containers) [50].

As discussed earlier, USW has a higher efficiency than FSSW and conventional RSW on the energy consumption and total time for welding. Table 2.1 shows the approximate requirement of welding energy and welding time during $1 \mathrm{~mm}$ aluminum sheet welding using three major spots joining technique as reported by Bakavos and Prangnell [45]. It could be seen that USW uses much lower energy of 0.6-1.5 kJ per weld compared to 3-6 kJ for FSSW and 50-100 kJ for RSW. The higher energy consumption in RSW could be attributed to a higher electrical conductivity of Al. Moreover, it can also be seen that the total welding time was slightly longer than RSW but shorter than FSSW.

With recent enhancement in the application of $\mathrm{Al}$ and $\mathrm{Mg}$ alloys in the automotive industry, the Ford Motor Company has studied the feasibility of applying USW to Al body assemblies with promising results and made a comparison with other processes [57,66]. Table 2.2 shows approximate equipment and relative cost comparison between various joining technologies such 
as RSW, self piercing rivet (SPR), gas metal arc welding (GMAW), adhesive bonding, USW, when applied to aluminum joining. It was observed that USW offers the possibility of joining aluminum automotive body structures in an environmentally friendly and cost-efficient manner.

Table 2.1: Comparison of the range of welding energy and welding time required for different spot joining process in $1 \mathrm{~mm}$ aluminum sheet [45].

\begin{tabular}{ccc}
\hline Joining process & Welding energy (kJ) & Welding time (s) \\
\hline RSW & $50-100$ & $0.15-0.3$ \\
FSSW & $3-6$ & $1.0-5.0$ \\
USW & $0.6-1.5$ & $0.25-0.6$ \\
\hline
\end{tabular}

Table 2.2: Cost comparison of different joining techniques [57].

\begin{tabular}{cccc}
\hline Joining methods & $\begin{array}{c}\text { Average } \\
\text { equipment cost }\end{array}$ & $\begin{array}{c}\text { Relative energy } \\
\text { consumption }\end{array}$ & $\begin{array}{c}\text { Relative cost per } \\
\text { joint }\end{array}$ \\
\hline RSW (8 mm welding cap) & $\$ 16,000$ & 6 & 5 \\
SPR (3 mm rivet) & $\$ 60,000$ & 1 & 10 \\
GMAW (25 mm) & $\$ 12,000$ & 18 & 3 \\
Adhesive Bonding (25x13 & $\$ 85,000$ & 1 & 1 \\
mm) & $\$ 28,000$ & 1 & \\
\hline
\end{tabular}

\subsection{Recent studies in the area of USW}

Although ultrasonic metal welding was first introduced in the early 1950s, its initial use was limited to the thin foils in additive manufacturing and wires for microelectronic packaging in the 
semiconductor industry, due to inadequate availability of the power [46,64,70-72]. A considerable amount of research has been done for these applications [71,73-78]. However, high power USW of sheet metal joining for structural applications in the automotive and aerospace industry is still in the early stage and therefore, necessary information is still lacking. Furthermore, with the development of new lightweight alloys to achieve lightweighting in the automotive and aerospace industries, the feasibility of joining these alloys with USW is still under research. In the last decade or so, there has been a significant increase in the research on joining lightweight $\mathrm{Mg}$, Al, steel, and Ti alloys using USW. Recent contributions in the similar and dissimilar joining of these alloys are discussed in the following sections.

\subsubsection{Welding of Mg alloys}

Magnesium (Mg) alloys are attractive for the transportation industries to achieve vehicle lightweighting due to their low density, high strength-to-weight ratio, and superior damping capacity. Welding and joining of magnesium alloys exert a profound effect on the application expansion of magnesium alloys, especially in the automotive and aerospace industries. The joining of $\mathrm{Mg}$ alloys requires a low and controlled power due to their specific physical properties. Also, magnesium alloys have a very high affinity for oxygen, which leads to the formation of thermodynamically stable oxide layer, which increases the complexity of the joining. Specifically, in the spot welding of Mg alloys, many joining processes such as RSW, laser spot welding (LSW), FSSW, and USW were used to join Mg alloys. Due to the challenges such as coarse grain structure, porosity in the weld, high oxidation potential, and weld cracking, solid-state joining techniques, FSSW and USW have recently attracted increasing interests due to their potential of obtaining superior joint properties compared with the fusion welding 
techniques. As discussed earlier, USW is emerging and promising spot welding technique with a low energy input and a higher efficiency. Furthermore, disadvantages such as keyhole left during welding, lower energy efficiency, and longer cycle time of FSSW, make USW even a more appealing joining technique. There are limited studies on the similar and dissimilar joining of Mg alloys using USW, with the majority of them being done in the last decade. The following section discusses the similar joining of Mg alloys.

\subsubsection{Microstructure analysis}

During USW, the near interface weld region defined as a nugget zone (NZ) experiences a significant change in microstructure due to friction heating and shear plastic deformation via out of phase rubbing of two sheets under clamping pressure [44,79]. Patel et al. [80-82] studied the USW of AZ31B-H24 Mg alloy sheet and examined the effects of welding energy on the microstructure and mechanical properties. Figure 2.6 shows the optical micrograph of AZ31BH24 BM and welded samples at different energy levels. (a) AZ31 BM, (b) $500 \mathrm{~J}$, (c) $1500 \mathrm{~J}$, (d) $2500 \mathrm{~J}$. It was observed that the grains (6.4 to $9.6 \mu \mathrm{m})$ in the welded samples at all energy levels were coarser than those in the as-received base metal $(5.46 \mu \mathrm{m})$ [80]. This change in the grain size was attributed to the dynamic recrystallization due to high temperature and plastic deformation during welding as also reported by Bakavos and Prangnell [45] and Allameh et al. [83]. It was reported that the dynamic recrystallization during USW of Mg alloys was due to lack of easily activated slip system, low stacking fault energy, and higher grain boundary diffusion rate in Mg alloys $[84,85]$. Furthermore, the aspect ratio of grains also increased with 
increasing welding energy, which was reasoned as a result of increasing shear forces at the weld interface.
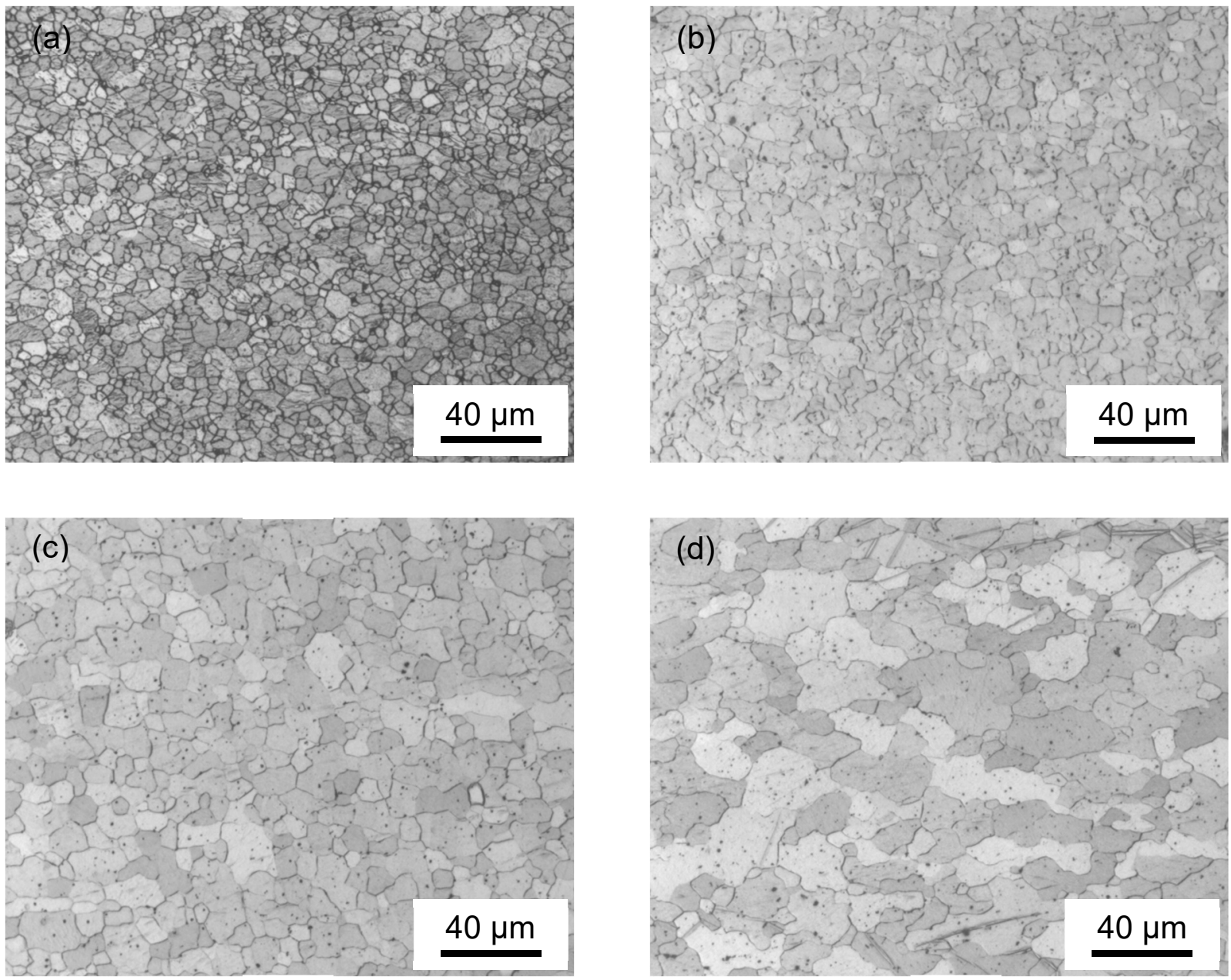

Figure 2.6: Optical micrograph of AZ31 BM and welded samples at different energy levels. (a) AZ31 BM, (b) $500 \mathrm{~J}$, (c) $1500 \mathrm{~J}$, (d) $2500 \mathrm{~J}$ [80].

Zener and Hollomon [85] established a combined effect of temperature and strain rate on the resulting grain size during rolling using parameter known as Zener-Hollomon parameter,

$$
Z=\dot{\varepsilon} \cdot e^{\frac{Q}{R T}}
$$


where $\dot{\varepsilon}$ is the strain rate, $R$ is the universal gas constant $(8.314 \mathrm{~J} / \mathrm{mol} \cdot \mathrm{K}), T$ is the absolute temperature in Kelvin, and $Q$ is the related activation energy. This parameter was widely used to predict grain size under the combined effect of temperature and strain rate [86]. Patel et al. [80] calculated this parameter for USWed AZ31-H24 Mg alloy similar joint by using experimentally measured interface temperature and calculated strain rate. The interface temperature measurement was carried out using a K-type thermocouple, which was placed into the interface by creating a groove. However, the change in the surface condition due to groove and the potential effect on the measured temperature were not acknowledged in this study. Furthermore, total shear strain rate was calculated using equation reported by Bates et al. [87] for vibration welding of thermoplastics as follows,

$$
\dot{\gamma}=\frac{2 f A}{h_{o}},
$$

where $f$ is the frequency of vibration, $h_{0}$ is the thickness of the melt layer between the plates, and $A$ is the amplitude of vibration. However, this equation was based on Nonhof et al. [88], who reported the average shear strain rate during ultrasonic plastic welding due to the driving velocity of $A f$ could be estimated by,

$$
\dot{\gamma}_{A f}=\frac{4 f A}{h_{o}},
$$

where $f$ is the frequency of vibration, $h_{o}$ is the slit thickness, and $A$ is the amplitude of ultrasonic vibration/rubbing. It leads to a discrepancy over which equation should be used to calculate strain rate. Since Bates et al. reported the equation for single reed vibration machine, it could be understood that the strain rate would be double for double reed vibration machine. Therefore, in contrast to Patel et al. [80], it was identified that the Nonhof et al. [88] equation would be more appropriate in the present dual wedge-reed USW machine. After identifying an 
appropriate equation, the strain rate equation also required an amplitude of vibration. As mentioned earlier, in the present welding system, ultrasonic vibration was a dependent parameter and cannot be controlled independently. Bursukov et al. [89] noted that the energy supplied to the workpiece is proportional to the square of amplitude and outputting coefficient $(\varnothing)$,

$$
E_{o} \sim \varnothing A^{2},
$$

where $\emptyset$ is defined as,

$$
\varnothing=\left(1-\frac{\rho_{1} \cdot c_{1}-\rho_{2} \cdot c_{2}}{\rho_{1} \cdot c_{1}+\rho_{2} \cdot c_{2}}\right)^{2},
$$

where $\rho$ is the density of the material and $c$ is ultrasonic velocity in the material. Here 1 is for workpiece material, and 2 is for sonotrode material. Patel et al. [80] assumed the value of $\emptyset$ as 1. Using the above equations, a relationship between the Zener-Hollomon parameter $(Z)$ and grain size was reported, where grain size decreased with increasing $Z$ value. Chang et al. [84] also developed a relationship between grain size and Zener-Holloman parameter $(Z)$ of friction stir processed (FSP) AZ31 Mg alloy. However, for a new low rare earth containing ZEK100 $\mathrm{Mg}$ alloy, there is no information about the feasibility of joining ZEK100 Mg alloy using USW. Only limited studies are reported on the FSSW and laser welding of ZEK100 Mg alloy.

Rao et al. [25] studied microstructure during FSSW of ZEK100 Mg alloy similar joints with varying process parameters (tool rotational rate, plunge depth). The grain structure in the stir zone (SZ) and thermos-mechanically affected zone (TMAZ) of the welds for $1500 \mathrm{rpm}$ and $2250 \mathrm{rpm}$ at a plunge depth of $0.2 \mathrm{~mm}$ along with as received base metal (BM) microstructure is shown in Figure 2.7. 

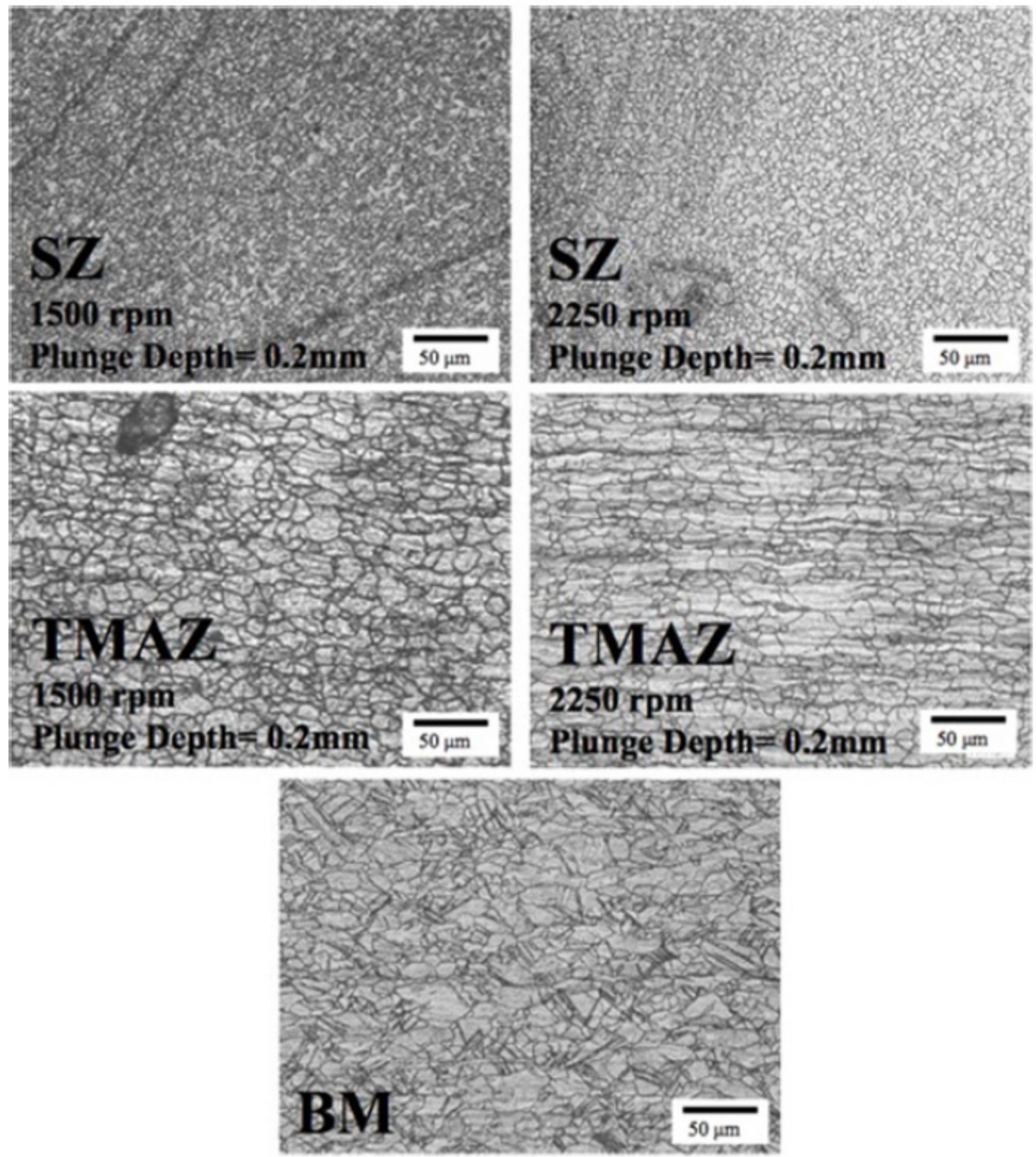

Figure 2.7: Representative microstructure of the friction stir spot welded (FSSWed) lap-shear coupons in the stir zone (SZ) at (a) $1500 \mathrm{rpm}$, (b) $2250 \mathrm{rpm}$, thermo-mechanically affected zone (TMAZ) at (c) $1500 \mathrm{rpm}$, (d) $2250 \mathrm{rpm}$, and (e) base material (BM) [25].

It can be seen that the BM consists of large irregular grains. As expected, a high degree of plastic deformation was observed in the SZ which resulted in the formation of very fine grains 
compared to as-received BM. The TMAZ experienced a high degree of heat but relatively less deformation and therefore, showed large partially recrystallized grains in this region. Furthermore, it was observed that grains at a higher tool rotation rate of $2250 \mathrm{rpm}$ were more recrystallized than at $1500 \mathrm{rpm}$ due to a higher heat generation. Similar observations were reported by Rodrigues et al. [90] during FSSW of ZEK100 Mg alloy. Harooni et al. [91] studied the effect of laser welding parameters such as laser power, scanning speed and gap between two sheets on weld bead surface quality and weld bead profile. It was observed that with increasing welding speed, a lower heat input resulted in a smaller bead width on the top surface. Moreover, an increasing welding power increased weld bead width on the top surface due to the increase in the heat input.

\subsubsection{Mechanical properties}

The process optimization for most welding techniques is judged based on the strength of the welded joints. In USW, important process parameters such as welding energy and time are optimized by analyzing their tensile lap shear strength. Since the performance of the welds is a function of properties of the material being welded. With the development of a new highperformance ZEK100 Mg alloy, there is a need to optimize USW process for joining it. As mentioned earlier, as per our knowledge there are no reports on the similar USW of ZEK100 Mg alloy. However, Patel et al. [82] analyzed the tensile lap shear strength of the USWed joints of a conventional AZ31-H24 Mg alloy at different welding energy levels as shown in Figure 2.8. It was shown that the strength increased initially with increasing welding energy, reached an optimum value and decreased with a further increase in the welding energy. The initial 
increase in strength with welding energy was attributed to high temperatures and strain rate, which increased diffusion at the weld interface. The decreasing trend of strength at higher welding energy levels was due to the formation of large tensile stresses at the edge of the nugget, resulting in extensive local plastic deformation and nugget pull-out during the lap shear test experiments. The maximum strength was $89 \mathrm{MPa}$ achieved at a welding energy of $2000 \mathrm{~J}$.

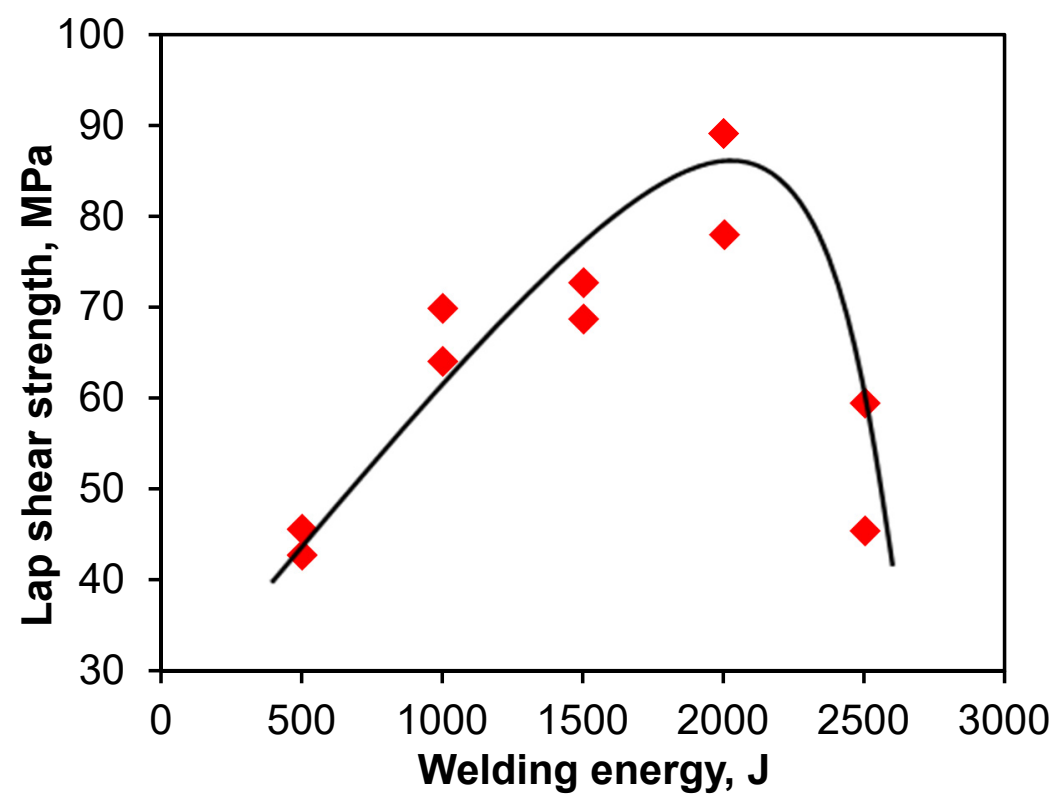

Figure 2.8: Tensile lap shear strength of USWed AZ31-to-AZ31 Mg alloy joints at varying energy inputs [82].

Rao et al. [25] used FSSW to join ZEK100 Mg alloy and studied the effect of process parameters (tool shoulder plunge depth and tool rotation rate) and microstructural attributes (hook height and hook width) on the strength of the joints as shown in Figure 2.9. Figure 2.9(a) showed an increase in tool shoulder plunge depth from 0 to $0.2 \mathrm{~mm}$ increases the average tensile lap shear strength, however, a further increase to $0.6 \mathrm{~mm}$, leads to a significant decrease in the average tensile lap shear strength. The decrease in the strength at higher tool shoulder plunge 
depth was attributed to the reduction in upper sheet thickness. Moreover, it was identified that a lower tool rotation speed and a lower tool shoulder plunge depths gave a higher strength than at a higher rotation speed and a higher tool shoulder plunge depth.

Figure 2.9(b) showed an effect of effective sheet thickness on the tensile lap shear strength. Effective sheet thickness was higher for samples welded at a lower tool rotation rate of 1500 rpm compared to $2250 \mathrm{rpm}$. Also, with an increase in the tool shoulder plunge depth, more material removed and effective sheet thickness was reduced. Interfacial hooking cracks during FSSW was identified as a prominent issue and has a significant effect on the strength of the joints. Figure 2.9(c) shows the lap shear strength as a function of hook width. It was observed that hook width increased with increasing tool rotational speed as well as a plunge depth. However, a weak correlation was observed between hook width and joint strength. From Figure 2.9(d), it was seen that a lower tool rotational rate of $1500 \mathrm{rpm}$ results in a higher strength compared to higher $2250 \mathrm{rpm}$. This difference in grain structure was attributed to the difference in grain size as shown in Figure 2.7.

\subsubsection{Welding of dissimilar alloys}

Today's multi-material design of various structural parts and components, especially in an automotive application, required dissimilar joining of $\mathrm{Mg}, \mathrm{Al}$, Steel, and $\mathrm{Cu}$. Therefore, there is a pressing need for technology to develop robust welding processes for producing a reliable and durable dissimilar joints. Due to a continuous increase in the usage of $\mathrm{Mg}$ and $\mathrm{Al}$ in the

industries, dissimilar joints such as Mg-to-Al, Al-to-steel, and $\mathrm{Mg}$-to- $\mathrm{Cu}$ are of special 
importance. In the following subsection, various literature reports on dissimilar Mg-to-Al, Alto-steel, and Mg-to-Cu joints will be briefly discussed.
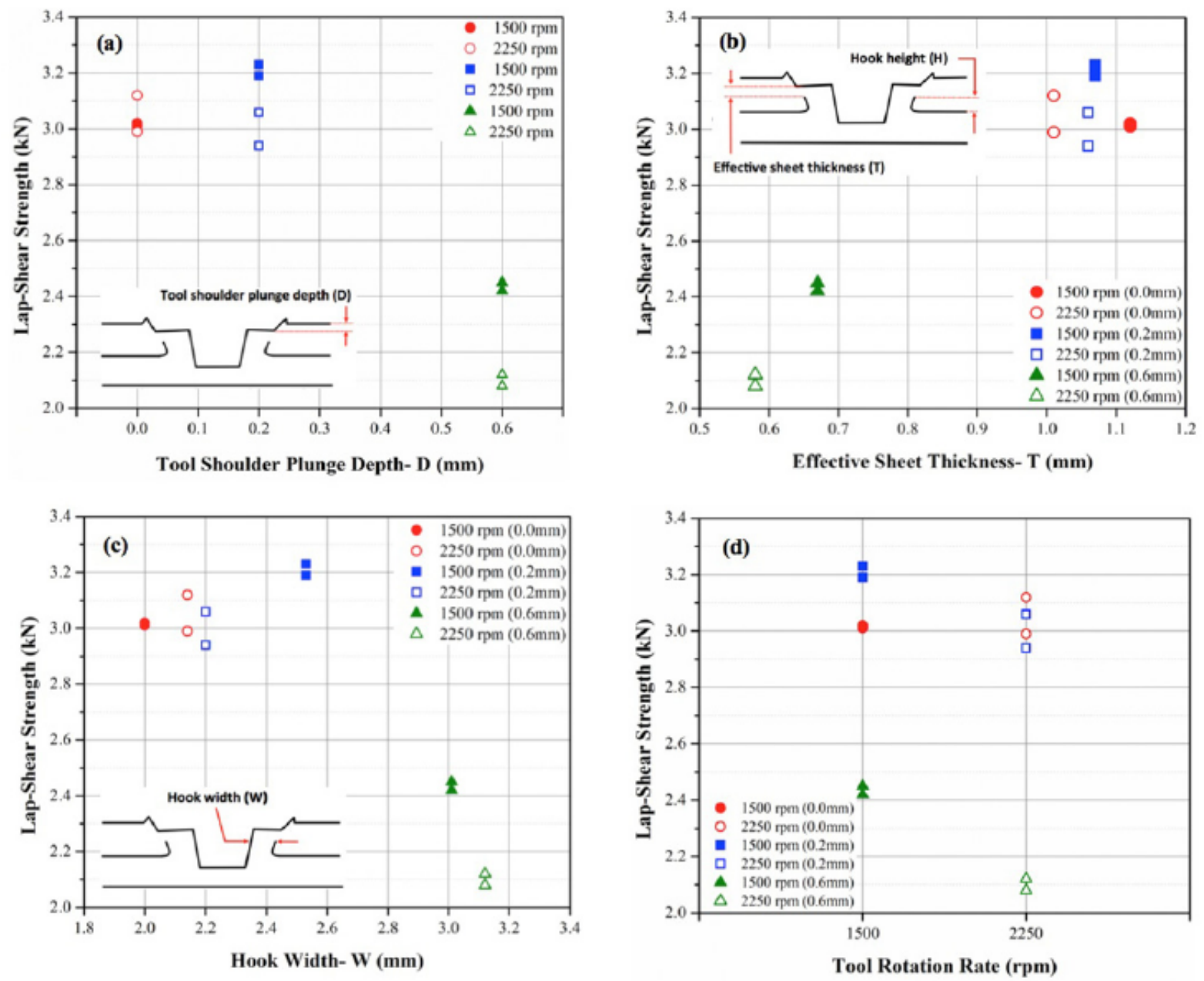

Figure 2.9: Lap shear strength of FSSWed ZEK100 Mg alloy as a function of (a) tool shoulder plunge depth, (b) effective sheet thickness, (c) hook width, and (d) tool rotation rate [25].

\subsubsection{Dissimilar Mg-to-Al joints}

With the increasing use of $\mathrm{Al}$ and $\mathrm{Mg}$ alloys in the automotive industry, there is a significant demand to develop a reliable and durable dissimilar Mg-to-Al joints. The major difficulty in 
the welding of $\mathrm{Al}$ and $\mathrm{Mg}$ alloys using conventional fusion processes is the formation of excessive IMCs, which have a detrimental effect on the joint strength [40,92]. As per the MgAl binary phase diagram [93], IMCs such as $\mathrm{Mg}_{17} \mathrm{Al}_{12}$ and $\mathrm{Mg}_{2} \mathrm{Al}_{3}$ can be formed during welding. This IMCs have microhardness in the range of 152 to $221 \mathrm{HV}$ while microhardness of base metal $\mathrm{Mg}$ and $\mathrm{Al}$ ranges from 25 to $60 \mathrm{HV}[94,95]$. The high hardness of IMCs indicates an increase in brittleness at the interface and results in a decrease in the strength. The key to increasing the joint strength is to control the formation of the IMCs as little as possible during the joining process. The three main approaches reported to eliminate or reduce the negative effect are to use (1) a lower welding temperature and (2) a shorter welding time, and (3) add filler material in-between the joint $[47,95]$. Recently, solid-state welding techniques, e.g., USW, FSW, linear friction welding (LFW), and FSSW, are gaining popularity for dissimilar joining applications due to their lower welding temperature, shorter reaction time and lower energy consumption, compared with fusion welding techniques.

There are some studies on the joining of $\mathrm{Mg}$ to Al using USW in recent years. Panteli et al. [52] studied USW of AZ31-H24 to A16111-T4 joints at varying welding energy levels. It was reported that a peak load of $2 \mathrm{kN}$ was achieved at $600 \mathrm{~J}(0.4 \mathrm{~s})$ of the optimum welding condition, where the interface layer thickness was $\sim 5 \mu \mathrm{m}$. It was identified that IMCs nucleates within microwelds at the weld interface within a very short welding time and spread as well as grow rapidly to form a continuous layer, composed of two sub-layers of $\mathrm{Mg}_{2} \mathrm{Al}_{3}$ and $\mathrm{Mg}_{17} \mathrm{Al}_{12}$ as shown in Figure 2.10 [52]. Also, liquation at the weld interface was observed at higher weld energy levels and longer welding times at temperatures below the equilibrium eutectic reaction temperature as indicated in the Al-Mg binary phase diagram [93]. 


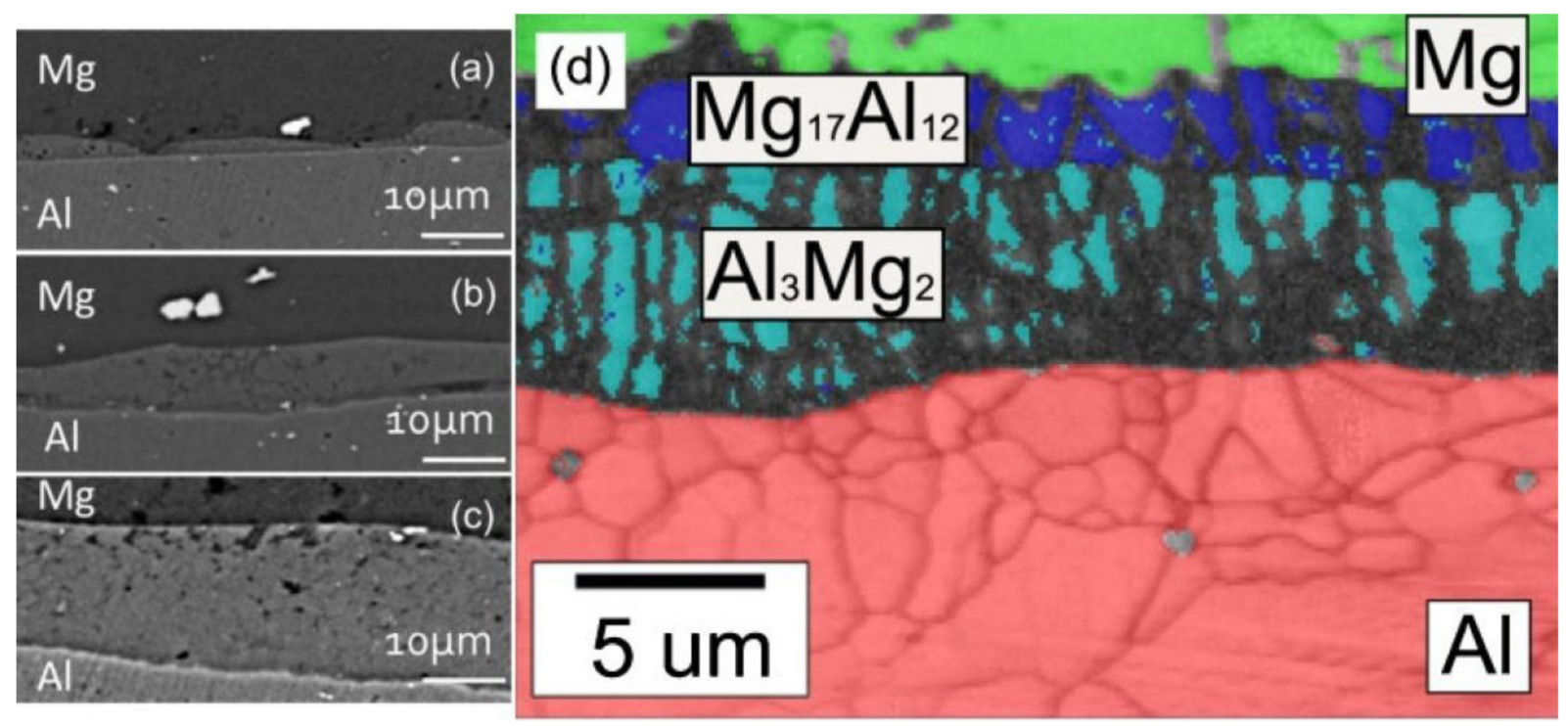

Figure 2.10: SEM images of the joint interface at weld center showing IMC growth at different welding time of (a) $0.24 \mathrm{~s}$, (b) $0.40 \mathrm{~s}$, (c) $0.70 \mathrm{~s}$, and (d) Electron backscatter diffraction (EBSD) phase map [52].

Robson et al. [96] proposed a new model to foresee IMCs formation and growth during the dissimilar USW of Mg and Al alloy using ultrasonic welding. As proposed, the nucleation of IMCs and formation of initial microbond occurred at $0.5 \mathrm{~s}$ during the welding. After that, this nucleated IMCs grow by combining with other microbond, which led to an increase in their thickness within a very short time of $1 \mathrm{~s}$. The further increase in IMC thickness was relatively slower due to the resistance to diffusion by the interface layer. Patel et al. [47] studied the effect of Sn interlayer on USW of AZ31-H24 Mg alloy to A15754-O Al alloy joints. Figure 2.11 shows the average lap shear strength as a function of welding energy, where it can be seen that some improvement in the weld strength was achieved via an addition of tin interlayer. Although the improvement was smaller ( 41 MPa with tin, $\sim 35 \mathrm{MPa}$ without tin), there was also some reduction in welding energy required to achieve the maximum weld strength. The improvement in strength was attributed to the absence of Mg-Al IMCs and the formation of solid solution of $\mathrm{Sn}$ with $\mathrm{Mg}$ and $\mathrm{Al}$ and the composite-like $\mathrm{Sn}$ and $\mathrm{Mg}_{2} \mathrm{Sn}$ eutectic structure in the interlayer. 


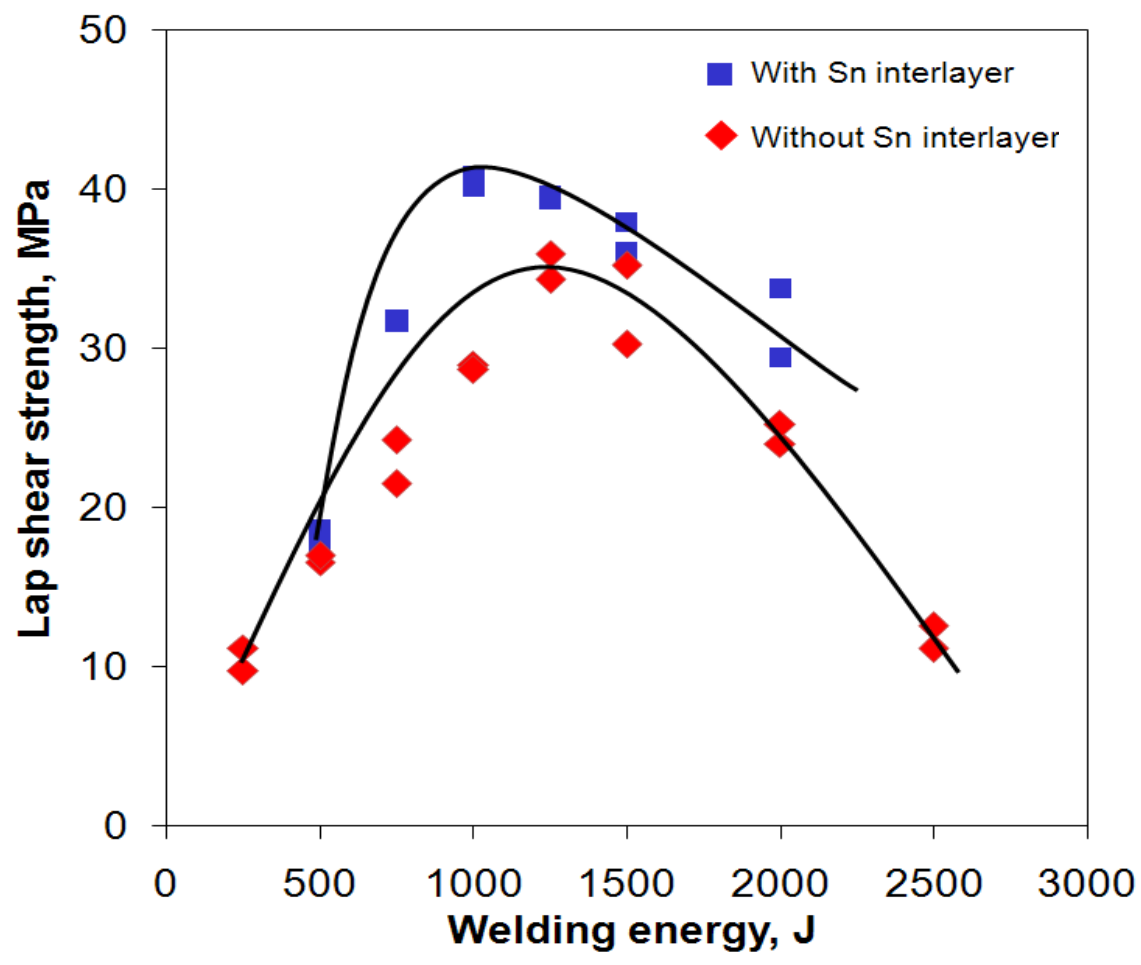

Figure 2.11: Lap shear strength as a function of welding energy for Mg-Al joints with and without Sn interlayer [47].

\subsubsection{Dissimilar Al-to-steel joints}

In the last decade, Al alloys have become increasingly popular for lightweighting in the automotive structural applications. Since it is very difficult to replace each and every part of a vehicle with Al counterparts, the use of hybrid structures made by joining dissimilar metals like Al alloys and HSLA steel has now become inevitable [27,97]. Previous studies showed that the most detrimental issue is controlling the formation of IMCs at weld interface, even with rapid solid-state welding process such as USW [69]. As per Al-Fe binary phase diagram [98,99], IMCs such as $\mathrm{Fe}_{3} \mathrm{Al}, \mathrm{FeAl}, \mathrm{FeAl}_{2}, \mathrm{Fe}_{2} \mathrm{Al}_{5}$, and $\mathrm{FeAl}_{3}$ can be formed during USW. There have been several studies on the USW of Al alloy to steel joints. Prangnell et al. [46] studied the USW of A16111-T4 and DC04 steel at various welding times. During tensile lap shear tests, a 
maximum failure load of $2.8 \mathrm{kN}$ was achieved at a weld time of $\sim 1.5 \mathrm{~s}$ or a welding energy of $\sim 2000$ J. Haddadi et al. $[100,101]$ showed that the tensile lap shear strength reduced from the maximum $3.1 \mathrm{kN}$ to minimum $1.7 \mathrm{kN}$ with increasing welding time due to the increase in $\mathrm{Fe}_{2} \mathrm{Al}_{5}$ and $\mathrm{FeAl}_{3} \mathrm{IMCs}$ at the interface of $\mathrm{Al}$ to steel USWed joints. Other studies have used interlayer or coating to either inhibit their growth or completely avoid the formation of such IMCs or form relatively ductile IMCs $[27,37,102,103]$. Chen et al. [102] used $\mathrm{Ni}$ interlayer to prevent the formation of IMCs inside fusion zone during laser penetration welding of $\mathrm{Al}$ to steel and improved joint strength. Meshram et al.[68] and Maldonado et al. [104] performed friction welding of $\mathrm{Al}$ to steel with a silver interlayer and reported the formation of $\mathrm{Ag}_{3} \mathrm{Al}$ phase along with the brittle Al-Fe IMCs. Ueda et al. [105] (in RSW), Chen et al. [106] (in friction stir welding), and Patel et al. [27] and Haddadi et al. [37] (in USW), etc., have used zinc coated steel to inhibit/eliminate Al-Fe IMCs during Al-steel joining and showed improved mechanical properties. However, it is unclear how Zn layer on galvanized HSLA steel would react with typical automotive heat-treatable Al alloy A16111-T4 during USW. Furthermore, Haddadi et al. [37] showed the formation of a distinct diffusion pattern during USW of Al6111-T4 to DX56Z steel, however, Patel et al. [27] did not observe similar diffusion pattern during USW of A15754-O to galvanized HSLA steel. Therefore, it is unclear whether similar diffusion pattern will form during USW of A16111-T4 to galvanized HSLA steel. Some have reported squeezing of Al-Zn eutectic during USW of $\mathrm{Al}$ to $\mathrm{Zn}$ coated steel. However, their role in mechanical properties of the joints is not clearly understood. Chen et al. [107] reported softening in weld zone immediately after welding of USWed A16111-T4 alloy and showed a rapid recovery by natural aging. However, it is unknown whether similar softening and recovery would occur during USW of A16111-T4 to galvanized HSLA steel. 


\subsubsection{Dissimilar Mg-to-Cu joints}

It has been reported that $\mathrm{Mg}-\mathrm{Cu}$ bimetals are widely used in the electronic and electrical industries, electrical appliances, machinery and automotive industries. The research and application of $\mathrm{Mg}-\mathrm{Cu}$ bimetals have been extended from navigation and military fields to civil products of additional high value such as an automobile, computer and communication equipment [34]. These applications involve welding and joining of two dissimilar materials: $\mathrm{Cu}$ and $\mathrm{Mg}$ alloy. Dissimilar welding of the Mg alloys to aluminum and steel is an imperative manufacturing process in the multi-material vehicle body $[52,108]$. To improve the $\mathrm{Mg}$ alloy and steel joint strength, several researchers [109-111] used $\mathrm{Cu}$ interlayer via different joining techniques. Similarly, Zhang et al. [112] used $\mathrm{Cu}$ interlayer to improve the strength of $\mathrm{Mg}$ to Al diffusion bonding. This indicates the importance of joining $\mathrm{Cu}$-to-Mg alloy. However, there are only a few studies on the joining of $\mathrm{Cu}$-to-Mg using diffusion bonding and TIG welding processes [34,112-115]. Mahendran et al. [34] performed $\mathrm{Cu}-\mathrm{Mg}$ joining using diffusion bonding process and achieved a maximum strength of $66 \mathrm{MPa}$ at a bonding temperature of $500^{\circ} \mathrm{C}$ and holding time of $15 \mathrm{~min}$, which indicates significantly higher energy consumption and longer weld time compared with the USWed dissimilar joints [49,116]. Liu et al. [115] performed TIG welding of Cu-to-AZ31B and reported that the interface diffusion layer was composed of $\mathrm{Mg}_{2} \mathrm{Cu}$ and $\mathrm{MgCu}_{2} \mathrm{IMCs}$ with a thickness of $\sim 150 \mu \mathrm{m}$. However, no information is available on the USW of Mg-Cu dissimilar joints in spite of widespread potential applications. It is unclear if both IMCs would form during USW of Mg-Cu bimetals and how the interfacial microstructure changes with varying ultrasonic welding energy levels. 


\subsection{Summary of the literature review}

Based on the above literature survey, it is clear that even though there are many studies on USW in the last decade, further studies in many areas are required, which are listed below.

- Most studies in USW of Mg alloy are focused on AZ31-H24 Mg alloy. However, with the development of new high-performance rare earth containing ZEK100 Mg alloy, there are only limited studies on FSSW, but no studies on USW have been reported. Therefore, it is necessary to develop and optimize USW process for this ZEK100 Mg alloy. It could be achieved by thermal profile measurements at weld interface, calculating strain rate, microstructure analysis, and hardness and tensile laps shear strength measurements.

- For the application of this ZEK100 Mg alloy, it is necessary to study the feasibility of joining ZEK100 Mg alloy with automotive grade Al alloy. However, such studies especially using USW technique are not reported. It is identified in the literature that $\mathrm{Mg}$ - $\mathrm{Al}$ joint strength is controlled by IMCs at the weld interface. However, it is unknown the type of IMCs and their growth behavior in the ZEK100 Mg alloy.

- There are several studies on USWed Al alloys to steel joints. However, most of them are performed using conventional steel, and there are only very few studies using HSLA steel. Formation of HAZ (soft zone) during similar welding of heat-treatable Al alloy using USW has been reported. Though, the presence of such zone during dissimilar joining with steel and its effects on weld strength have not yet been studied.

- Many studies have shown squeezed-out eutectic liquid or interlayer liquid outside the nugget, but their effects on strength and failure mode of the joints are not well understood. 
- To the author's knowledge, there are no studies reported on the development and optimization of USW for Mg-to-Cu joints.

Therefore, the present work is aimed at identifying the solution for the above questions and gaining a better understating of USW for the similar and dissimilar joining of lightweight alloys with particular emphasis on the microstructural evolution and mechanical properties. A number of experiments were undertaken to achieve the listed objectives. 


\section{Chapter 3. Materials and Experimental Procedure}

This chapter includes details of the materials and experimental procedures used in the present study to characterize the USWed similar and dissimilar joints.

\subsection{Materials}

The materials used in the present study were based on recent research trends for structural applications in the automotive and aerospace industries. The current research involves commercial $1.5 \mathrm{~mm}$ and $2 \mathrm{~mm}$ thick sheet of ZEK100-O rolled $\mathrm{Mg}$ alloy supplied by Magnesium Electron North America, Inc. via Magna International Inc. and University of Waterloo, $1.5 \mathrm{~mm}$ thick sheet of A15754-O Al alloy and 1.25 mm thick Al6111-T4 Al alloy supplied by General Motors, USA, $1.2 \mathrm{~mm}$ thick sheet of galvanized HSLA 340 steel supplied by ArcelorMittal Dofasco via University of Waterloo, and $2 \mathrm{~mm}$ thick sheet of AZ31B-H24 $\mathrm{Mg}$ alloy supplied by General Motors, USA. The chemical composition of each of these materials is shown in Table 3.1 to 3.5. The physical properties of materials used in this research are shown in Table 3.6.

Table 3.1: Chemical composition of the ZEK100-O Mg alloy [44].

\begin{tabular}{cccccc}
\hline Elements & $\mathrm{Zn}$ & $\mathrm{Zr}$ & $\mathrm{Nd}$ & $\mathrm{Mn}$ & $\mathrm{Mg}$ \\
\hline $\mathrm{wt} \%$ & 1.3 & 0.25 & 0.2 & 0.01 & Bal. \\
\hline
\end{tabular}

Table 3.2: Chemical composition of the Al5754-O Al alloy [117].

\begin{tabular}{cccccc}
\hline Elements & $\mathrm{Mg}$ & $\mathrm{Mn}$ & $\mathrm{Sc}$ & $\mathrm{Zr}$ & $\mathrm{Al}$ \\
\hline $\mathrm{wt} \%$ & 3.42 & 0.63 & 0.23 & 0.22 & $\mathrm{Bal}$. \\
\hline
\end{tabular}


Table 3.3: Chemical composition of the Al6111-T4 Al alloy.

\begin{tabular}{ccccccc}
\hline Elements & $\mathrm{Si}$ & $\mathrm{Cu}$ & $\mathrm{Mg}$ & $\mathrm{Fe}$ & $\mathrm{Mn}$ & $\mathrm{Al}$ \\
\hline $\mathrm{wt} \%$ & 0.82 & 0.59 & 0.58 & 0.26 & 0.20 & $\mathrm{Bal}$. \\
\hline
\end{tabular}

Table 3.4: Chemical composition of the HSLA 340 steel.

\begin{tabular}{ccccccccccc}
\hline Elements & $\mathrm{C}$ & $\mathrm{Si}$ & $\mathrm{Mn}$ & $\mathrm{Ni}$ & $\mathrm{Cr}$ & $\mathrm{Mo}$ & $\mathrm{Cu}$ & $\mathrm{Al}$ & $\mathrm{Nb}$ & $\mathrm{Fe}$ \\
\hline $\mathrm{wt}^{2} \%$ & 0.06 & 0.227 & 0.624 & 0.013 & 0.041 & 0.005 & 0.044 & 0.039 & 0.021 & Bal. \\
\hline
\end{tabular}

Table 3.5: Chemical composition of the AZ31B-H24 Mg alloy.

\begin{tabular}{ccccccc}
\hline Elements & $\mathrm{Al}$ & $\mathrm{Zn}$ & $\mathrm{Mn}$ & $\mathrm{Ni}$ & $\mathrm{Fe}$ & $\mathrm{Mg}$ \\
\hline $\mathrm{wt} \%$ & 3 & 1 & 0.6 & 0.005 & 0.005 & Bal. \\
\hline
\end{tabular}

Table 3.6: Physical properties of the common materials used in this study $[27,44]^{*}$.

\begin{tabular}{|c|c|c|c|c|c|c|c|}
\hline Materials & $\begin{array}{l}\text { Density } \\
, \mathrm{g} / \mathrm{cm}^{3}\end{array}$ & $\begin{array}{l}\text { Modulus } \\
\text { of } \\
\text { elasticity, } \\
\text { GPa }\end{array}$ & $\begin{array}{l}\text { Yield } \\
\text { Strength } \\
, \mathrm{MPa}\end{array}$ & $\begin{array}{l}\text { Ultimate } \\
\text { Tensile } \\
\text { Strength, } \\
\mathrm{MPa}\end{array}$ & $\begin{array}{l}\text { Elongation, } \\
\%\end{array}$ & $\begin{array}{l}\text { Thermal } \\
\text { conductivity } \\
\text {, W/m.K }\end{array}$ & $\begin{array}{l}\text { Melting } \\
\text { point, } \\
{ }^{\circ} \mathrm{C}\end{array}$ \\
\hline $\begin{array}{c}\text { ZEK100- } \\
\text { O }\end{array}$ & 1.77 & 45 & 190-199 & $248-253$ & $14.2-17.8$ & 96 & $\begin{array}{l}605- \\
630\end{array}$ \\
\hline $\begin{array}{c}\text { AZ31B- } \\
\text { H24 }\end{array}$ & 1.77 & 45 & 220 & 290 & 15 & 96 & $\begin{array}{l}605- \\
630\end{array}$ \\
\hline $\begin{array}{c}\text { A15754- } \\
\text { O }\end{array}$ & 2.71 & 71 & 96 & 220 & 26 & 125 & $\begin{array}{l}640- \\
660\end{array}$ \\
\hline $\begin{array}{c}\text { Al6111- } \\
\text { T4 }\end{array}$ & 2.71 & 71 & 150 & 280 & 26 & 154 & $\begin{array}{l}585- \\
650\end{array}$ \\
\hline $\begin{array}{c}\text { HSLA } \\
340 \text { steel }\end{array}$ & 7.87 & 205 & 370 & 445 & 26.7 & 43 & $\begin{array}{l}1500- \\
1550\end{array}$ \\
\hline
\end{tabular}

*Data were taken from (www.matweb.com) 


\subsection{USW process parameters}

A dual wedge-reed, Sonobond-MH2016 USW system operated at a frequency of $20 \mathrm{kHz}$ was used. The samples were welded at various energy levels ranging from 250 to $3000 \mathrm{~J}$ at a constant power setting of $2000 \mathrm{~W}$, an impedance setting of 8 , and a pressure of $0.4 \mathrm{MPa}$. The samples for all joint configurations were sheared from the sheets to the size of $80 \mathrm{~mm} \times 15 \mathrm{~mm}$ except for $\mathrm{Al}$ to steel joints where $60 \mathrm{~mm} \times 15 \mathrm{~mm}$ were used. Figure 3.1 shows a schematic diagram of the lap joint. To maintain a consistent surface condition, the surfaces of all samples were ground using 120 grit grinding papers perpendicular to the vibration direction and parallel to the rolling direction and then cleaned using acetone and dried out. The joints were achieved by a relative transverse displacement between the sheets with a $20 \mathrm{~mm}$ overlap having a vibration direction perpendicular to the rolling direction. The joints were prepared using energy mode setting on USW machine, where the weld energy $(E$, in $\mathrm{J})$ is determined by the level of power $(P$, in $\mathrm{kW})$ and weld time $(t$, in s), i.e., $E \approx P \times t$. For example, $1000 \mathrm{~J}$ at $2 \mathrm{~kW}$ is equivalent to $\sim 0.5 \mathrm{~s}$.
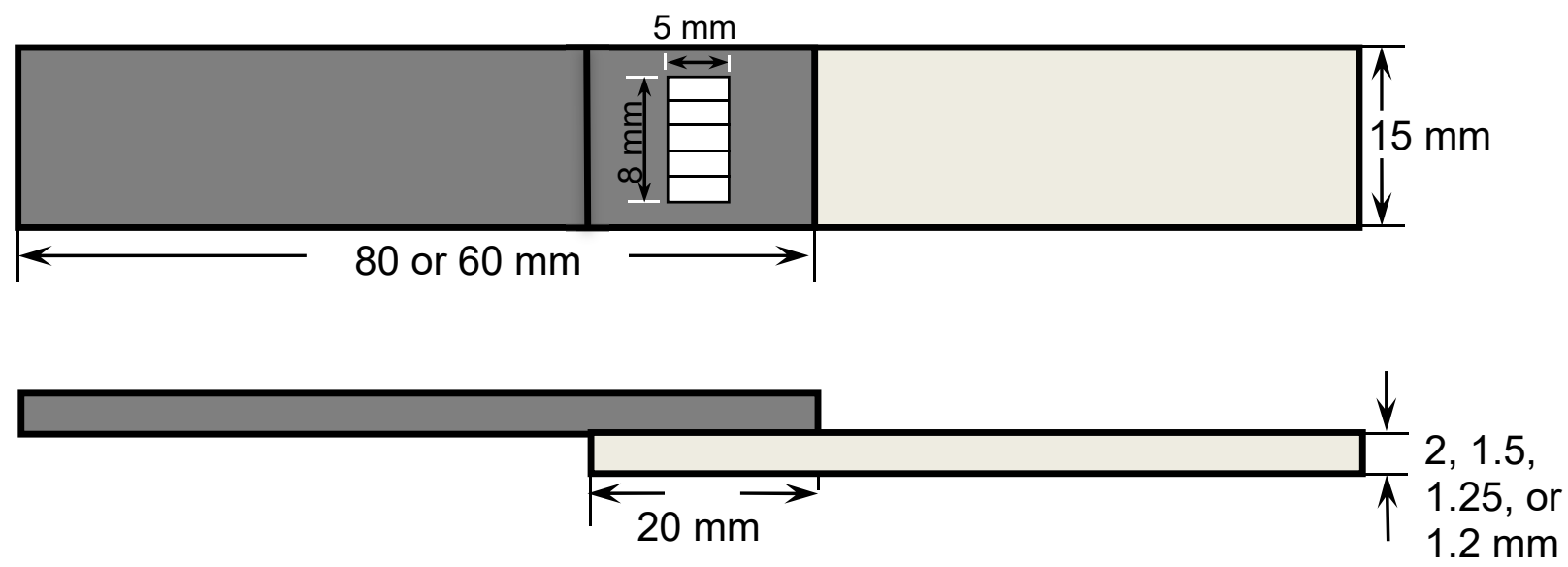

Figure 3.1: Schematic diagram of the lap joint. 
As discussed earlier, ultrasonic vibration is applied through a tool called welding tip or sonotrode tip. The tip design has a significant influence on the joint efficiency and strength. Figure 3.2 shows detail macrograph of the tip used in the present study. Standard $8 \times 5 \mathrm{~mm}$ flat serrated (knurl pattern) tips having nine parallel teeth were used for all the joints to ensure good grasping of top and bottom sheets so as to eliminate the relative motion between the sonotrode tip and sheet.

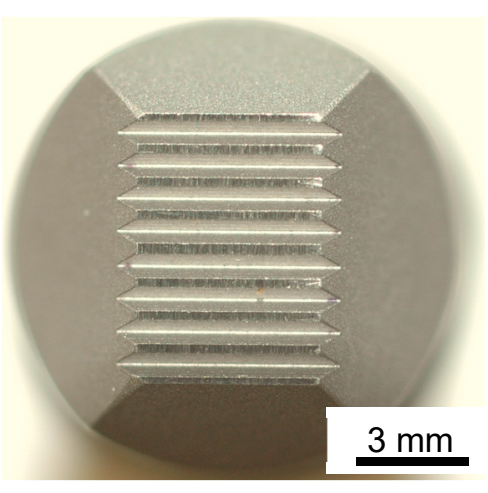

Figure 3.2: Images of the welding tip with its knurl pattern.

\subsection{Temperature profile during USW}

The temperature profile during USW was measured using a K-type thermocouple, which was placed at a center of nugget through a small machined groove in the bottom $\mathrm{Mg}$ sheet at the interface between two sheets to be joined and parallel to the vibration direction as shown in Figure 3.3. It was noted that the thermocouples embedded in a small groove might slightly change the interface condition, and the related heat generation and therefore might affect the accuracy of temperature measurements. To minimize this effect, I used a relatively small 0.076 $\mathrm{mm}(0.003$ inch in diameter) thermocouple wire with a time constant of about $0.05 \mathrm{sec}$ and a 
data collection rate of $0.005 \mathrm{sec}$. Several other researchers have also measured temperatures at the interface during USW in this way $[80,118,119]$.

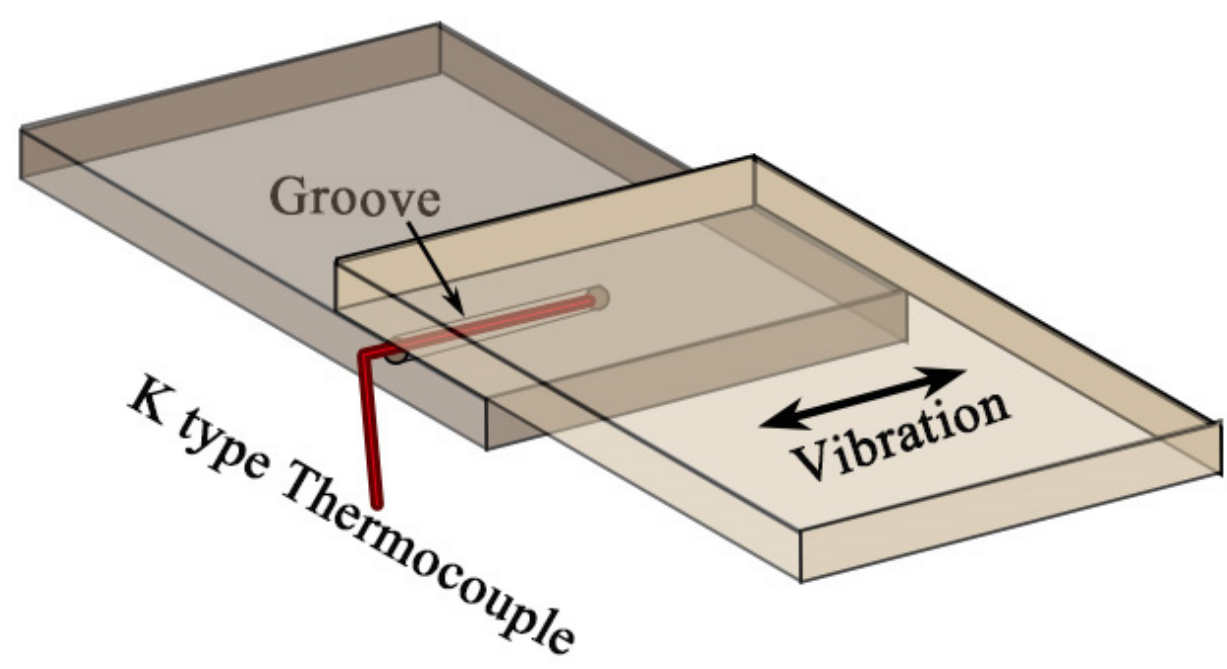

Figure 3.3: Schematic diagram showing the positioning of thermocouple during temperature measurement.

\subsection{Metallography}

The welded joints were sectioned across the center of the nugget, parallel to the direction of vibration using a slow speed diamond cutter for optical microscopy (OM) and JSM-6380LV scanning electron microscope (SEM) analysis. The samples were then cold-mounted in epoxy and mechanically polished to a mirror-like surface using abrasive papers, diamond paste, and colloidal silica. Ultrasonic cleaning system along with ethanol as a cleaning agent was used during the polishing stages. The microstructural features for Mg-to-Mg joints were revealed using an etchant of acetic picral solution (i.e., $4.2 \mathrm{~g}$ picric acid, $10 \mathrm{ml}$ acetic acid, $10 \mathrm{ml} \mathrm{H}_{2} \mathrm{O}$ and $70 \mathrm{ml}$ ethanol). 


\subsection{Quantitative image analysis}

The etched samples were examined using an optical microscope (OM) equipped with an image analysis system. For ZEK100-ZEK100 welded joints, grain sizes were measured using a linear interpolation method on twenty images taken at a magnification of $1000 \times$ at the weld interface using the Clemex image analysis system. The Clemex image analysis system was composed of Clemex CMT software adaptable to ASTM standards, a Nikon optical microscope (10× eyepiece, five different object lenses with magnifications of $5 \times, 10 \times, 20 \times, 40 \times$, and $100 \times$ ), a high-resolution digital camera, and a high-performance computer to perform the detailed analysis. The polished samples of Mg-to-Al, Al-to-steel and $\mathrm{Mg}$-to-Cu joints and fracture surface of tensile and fatigue failed samples were examined by SEM (JSM-6380LV, JEOL Co. Ltd., Akishima, Japan) equipped with Oxford EDS, EBSD, and 3D surface/fractographic analysis capacities.

\subsection{Phase identification by X-ray diffraction}

Phase identification analysis was performed using a PANalytical X'Pert PRO MRD (PANalytical B.V., Almelo, Netherlands) high-resolution X-ray diffractometer using $\mathrm{Cu}-\mathrm{K} \alpha$ radiation at $45 \mathrm{kV}$ and $40 \mathrm{~mA}$. Phase identification was performed on both matching fracture surfaces of samples failed during tensile lap shear tests. During XRD measurements, diffraction angle was varied from $20^{\circ}$ to $100^{\circ}$ for Mg-to-Al joints, and $20^{\circ}$ to $90^{\circ}$ for Al-to-steel joint and $\mathrm{Mg}$-to- $\mathrm{Cu}$ joints. The scan time in each step was $2 \mathrm{~s}$ for $\mathrm{Mg}$-to-Al joints and $3 \mathrm{~s}$ for Al-to-steel joint and $\mathrm{Mg}$-to-Cu joints. For all joints, a step size of $0.05^{\circ}$ was used. To coordinate the highly 
sophisticated movements of the X-ray source, and detector, X'pert Data Collector software (PANalytical B.V.) was used to automate the measurement and data collection. The analysis of the measured data was performed using X'pert Highscore Plus (PANalytical B.V.).

\subsection{Microhardness tests}

Vickers microhardness tests were performed on the polished cross-section using a computerized Buehler micro-hardness testing machine (Micromet-5100). For Mg-to-Mg joints, the indentation was done in the vicinity of the interface using a load of $100 \mathrm{~g}$ with a dwell time of $15 \mathrm{~s}$ in all energy conditions. The hardness measurements were averaged over twenty-five data points. For Al-to-steel joints, the samples welded at $2000 \mathrm{~J}$ welding energy conditions and sectioned at the nugget center along and across the vibration direction for transverse and longitudinal measurements. The test was done at different time intervals after welding to identify the effect of natural aging of Al alloy 6111-T4 after USW. A load of $100 \mathrm{~g}$ and a dwell time of $15 \mathrm{~s}$ was used in each test. The indentations were sufficiently spaced to avoid any potential strain field effect caused by adjacent indentations. For Mg-to-Cu joints, hardness was measured diagonally across the joints as shown in Figure 3.4, using a load of $200 \mathrm{~g}$ and a dwell time of $15 \mathrm{~s}$ except for the thin interface layer $(10-200 \mu \mathrm{m})$, where a load of $10 \mathrm{~g}$ was used for $15 \mathrm{~s}$.

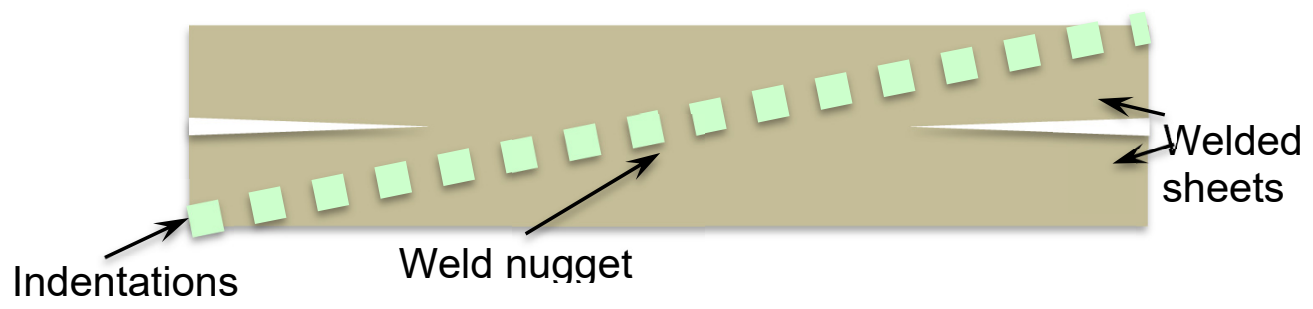

Figure 3.4: Microhardness indentation made diagonally across the welded joints. 


\subsection{Tensile lap shear tests}

To identify the optimum welding condition and evaluate the strength of the joints, the tensile lap shear tests were performed using samples as shown in Figure 3.5 to measure the lap shear failure load using a fully computerized United testing machine in air at a constant crosshead speed of $1 \mathrm{~mm} / \mathrm{min}$ in all welding energy conditions at RT for all the joints. Furthermore for Mg-to-Mg similar joints, the samples made with an optimized condition were selected to perform the tensile tests at varying test temperatures at $233 \mathrm{~K}\left(-40^{\circ} \mathrm{C}\right)$ and $453 \mathrm{~K}\left(180^{\circ} \mathrm{C}\right)$. In the tensile lap shear testing, restraining shims or spacers were used. Two samples were tested in each welding condition. The total failure energy was calculated from the area under the loaddisplacement curve up to the peak load.

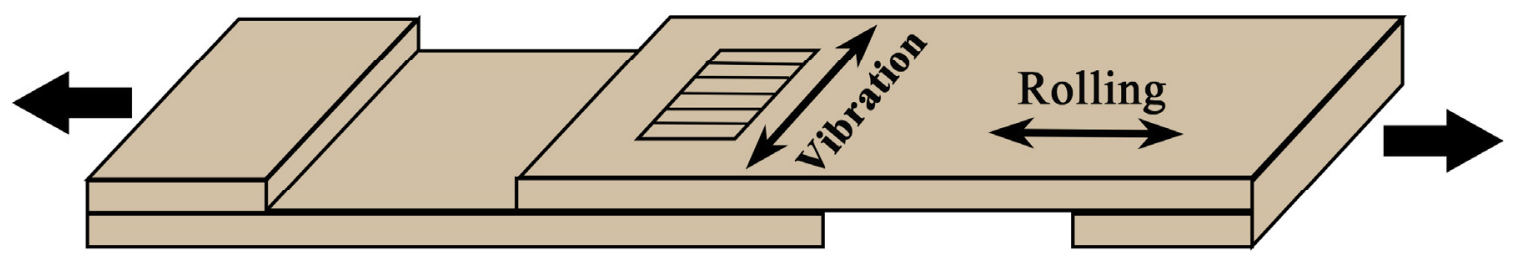

Figure 3.5: Schematic of specimen used for tensile lap shear and fatigue tests.

\subsection{Fatigue tests}

Fatigue tests were conducted on the welded joints using a fully computerized Instron 8801 servo-hydraulic testing system under load control at different maximum load levels. A load ratio of $\mathrm{R}\left(P_{\min } / P_{\max }\right)$ equal to 0.2 , sinusoidal waveform, and frequency of $50 \mathrm{~Hz}$ were used in 
all the tests. In the fatigue testing, restraining shims or spacers were also attached at both ends of the specimen. Generally, two samples were tested at each chosen load level. 


\title{
Chapter 4. Ultrasonic Spot Welding of a Rare-Earth Containing ZEK100 Magnesium
}

\begin{abstract}
Alloy $^{\dagger}$
In this Chapter, USW of similar Mg-to-Mg lap joints is discussed. Microstructure changes, microhardness, and tensile strength at varying welding energy inputs were systematically studied. The influence of the welding energy input on the strain rate and temperature generated during USW was evaluated and modeled. A relationship between grain size and ZenerHollomon parameter and Hall-Petch type of relation between grain size and microhardness was established. In addition, the effect of high and low test temperatures on the strength of the joints was evaluated.
\end{abstract}

\subsection{Microstructure characterization}

During USW of ZEK100-O Mg alloy, the near-interface weld region defined as a nugget zone (NZ) undergoes significant microstructural changes due to plastic deformation and frictional heat generated. Figure 4.1 shows a typical microstructure of the base metal (BM) and NZ of welded samples made at a welding energy of $500 \mathrm{~J}, 1000 \mathrm{~J}, 1500 \mathrm{~J}$, and $2000 \mathrm{~J}$, respectively. The as-received microstructure of the BM consisted of mainly fine equiaxed and recrystallized grains with an average grain size of $5.7 \mu \mathrm{m}$, as shown in Figure 4.1(a). It was due to the occurrence of dynamic recrystallization (DRX) during warm rolling followed by an annealing

\footnotetext{
$\dagger$ This chapter is based on the following publications of the author:

A. Macwan and D.L. Chen: 'Ultrasonic spot welding of a rare-earth containing ZEK100 magnesium alloy: Effect of welding energy', MMT-A, 47 (4), 2015, 1686-1697.

B. A. Macwan, D.L. Chen, Similar and dissimilar ultrasonic spot welding of rare-earth containing ZEK100 magnesium alloy, Magnesium Technology 2016, edited by A. Singh, K. Solanki, M.V. Manuel, and N.R. Neelameggham, TMS (The Minerals, Metals \& Materials Society), 2016, pp.109-112.
} 
treatment $[8,10,120]$. The relatively fine grain structure of the BM was attributed to the resistance to grain growth by alloying elements, neodymium $(\mathrm{Nd})$ and the zirconium $(\mathrm{Zr})$, as also reported by others[8,10,12]. After welding, it can be seen from Figure 4.1(b)-(e) that the grain size became coarser, and with increasing welding energy from $500 \mathrm{~J}$ to $2000 \mathrm{~J}$, the average grain size in the NZ increased from 7.6 to $13.6 \mu \mathrm{m}$. Figure 4.1(f) shows a lower magnification micrograph of weld interface at a welding energy of $2000 \mathrm{~J}$, where grains close to the weld interface were relatively coarser. Figure 4.2 shows a change of the average NZ grain size with welding energy. A linear increase in the grain size with increasing welding energy was observed. A similar increase in the grain size of $\mathrm{NZ}$ of AZ31-H24 Mg alloy welded joints was also observed after USW [80,82] and FSW [121,122]. The increase in the grain size was attributed to the rise in the temperature due to frictional heating and severe plastic deformation, which resulted in the partial recrystallization of elongated/deformed grains and the coarsening of original equiaxed grains in the BM. During USW, high strain rate deformation coupled with exposure to high temperatures, caused the grain growth by the migration of grain boundary via a short-range diffusion of atoms from one side of grain boundary to the other, which led to grains common to both pieces, and therefore helped in the formation of bonds $[123,124]$. The grain growth during USW could be rationalized by the grain boundary movement or atomic migration [123]. DRX in Mg alloys can be attributed to the inadequate slip systems, low stacking fault energy $\left(60-78 \mathrm{MJ} / \mathrm{m}^{2}\right.$ for pure $\left.\mathrm{Mg}\right)$, and higher grain boundary diffusion rate [125]. Several researchers also reported DRX during USW of Mg alloys [45,80,83]. 

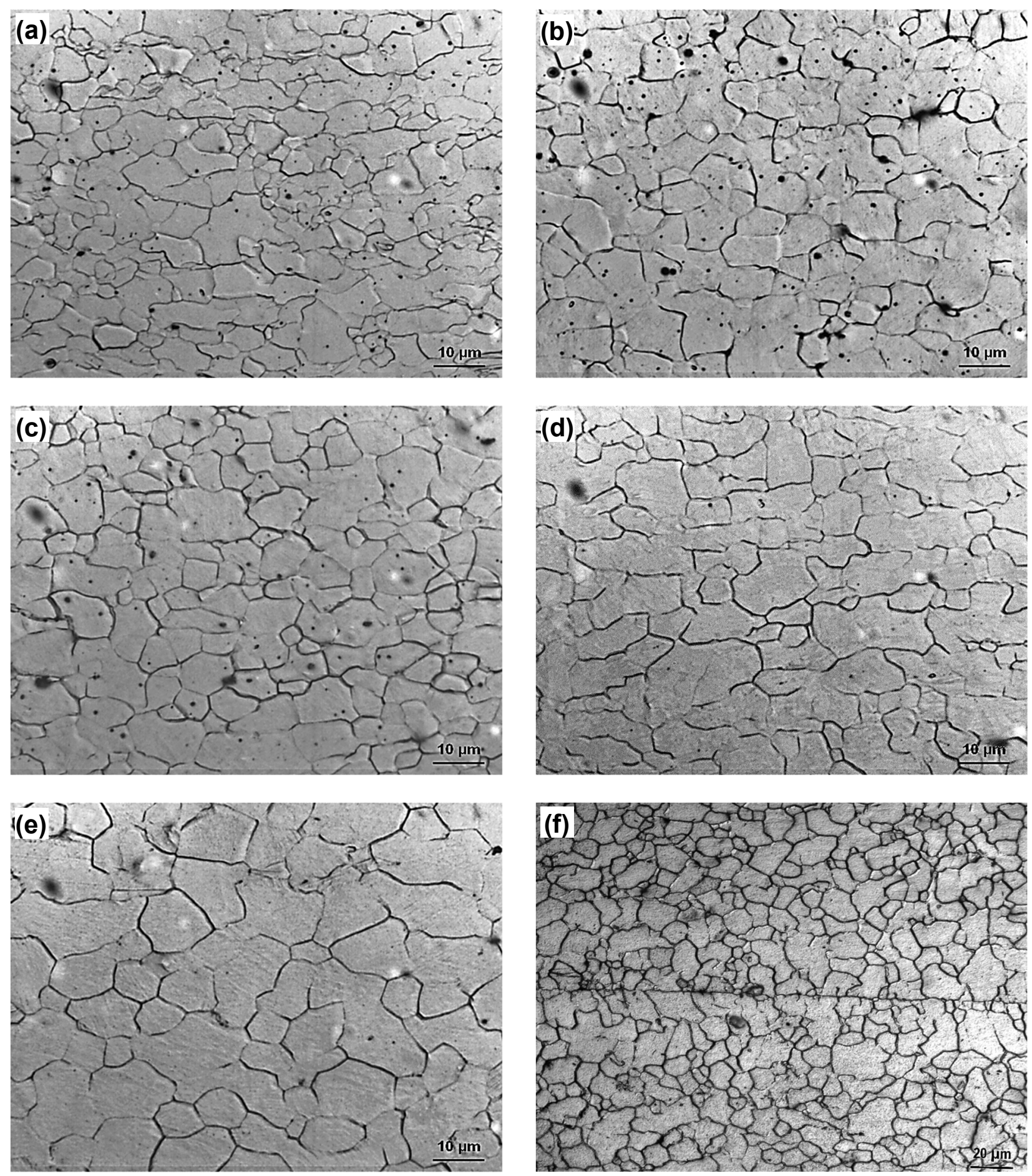

Figure 4.1: Optical micrographs of (a) ZEK100-O base metal, and samples welded at a welding energy of (b) $500 \mathrm{~J}$, (c) $1000 \mathrm{~J}$, (d) $1500 \mathrm{~J}$, and (e, f) $2000 \mathrm{~J}$ ((e) $1000 \times$ and (f) 400×), respectively. 


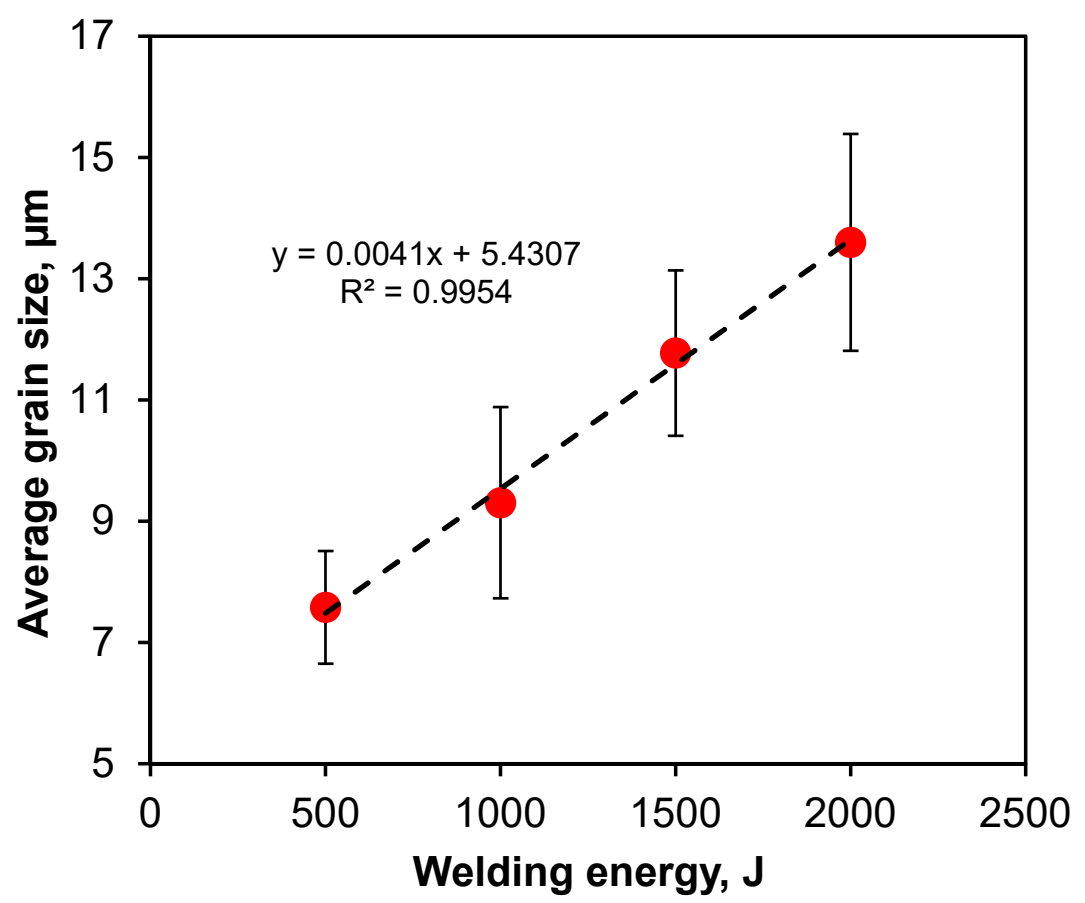

Figure 4.2: Average grain size in NZ as a function of welding energy where error bar indicates standard deviation for 15 repeats.

\subsection{Zener-Hollomon parameter and grain size}

\subsubsection{Shear strain rate during USW}

In the USW, the rubbing at a high frequency of $20 \mathrm{kHz}$ causes severe cyclic deformation of the material. It leads to a very high strain rate of about $10^{3} \mathrm{~s}^{-1}[126]$ within a welding time of less than 1 s. It means that the material experiences 20,000 deformation cycles with a cumulative strain of $\sim 1000$. However the strain amplitude is small $(<\sim 0.1)$ [107]. The strain rate estimated by Sriraman et al. [127] for copper foil was even higher about $10^{5} \mathrm{~s}^{-1}$. Nonhof et al. [88] reported that the average shear strain rate during USW due to the driving velocity of $A f$ could be estimated by, 


$$
\dot{\gamma}_{A f}=4 \frac{A f}{h_{o}}
$$

where $f$ is the frequency, $h_{o}$ is the reduced thickness of the welded sheets between the sonotrodes, and $A$ is the amplitude of ultrasonic vibration/rubbing. It has been reported that the amplitude generated during USW varies from 30 to $60 \mu \mathrm{m}$. Furthermore, Barsukov et al. [89] noted that the energy supplied to the workpiece is proportional to the square of amplitude and outputting coefficient $(\varnothing)$

$$
E_{o} \sim \varnothing A^{2}
$$

where $\emptyset$ is defined as,

$$
\emptyset=\left(1-\frac{\rho_{1} \cdot c_{1}-\rho_{2} \cdot c_{2}}{\rho_{1} \cdot c_{1}+\rho_{2} \cdot c_{2}}\right)^{2}
$$

where $\rho$ is the density of the material and $c$ is ultrasonic velocity in the material. Here 1 is for workpiece material, and 2 is for sonotrode material. The calculated value of outputting coefficient $(\varnothing)$ for $\mathrm{Mg}$ is 1.63 . Using the above equations (4.1)-(4.3), the average shear strain rate for the ZEK100 USWed samples could be calculated and shown in the Table III. It is seen that the calculated average shear strain rate varies from $\sim 500 \mathrm{~s}^{-1}$ to $\sim 2100 \mathrm{~s}^{-1}$ for the welding energy input from $500 \mathrm{~J}$ to $2000 \mathrm{~J}$, respectively.

This could result in high strain rate deformation heating under adiabatic conditions, giving rise to a large temperature increase [128]. The flow stress of the material decreased with temperature rise and increased by the high strain rate [129]. Between these two competing processes, the temperature rise would prevail, resulting in work softening through dynamic recovery and recrystallization $[129,130]$. 


\subsubsection{Weld interface temperature}

Heat is generated due to friction and plastic deformation at the weld interface in the USW process. This heat generation during USW causes an increase in the temperature at the weld interface, which plays an important role in softening and joining the material. Since the temperature distribution at the interface directly influences the microstructure, such as grain size, and the resultant mechanical properties of the welds, it is important to obtain information about the temperature distribution during USW. There are only limited data published on the thermal measurements during USW because of the small size of the welds and short weld times $[38,45]$. To measure the maximum temperatures reached at the joint interface in the welds, small $(0.076 \mathrm{~mm}(0.003 \mathrm{in})$ in diameter) thermocouples were embedded in a machined groove in the weld center of the bottom sheet of each sample. The typical temperature profile and peak temperature reached for different weld energies are shown in Figure 4.3(a) and (b), respectively. It can be seen that the temperature rises very rapidly with a high heating rate of up to $\sim 939 \mathrm{~K} / \mathrm{s}$ $\left(666^{\circ} \mathrm{C} / \mathrm{s}\right)$, reached a maximum temperature, and then decreased also quickly in the initial cooling stage but the cooling rate became gradually smaller. As reported in [131], smaller thermocouples of $0.025 \mathrm{~mm}(0.001 \mathrm{in})$ in diameter would give a higher heating rate due to a better response time than $0.076 \mathrm{~mm}(0.003 \mathrm{in})$ thermocouples; however they are also more likely to break during welding [89]. Therefore, the thermocouples of $0.076 \mathrm{~mm}(0.003 \mathrm{in})$ in diameter were used in the present study. From Figure 4.3(b), it is seen that with increasing welding energy from $500 \mathrm{~J}$ to $1500 \mathrm{~J}$ the peak temperature increased from 537 to $754 \mathrm{~K}$ ( 264 to $481^{\circ} \mathrm{C}$ ). The temperature increase from $1000 \mathrm{~J}$ to $1500 \mathrm{~J}$ was relatively small, exhibiting a plateau character. 

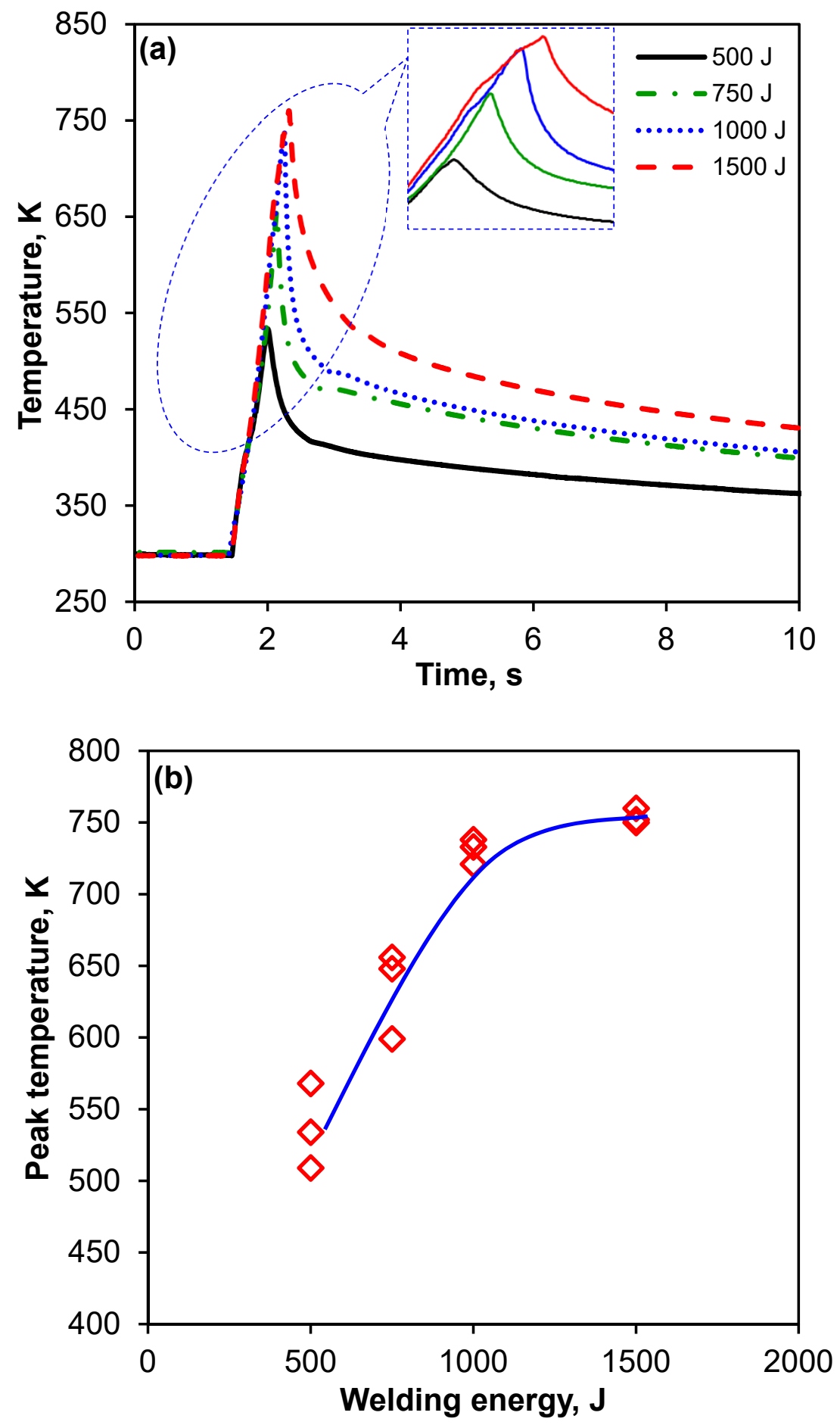

Figure 4.3: (a) Temperature profiles and (b) peak temperatures, measured at the center of the weld during USW at a welding energy of $500 \mathrm{~J}, 750 \mathrm{~J}, 1000 \mathrm{~J}$ and $1500 \mathrm{~J}$, respectively. 
Indeed, I tried to measure temperatures at $1750 \mathrm{~J}$ and $2000 \mathrm{~J}$ as well, but the samples broke during the measurements due to the sheet thinning and the presence of a machined groove. This could be attributed to the occurrence of overly high peak temperatures leading to the excessive softness of the sheets, even some localized melting. It is likely that the phenomenon of melting point depression was present due to an increase in the vacancy concentration as a result of very high strain rate experienced during USW [49,80,126,132]. The localized liquid would, in turn, decrease the friction or viscosity of the plasticized material flow, and therefore, little frictional heating could be further generated at a welding energy of above $1500 \mathrm{~J}$, leading to a plateaulike characteristic (Figure 4.3(b)). Temperature measurements at the weld interface are in good agreement with the modeling results of Elangovan et al. [133] and the experimental results of Patel et al. [80].

\subsubsection{Zener-Hollomon parameter}

The effects of strain rate and temperature on the flow stress of material could be explained in terms of DRX and dislocation mechanisms in polycrystalline metals. DRX phenomenon is sensitive to the temperature and processing time. The combined effect of temperature and strain rate could be expressed via the following Zener-Hollomon parameter (a temperaturecompensated strain rate) [85],

$$
Z=\dot{\varepsilon} \exp \left(\frac{Q}{R T}\right)
$$

where $\dot{\varepsilon}$ is the strain rate $\left(\mathrm{s}^{-1}\right), R$ is the universal gas constant $(8.314 \mathrm{~J} / \mathrm{mol} \mathrm{K}), T$ is the absolute temperature (K), $Q$ is the activation energy for the deformation, for the consistency, it is chosen at the $135 \mathrm{~kJ} / \mathrm{mol}[134]$. 
Zener-Hollomon parameter for different energy inputs was estimated using Eqn. (4.4) and are shown in Table 4.1. The strain rate values calculated from Eqn. (4.1) and the peak temperatures measured as shown in Figure 4.3(a) \& (b) were used to calculate the Zener-Hollomon parameter.

Table 4.1: A summary of the calculated strain rate and Zener-Hollomon parameter at different levels of welding energy.

\begin{tabular}{ccccccc}
\hline $\begin{array}{c}\text { Energy } \\
(\boldsymbol{E}), \mathbf{J}\end{array}$ & $\begin{array}{c}\text { Temperature } \\
(\boldsymbol{T}), \mathbf{K}\end{array}$ & $\begin{array}{c}\text { Amplitude } \\
(\boldsymbol{A}), \boldsymbol{\mu m}\end{array}$ & $\begin{array}{c}\text { Reduced } \\
\mathbf{A v g} . \\
\text { thickness } \\
\left(\boldsymbol{h}_{\boldsymbol{o}}\right) \mathbf{m} \mathbf{m m}\end{array}$ & $\begin{array}{c}\text { Strain } \\
\text { rate } \\
(\dot{\gamma}), \mathbf{s}^{-1}\end{array}$ & $\begin{array}{c}\text { Zener- } \\
\text { Holloman } \\
\text { parameter } \\
(\boldsymbol{Z}), \mathbf{s}^{-\mathbf{1}}\end{array}$ & $\begin{array}{c}\text { Grain } \\
\text { size } \\
(\boldsymbol{D}), \\
\boldsymbol{\mu m}\end{array}$ \\
\hline 500 & 537.0 & 17.5 & 2.83 & 496 & $6.7 \times 10^{15}$ & 7.6 \\
750 & 634.3 & 21.5 & 2.70 & 635 & $8.3 \times 10^{13}$ & 8.1 \\
1000 & 730.7 & 24.8 & 2.63 & 753 & $3.4 \times 10^{12}$ & 9.3 \\
1500 & 754.0 & 30.3 & 1.45 & 1674 & $3.8 \times 10^{12}$ & 11.8 \\
2000 & - & 35.0 & 1.33 & 2107 & - & 13.6 \\
\hline
\end{tabular}

* Gas constant $(R), 8.314 \mathrm{~J} / \mathrm{mol}-\mathrm{K}$

* Activation Energy $(Q), 135,000 \mathrm{~J} / \mathrm{mol}[8]$

* Frequency $(f), 20,000 \mathrm{~Hz}$

The variation of DRX grain size with the Zener-Hollomon parameter is shown in Figure 4.4. It is seen that the DRX grain size decreased with increasing $Z$ value, i.e., with increasing strain rate and decreasing temperature based on Eqn. (4.4). The following relationship between the DRX grain size and $Z$ value has been used [135],

$$
d_{D R X}=A Z^{-n},
$$

where $A$ is constant and $n$ is the power law exponent. In the present study, the value of $A$ and $n$ were determined from Figure 4.4 to be 36.3 and 0.044 , respectively. This form of the equation has been used to predict the DRX grain size in other Mg alloys [136,137]. In an AZ31 alloy in different initial states and deformation modes, Beer [138] reported a range of 0.09-0.13 for $n$, 
which was higher than $n$ value of the present ZEK100 alloy. This could be attributed to the very high strain rate generated during USW (Table III), compared with the strain rate used by Beer [138]. The previous studies via compression testing, tensile testing and friction stir processing showed that the average DRX grain size increased with increasing test temperature and decreasing strain rate $[84,139]$. However, in this investigation both temperature and strain rate increased dramatically as the energy input increased from $500 \mathrm{~J}$ to $2000 \mathrm{~J}$, resulting in an increase in grain size due to the effect of the temperature overwhelming the opposing effect of the strain rate. It should be noted that the DRX grains developed at higher $Z$ values are much smaller than those generated at lower $Z$ values (Figure 4.4). The relationship between the DRX grain size and Zener-Hollomon parameter in the present study follows a similar trend to that in the friction stir welding, tensile and compressive testing [84,139].

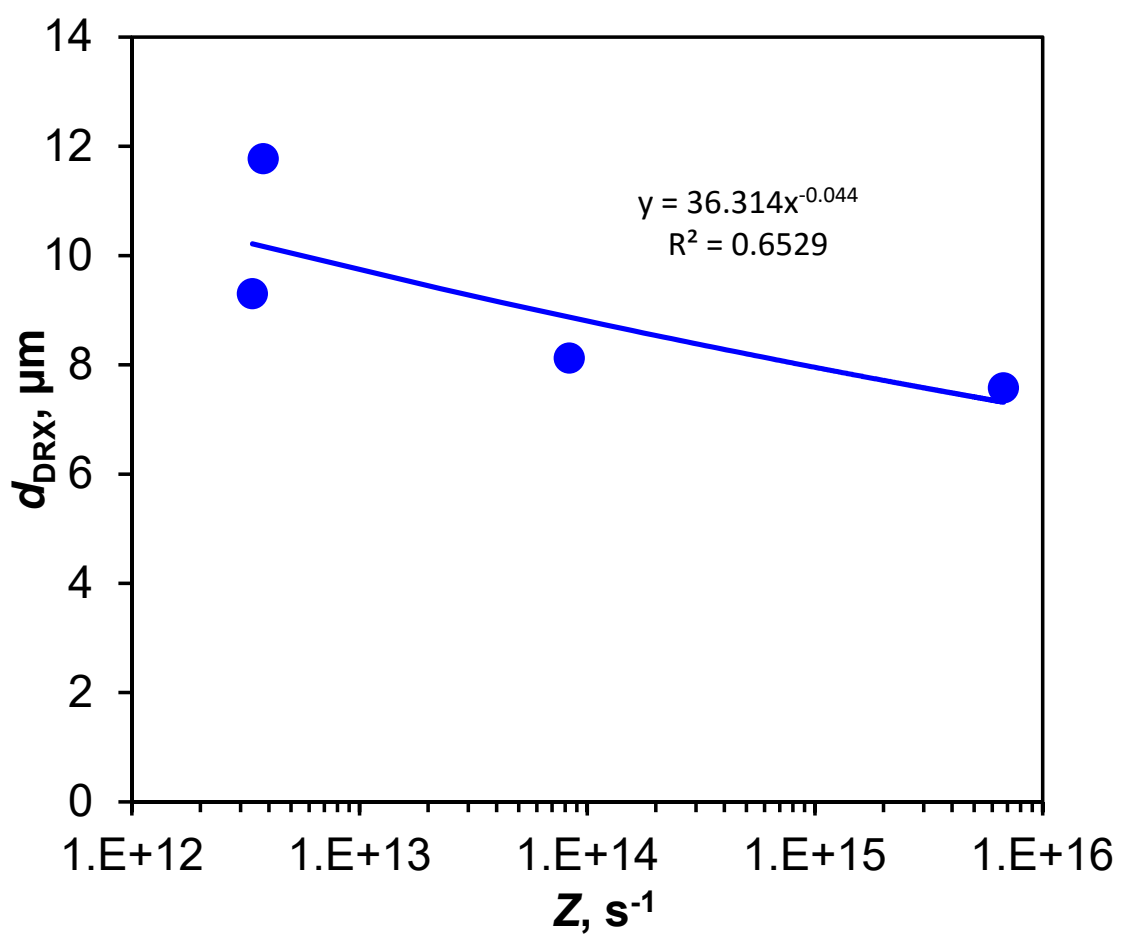

Figure 4.4: Relationship between DRX grain size and Zener-Hollomon parameter for the samples welded at different levels of welding energy. 


\subsection{Microhardness}

Vickers microhardness was measured in the BM, and NZ for samples welded at different levels of welding energy. No noticeable HAZ was observed during USW of ZEK100 Mg alloy. The average value of hardness in the BM was observed to be slightly higher than that in the NZ. That is, the hardness decreased gradually from about $57-61 \mathrm{HV}$ in the $\mathrm{BM}$ to $50-57 \mathrm{HV}$ in the NZ. This was attributed to the effect of temperature changes during welding on the microstructure in the NZ. Figure 4.5(a) shows the change of microhardness in the NZ with welding energy. With increasing welding energy, the hardness in the NZ linearly decreased due to increase in the grain size. Similar results were obtained during USW and FSSW of AZ31 Mg alloy $[42,80,140]$.

Grain boundaries are major barriers to the slip of dislocations. This means that finer grains at a lower welding energy would have a greater resistance to localized plastic deformation, i.e., a higher hardness or strength, due to more grain boundaries compared with larger grains at a higher welding energy. The dependence of hardness (or strength) on the grain size in the NZ of USWed ZEK100 Mg alloy is shown in Figure 4.5(b). A Hall-Petch type relationship was obtained from the measured values of the hardness and grain size in the NZ, which could be expressed as,

$$
H V=47.0 D^{-1 / 2}+39.4,
$$

where $H V$ is Vickers hardness and $D$ is average grain size near weld interface. Similar HallPetch type relationships were also reported in the FSWed AZ31-H24 Mg alloy [121,122]. 

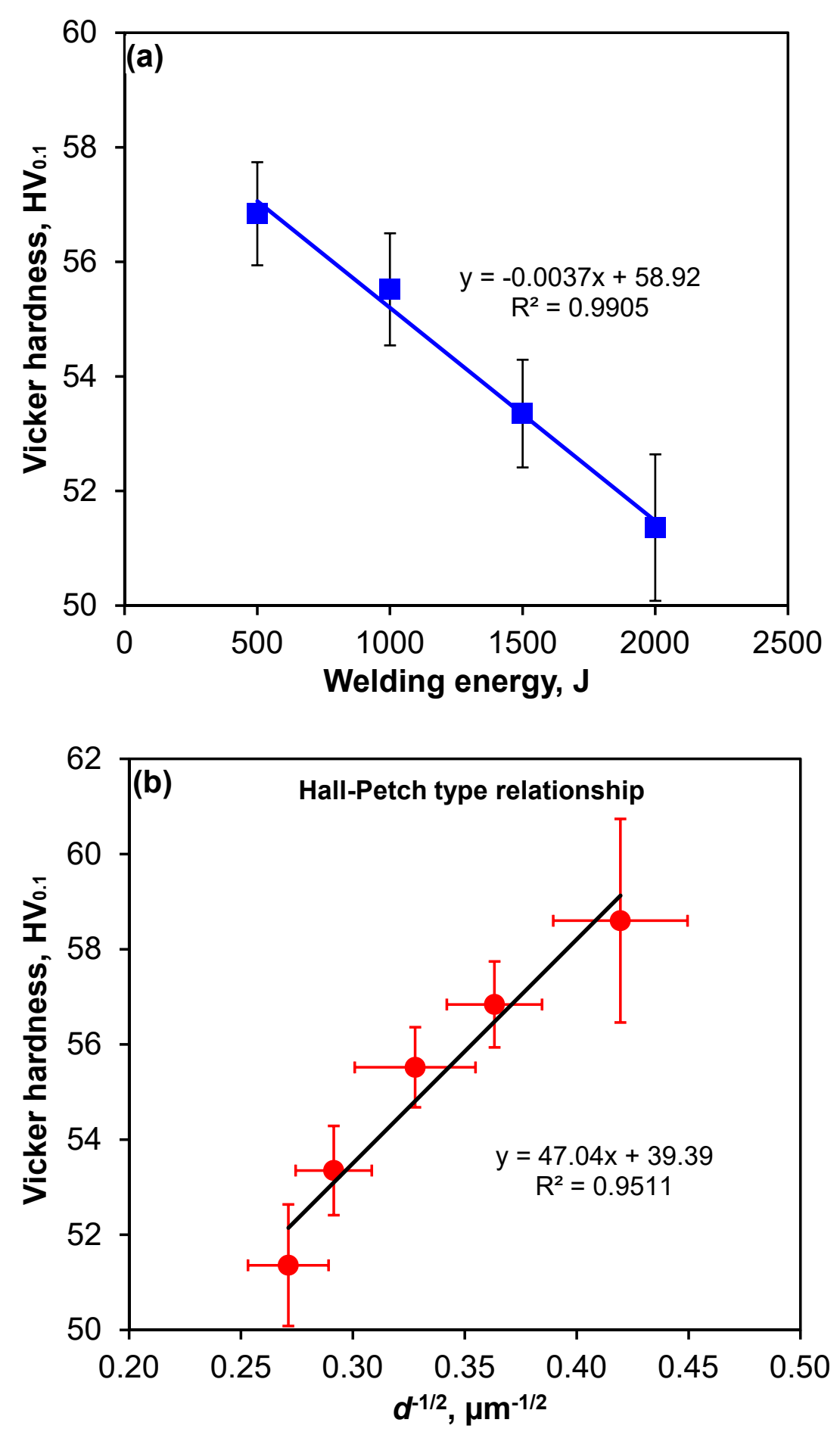

Figure 4.5: (a) Vickers microhardness in the nugget zone as a function of welding energy, and (b) Hall-Petch type relationship between the microhardness and grain size in the USWed ZEK100 Mg alloy. Error bar indicates standard deviation for 15 repeats of grain size and 25 repeats of hardness. 


\subsection{Tensile lap shear strength}

Figure 4.6(a)-(c) shows the maximum tensile shear load, strength and total failure energy as a function of welding energy (or welding time) at a constant power of $2 \mathrm{~kW}$ and clamping pressure of 0.4 MPa. It is seen that the tensile lap shear load, strength, and total failure energy first increased with increasing welding energy up to $1500 \mathrm{~J}$, and then decreased with a further increase in the welding energy. As the welding energy increased, the ensuing temperature rise resulted in a lower yield strength of the base material. It facilitated the localized plastic deformation at the interface, leading to micro-bonding via metallurgical adhesion and mechanical interlocking $[45,141,142]$, which expanded with increasing welding energy. At a lower welding energy of $500 \mathrm{~J}$ and $1000 \mathrm{~J}$, the interface temperature and strain rate were relatively low and therefore, the flowability of metal was limited yet the yield strength of the base material remained relatively high, which led to an incomplete coalescence of the bonding surfaces [143]. Furthermore, welding time was short, giving rise to an inferior weld strength and lower total failure energy. When the welding energy was increased to $1500 \mathrm{~J}$, the increase in the temperature and welding time, as well as higher strain rate plastic deformation, resulted in a complete coalescence of the metallic interface. It follows that the tensile lap shear strength and total failure energy naturally improved and achieved a maximum average value of $72 \mathrm{MPa}$ and $3.45 \mathrm{~J}$, respectively. As the welding energy further increased to $1750 \mathrm{~J}$ and $2000 \mathrm{~J}$, weld time increased which lead to deeper penetration of sonotrode and therefore effective sheet thickness was reduced and high-stress concentration was generated at the edge of the nugget. It resulted in the reduced tensile lap shear strength and total failure energy at the welding energy of $1750 \mathrm{~J}$ and $2000 \mathrm{~J}$, with the failure via nugget pullout as shown later. The average maximum 
tensile shear load achieved at $1500 \mathrm{~J}(2.9 \mathrm{kN})$ was slightly lower than that reported $(3.2 \mathrm{kN})$ using friction stir spot welding; however the average tensile lap shear strength (72 MPa) was higher than that reported using friction stir spot welding technique [25]. It should be noted that the shear strength of FSSWed ZEK100 alloy was calculated using the shoulder and pin diameters, and the corresponding maximum failure load of $3.2 \mathrm{kN}$ reported in [25]. Based on the above results, the optimum energy density required for good bonding was estimated to be $37.5 \mathrm{~J} / \mathrm{mm}^{2}$, and the specific energy per unit volume was $\sim 12.5 \mathrm{~J} / \mathrm{mm}^{3}$. It should be noted that a nominal area (or tip size) of $8 \times 5 \mathrm{~mm}^{2}$ was used to estimate the above parameters.

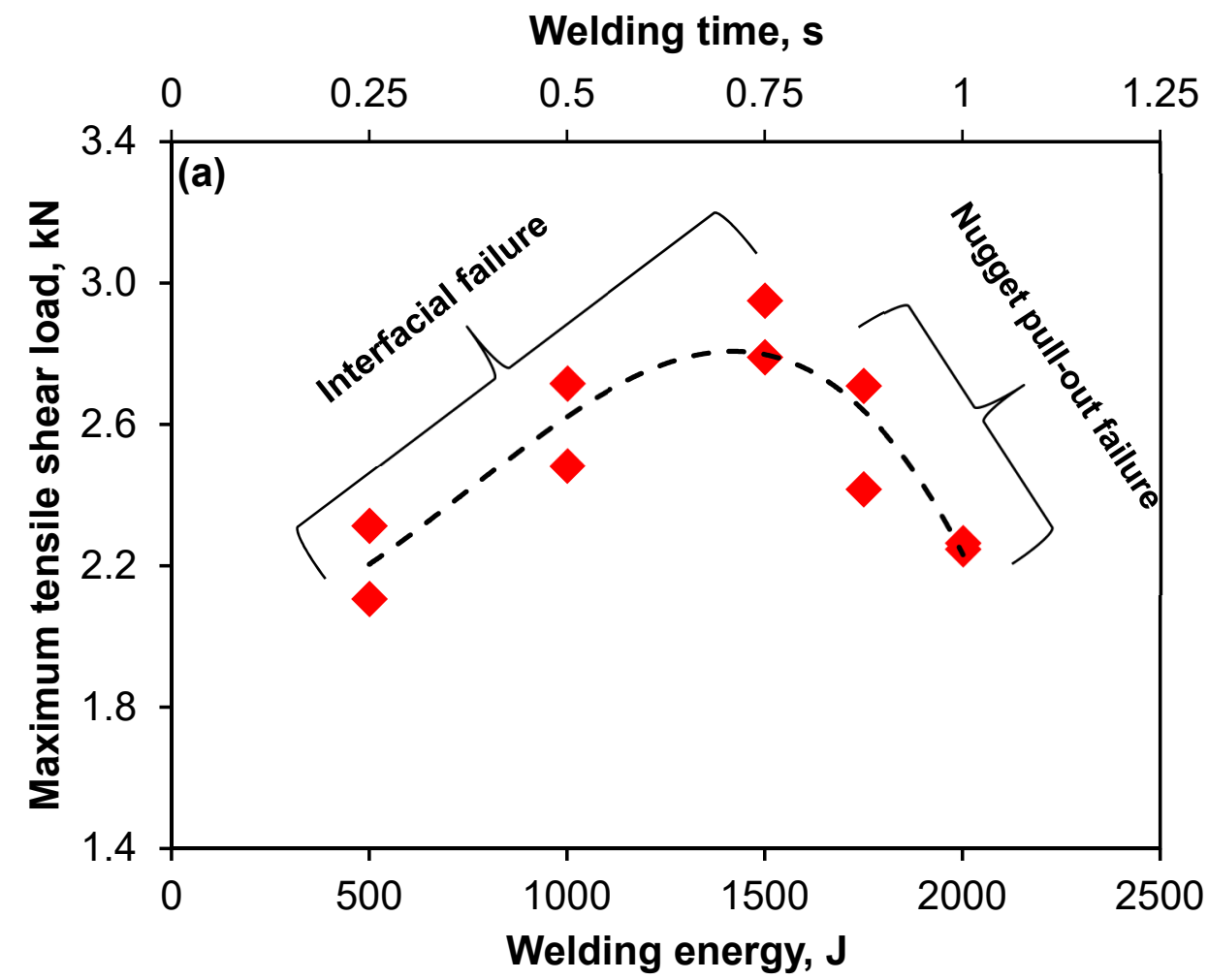

Figure 4.6: (a) The maximum tensile shear load as a function of welding energy (or welding time), at a welding power of $2 \mathrm{~kW}$ and a clamping pressure of $0.4 \mathrm{MPa}$. 

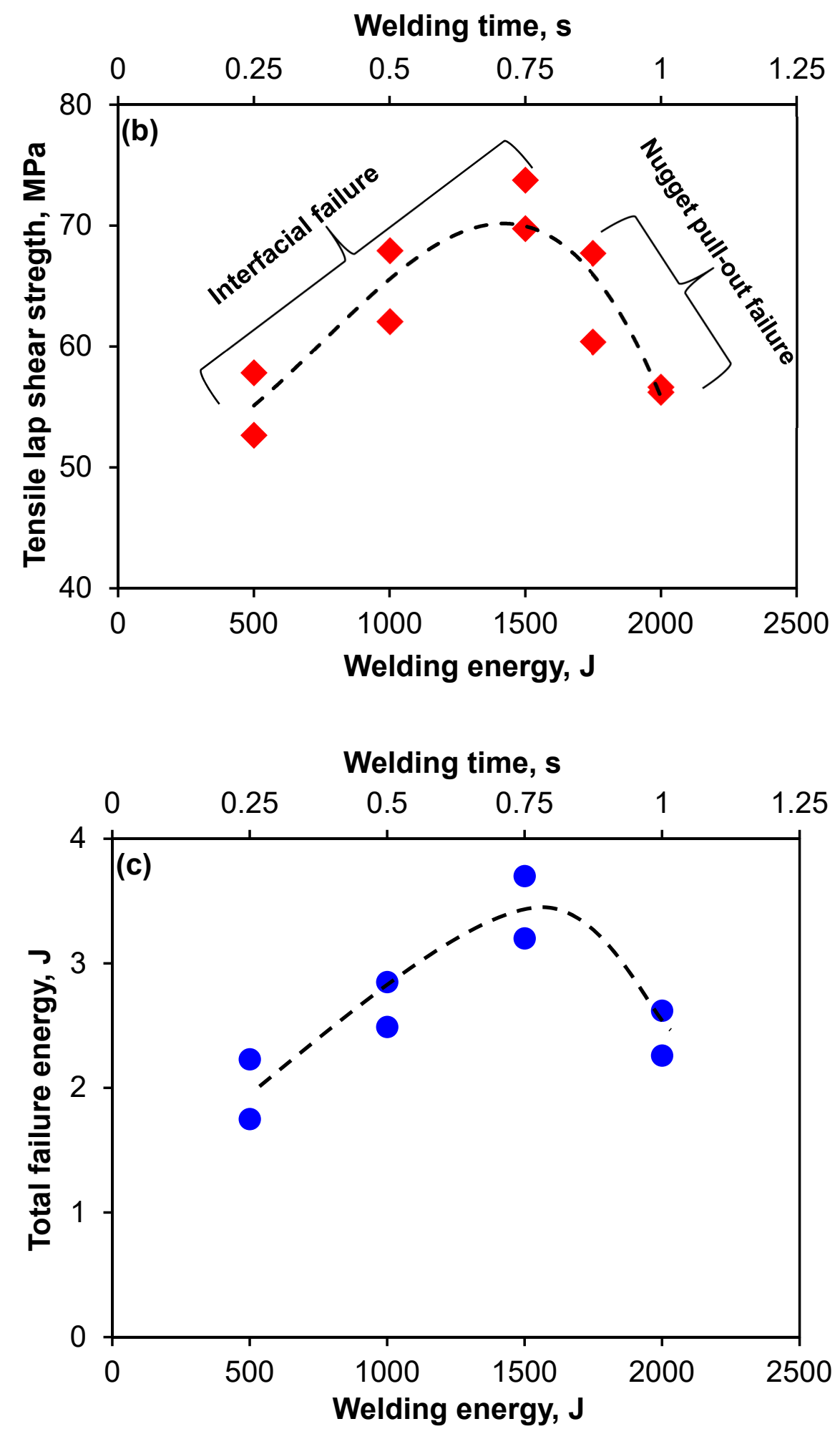

Figure 4.6: (b) The tensile lap shear strength, and (c) total failure energy as a function of welding energy (or welding time), at a welding power of $2 \mathrm{~kW}$ and a clamping pressure of 0.4 $M P a$. 
Figure 4.7 shows a change of the outer and inner thickness in the NZ with increasing welding energy. It is seen that there was a significant reduction in the weld thickness due to the increased flowability (or softness) of the material with increasing welding energy. The reduction of inner thickness would lower the load-bearing capacity, which was detrimental to the strength of the joint. As the inner thickness changed from $1 \mathrm{~mm}$ at $1500 \mathrm{~J}$ to $0.86 \mathrm{~mm}$ at $2000 \mathrm{~J}$, the failure mode subsequently changed from the interfacial fracture to the nugget pull-out.

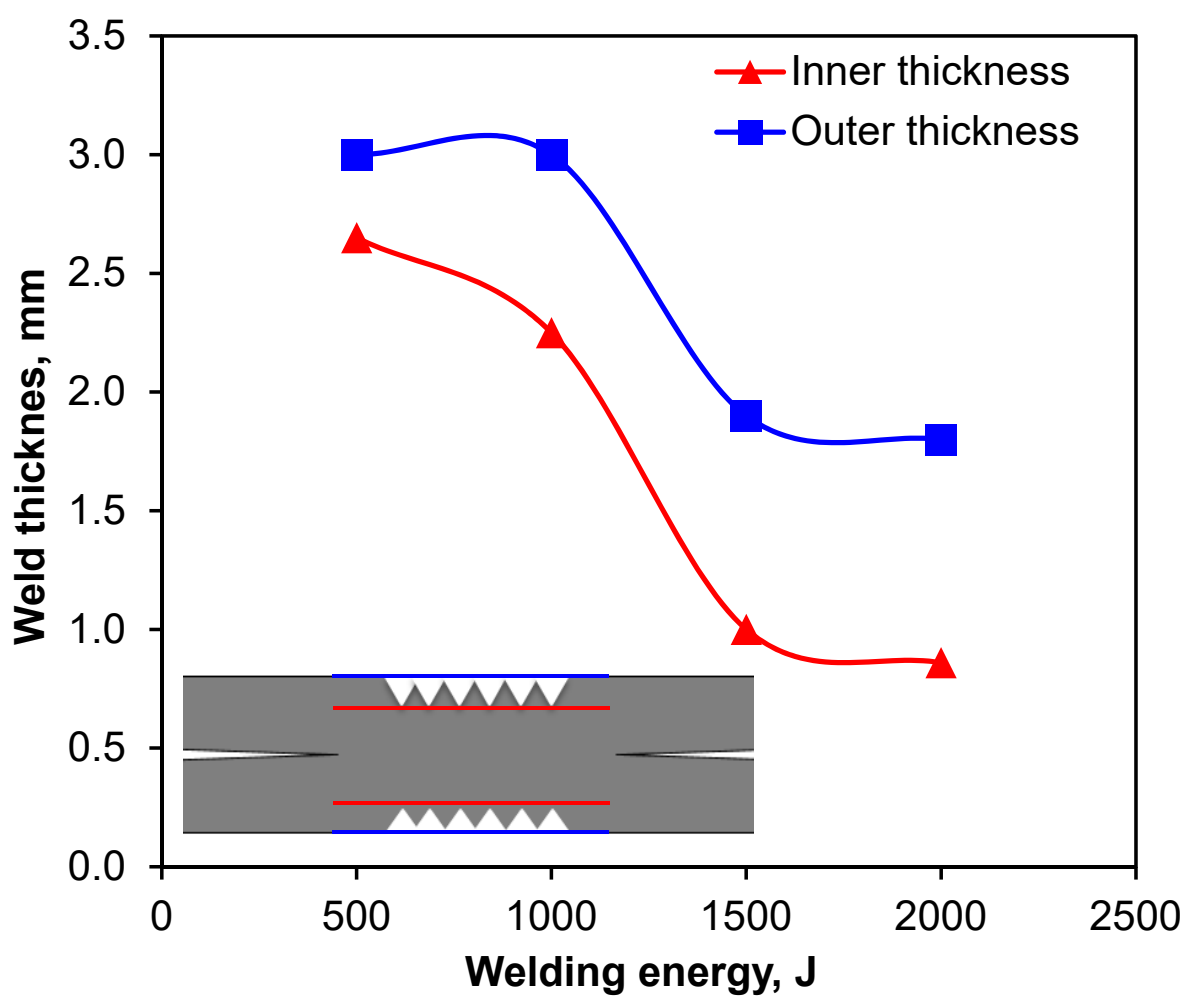

Figure 4.7: The change of weld thickness with welding energy (or welding time). 
Figure 4.8 shows two kinds of failure mode observed in the tensile lap shear testing of USWed ZEK100 Mg alloy at room temperature. The energy conditions of $500 \mathrm{~J}, 1000 \mathrm{~J}$ and $1500 \mathrm{~J}$ showed an interfacial failure mode, where substantial plastic deformation was observed especially at the edge of nugget in the sample welded at $1500 \mathrm{~J}$. This might result from a nonuniform contact pressure under sonotrode tip, which is highest near the edge of the nugget. Therefore, initial bonding would occur first near the edge of the nugget. This higher pressure at the edge was caused by the elastic deflection of the sheets as the gap between them was close under the clamping pressure. In the conventional lower power USW, bonding was also usually observed to be highest at the edge of the nugget [71]. Evidence of the fracture surfaces (Figure 4.8) confirmed that microbonding first occurred in the areas of higher pressure. Welding energy conditions of $1750 \mathrm{~J}$ and $2000 \mathrm{~J}$ showed a failure mode of nugget pull-out due to the thinning of the NZ (Figure 4.7) and the presence of stress concentration at the edge of the nugget. The stress concentration at the nugget edge was due to the higher pressure at the edge, the increased welding time at these energy conditions. While the nugget pull-out was considered as a preferred mode of failure for the resistance spot welding (RSW), the maximum strength in the present USW was achieved at a welding energy of $1500 \mathrm{~J}$, where the sample failed in the interfacial mode with significant plastic deformation at the nugget edge. 

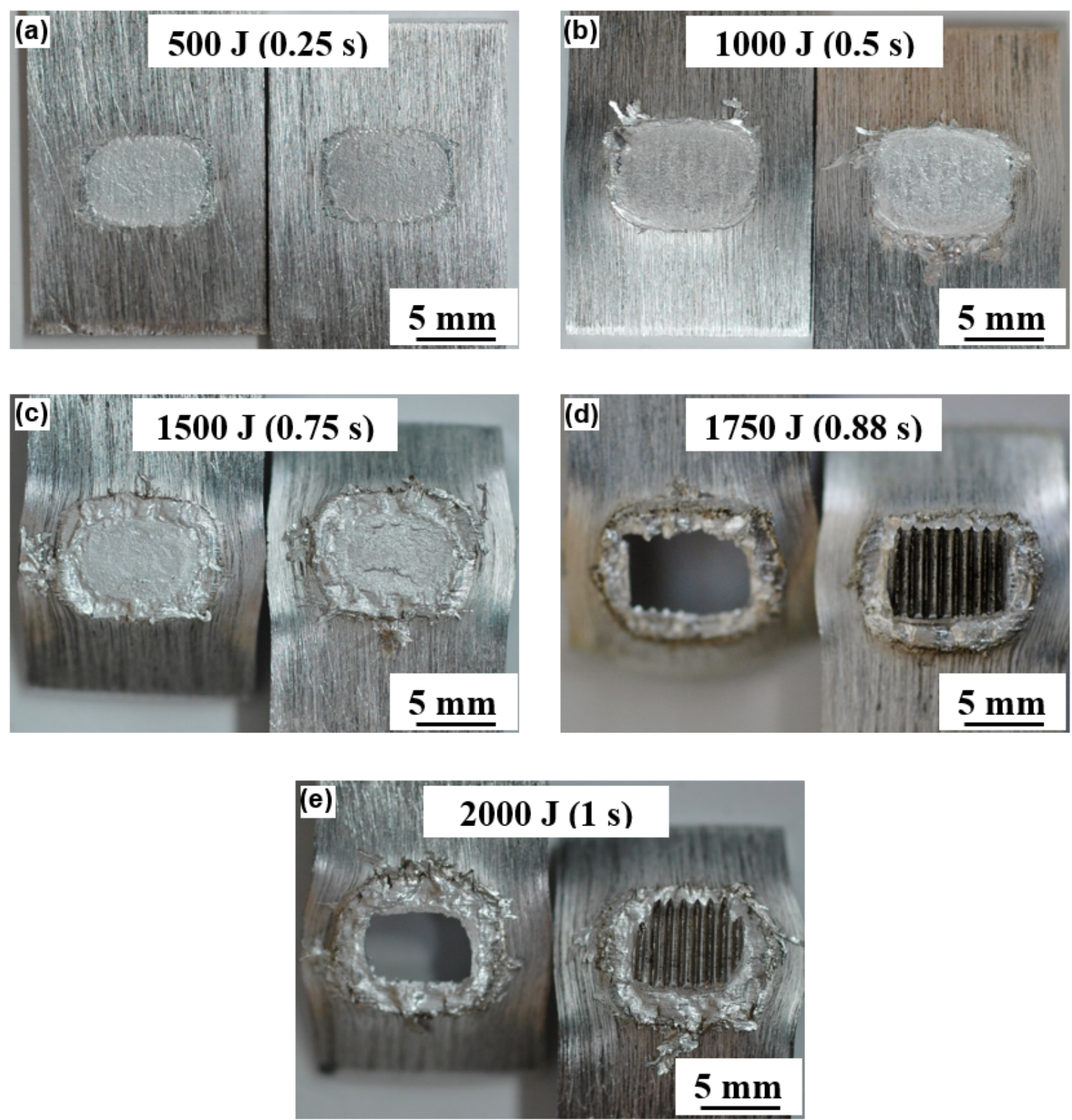

Figure 4.8: Macroscopic images of the failed tensile lap shear samples welded at different levels of welding energy.

\subsection{Fractography}

Figure 4.9 shows typical fracture surfaces of the samples welded at a welding energy of $1000 \mathrm{~J}$ and $1500 \mathrm{~J}$. The overall images of the fracture surfaces in Figure 4.9(a) and (b) showed that the 
nugget area for the sample welded at $1500 \mathrm{~J}$ was larger than that welded at $1000 \mathrm{~J}$. This corroborates our earlier discussion that the increasing temperature at a higher welding energy resulted in an increased flowability of the material which gave rise to an increased bonding area and hence the strength (Figure 4.6(a,b)). Furthermore, the region of higher deformation at the nugget edge compared with the nugget center indicated the presence of a higher stress concentration at the edge. No cracks at the nugget edge were observed in both conditions. Figure 4.9(c-f) showed higher $(100 \times$ and $1000 \times)$ magnification images of fracture surfaces of the samples welded at $1000 \mathrm{~J}$ and $1500 \mathrm{~J}$. These fracture surfaces appeared similar and showed features of shear failure, which was well explained by Truog [144].

\subsection{Effect of test temperature on the tensile lap shear strength}

The effect of test temperatures on the tensile lap shear strength and total failure energy of the joints was further evaluated for the optimum condition with a welding energy of $1500 \mathrm{~J}$. Figure 4.10(a) shows the typical load-displacement curves for the samples tested at $\mathrm{LT}\left(233 \mathrm{~K}\left(-40^{\circ} \mathrm{C}\right)\right)$, RT $\left(298 \mathrm{~K}\left(25^{\circ} \mathrm{C}\right)\right)$ and HT $\left(453 \mathrm{~K}\left(180^{\circ} \mathrm{C}\right)\right)$. Similar curves were obtained at the LT and RT while the curve at the HT had a significant deviation from that at RT. The decrease in the slope of the curve at the HT could be attributed to the change in the Young's modulus. As the temperature is increased, thermal agitation increased, and it became easier for dislocations to overcome obstacles in the matrix so that an average slip distance would increase. As a result, the Young's modulus would decrease [145]. The tensile lap shear failure load was obtained to be $(2.97 \pm 0.11 \mathrm{kN})$ at LT, which was slightly higher or equivalent to that at $\mathrm{RT}(2.87 \pm 0.5 \mathrm{kN})$ considering the experimental scatter, as shown in Figure 4.10(b). 

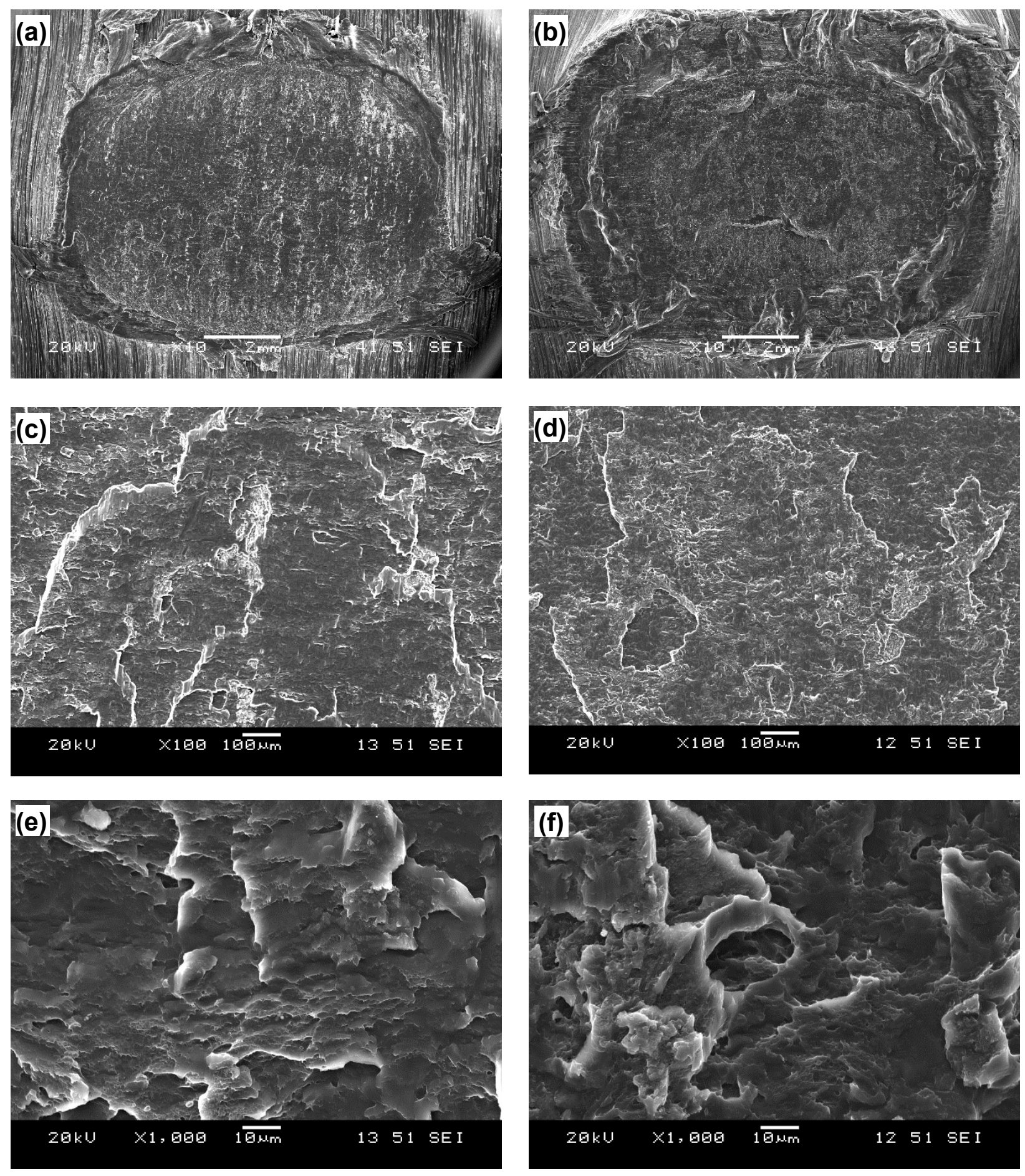

Figure 4.9: Typical fracture surface SEM images of tensile lap shear failed samples welded at a welding energy of $(a, c, d) 1000 \mathrm{~J}$ and $(b, d, f) 1500 \mathrm{~J} .(a, b)$ Overall view of the entire fracture surfaces, $(c, d, e, f)$ higher magnification images of the fracture surfaces. 

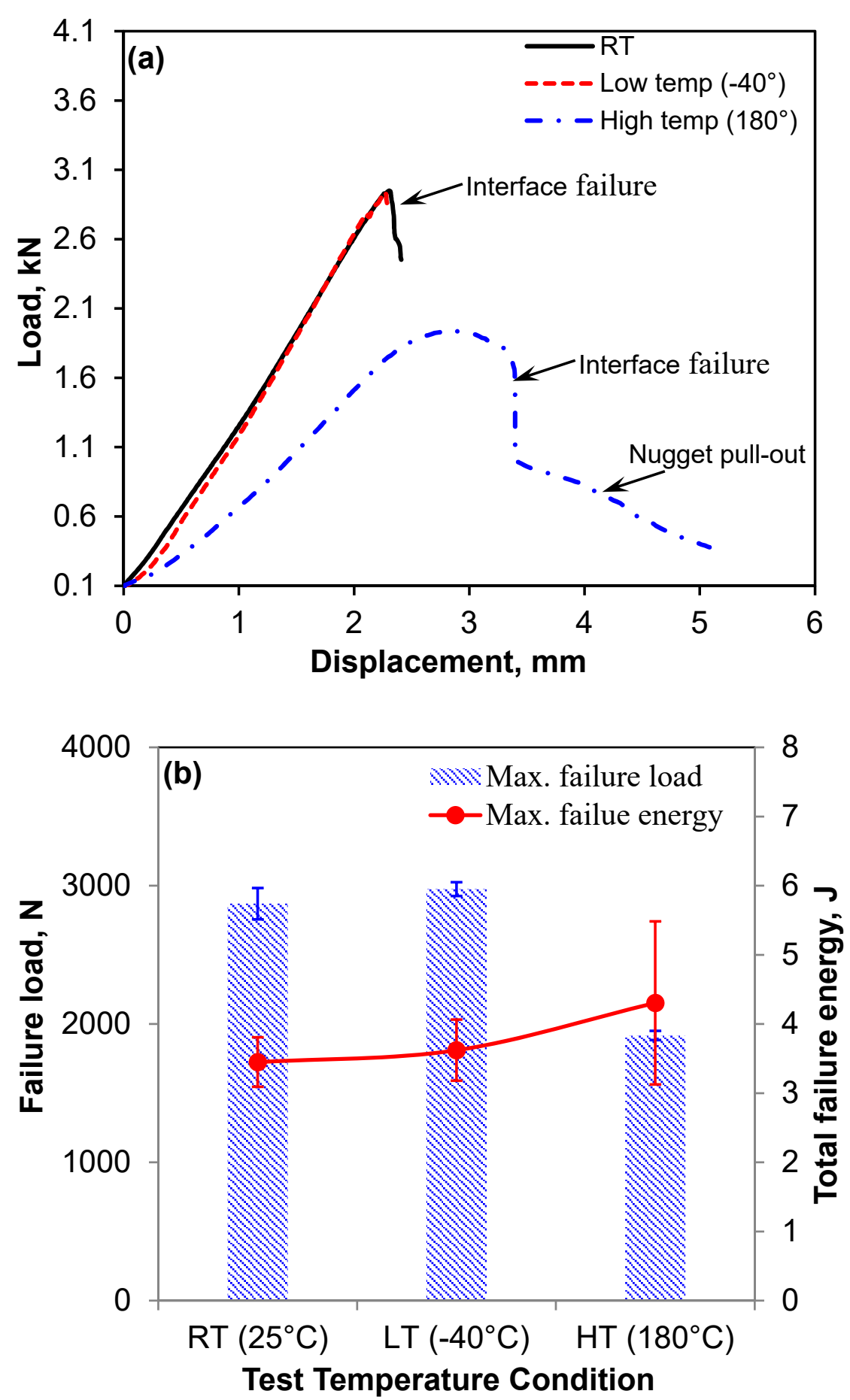

Figure 4.10: (a) Typical tensile lap shear test curves of the samples welded at an optimal welding energy of $1500 \mathrm{~J}$, and (b) variation of the tensile lap shear failure load and total failure energy with test temperatures. Error bars indicates range for 2 repeats. 
This indicates that the performance of welded joints would not deteriorate under such cold weather conditions within the test temperature range. With increasing temperature from RT to HT, the tensile lap shear failure load decreased (Figure 4.10(b)). However, significantly higher plastic deformation occurred at HT (Figure 4.10(a)), which indeed gave rise to a higher failure energy in comparison with that at LT and RT, as seen from Figure 4.10(b). It could be understood by considering the plastic deformation mechanism that involves the gliding of dislocations along definite crystallographic or slip planes. When the critical resolved shear stress (CRSS) applied on the slip plane and in the slip direction exceeds a critical value, a movement of dislocations will occur. In general, the CRSS for magnesium alloys varies with the temperature. At RT, the movement of dislocations is easier on the basal slip systems due to the lower CRSS value. Thus, the basal plane slip is expected to dominate at RT, and only small amounts of non-basal slip may occur $[143,146]$ along with twinning $[147,148]$. At LT the CRSS is somewhat higher but not significant, resulting in a similar behavior to that at RT. At HT the CRSS of pyramidal and prismatic slip systems decreased, thereby increasing the number of activated slip systems, and leading to significantly increased deformability for magnesium alloys. As a result, a higher failure energy was observed at HT (Figure 4.10(b)).

Figure 4.11 shows the failure mode of the tensile lap shear samples welded at an optimal welding energy of $1500 \mathrm{~J}$ and tested at LT and HT. It is seen that interfacial failure occurred when the tensile lap shear test was conducted at LT (Figure 4.11(a)), which was similar to the situation observed at RT (Figure 4.8(c)). Therefore, similar tensile lap shear failure loads at LT and RT were obtained (Figure 4.10). 
However, as the test temperature increased the failure mode changed from the interfacial failure at LT (Figure 4.11(a)) and RT (Figure 4.8(c)) to a mixed mode of partial interfacial failure and partial nugget pull-out, as shown in Figure 4.11(b). This could be attributed to the reduction in the strength of the base material with increasing temperature, which caused the thinned nugget region (Figure 4.7) to be weakened and thus increased the tendency of nugget pull-out.
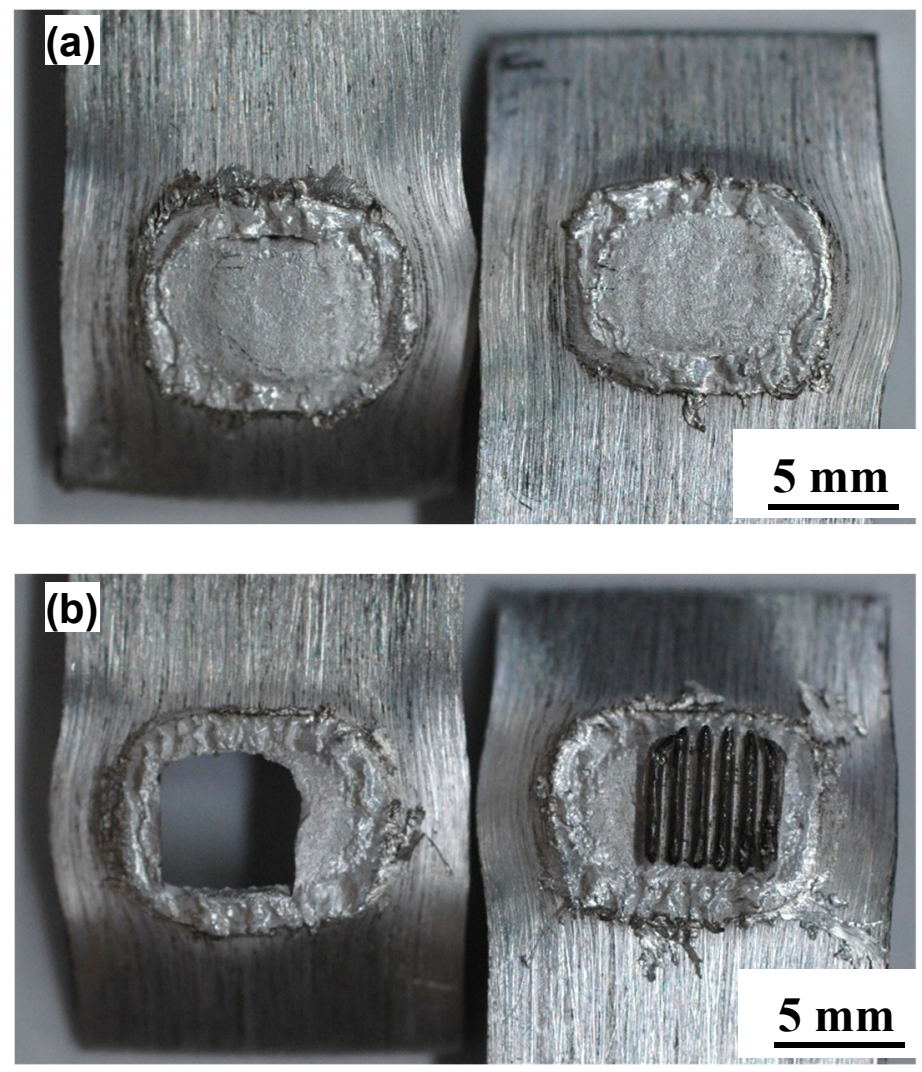

Figure 4.11: Macroscopic images of the failed tensile lap shear samples welded at an optimal welding energy of $1500 \mathrm{~J}$ and tested at (a) LT and (b) HT.

\subsection{Summary}


High power USW was used to join a low rare-earth containing ZEK100 Mg alloy at different levels of welding energy, and tensile lap shear tests were performed to determine the failure load and failure energy. The following conclusions could be drawn from this study.

1. Dynamic recrystallization (DRX) occurred in the NZ during USW. The grain size in the NZ increased with increasing welding energy due to the predominant effect of temperature rise. The interface experienced severe plastic deformation at very high strain rates during USW, which increased from $496 \mathrm{~s}^{-1}$ to $2107 \mathrm{~s}^{-1}$ with increasing welding energy from $500 \mathrm{~J}$ to 2000 J.

2. A relationship between the DRX grain size and Zener-Hollomon parameter was established for the USWed ZEK100 Mg alloy. The microhardness in the NZ decreased with increasing energy input due to the coarsening of grains. A Hall-Petch type relationship was established to describe the effect of grain size on the hardness or strength.

3. Both the tensile lap shear strength and failure energy first increased with increasing welding energy, reached the maximum values at $1500 \mathrm{~J}$, and then decreased with a further increase in the welding energy. The optimal welding condition was thus achieved at a short weld time of $\sim 0.75 \mathrm{~s}$.

4. Two types of failure modes - interfacial failure and nugget pull-out failure - were observed during the tensile lap shear tests at RT, where the samples welded at a welding energy lower than and equal to $1500 \mathrm{~J}$ exhibited an interfacial failure mode. The fracture surfaces showed a typical shear fracture.

5. The tensile lap shear strength, failure energy, and failure mode remained almost the same at LT and RT. While the tensile lap shear strength became lower when the tests were 
conducted at HT, the failure energy was higher due to significantly increased deformability. The failure mode changed from the interfacial failure at RT to a mixed mode of partial interfacial failure and partial nugget pull-out at HT.

In this Chapter, A similar sound joining of newly developed high-performance rare earth containing ZEK100 Mg alloy using USW was successfully achieved, which shows the potential of USW process to join Mg alloy in spot welding industry. As discussed earlier, $\mathrm{Al}$ alloys have a wide variety of applications in the automotive industry due to their excellent properties, such as good ductility, formability, and thermal conductivity. To achieve a combination of properties of both alloys, recently, dissimilar metal joints of Mg-to-Al alloy has become focused of many researches. Furthermore, with the development of new high-performance Mg alloys such as ZEK100 Mg alloy, feasibility, and optimization study on USW of dissimilar ZEK100 with automotive grade $\mathrm{Al}$ alloy is necessary. Therefore, In Chapter 5, will characterize the USW of ZEK100-to-A15754 joints. 


\section{Chapter 5. Ultrasonic Spot Welding of Magnesium Alloy-to-Aluminum Alloys}

The aim of this study was to examine the feasibility of joining a low rare-earth containing ZEK100 Mg alloy to $5754 \mathrm{Al}$ alloy via solid-state ultrasonic spot welding (USW), and to evaluate diffusion kinetics at the joint interface and to identify the effect of welding energy on the interface diffusion layer, tensile lap shear strength, and fatigue life. The analysis was carried out by microstructural changes, tensile lap shear strength, fatigue strength, and fracture surface at varying level of welding energy. Furthermore, comparison with various $\mathrm{Mg}$-Al joints made by other techniques was made.

\subsection{Microstructure characterization}

The commonly observed bonding mechanisms during USW of metals were metallurgical adhesion, interface diffusion, localized melting, and mechanical interlocking. During USW oxide film would first break locally at asperities allowing metal-to-metal contact, where interdiffusion would occur, allowing the formation of intermetallic products under a sufficiently rapid kinetic reaction at the interface. Figure 5.1 shows typical interfacial microstructures of welds made at welding energy levels of $250 \mathrm{~J}, 500 \mathrm{~J}$, and $1000 \mathrm{~J}$. It can be seen that at a welding energy of $250 \mathrm{~J}$ the diffusion at the initially touched asperities resulted in the formation of nonuniform and isolated diffusion layer islands indicated by an arrow (Figure 5.1(a)). The non-

\footnotetext{
*This chapter is based on the following publications of the author:

A. Macwan and D.L. Chen, "Ultrasonic spot welding of rare-earth containing ZEK100 magnesium alloy to 5754 aluminum alloy", Material Science and Engineering A, 666, 2016, 139-148.

B. A. Macwan, D.L. Chen, Similar and dissimilar ultrasonic spot welding of rare-earth containing ZEK100 magnesium alloy, Magnesium Technology 2016, edited by A. Singh, K. Solanki, M.V. Manuel, and N.R. Neelameggham, TMS (The Minerals, Metals \& Materials Society), 2016, pp.109-112.
} 
uniform and discontinuous nature of the diffusion layer was attributed to a non-uniform temperature distribution along the interface within a short welding time [9]. As the welding energy increased to $500 \mathrm{~J}$, a thin continuous diffusion layer was formed as seen from Figure 5.1(b) due to an increase in temperature and strain rate at the interface. Further increase in the welding energy to $1000 \mathrm{~J}$ (Figure 5.1(c)) resulted in the thickening of the diffusion layer.
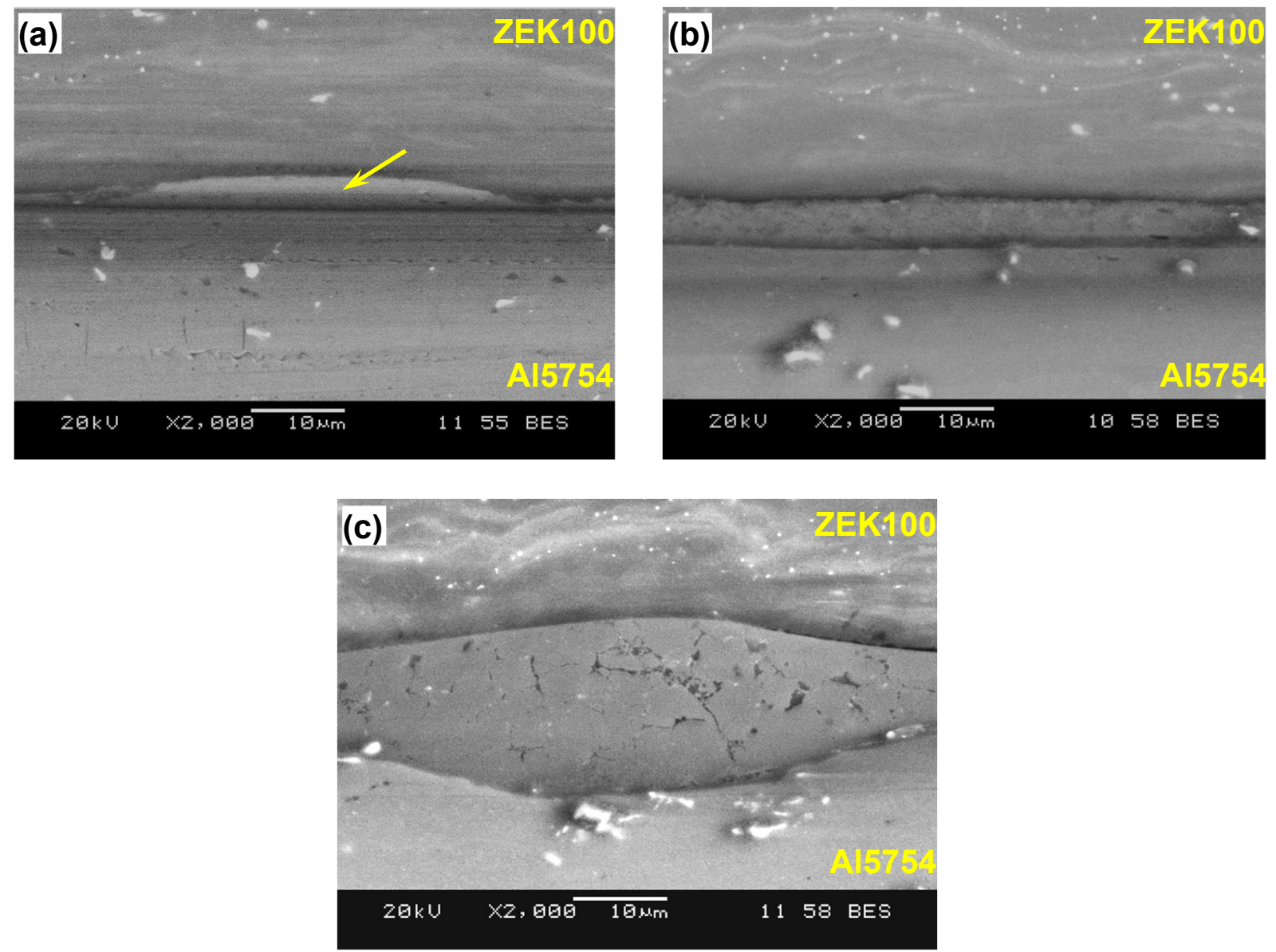

Figure 5.1: Typical SEM images at the interface of ZEK100-Al5754 joints at a welding energy of (a) $250 \mathrm{~J}$, (b) $500 \mathrm{~J}$, and (c) $1000 \mathrm{~J}$.

\subsubsection{Energy-dispersive X-ray spectroscopy analysis}


The elemental distribution across the interface of the joints was determined via EDS line analysis. Figure 5.2 shows typical results of EDS line scan at a welding energy of $250 \mathrm{~J}, 500 \mathrm{~J}$ and $1000 \mathrm{~J}$, respectively. The concentration of $\mathrm{Mg}$ and $\mathrm{Al}$ at $250 \mathrm{~J}$ as shown in Figure 5.2(a) indicated no significant diffusion across the interface except at localized asperities. Figure 5.2(b) shows a change in the concentration profile at the interface due to the formation of a thin continuous layer with a thickness of about $3-5 \mu \mathrm{m}$. With a further increase in the welding energy, the diffusion layer thickness increased and reached about 5-15 $\mu \mathrm{m}$ as shown in Figure 5.2(c). The concentration profile in Figure 5.2(b) and (c) showed mainly $\mathrm{Mg}$ and $\mathrm{Al}$ present at the interface $\$$. The point analysis in Figure 5.2(c) showed a stoichiometric proportion of 56.6 at.\% $\mathrm{Mg}, 43$ at.\% Al, and 0.4 at.\% $\mathrm{Zn}$. By referring to the Al-Mg binary phase diagram [93], the interface diffusion layer should consist of a eutectic structure of $\alpha-\mathrm{Mg}$ and $\mathrm{Al}_{12} \mathrm{Mg}_{17} \mathrm{IMC}$ phase via a eutectic reaction $\left(\mathrm{L} \rightarrow \alpha-\mathrm{Mg}+\mathrm{Al}_{12} \mathrm{Mg}_{17}\right)$. Several researchers have also reported the formation of $\mathrm{Al}_{12} \mathrm{Mg}_{17} \mathrm{IMC}$ phase during welding of $\mathrm{Mg}$ to $\mathrm{Al}[41,49,52,149,150]$. It was shown in our previous study [17] that the $\mathrm{Al}_{12} \mathrm{Mg}_{17}$ was a very brittle phase and could have a deteriorating effect on the strength of joints. Therefore, an optimum thickness of interface layer is required to achieve the greater strength.

\subsubsection{X-ray diffraction phase identification}

To further validate the above analysis, XRD phase identification was performed on the fracture surface of $\mathrm{Mg}$ side and $\mathrm{Al}$ side after the tensile lap shear test of a joint made at a welding energy of $1000 \mathrm{~J}$, as shown in Figure 5.3.

\footnotetext{
$\S$ During EDS line scan, all possible elements (Al, Mg, Zn, Zr, Mn, Sc, Nd) in both ZEK100 Mg alloy and $5754 \mathrm{Al}$ alloy were selected, aiming not to miss out any potential presence of alloying elements in the diffusion interlayer.
} 

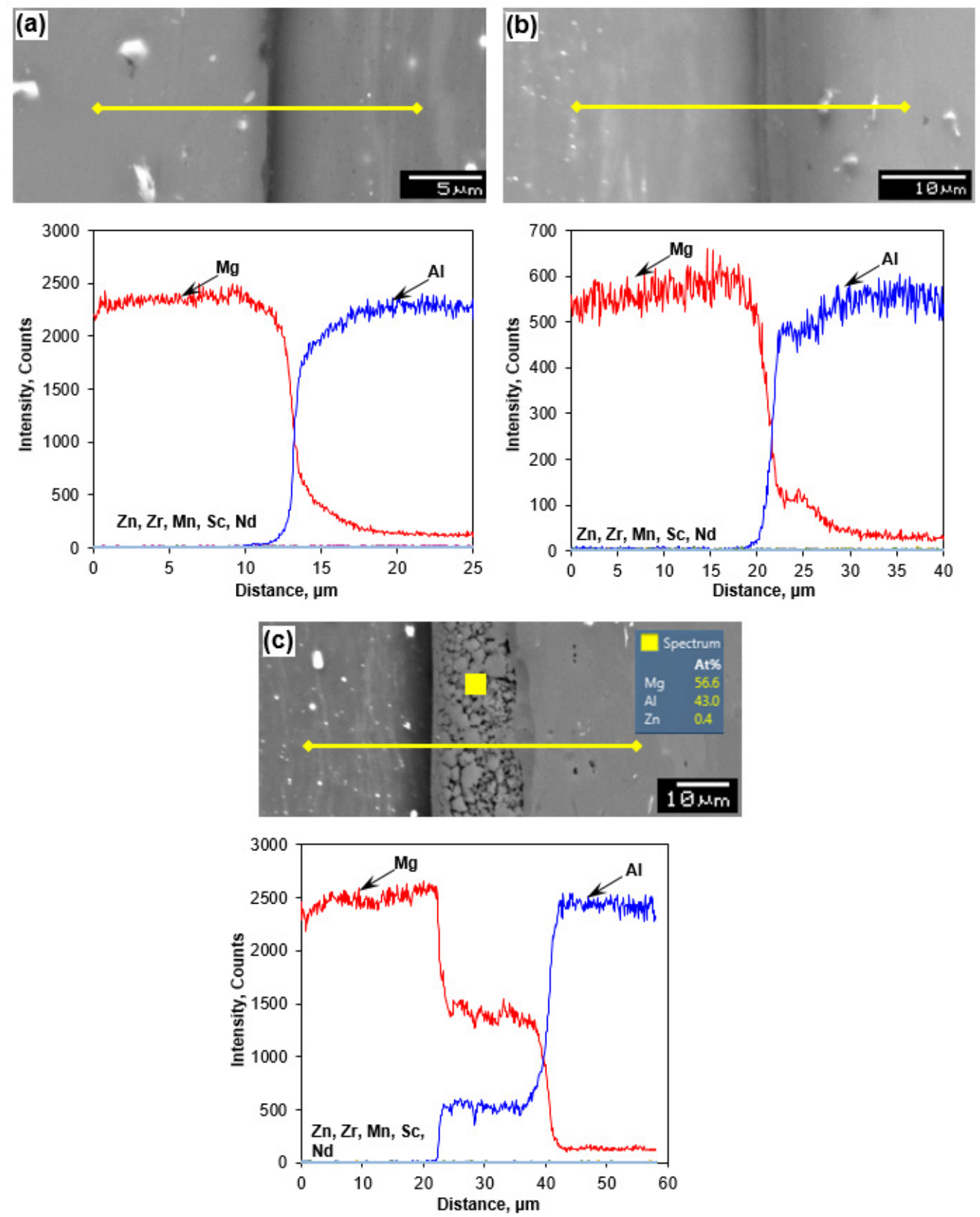

Figure 5.2: SEM micrographs showing the positions of EDS line scan and the relevant EDS line scan results at a welding energy of (a) $250 \mathrm{~J}$, (b) $500 \mathrm{~J}$, and (c) $1000 \mathrm{~J}$ along with the EDS point analysis results.

Multiple peaks of $\mathrm{Mg}$ and $\mathrm{Al}_{12} \mathrm{Mg}_{17}$ were observed on both sides, along with $\mathrm{Al}$ peaks on the Al side. This confirmed that the interface diffusion layer was containing $\mathrm{Al}_{12} \mathrm{Mg}_{17} \mathrm{IMC}$, which 
was in agreement with the above EDS point and line analyses. Furthermore, the presence of $\alpha$ $\mathrm{Mg}$ and $\mathrm{Al}_{12} \mathrm{Mg}_{17}$ on both sides suggested that cohesive failure occurred within the interface diffusion layer, which is usually a desired mode of failure.
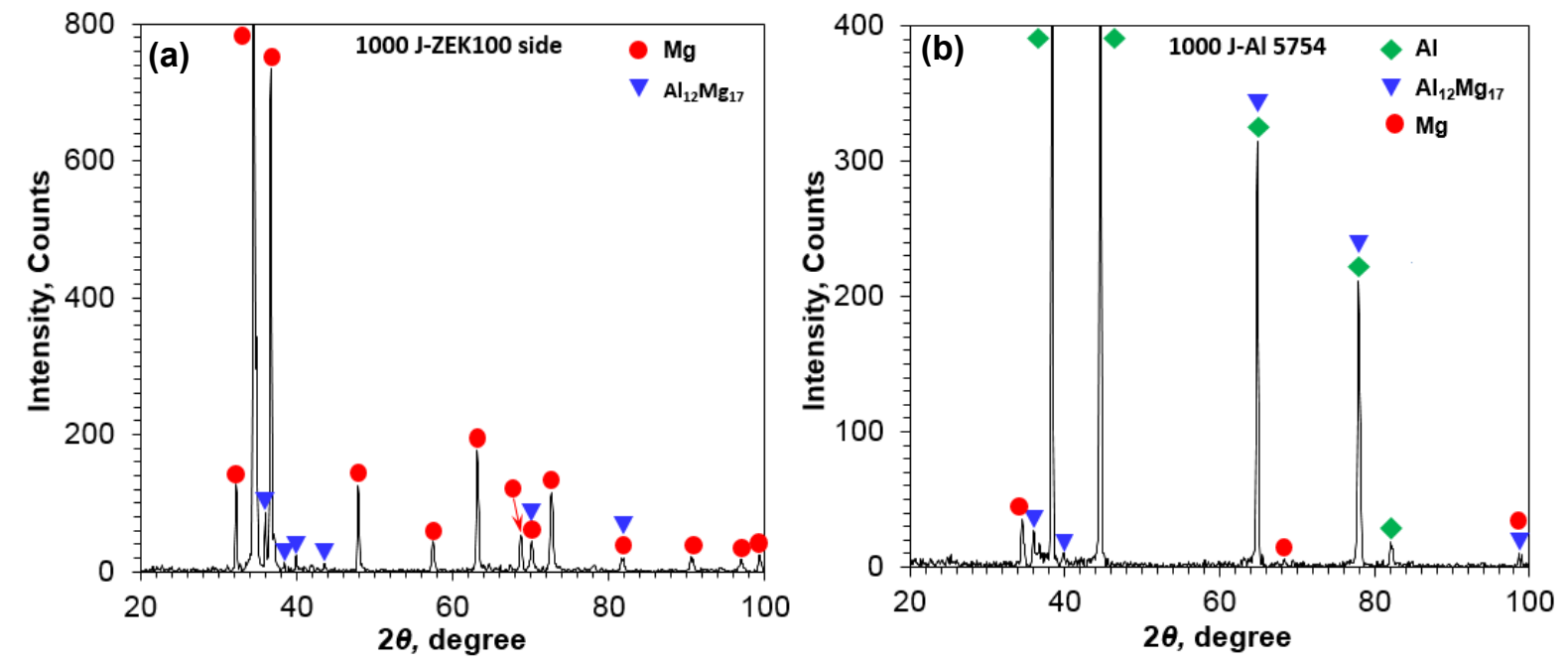

Figure 5.3: XRD patterns obtained on both matching surfaces of Mg side and Al side after the tensile lap shear test of a sample welded at a welding energy of $1000 \mathrm{~J}$.

\subsection{Tensile lap shear strength}

Figure 5.4 shows the maximum tensile shear load as a function of welding energy at a constant power of $2 \mathrm{~kW}$ and a constant clamping pressure of $0.4 \mathrm{MPa}$, where the maximum tensile shear load was evaluated from the load-displacement curve obtained from the tensile lap shear tests. Although there was some experimental scatter, the maximum tensile shear load first increased with increasing welding energy, reached its peak value of $2.2 \mathrm{kN}$ at a welding energy of $500 \mathrm{~J}$, and then decreased with further increasing welding energy. As mentioned above, at a low welding energy of $250 \mathrm{~J}$, the interface diffusion was limited, and the interface diffusion layer was discontinuous and thin (Figure 5.1(a)). Furthermore, the flowability of metal was limited 
since the yield strength of the base material remained high due to the lower interface temperature, which led to an incomplete coalescence of the bonding surfaces [38]. Therefore, the inadequate diffusion and incomplete coalescence at the weld interface gave rise to an inferior joint strength. As the welding energy and the resultant interface temperature increased, flowability improved, which resulted in sufficient diffusion and complete coalescence by forming a thin and continuous diffusion layer (Figure 5.1(b)). Though the diffusion layer contained brittle IMC $\mathrm{Al}_{12} \mathrm{Mg}_{17}$, the presence of $\alpha-\mathrm{Mg}$ in the eutectic structure increased plasticity and bonding strength. Also, the plastic deformation of the surface asperities led to an intimate contact, which balanced the embrittlement due to the presence of the intermetallic $\mathrm{Al}_{12} \mathrm{Mg}_{17}$ phase. As the welding energy further increased $(>500 \mathrm{~J})$, the higher interface temperature and larger vacancy concentration led to a thicker diffusion layer, which increased the brittleness of the interface diffusion layer, and a higher internal stress generated during the subsequent rapid cooling after welding, thus resulting in a lower joint strength. Patel et al. [41,47] also obtained similar results during their USW of AZ31 Mg alloy to A15754 alloy.

It is of interest to observe from Figure 5.4 that the maximum tensile lap shear load of ZEK100A15754 joints was significantly higher than that reported for the joints of AZ31-A15754 [41] and AZ31-A15754 with Sn interlayer [47]. It should be noted that this comparison was made based on the highest possible tensile lap shear load achieved at their respective optimum welding energy level; for the three types of dissimilar joints all other process parameters including sample preparation, welding system, welding power, control mode, clamping pressure, sonotrode tip size, sample geometry etc., were kept the same. Additionally, the peak 
value of ZEK100-A15754 joints was achieved at a lower welding energy of $500 \mathrm{~J}$, compared to $1500 \mathrm{~J}$ for AZ31-A15754 joints and $1000 \mathrm{~J}$ for AZ31-A15754 joints with Sn interlayer.

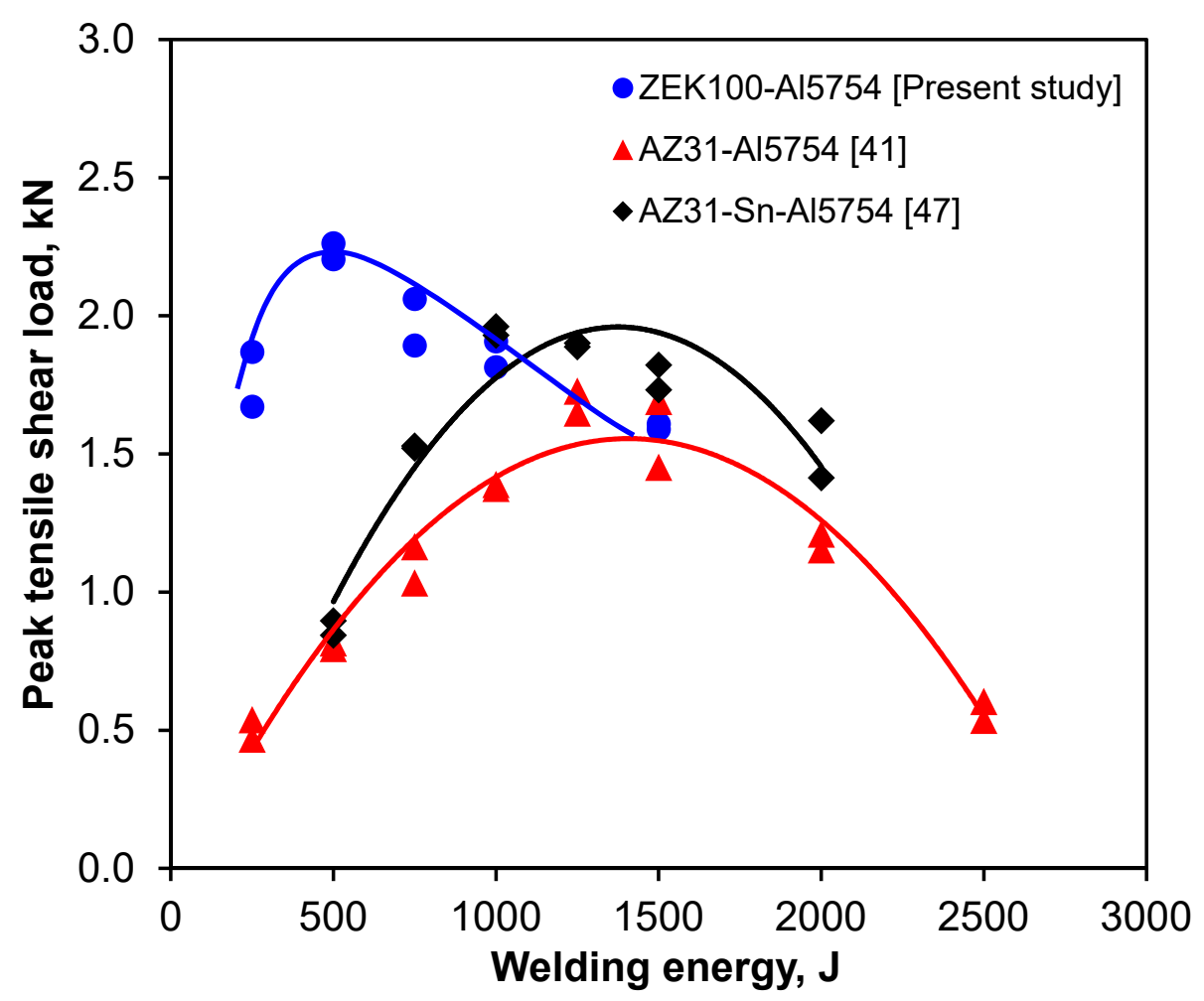

Figure 5.4: The maximum tensile shear load as a function of welding energy at a constant welding power of $2 \mathrm{~kW}$ and a constant pressure of 0.4 MPa for (a) ZEK100-Al5754, (b) AZ31Al5754 [41], and (d) AZ31-Al5754 with Sn interlayer [47].

This could be attributed to the difference in the mechanical properties (mainly the formability and ductility) and chemical composition between ZEK100 and AZ31 Mg alloys. The limiting dome height tests demonstrated the superior formability of ZEK100 over AZ31 particularly at temperatures below $200^{\circ} \mathrm{C}[26,151]$. The ductility of ZEK100 alloy determined at a strain rate of $10^{-2} \mathrm{~s}^{-1}$ at room temperature exceeded over $13 \%[8,10]$. The higher ductility would result in better flowability and coalescence of bonding at the joint interface between ZEK100-O to A15754-O at a lower welding energy (with a lower interface temperature), compared with the 
AZ31-H24 to A15754-O, thus giving rise to a higher maximum tensile lap shear load. Furthermore, AZ31 contains 3 wt.\% Al and ZEK100 do not have any Al alloying element, and thus, a concentration gradient is higher for ZEK100 than AZ31 in contact with A15754-O alloy. According to Fick's diffusion law, this would drive a relatively faster diffusion in ZEK100-O to A15754-O joints compared with AZ31-H24 to A15754-O joints. As also seen from Figure 5.1(b), the thickness of IMC containing diffusion layer was about 4-5 $\mu \mathrm{m}$ in ZEK100-O to A15754-O joints, compared with that of 1-2 $\mu \mathrm{m}$ in AZ31-H24 to A15754-O joints [41] made at the same welding energy of $500 \mathrm{~J}$. This means that ZEK100-O to A15754-O joints reached the optimum thickness of diffusion layer (i.e., the thickness corresponding to the maximum tensile lap shear load) at a lower energy than ZEK100-O to A15754-O joints. As a result, ZEK100-O to A15754-O joint exhibited the optimum strength at a lower welding energy compared to AZ31-H24 to A15754-O joints.

Figure 5.5(a) shows a comparison of average maximum strengths (calculated as the maximum tensile lap shear load divided by the nugget area of $8 \times 5 \mathrm{~mm}^{2}$ ) of ZEK100-A15754 (Mg-Al) dissimilar joints with those of similar A15754-A15754 (Al-Al) and ZEK100-ZEK100 (Mg-Mg) joints. It can be seen that about $78 \%$ of ZEK100-ZEK100 similar joint strength and about 55\% of Al5754-A15754 similar joint strength were achieved in the ZEK100-A15754 dissimilar welding via USW. It should be noted that this comparison was made based on the highest possible tensile lap shear load achieved at their respective optimum welding energy level; for the three types of joints all other process parameters including sample preparation, welding system, welding power, control mode, clamping pressure, sonotrode tip size, sample geometry etc., were kept the same. Figure 5.5(b) shows a comparison of the maximum lap shear strength 
of dissimilar $\mathrm{Mg}$ to $\mathrm{Al}$ joints of different alloys produced with different joining techniques $[41,47,52,53,152-156]$. The tensile lap shear strength was calculated by dividing the maximum tensile lap shear load by the tip area for USW. Similarly, the nugget diameter in the case of RSW and the shoulder and pin diameters in the case of FSSW were used to calculate an approximate value of tensile lap shear strength. It can be seen that the highest tensile lap shear strength was achieved in the ZEK100-A15754 dissimilar joint, compared with other Mg-Al dissimilar welded joints. However, it should be noted that there were different sample geometry as well as different alloys of $\mathrm{Mg}$ and $\mathrm{Al}$ with different thickness of the sheets, which could have an effect on the strength of the joints. Therefore, further studies are required to validate the above comparison.

\subsection{Fractography}

The tensile lap shear samples failed in an interfacial mode in all the welding energy conditions. To study the fracture characteristics, the failed samples joined at a welding energy of $1000 \mathrm{~J}$ were analyzed using SEM. Figure 5.6 (a) and (b) show the SEM images of the overall fracture surface on the $\mathrm{Mg}$ side and $\mathrm{Al}$ side, respectively. Two distinct regions in the nugget zone, as well as the clear region of higher stress concentration around the nugget edge, were observed on both Mg side and Al side. The EDS box analyses were performed on these distinct regions identified as A, B, C, D, and E, with the results being given on the corresponding images in Figure 5.6(c-g). 

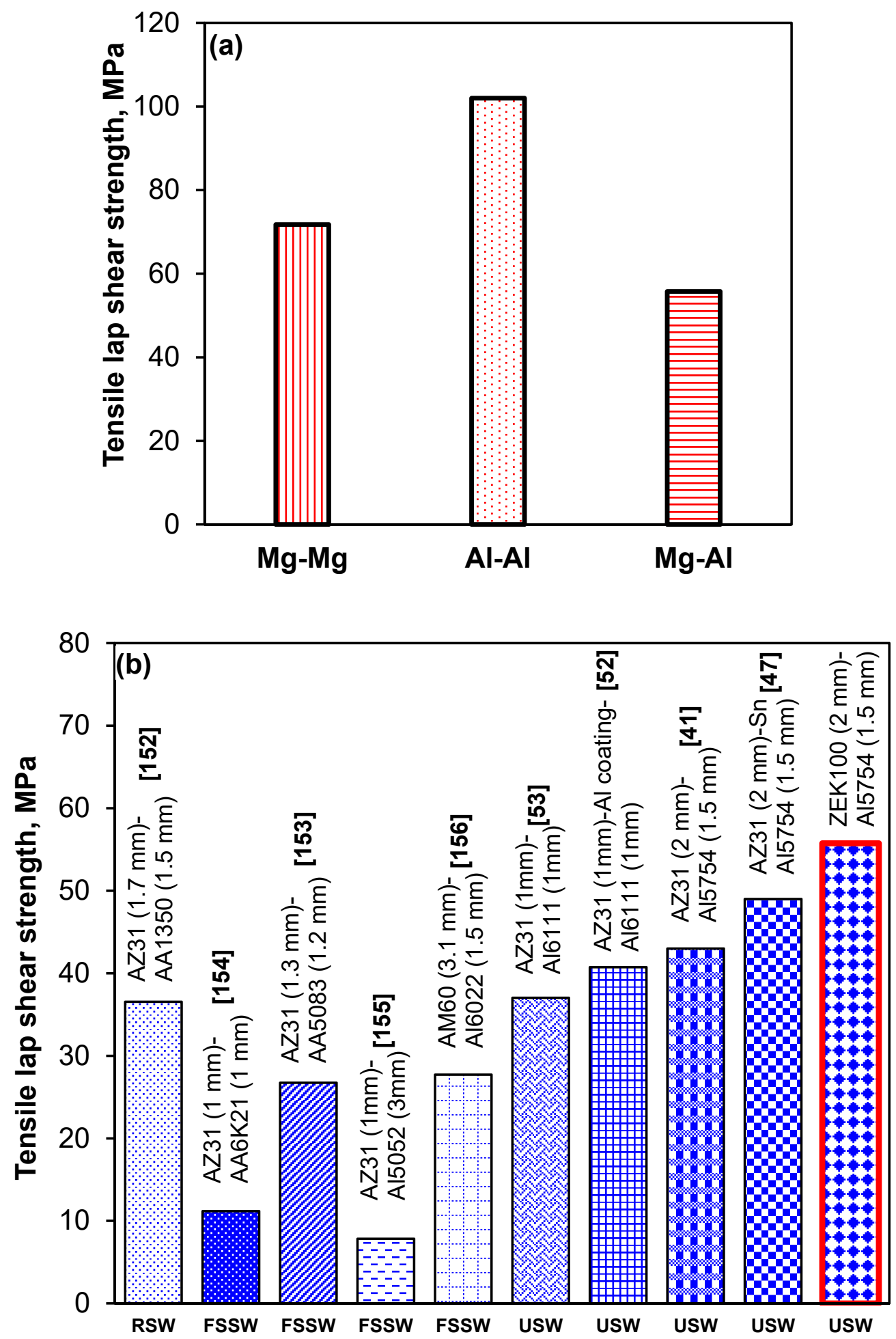

Figure 5.5: (a) tensile lap shear strength comparison of $\mathrm{Mg}$-Al dissimilar joints with the $\mathrm{Mg}$ $\mathrm{Mg}$ and Al-Al similar joints. (b) Comparison of the tensile lap shear strengths of the $\mathrm{Mg}-\mathrm{Al}$ joints made with different $\mathrm{Mg}$ and Al alloys and different joining techniques. 
The EDS analysis in region A showed a composition of 67.6 at.\% Mg, 31.8 at.\% Al, 0.4 at.\% $\mathrm{Zn}$ and 0.1 at. $\% \mathrm{Zr}$, which reflected the approximate composition of interface diffusion layer of $\alpha-\mathrm{Mg}+\mathrm{Al}_{12} \mathrm{Mg}_{17}$. Region B consisted of a composition of 99.3 at.\% $\mathrm{Mg}, 0.5$ at.\% $\mathrm{Zn}$ and 0.1 at.\%, which indicated that region $\mathrm{B}$ was just $\mathrm{Mg}$ alloy. The region $\mathrm{C}$ box analysis showed a composition of 68.8 at. $\% \mathrm{Mg}, 30.7$ at.\% $\mathrm{Al}, 0.4$ at. $\% \mathrm{Zn}$ and 0.1 at. $\% \mathrm{Zr}$, which was similar to region $\mathrm{A}$, being eutectic of $\alpha-\mathrm{Mg}+\mathrm{Al}_{12} \mathrm{Mg}_{17}$. Region $\mathrm{D}$, which was a matching image of region A, showed a composition of 86.6 at. $\% \mathrm{Al}, 13.1$ at. $\% \mathrm{Mg} 0.1$ at. $\% \mathrm{Zn}$ and 0.1 at.\% $\mathrm{Mn}$, indicating the sticking of $\mathrm{Mg}+\mathrm{Al}_{12} \mathrm{Mg}_{17}$ on the $\mathrm{Al}$ side. Similarly, region $\mathrm{E}$ was a matching image of region $\mathrm{B}$ with a similar composition, indicating that the $\mathrm{Mg}$ alloy was stuck on the $\mathrm{Al}$ side. These observations revealed clearly that cohesive failure occurred through the most of the diffusion layer consisting of a eutectic structure of $\alpha-\mathrm{Mg}+\mathrm{Al}_{12} \mathrm{Mg}_{17}$ in the nugget zone (i.e., region A or D), and only a small part of cracking penetrated into the ZEK100 Mg alloy during the tensile lap shear testing.

\subsection{Fatigue behavior and failure mode}

USWed Mg-to-Al joints at a welding energy of $500 \mathrm{~J}$ and $1000 \mathrm{~J}$ were evaluated for their fatigue performance at various cyclic load amplitudes. The fatigue tests were performed at room temperature, a load ratio of $R=0.2$ and a frequency of $50 \mathrm{~Hz}$, and the obtained results are shown in Figure 5.7(a). It can be seen that at a maximum cyclic load of $2.0 \mathrm{kN}$ and $1.5 \mathrm{kN}$ (i.e., in the regime of low cycle fatigue), the samples made at a welding energy of $500 \mathrm{~J}$ showed a longer fatigue life than those made with $1000 \mathrm{~J}$. 

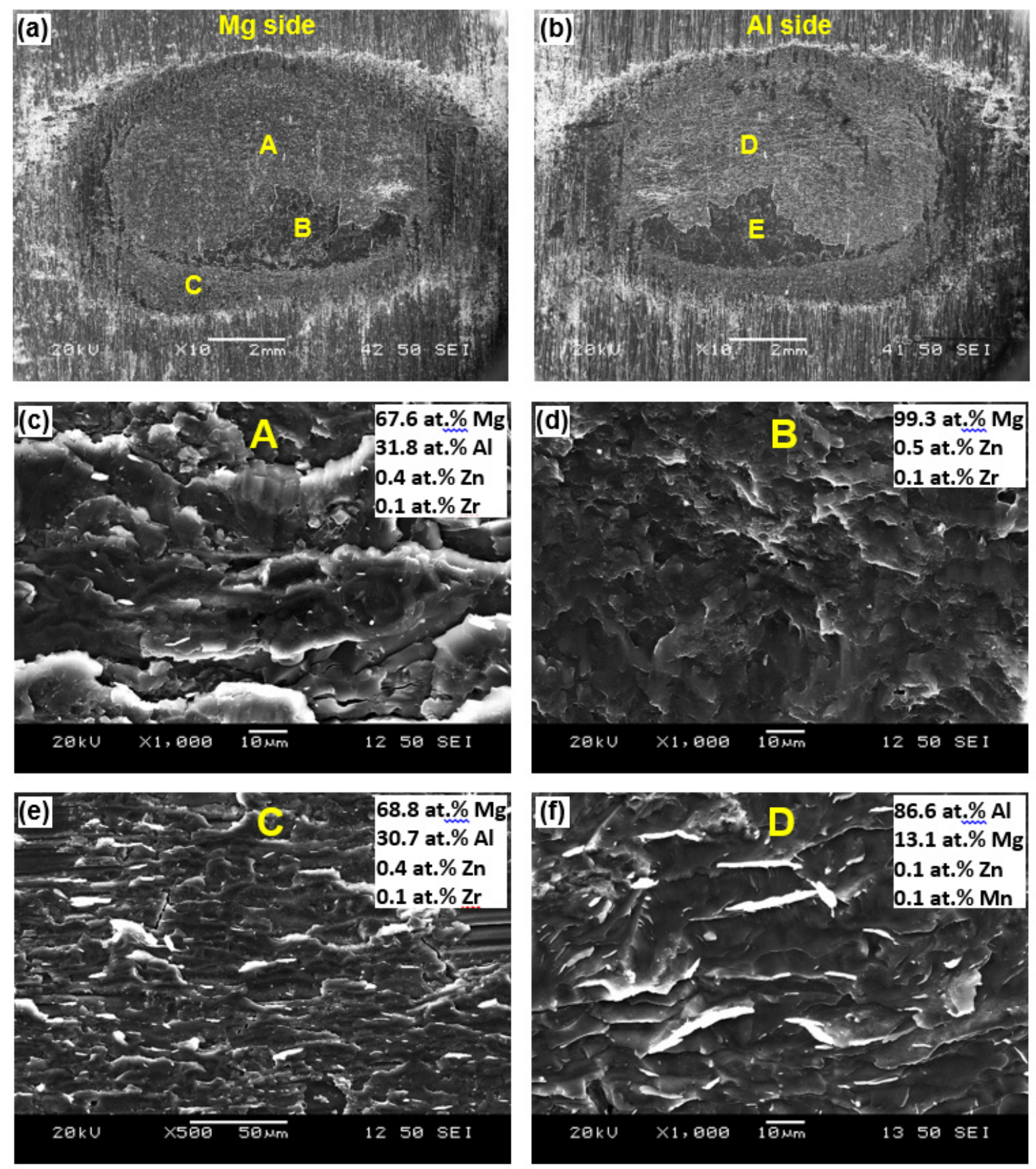

Figure 5.6: SEM images showing the typical fracture surface of a tensile lap shear failed sample welded at a welding energy of $1000 \mathrm{~J}$, (a) overall view on the $\mathrm{Mg}$ side, (b) overall view on the Al side, ( $c, d, e)$ higher magnification images in region $A, B$, and $C$ on the $M g$ side, $(f, g)$ higher magnification images in region $D$ and $E$ on the Al side. 


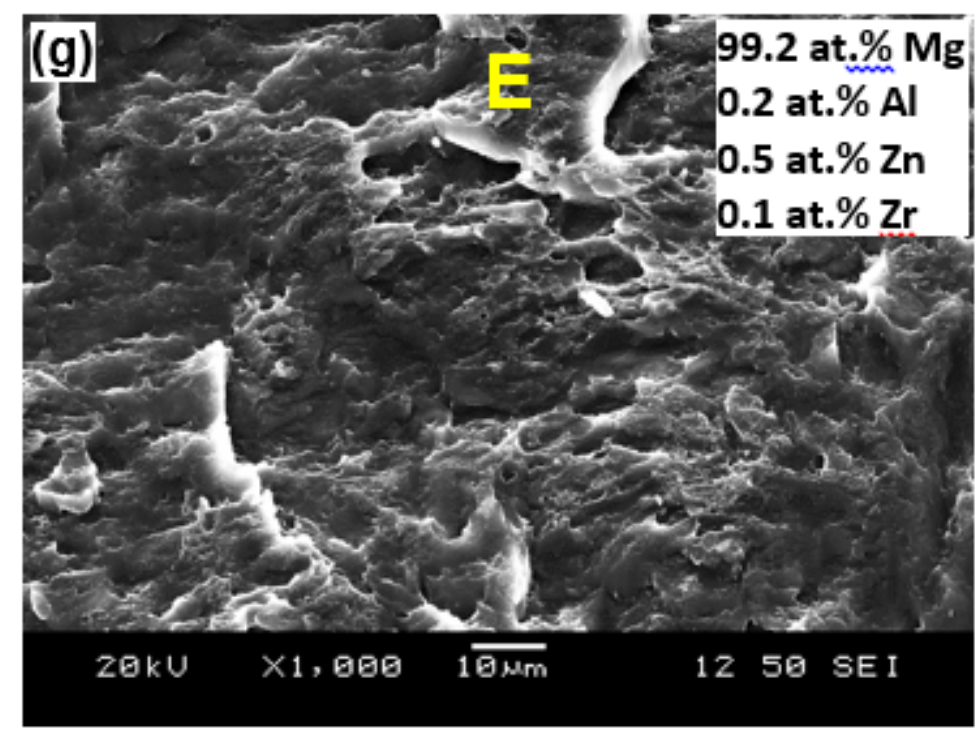

Figure 5.6: SEM images showing the typical fracture surface of a tensile lap shear failed sample welded at a welding energy of $1000 \mathrm{~J}$, (a) overall view on the $\mathrm{Mg}$ side, (b) overall view on the Al side, $(c, d, e)$ higher magnification images in region $A, B$, and $C$ on the $M g$ side, $(f, g)$ higher magnification images in region $D$ and $E$ on the Al side. (Repeated)

This was consistent with the tensile lap shear test result (Figure 5.4), where the samples welded at $500 \mathrm{~J}$ had a higher strength compared with those welded at $1000 \mathrm{~J}$. However, the samples made at a welding energy of $500 \mathrm{~J}$ exhibited an equivalent fatigue life to that at $1000 \mathrm{~J}$ at a lower maximum cyclic load of $1 \mathrm{kN}$ and $0.5 \mathrm{kN}$ (i.e., in the regime of high cycle fatigue). It could be better seen when the cyclic stress amplitude vs. the number of reversals to failure $\left(2 \mathrm{~N}_{\mathrm{f}}\right)$ in a double log scale is plotted, as shown in Figure 5.7(b). A bi-linear change could be used to represent the fatigue life at the higher and lower stress amplitudes, respectively. Such a bi-linear behavior corresponded well to the failure modes as shown in Figure 5.8(a-f), where the macroscopic images on the fatigue failed samples made at a welding energy of $500 \mathrm{~J}$ and 1000 $\mathrm{J}$, and tested at a maximum load of $0.5 \mathrm{kN}, 1 \mathrm{kN}$, and $1.5 \mathrm{kN}$ are presented. 

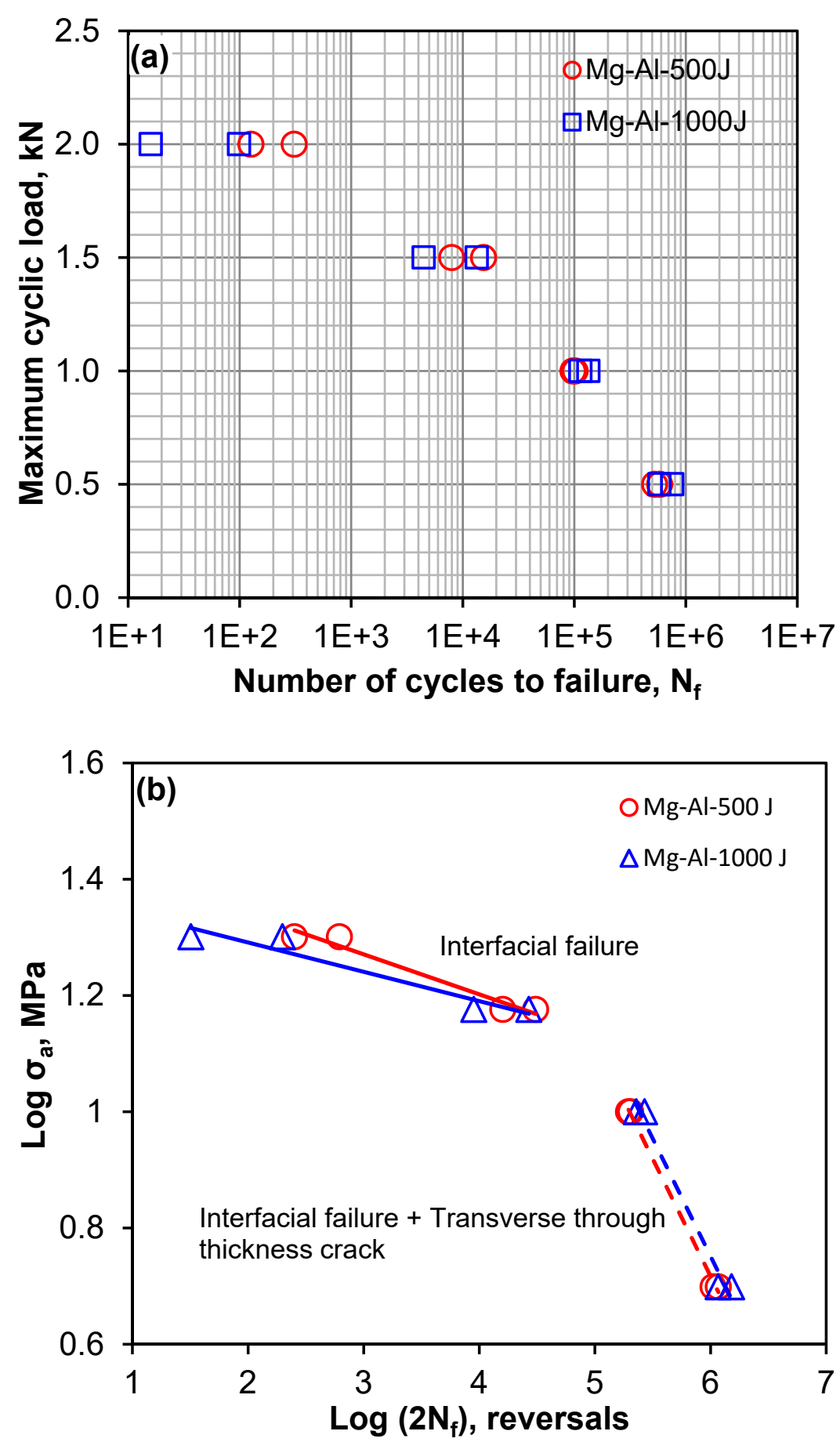

Figure 5.7: (a) S-N curves and (b) the stress amplitude vs. the number of reversals to failure on a log-log scale for the USWed ZEK100-Al5754 dissimilar joints made at a welding energy of $500 \mathrm{~J}$ and $1000 \mathrm{~J}$, tested at $R T, R=0.2$, and a frequency of $50 \mathrm{~Hz}$. 
During dynamic fatigue tests at a higher cyclic load level of $1.5 \mathrm{kN}$, only interfacial failure occurred in both welding conditions of $500 \mathrm{~J}$ and $1000 \mathrm{~J}$, which was attributed to the presence of interface layer consisting of eutectic $\mathrm{Mg}+\mathrm{Al}_{12} \mathrm{Mg}_{17}$ (Figures 5.1 and 5.2). While the interfacial failure mode remained at the low cyclic loading levels of $0.5 \mathrm{kN}$ and $1 \mathrm{kN}$ and in both welding conditions, the formation of transverse-through-thickness (TTT) crack (perpendicular to the loading direction) could be clearly seen at the edge of the nugget zone on the softer Mg side, as indicated by the yellow arrows in Figure $5.8(\mathrm{a}, \mathrm{b})$ and $(\mathrm{d}, \mathrm{e})$. During welding the relatively softer $\mathrm{Mg}$ alloy experienced a larger extent of deformation under clamping pressure and higher temperature in the nugget zone than $\mathrm{Al}$ alloy, resulting in an outward flow of the material at the nugget edge and as a result, a slight bending of the Mg sheet. This would cause a higher stress concentration and the formation of micro-level crack at the notch of two sheets (i.e., the nugget edge). Similar observations were made during USW of MgMg joint [81] and RSW of DP600 dual-phase steel [157]. It follows that a mixed mode of interfacial failure and TTT cracking at the lower cyclic load levels led to the bi-linear behavior in the S-N curves shown in Figure 5.7(b). Similar bi-linear S-N curve behavior along with the resultant failure modes was also reported in the weld-bonded AZ31B-H24 similar joints [158], USWed AZ31B-H24 similar lap joints [81], friction stir spot welded dissimilar joints of AZ31 magnesium and 5754 aluminum alloys $[149,150]$. This also corresponded well to the statement given by Roesler et al. [159] who pointed out that the fatigue strength of a material under dynamic cyclic loading was much more susceptible to the manufacturing process and materials than the static strength, and the fatigue strength or life was also much more sensitive to the lower level cyclic load than the higher level cyclic load. 

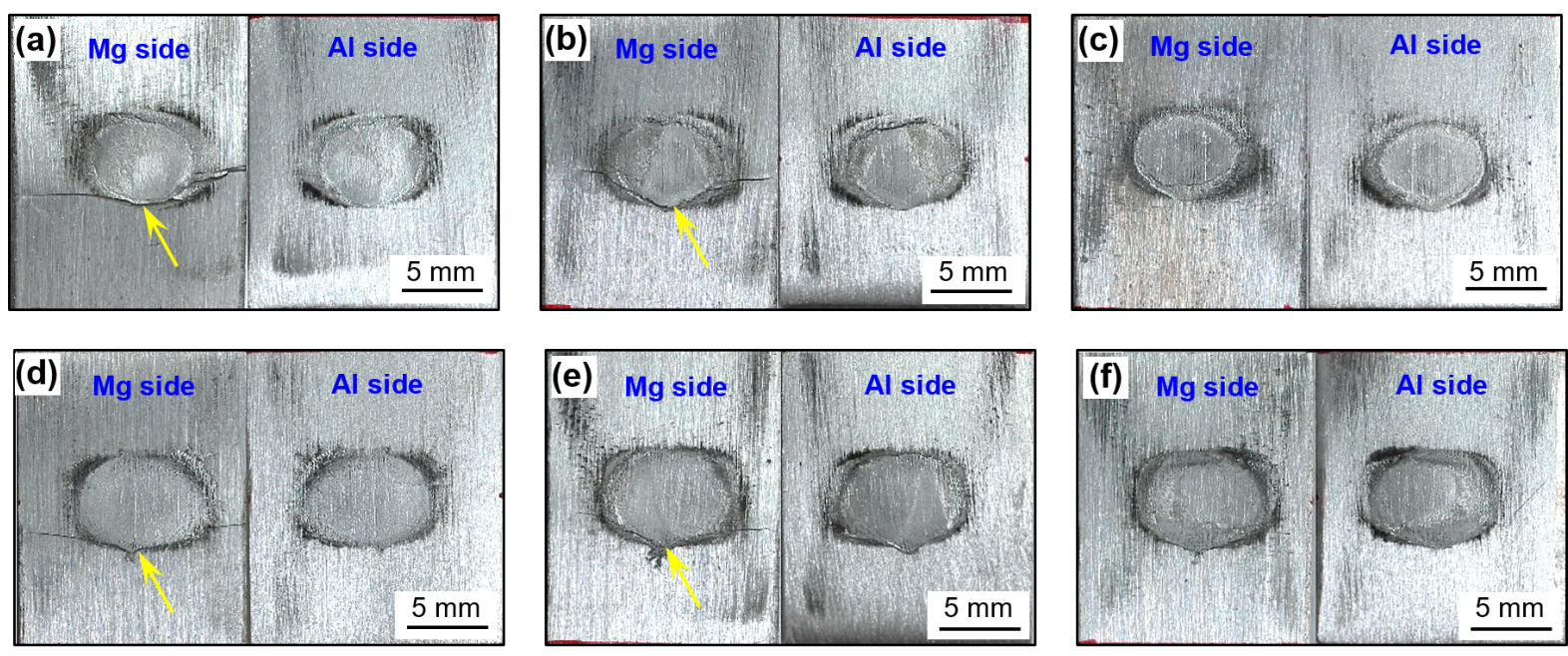

Figure 5.8: Macroscopic images showing fatigue failed samples of the USWed ZEK100-Al5754 dissimilar joints tested in the condition of (a) $500 \mathrm{~J}-0.5 \mathrm{kN}$, (b) $500 \mathrm{~J}-1.0 \mathrm{kN}$, (c) $500 \mathrm{~J}-1.5 \mathrm{kN}$, (d) $1000 \mathrm{~J}-0.5 \mathrm{kN}$, (e) $1000 \mathrm{~J}-1.0 \mathrm{kN}$, and (f) $1000 \mathrm{~J}-1.5 \mathrm{kN}$.

More detailed observations via SEM are shown in Figure 5.9, where the typical fracture surface of a fatigue failed sample welded at a welding energy of $500 \mathrm{~J}$ and tested at a maximum load of $0.5 \mathrm{kN}$ was examined. It is clear that TTT cracks formed at the nugget edge only on the $\mathrm{Mg}$ side (Figure 5.9(a) and propagated along the sample width and thickness directions. In the nugget zone, two distinct regions could be identified on the $\mathrm{Mg}$ side as indicated by $\mathrm{A}$ and $\mathrm{B}$ and on the Al side as marked by $\mathrm{C}$ and $\mathrm{D}$. Similar regions were also observed after tensile lap shear tests as discussed earlier (Figure 5.6(a) and (b)). For the further analysis, each region was magnified, and EDS point or box analyses were performed as shown in Figure 5.9(c-f). Figure 5.9(c) shows that region A was mainly composed of $\mathrm{Mg}$ alloy and $\mathrm{Mg}-\mathrm{Al}_{12} \mathrm{Mg}_{17}$ eutectic. Figure 5.9(d) shows that region B was base Mg alloy. On the Al side, region C contained mainly Al alloy and $\mathrm{Mg}-\mathrm{Al}_{12} \mathrm{Mg}_{17}$ eutectic. Region $\mathrm{D}$ was similar to region $\mathrm{B}$ that was only $\mathrm{Mg}$ alloy. It was also observed from Figure 5.9( $\mathrm{a}$ and $\mathrm{b}$ ) that the sample welded at a welding energy of 500 $\mathrm{J}$ had a smaller ( $\sim 40 \%)$ region containing the mainly eutectic structure and a larger $(\sim 60 \%)$ region containing $\mathrm{Mg}$. 

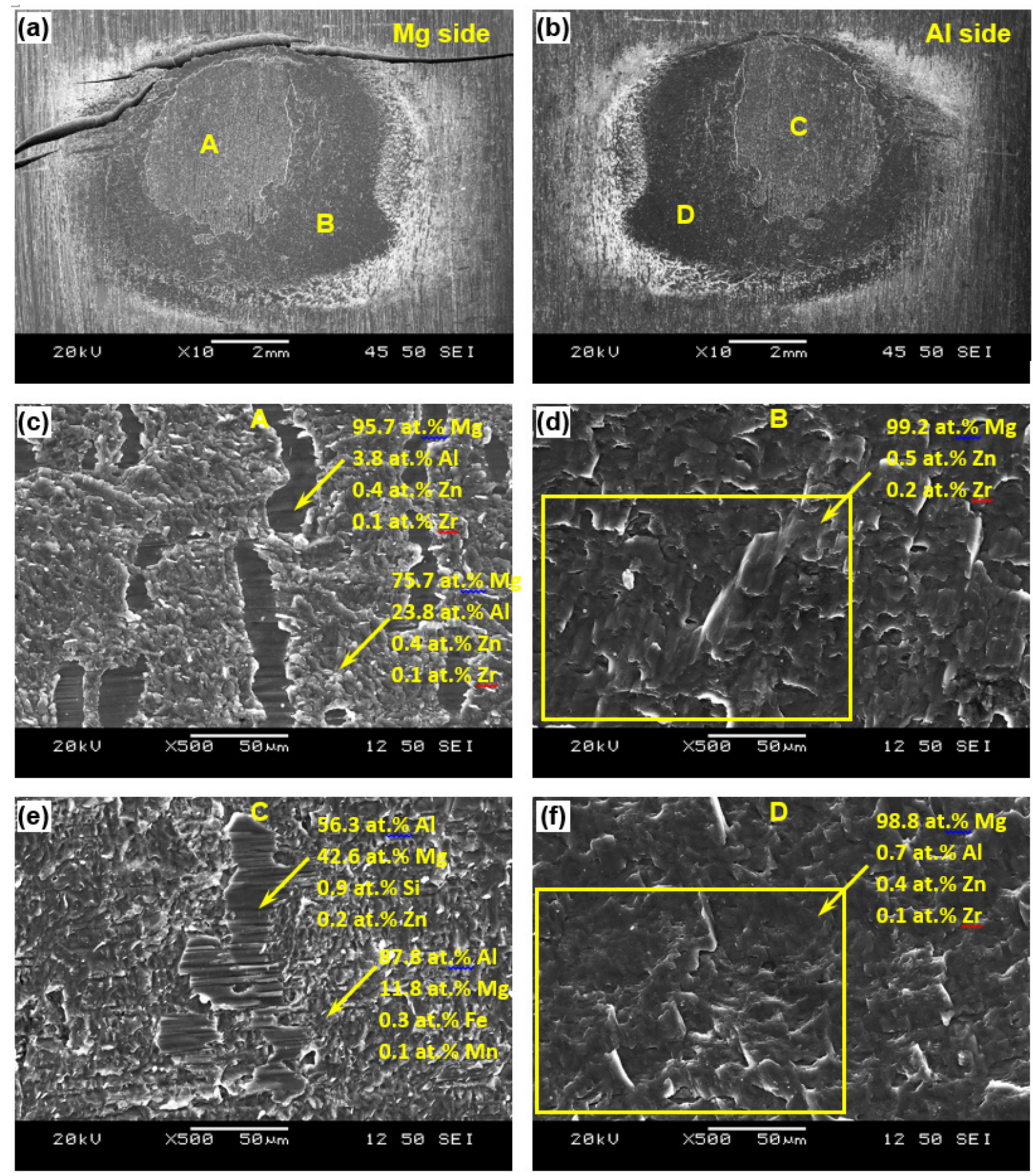

Figure 5.9: SEM images of a fatigue failed sample made at a welding energy of $500 \mathrm{~J}$ and tested at a maximum load of $0.5 \mathrm{kN}$. (a,b) Overall view of the entire fracture surfaces on the $\mathrm{Mg}$ side and Al side, respectively, and (c,d,e,f) magnified view of the regions of interest indicated in (a) and (b). 
While the sample welded at a welding energy of $1000 \mathrm{~J}$ had a larger $(\sim 80 \%)$ region containing the eutectic structure and a smaller ( 20\%) region containing Mg (Figure 5.6(a and b)). The larger $\mathrm{Mg}$ area suggested that ZEK100 Mg alloy intimately stuck to the $5754 \mathrm{Al}$ alloy, indicating a superior bonding there. As a result, it would be understandable that a higher strength of the sample welded at a welding energy of $500 \mathrm{~J}$ was achieved, in comparison with the sample made at a welding energy of $1000 \mathrm{~J}$, as shown in Figure 5.4.

\subsection{Summary}

The USW of ZEK100 Mg alloy to $5754 \mathrm{Al}$ alloy was performed at various levels of welding energy, and the interface microstructure, tensile lap shear strength, and fatigue life were evaluated. The following conclusions could be drawn:

1) The enhanced diffusion at the joint interface during USW resulted in the formation of an interface diffusion layer consisting of a eutectic structure of $\alpha-\mathrm{Mg}$ and $\mathrm{Al}_{12} \mathrm{Mg}_{17}$. The thickness of the interface diffusion layer is increased with increasing welding energy.

2) The maximum tensile lap shear load increased with increasing welding energy, reached a peak value of about $2.2 \mathrm{kN}$ at a welding energy of $500 \mathrm{~J}$ and then decreased.

3) The peak tensile lap shear load of the ZEK100-A15754 dissimilar joints was higher than that of AZ31-A15754 dissimilar joints even with a tin interlayer. This was mainly attributed to the superior ductility and formability of ZEK100 Mg alloy which led to enhanced flowability and coalescence at the joint interface during USW. 
4) The tensile lap shear test samples failed in an interfacial mode with partial cohesive failure through the interface diffusion layer and partial cohesive failure through $\mathrm{Mg}$ alloy, where $\mathrm{Mg}$ alloy was stuck on the Al side.

5) Fatigue resistance of the samples welded at a welding energy of $500 \mathrm{~J}$ was higher than that at a welding energy of $1000 \mathrm{~J}$ at higher cyclic loading levels; it became equivalent at lower cyclic loading levels. The bi-linear characteristics of S-N curves were directly associated with the difference in the failure modes, where the interfacial failure occurred at higher cyclic loading levels while the transverse-through-thickness (TTT) crack was observed to form at the nugget edge at lower cyclic loading levels.

In this study, a sound joint of USWed ZEK100 Mg alloy to A15754 alloy was achieved with a tensile strength higher than those made by other joining technique. Other important joints for automotive lightweight structural applications as observed in superlight-Car design were Al-tosteel joints. Moreover, with increasing usage of new HSLA steel, joining of Al-to-HSLA steel is important. Furthermore, this new HSLA steel is galvanized $\mathrm{Zn}$ coated to improve their corrosion resistance. Next Chapter will focus on the characterization of Al-to-HSLA steel joints and study effect of $\mathrm{Zn}$ coating on interface microstructure and mechanical properties of the joints. 


\section{Chapter 6. Ultrasonic Spot Welding of Aluminum Alloy-to-HSLA Steel}

A multi-material design of automotive structures inevitably involves dissimilar joining of lightweight aluminum (Al) alloys with HSLA steel. Here, since many studied have already shown that joining of Al and steel alloys produces brittle IMCs, in this study, only USW of Alto-galvanized ( $\mathrm{Zn}$ coated) HSLA steel was conducted with the aiming of eliminating or minimize the IMC thickness. USW technique was used to join Al alloy 6111-T4 to galvanized HSLA steel. Microstructure and mechanical properties of the joints were evaluated in close relation with an important process parameter, welding energy.

\subsection{Microstructure characterization}

During USW, the near-interface weld region defined as a nugget zone (NZ) undergoes significant microstructural changes due to high strain rate plastic deformation and temperature rise via frictional heating [44,117]. Figure 6.1 shows typical SEM images of the NZ of USWed Al6111-T4-HSLA steel joints made at a welding energy ranging from $500 \mathrm{~J}$ to $3000 \mathrm{~J}$ with an interval of $500 \mathrm{~J}$. It is seen that at a low welding energy of $500 \mathrm{~J}$ (Figure 6.1(a)), the interface was mainly composed of original Zn coating layer as identified by an EDS point analysis (91.5 at.\% $\mathrm{Zn}, 4.3$ at.\% $\mathrm{Al}$, and 4.2 at.\% Fe). However, some small and discrete $\mathrm{Zn}$ clusters could be observed on the Al side, indicating the onset of diffusion at the interface. This was a result of relatively lower temperature and strain rate as well as shorter welding time at a lower welding

energy of $500 \mathrm{~J}$. Similar results were observed during USW of $\mathrm{Al} / \mathrm{Mg} / \mathrm{Al}$ clad sheet to galvanized HSLA steel [9]. 

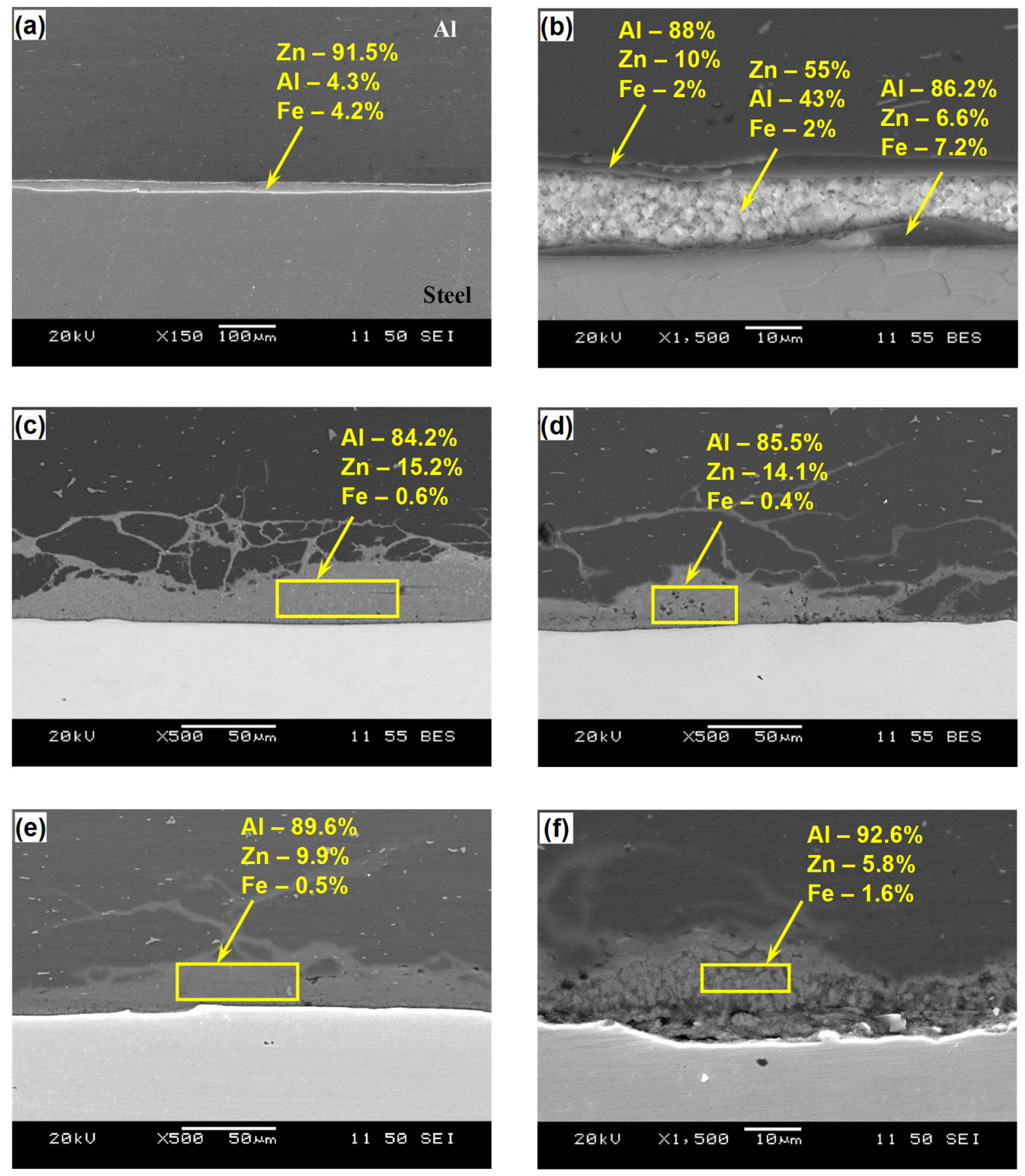

Figure 6.1: Typical SEM images showing the nugget interface microstructure of the USWed Al6111-HSLA steel joint at a welding energy of (a) $500 \mathrm{~J}$, (b) $1000 \mathrm{~J}$, (c) $1500 \mathrm{~J}$, (d) $2000 \mathrm{~J}$, (e) $2500 \mathrm{~J}$, and (f) $3000 \mathrm{~J}$, respectively (composition in at.\%). 
As the welding energy increased, the temperature at the interface rose due to heat generation by friction and plastic deformation and there was an increase in strain rate and welding time [44]. These led to more interdiffusion of $\mathrm{Zn}$ and $\mathrm{Al}$ at the interface and the formation of an interdiffusion layer as shown in Figure 6.1(b) for the sample welded at a welding energy of $1000 \mathrm{~J}$. Close examination revealed that the interdiffusion layer had three distinct regions as indicated by three arrows in Figure 6.1(b), which were analyzed using EDS point analysis. The bright middle layer had a composition of (at.\%): 44\% Al, 54\% Zn, and 2\% Fe. According to the Al-Zn binary phase diagram, this region should be Al-Zn eutectoid via a solid-state reaction between $\mathrm{Al}$ and $\mathrm{Zn}$ at an equilibrium temperature of $277^{\circ} \mathrm{C}$ to form $\mathrm{Al}-\mathrm{Zn}$ solid solution of 59 at.\% $\mathrm{Zn}[160]$. Haddadi et al. [37] showed that the temperature at the interface during USW of Al to $\mathrm{Zn}$ coated steel would be lower than the equilibrium eutectic temperature of $381^{\circ} \mathrm{C}$ for $0.5 \mathrm{~s}$ (equivalent to $1000 \mathrm{~J}$ in the present study). Indeed, the Al-Zn eutectoid could be formed below the equilibrium temperature of $277^{\circ} \mathrm{C}$ since the phenomenon of "melting-point depression" as reported by Gunduz et al. [126] existed during USW. It was reported earlier that strain rates during USW could reach as high as $10^{3} \mathrm{~s}^{-1}[44,107,126]$, which led to several orders of magnitude increase in the concentration of vacancies, up to $7 \times 10^{-2}$ in aluminum [126]. The higher vacancy concentration resulted in "melting-point depression" as shown by Gunduz et al. [126], thus making the formation of Al-Zn eutectoid (or eutectic-like structure) possible at a temperature lower than its equilibrium temperature of $277^{\circ} \mathrm{C}$. Therefore, it is likely that the Al$\mathrm{Zn}$ eutectoid formed at the interface even in a lower energy condition like $1000 \mathrm{~J}$ as observed in Figure 6.1(b). The upper and lower thin gray layer in Figure 6.1(b) had a similar composition (in at. $\%$ ) of $88 \% \mathrm{Al}, 10 \% \mathrm{Zn}, 2 \% \mathrm{Fe}$ and $86.2 \% \mathrm{Al}, 6.6 \% \mathrm{Zn}, 7.2 \%$ Fe. They could be Al-rich diffusion layer, where the composition had not reached Al-Zn eutectoid composition due to the 
pure solid-state eutectoid reaction/diffusion in a relatively short time. In the case of $1000 \mathrm{~J}$ energy input, the welding could be stopped just after eutectoid formation, without the occurrence of $\mathrm{Al}-\mathrm{Zn}$ eutectic at 88.7 at. $\% \mathrm{Zn}$ and an equilibrium temperature of $381^{\circ} \mathrm{C}$. Further increase in the welding energy to $1500 \mathrm{~J}$ increased interface temperature and welding time, which would allow the occurrence of Al-Zn eutectic structure. Previous studies of USW of Al to $\mathrm{Zn}$ coated steel also showed the formation of Al- $\mathrm{Zn}$ eutectic at the weld interface $[9,27,37,161]$. However, most of the Al-Zn diffusion layer was squeezed out of the nugget zone (NZ) due to the shear motion under a moderate clamping pressure, leaving Al-rich diffusion layer exhibiting a distinctive flow pattern with an extensive penetration mainly along high angle grain boundaries as shown in Figure 6.1(c-f). This was due to the fact that in the ultrasonic welding, vacancy concentration caused by the high strain-rate deformation considerably enhanced diffusion induced zinc penetration along the $\mathrm{Al}$ grain boundaries by many orders of magnitudes $[37,126]$. The NZ interface diffusion layer was mainly composed of Al-rich layer with diffused $\mathrm{Zn}$ element having a composition of $84.2 \mathrm{Al}, 15.2 \% \mathrm{Zn}$, and $0.6 \% \mathrm{Fe}$ (in at.\%). Similar microstructures were observed at a welding energy of $2000 \mathrm{~J}, 2500 \mathrm{~J}$ and $3000 \mathrm{~J}$. However, the percentage of $\mathrm{Zn}$ element in the interface diffusion layer decreased consistently with increasing welding energy. This could be understood as follows: with increasing welding energy, welding time and temperature increased, which allowed more and more $\mathrm{Zn}$ to combine with $\mathrm{Al}$ to form more $\mathrm{Al}-\mathrm{Zn}$ eutectoid/eutectic that kept squeezing out of the interface. As a result, there was a continuous drop in $\mathrm{Zn}$ concentration in the interface diffusion layer as seen in EDS point scan results shown in Figure 6.1(c-f). It should be noted that the growth of the interface diffusion layer was always towards Al side after a continuous layer was formed. This could be attributed to several reasons including, much closer melting point of $\mathrm{Zn}\left(419.6^{\circ} \mathrm{C}\right)$ to 
that of $\mathrm{Al}\left(660.4^{\circ} \mathrm{C}\right)$ compared to that of $\mathrm{Fe}\left(1538^{\circ} \mathrm{C}\right)$; smaller atomic radius of $\mathrm{Zn}(0.133 \mathrm{~nm})$ than that of $\mathrm{Al}(0.143 \mathrm{~nm})$ but larger than that of $\mathrm{Fe}(0.124 \mathrm{~nm})$; and much higher lattice diffusivity of $\mathrm{Zn}$ in $\mathrm{Al}\left(1.208 \times 10^{-17} \mathrm{~m}^{2} / \mathrm{s}\right)$ at $240^{\circ} \mathrm{C}$ than that of $\mathrm{Zn}$ in $\mathrm{Fe}\left(4.5 \times 10^{-24} \mathrm{~m}^{2} / \mathrm{s}\right)$ even at $400^{\circ} \mathrm{C}[162,163]$.

Figure 6.2 (a-c) shows typical SEM images of distinctive flow features of interface diffusion layer penetrated into A16111 alloy during USW, mostly at the nugget edge in different welding energy conditions of $1500 \mathrm{~J}, 2000 \mathrm{~J}$, and $2500 \mathrm{~J}$, respectively. Macwan et al. [9] and Haddadi et al. [37] also reported that diffusion induced $\mathrm{Zn}$ to penetrate along the high angle grain boundaries. The penetration depth of interface diffusion layer into Al alloy could reach as high as $\sim 500 \mu \mathrm{m}$ observed at a welding energy of $2000 \mathrm{~J}$ as shown in Figure 6.2(b). This was very large for a normal solid-state diffusion process, especially in view of the current very short welding time of 0.5-1.5 s. The formation of Zn-related diffusion pattern at higher welding energy conditions could also be another reason for the continuous drop of $\mathrm{Zn}$ concentration in the interface diffusion layer with increasing welding energy, as shown in Figure 6.1(c-f). Figure 6.2(d) shows the deposition of Al-Zn diffusion layer at the nugget edge that was squeezed out from the nugget region during USW along with an EDS point analysis. The EDS analysis revealed grey region had a composition of 55.6 at.\% Zn, 42.9 at.\% Al and 1.5 at.\% Fe, which was very close to the ideal (59.0 at.\% Zn) Al-Zn eutectoid (a divorced eutectic-like structure) and white region had a composition of 90.7 at.\% $\mathrm{Zn}, 8.2$ at.\% $\mathrm{Al}$ and 1.1 at.\% Fe, which was very close to the ideal ( 88.7 at.\% Zn) Al-Zn eutectic based on the Al-Zn phase diagram. Other researchers also observed a similar squeezing effect during USW of Al to steel [27,37]. The squeezed out Al-Zn eutectic liquid at a high temperature solidified at the edge of the nugget and 
generated a brazing effect there. This will play a significant role in the strengthening of the Al to steel joints via reducing the stress concentration at the nugget edge, which will be discussed later.
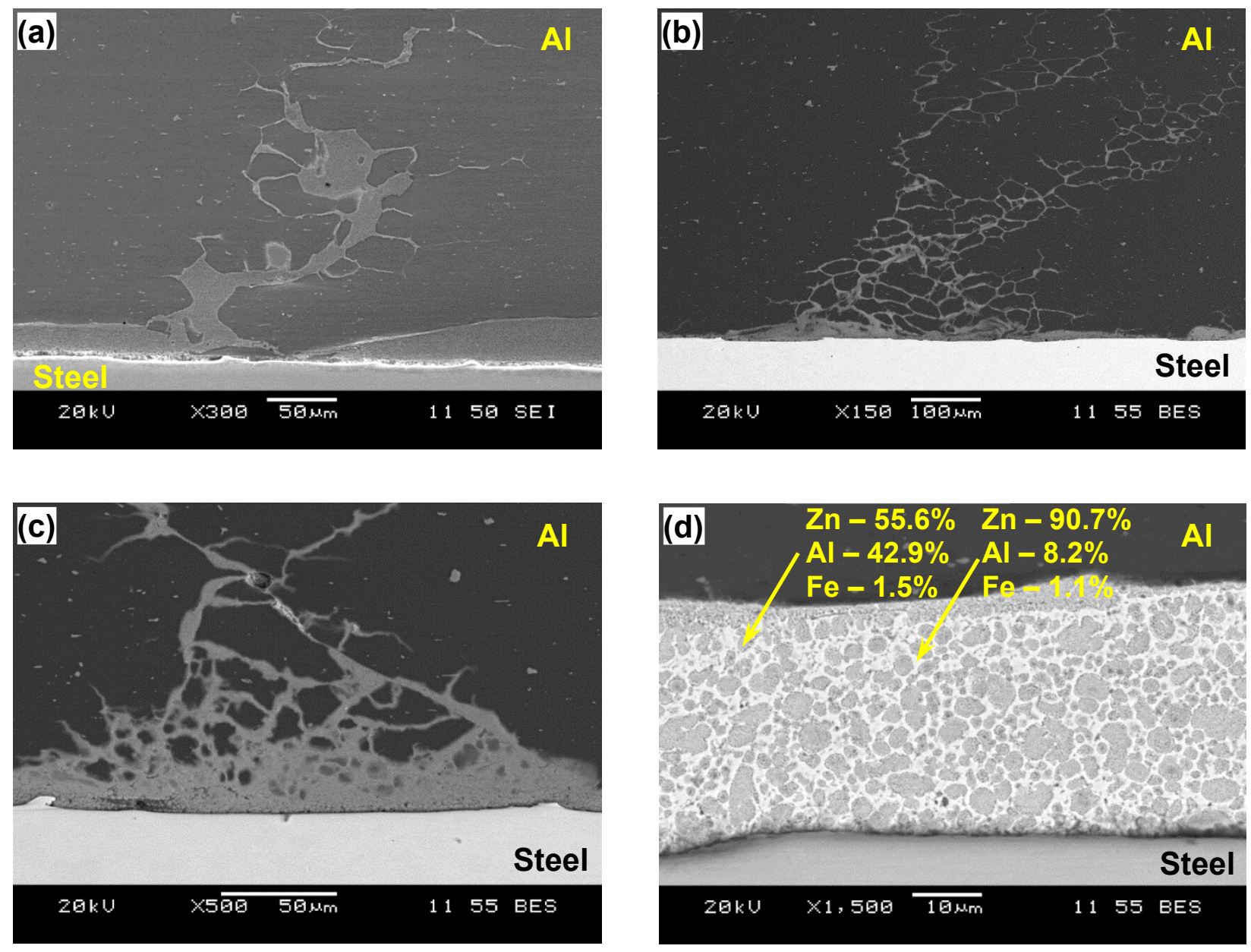

Figure 6.2: SEM micrographs showing characteristic diffusion patterns of Al-Zn eutectoid at the nugget edge in the Al6111-HSLA steel dissimilar joints made at a welding energy of (a) $1500 \mathrm{~J}$, (b) $2000 \mathrm{~J}$, and (c) $2500 \mathrm{~J}$, and (d) magnified view of the squeezed-out diffusion layer outside the nugget edge at a weld energy of $1500 \mathrm{~J}$ (composition in at.\%).

6.1.1 Energy-dispersive X-ray spectroscopy analysis 

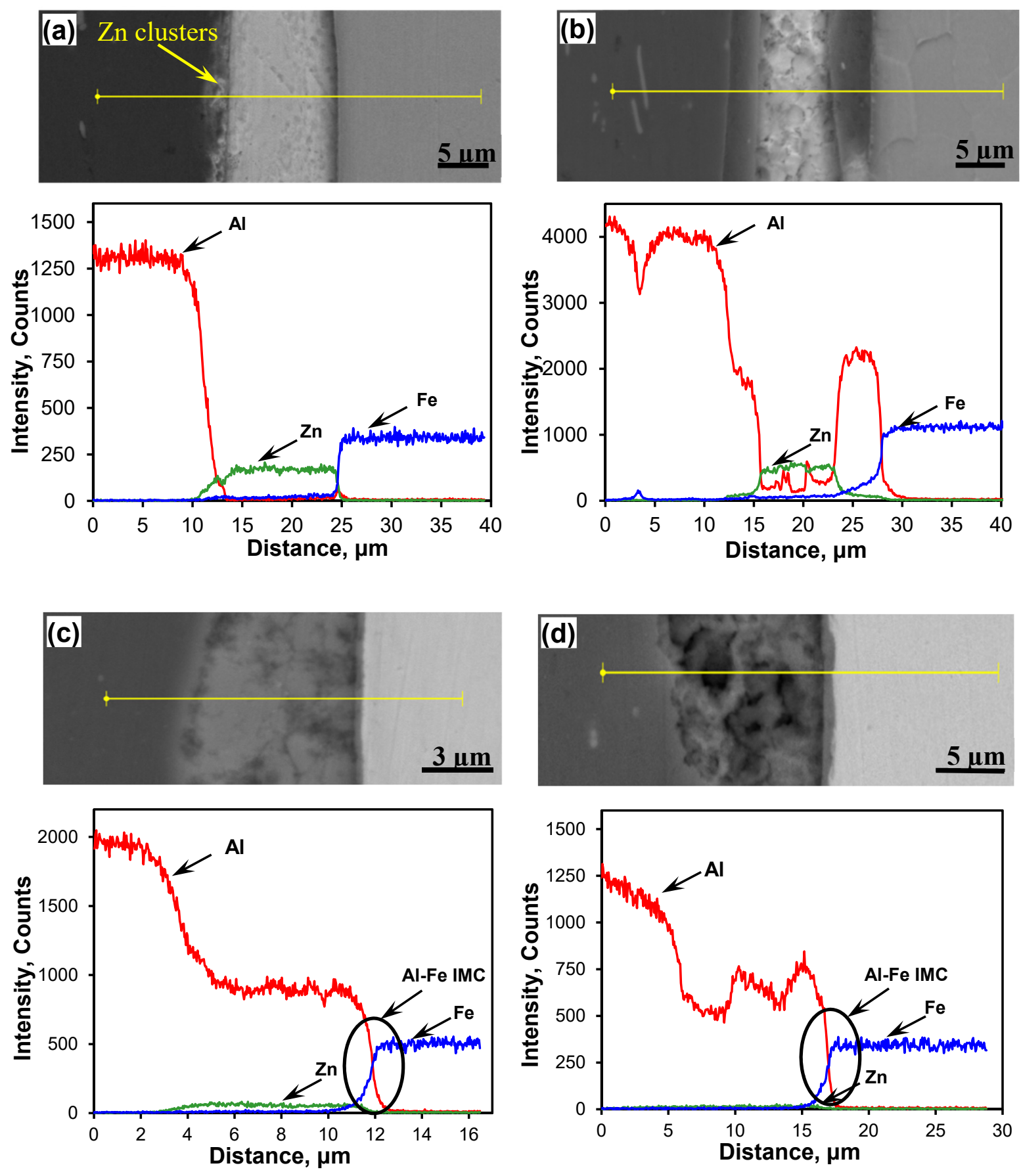

Figure 6.3: Results of EDS line scan analyses at the nugget interface of the USWed Al6111HSLA steel dissimilar joints made at a welding energy of (a) $500 \mathrm{~J}$, (b) $1000 \mathrm{~J}$, (c) $2000 \mathrm{~J}$, and (d) $3000 \mathrm{~J}$, respectively. 
EDS line scan analyses in various energy conditions were also performed to verify the phases present in the interface diffusion layer and the obtained results are shown in Figure 6.3. It is seen from Figure 6.3(a) that the interface layer at a welding energy of $500 \mathrm{~J}$ was mainly composed of the original $\mathrm{Zn}$ coating as also observed in Figure 6.1(a). Also, the small $\mathrm{Zn}$ clusters were clearly visible in getting into the Al side, indicating the onset of diffusion at the weld interface. Figure 6.3(b) showed EDS line analysis at a welding energy of $1000 \mathrm{~J}$ which confirmed the presence of Al-rich diffusion layer on both Al and $\mathrm{Zn}$ sides. The EDS line analysis results shown in Figure 6.3(b-d) at $1000 \mathrm{~J}, 2000 \mathrm{~J}$ and $3000 \mathrm{~J}$ revealed clearly a gradual reduction of $\mathrm{Zn}$ in the interface diffusion layer with increasing welding energy, being consistent with the earlier point analysis results shown in Figure 6.1(b-f). However, careful observations revealed a possible very thin $(\sim 1 \mu \mathrm{m}) \mathrm{Al}-\mathrm{Fe}$ intermetallic layer at the interface on the steel side, as indicated by black elliptical region in Figure 6.3(c,d). This could be $\mathrm{FeAl}_{3}$ or $\mathrm{Fe}_{2} \mathrm{Al}_{5}$ IMCs as suggested in several previous studies $[27,46,101,161]$. It can be reasoned that at a welding energy of $2500 \mathrm{~J}$ and $3000 \mathrm{~J}$ most of the Al-Zn diffusion layer was squeezed out of nugget, hence creating a possibility of $\mathrm{Al}$ coming in direct contact with Fe and forming the Al-Fe IMCs.

\subsubsection{X-ray diffraction phase identification}

To further validate the above analysis, XRD phase identification was performed on both $\mathrm{Al}$ side and steel side of the tensile failed samples welded at a welding energy of $1000 \mathrm{~J}$ and $1500 \mathrm{~J}$, and the results are shown in Figure 6.4. It can be seen that basically only $\mathrm{Zn}$ and $\mathrm{Al}$ peaks were present on the Al side fracture surface in both conditions, which were also consistent with the results in Figure 6.1(b,c), showing Al-Zn eutectoid/eutectic (with more or less equivalent Al 
and Zn peaks (Figure 6.4(a)) and Al-enriched interface diffusion layer (much stronger Al peaks in comparison with Zn peaks, Figure 6.4(c)) in the nugget region.
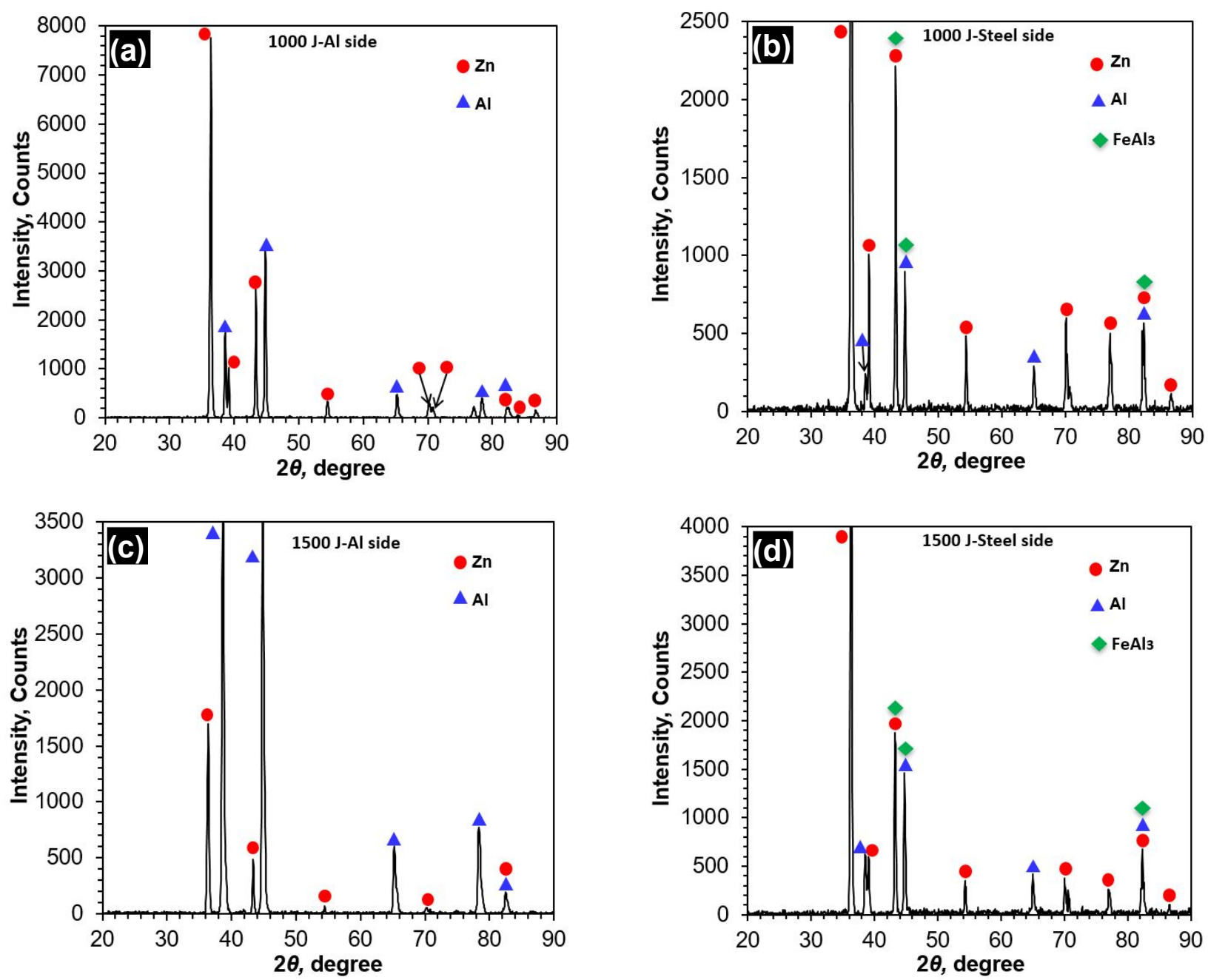

Figure 6.4: XRD patterns obtained from the fracture surface of the tensile failed samples welded at a welding energy of (a) $1000 \mathrm{~J}$, Al side, (b) $1000 \mathrm{~J}$, steel side, (c) $1500 \mathrm{~J}$, Al side, and (d) $1500 \mathrm{~J}$, steel side.

On the steel side, mainly $\mathrm{Zn}$ and $\mathrm{Al}$ peaks were observed along with a few combined peaks of $\mathrm{FeAl}_{3}$ intermetallic. The presence of $\mathrm{Al}$ and $\mathrm{Zn}$ on both sides suggested that cohesive failure occurred in the dissimilar joints. Furthermore, the fewer $\mathrm{FeAl}_{3}$ peaks could be the result of very 
thin $(\sim 1 \mu \mathrm{m})$ IMC layer as observed in Figure 6.3(c-d) and a limited penetration by the X-ray beam. Previous studies also showed the presence of $\mathrm{FeAl}_{3}$ and $\mathrm{Fe}_{2} \mathrm{Al}_{5}$ at the USWed $\mathrm{Al}$-steel joint interface $[27,46,101,161]$. The formation of $\mathrm{FeAl}_{3}$ is kinetically favored as it has the lowest effective free energy of formation. In the later stages, $\mathrm{FeAl}_{3}$ and $\mathrm{Fe}$ phases react to form phases with a composition between those of the interacting phases, i.e., $\mathrm{Fe}_{2} \mathrm{Al}_{5}, \mathrm{FeAl}_{2}, \mathrm{FeAl}$, and $\mathrm{Fe}_{3} \mathrm{Al}$ [27]. Since $\mathrm{FeAl}_{3}$ itself is in extremely small quantity, it is unlikely to form any other above mentioned phases in such a short time during USW.

\subsection{Tensile lap shear strength}

Figure 6.5 shows the maximum tensile lap shear strength of USWed Al6111-HSLA steel dissimilar joints as a function of welding energy at a constant power of $2 \mathrm{~kW}$ and a constant clamping pressure of $0.4 \mathrm{MPa}$ at room temperature. The maximum tensile lap shear strength increased with increasing welding energy, reached a peak value of about $4.3 \mathrm{kN}$, and thereafter decreased with a further increase in welding energy. Many previous studies on USW of similar or dissimilar joints showed similar behavior [38,44,69]. At a lower welding energy of $500 \mathrm{~J}$, there was limited diffusion at the weld interface as observed in Figure 6.1(a) and Figure 6.3(a) due to a lower interface temperature, smaller strain rate, and shorter welding time. Furthermore, the yield strength of the material during USW remained high, which led to an incomplete coalescence of the bonding surface [38], and therefore resulted in an inferior joint strength. The increase in strength with increasing welding energy up to $2000 \mathrm{~J}$ was due to an increase in interface temperature, strain rate, and welding time, which led to increased $\mathrm{Zn}$ and $\mathrm{Al}$ interdiffusion and better coalescence of the bonding surface. Also with increasing welding 
energy, the effective bonding area increased [37], resulting in a higher joint strength. The optimum strength of about $4.3 \mathrm{kN}$ as mentioned earlier was achieved at a welding energy of $2000 \mathrm{~J}$, and a further rise in energy showed a decrease in the joint strength. This could be well explained by the failure mode during testing. It was observed that as the energy input increased, the failure mode changed from interfacial failure to base metal failure and then to nugget edge failure, as shown in Figure 6.6. The overall tensile lap shear strength of the welded specimen is a function of interface bonding strength, nugget area, nugget thickness and base metal sheet thickness. Interfacial failure can be more related to interface bond strength and nugget area, and less to base metal thickness while base metal failure was strongly related to sheet thickness as well as joint strength [36].

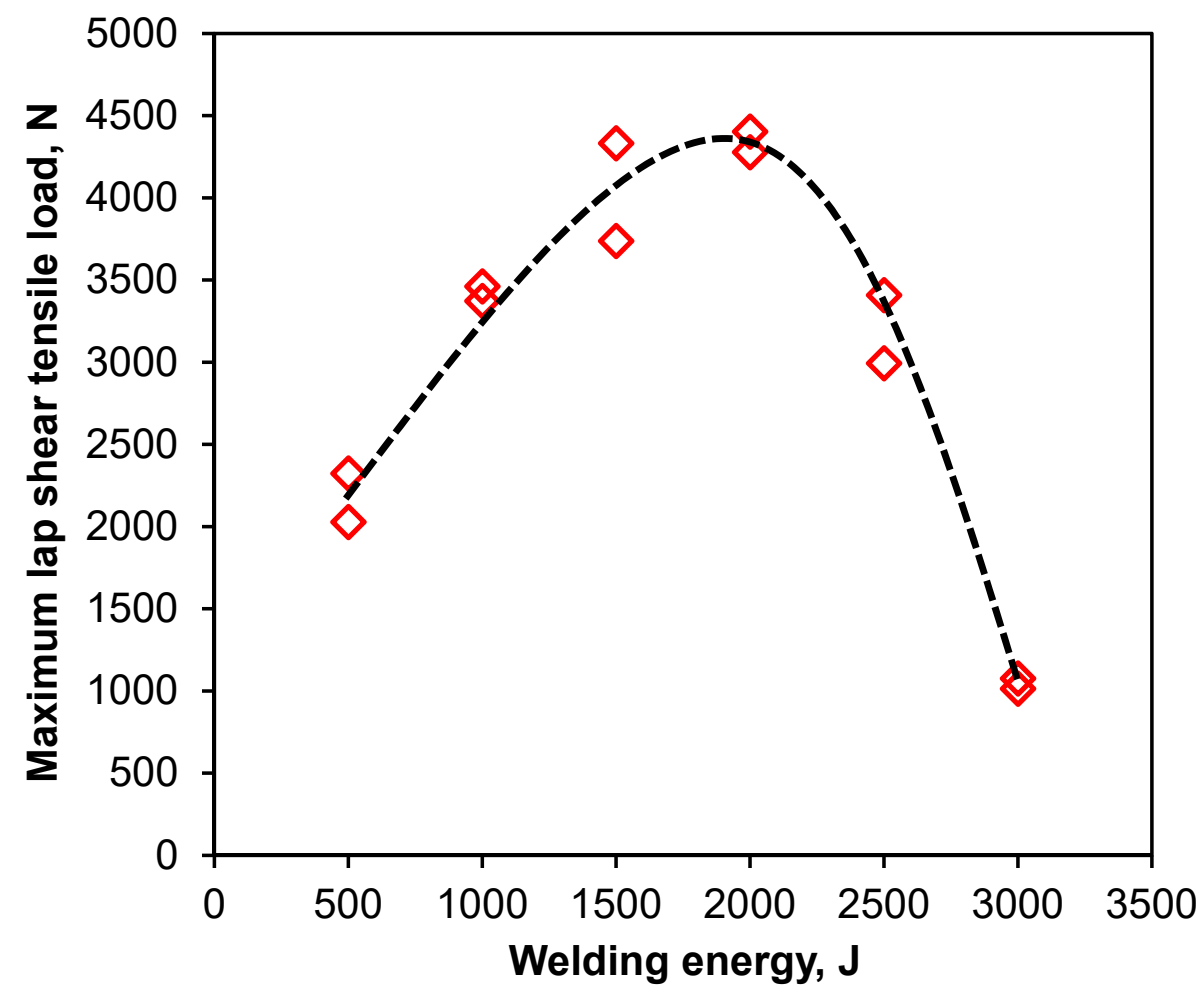

Figure 6.5: Maximum tensile lap shear load of USWed Al6111-HSLA steel joints as a function of welding energy at a constant power of $2000 \mathrm{~W}$ and clamping pressure of $0.4 \mathrm{MPa}$. 
Figure 6.6(a) shows the interfacial shear failure that occurred at a welding energy of $1000 \mathrm{~J}$, which was also the case at a welding energy of $500 \mathrm{~J}$ and $1500 \mathrm{~J}$. However, at a welding energy of $2000 \mathrm{~J}$, the failure mode changed from interfacial shear failure to transverse through thickness normal failure in the base metal ( $\sim 2 \mathrm{~mm}$ away from nugget edge) as shown in Figure 6.6(b). This means that the joint strength became higher than that of the base metal. With a further increase in the welding energy $(2500 \mathrm{~J}, 3000 \mathrm{~J})$, the sheet thickness in NZ significantly decreased due to a deeper penetration of sonotrode tip as a result of softening of base metal at higher temperatures. This led to a higher stress concentration and ultimately failure from nugget edge resulted in a lower joint strength. It should be noted that the welded joints made at a higher welding energy may be stronger, but the overall strength of the specimen was limited by the higher stress concentration at a thinner nugget edge.
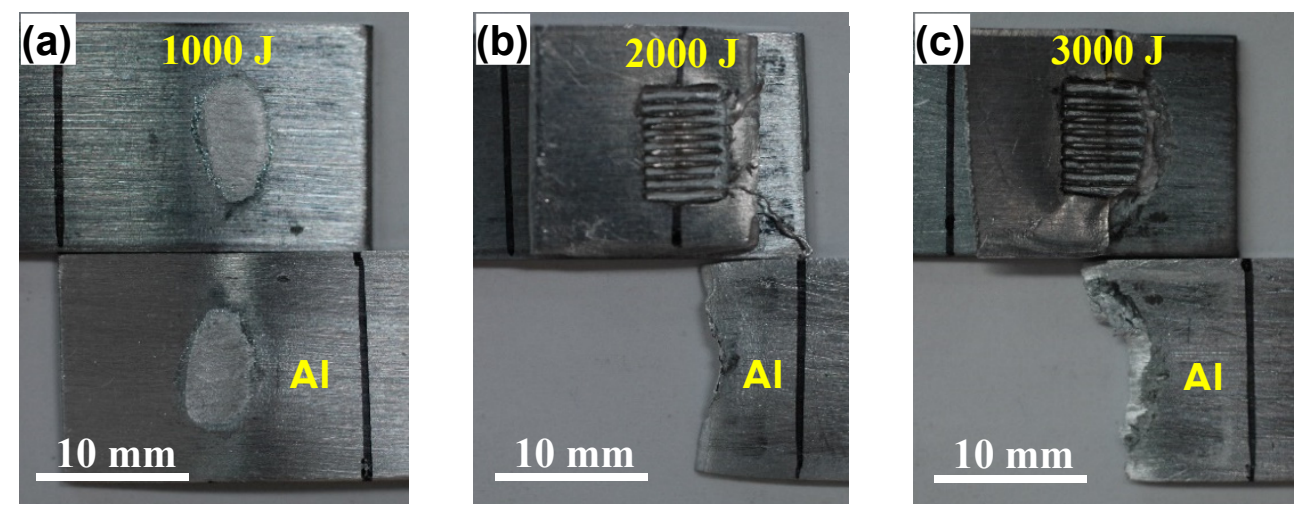

Figure 6.6: Macroscopic images of tensile failed samples welded at a welding energy of (a) $1000 \mathrm{~J}$, (b) $2000 \mathrm{~J}$, and (c) $3000 \mathrm{~J}$, respectively.

Figure 6.7(a) shows a comparison of the average maximum tensile lap shear strengths of $\mathrm{Al}-\mathrm{Al}$, HSLA steel-HSLA steel, and Al-HSLA steel joints. It is seen that the Al-HSLA steel joint (4.3 $\mathrm{kN})$ was higher than the Al-Al joint $(3.7 \mathrm{kN})$ and HSLA steel-HSLA steel joint $(3.8 \mathrm{kN})$ 
reported in [40]. This was attributed to the formation of interface diffusion layer (Figure 6.1(d)) and additional brazing effect due to solidified Al-Zn eutectic at the nugget edge. Figure 6.7(b) shows a comparison of the maximum tensile lap shear strength of dissimilar Al to steel joints using different alloys produced via different joining techniques [27,100,105,164-167]. The approximate strength was calculated by dividing the maximum failure load with an area, which was calculated using sonotrode tip size for USW, electrode diameter for RSW, and shoulder and pin diameter for FSSW. It is seen that the strength achieved in the present study was the highest in comparison with those reported earlier for various alloy combinations and various techniques, considering the experimental scatter. However, it should be noted that there were different sample geometries as well as different alloys of $\mathrm{Al}$ and steel with different sheet thicknesses, which could have an effect on the strength of the welded joints. Therefore, further studies are needed to validate the above comparison.

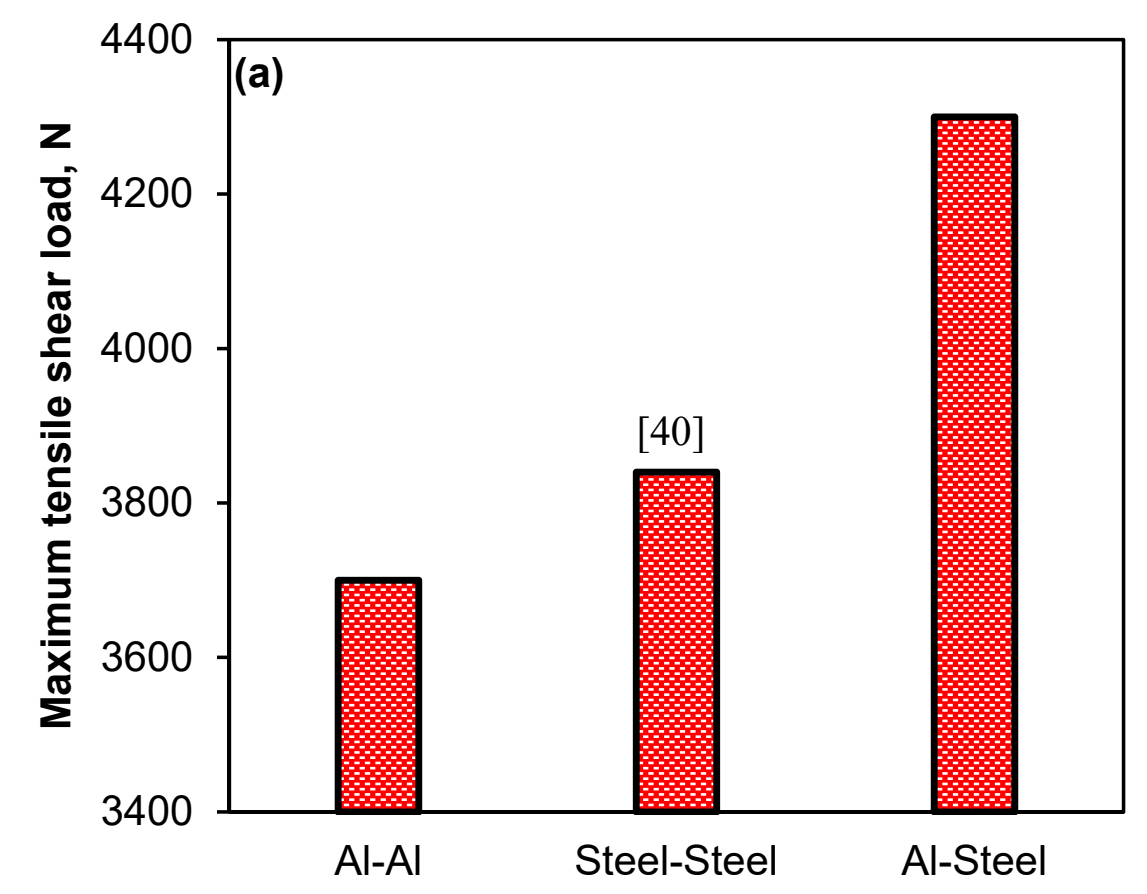

Figure 6.7: (a) Comparison of average maximum tensile lap shear failure load of USWed Al$\mathrm{Al}$, steel-steel, and Al-steel joints. 


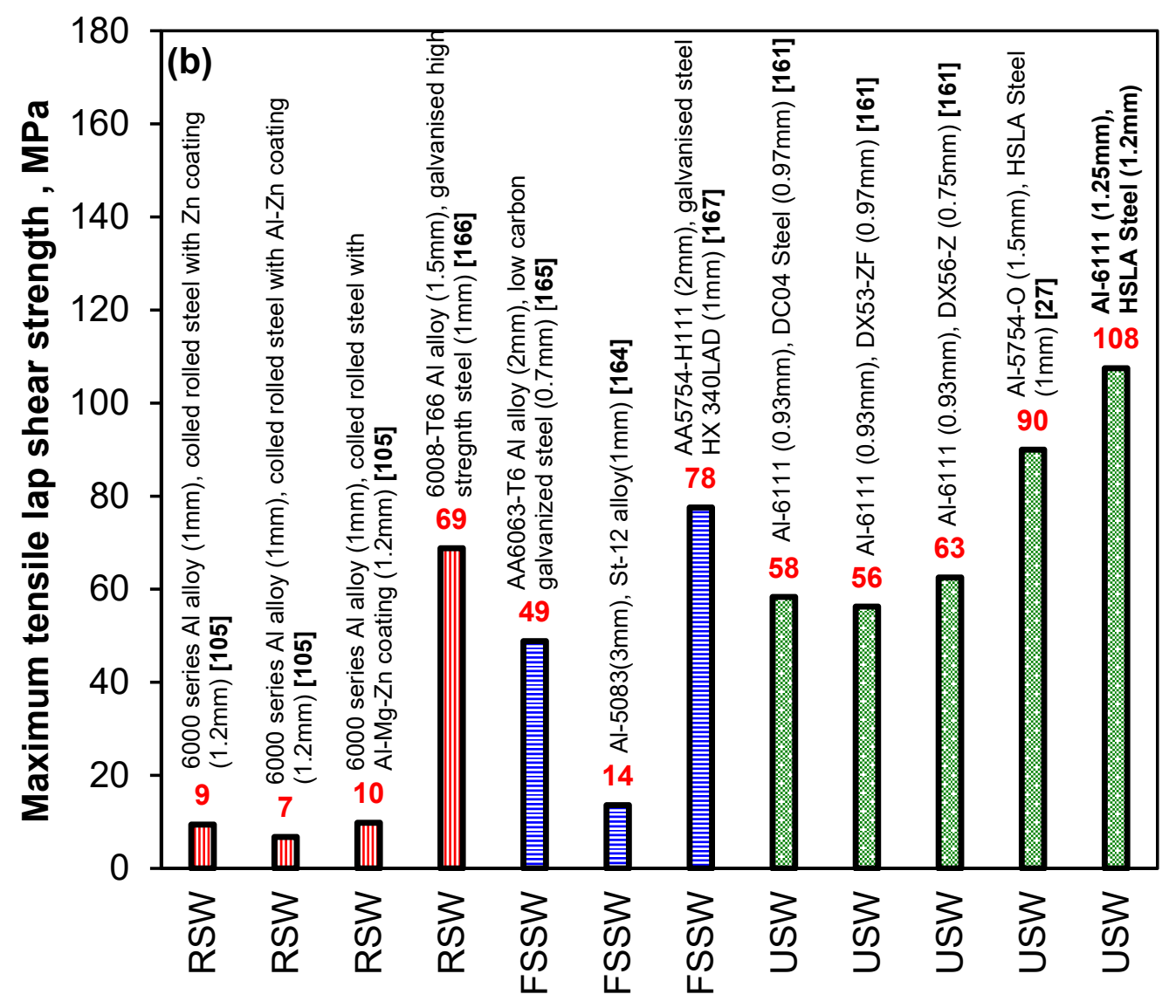

Figure 6.7: (b) Comparison of the average maximum tensile strength of Al-Steel using FSSW and USW techniques.

\subsection{Tensile fractography}

SEM fractography was performed on the tested tensile sample which failed in an interfacial mode at a welding energy of $1500 \mathrm{~J}$. Figure 6.8(a) and (d) shows the overall SEM images of fracture surface on Al side and steel side, respectively. Two distinct regions, nugget center and nugget edge, were observed on both $\mathrm{Al}$ and steel sides. Figure 6.8(b) shows a magnified and $90^{\circ}$ rotated view of a box in Figure 6.8(a) on the Al side, covering nugget, nugget edge, and base metal, where EDS point and line scan analyses were performed. 

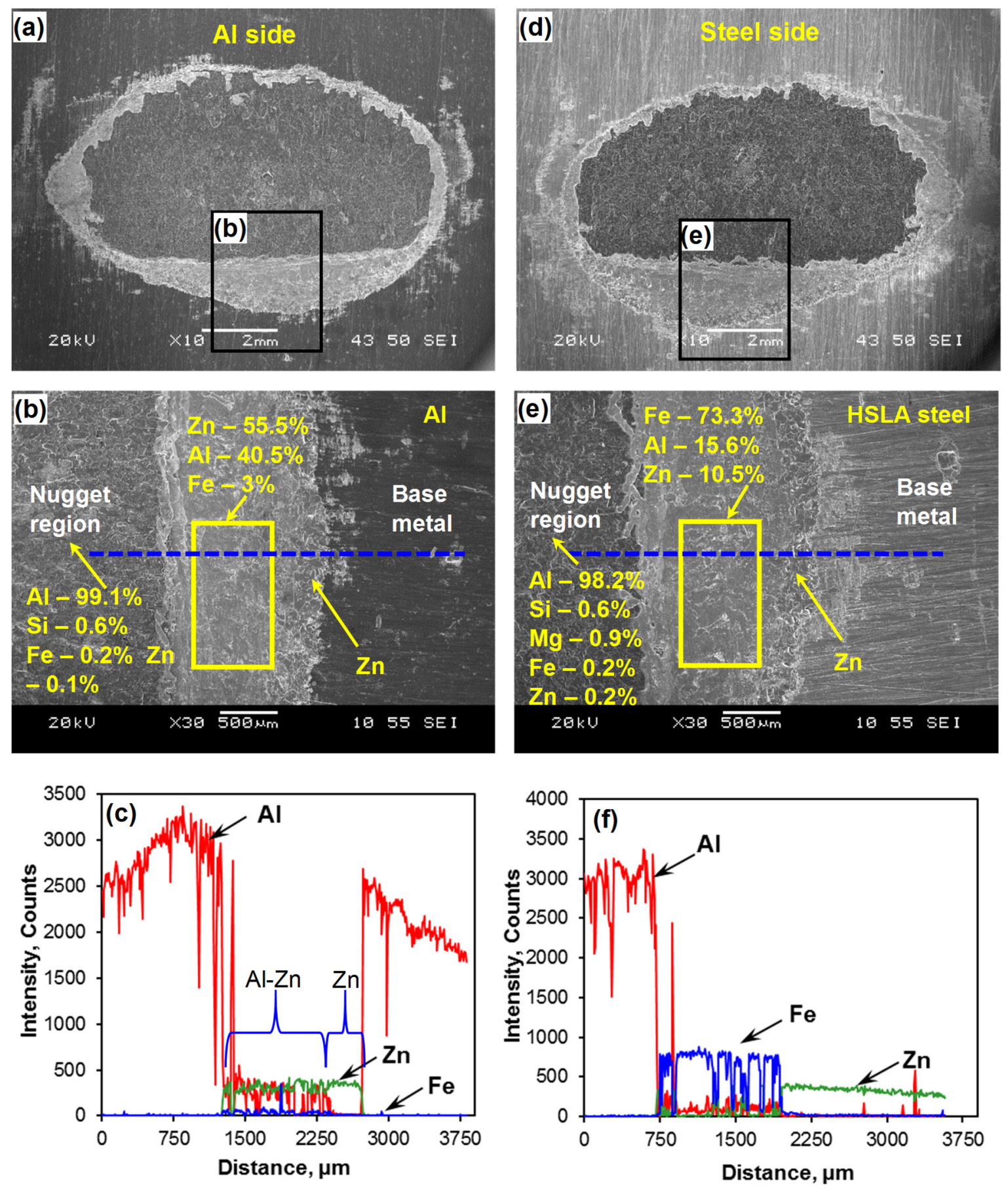

Figure 6.8: SEM images of a tensile failed sample made at a welding energy of $1500 \mathrm{~J}$, (a) overall view of Al side, (b) 900 clockwise rotated and magnified image of box in (a), and (c) the results of EDS line scan in (b); (d) overall view of steel side, (e) 900 clockwise rotated and magnified image of box in (d), and (f) the results of EDS line scan in (e) (composition in at.\%). 
The EDS point analysis showed that nugget edge had a composition of $55.5 \% \mathrm{Zn}, 40.5 \% \mathrm{Al}$, and 3\% Fe, which was close to Al-Zn eutectoid composition as per Al-Zn binary phase diagram [160]. Figure 6.8(c) shows the results of EDS line analysis across the nugget edge. It is seen that the nugget region consisted mainly of Al, while the nugget edge region was composed of Al-Zn eutectoid phase and Zn-rich layer. This supports our previous observation during SEM analysis in Figure 6.2(d) that Al-Zn liquid along with melted $\mathrm{Zn}$ was squeezed out from the nugget region and solidified outside the nugget forming Al-Zn eutectoid and eutectic layer along with $\mathrm{Zn}$-rich layer. The melted $\mathrm{Zn}$ layer was attributed to the lower melting point of $\mathrm{Zn}$ $\left(419.6^{\circ} \mathrm{C}\right)$ compared to $\mathrm{Al}\left(660.4^{\circ} \mathrm{C}\right)$ in conjunction with melting point depression arising from higher vacancy concentration during USW. The Al-Zn and Zn liquid squeezed out from NZ and created a brazing effect at the nugget edge as mentioned earlier, which generated extra strength and reduced stress concentration at the nugget edge [37]. This could be one of the reasons for the base metal failure in the $2000 \mathrm{~J}$ energy condition rather than interfacial or nugget edge failure. Similarly, EDS point and line scan analyses were performed on the steel side and the results are shown in Figure 6.8(e) and (f). The point analysis results showed that the NZ was mainly composed of $\mathrm{Al}$ while nugget edge region composition was 73.9 at.\% Fe, 15.6 at.\% $\mathrm{Al}$, and 10.5 at.\% $\mathrm{Zn}$, indicating that there were some $\mathrm{Al}-\mathrm{Zn}$ eutectic/eutectoid and remaining $\mathrm{Zn}$ on the Fe surface. The EDS line scan results in Figure 6.8(f) also revealed this. It was of interest to see that the nugget region also showed Al phase on the steel side. This implies that failure took place in the Al base metal, indicating a strong interfacial bonding strength, despite the presence of $\mathrm{FeAl}_{3}$ (Figures 6.3 and 6.4). Since the $\mathrm{FeAl}_{3} \mathrm{IMC}$ was very thin $(<2-3 \mu \mathrm{m})$, it did not exhibit an obvious detrimental effect on the joint strength. It has indeed been reported that a thin IMC layer is essential for a good metallurgical bonding of dissimilar joints $[103,168]$. 


\subsection{Vickers's microhardness}

To study softening and the effect of natural aging in A16111-T4 alloy after welding, microhardness tests were performed along the transverse and longitudinal directions. Figure 6.9(a) shows a schematic diagram showing the location of indentations from the weld interface and the distance between two adjacent indentations. The indentations for a particular test (e.g., 3 hours) were $0.6 \mathrm{~mm}$ apart. The indentations for the next test after 3 days were done at a spacing of $0.2 \mathrm{~mm}$ away from the previous indentations (e.g., 3 hours). Similarly, the indentations for the next test (e.g., 2 weeks) were at a spacing of $0.2 \mathrm{~mm}$ away from those of the test after 3 days. In this way the possible errors due to the sample-to-sample variation could be eliminated while ensuring that all two adjacent indentations were apart by more than 3 times the diagonal indentation length $(\sim 57 \mu \mathrm{m})$. The hardness of Al6111 base metal was measured on a polished cross-section perpendicular to the rolling direction (the same as in the welded sample), and the average was obtained to be $95 \mathrm{HV}$. Figure 6.9(b) shows the results of transverse microhardness of a sample welded at a welding energy of $2000 \mathrm{~J}$ after $3 \mathrm{hrs}, 3$ days and 2 weeks. It is seen that the hardness was significantly lower in the nugget region and increased with increasing distance from the nugget region on both sides. This was likely due to the dissolution of pre-existing precipitates and grain growth in the nugget region arising from the rise in the temperature. During natural aging, the hardness was quickly recovered as the average microhardness in the nugget region increased from $\sim 65 \mathrm{HV}$ after 3 hours to $\sim 77 \mathrm{HV}$ after 3 days and then to $\sim 84 \mathrm{HV}$ after 2 weeks. Chen et al. [35] have also reported significant softening at nugget edge during USW of similar Al6111-T4 joints, however, such HAZ softening was not present in the present dissimilar A16111-HSLA steel joints. 

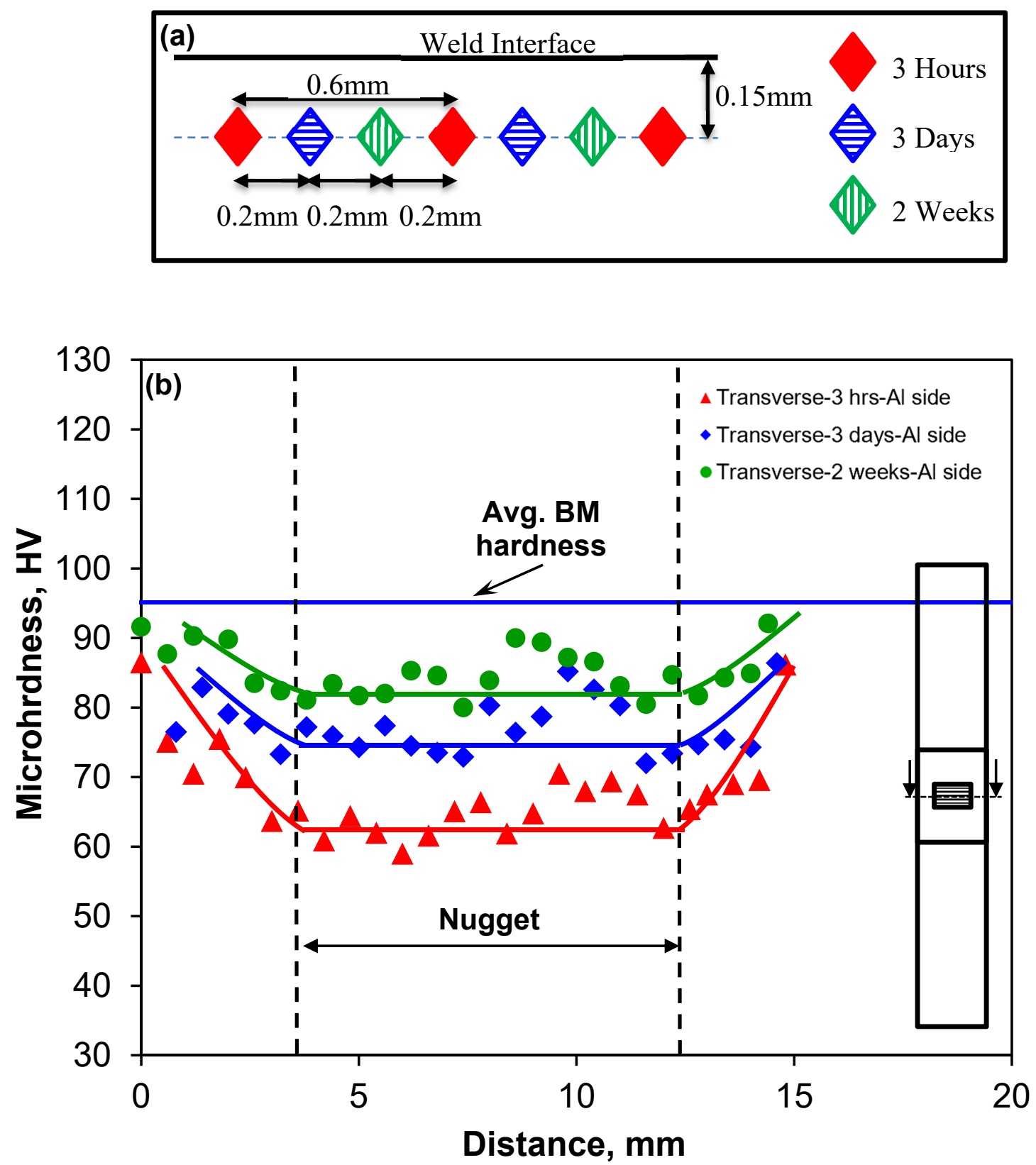

Figure 6.9: (a) Schematic diagram illustrating the hardness measurement procedure, (b) hardness profile across transverse cross-section measured after 3 hrs, 3 days and 2 weeks of welding, for an Al6111-HSLA steel weld made at a welding energy of $2000 \mathrm{~J}$.

As discussed in section 3.3 (tensile lap shear strength), samples made at a welding energy of $2000 \mathrm{~J}$ failed in the base metal at $\sim 2-2.5 \mathrm{~mm}$ away from the nugget edge. It was suspected that 
there may be a soft zone in the longitudinal direction, which may have caused failure in that area. To ascertain this, microhardness test was done on the longitudinal cross-section as well.

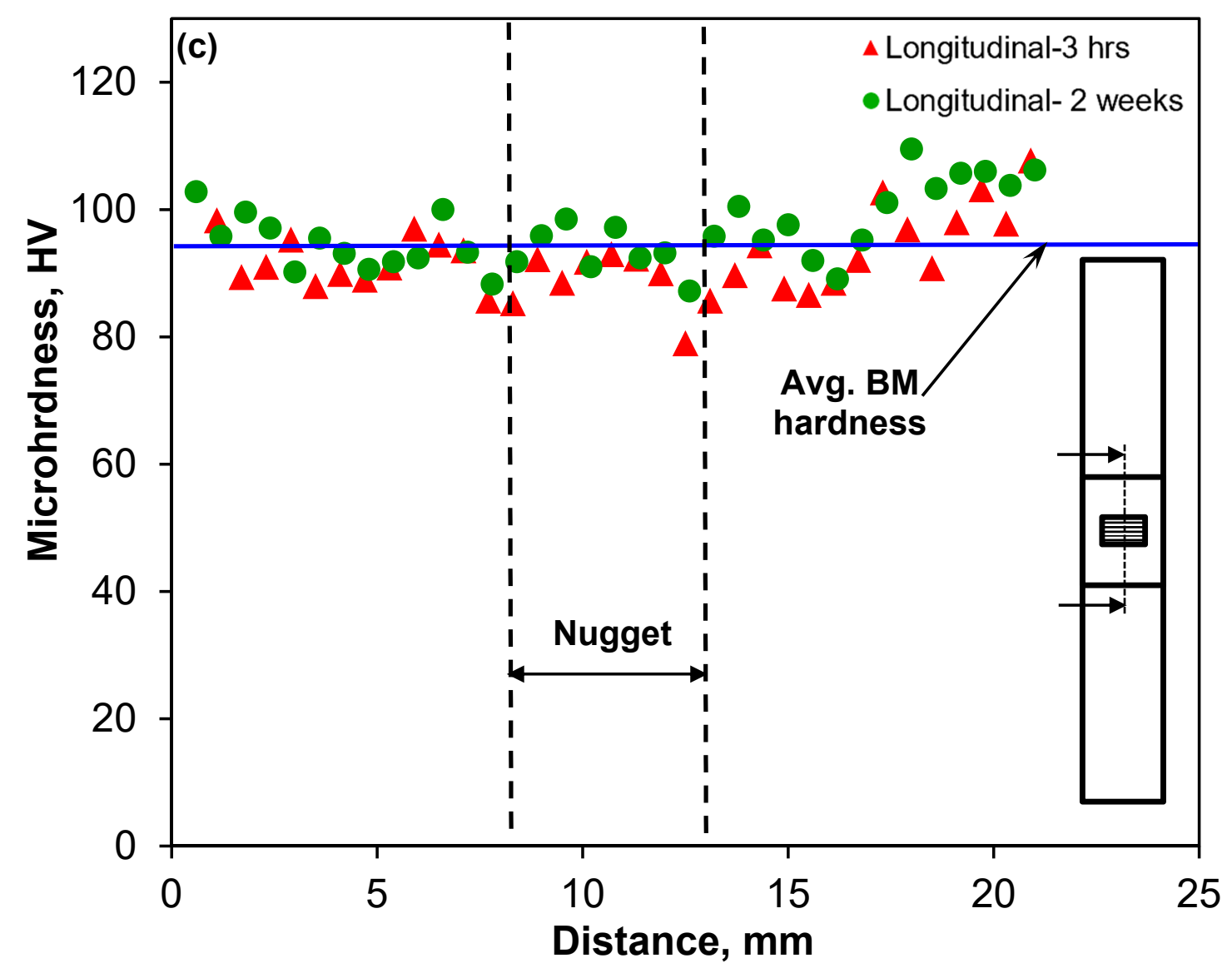

Figure 6.9: (c) hardness profile across longitudinal cross-section measured after 3 hrs and 2 weeks of welding, for an Al6111-HSLA steel weld made at a welding energy of $2000 \mathrm{~J}$.

Figure 6.9(c) shows the hardness profile in the longitudinal direction measured after $3 \mathrm{hrs}$ and 2 weeks of welding. It is seen that the hardness remained constant being almost the same as that of base metal throughout the length, indicating the absence of soft zone. Also, there was no significant change in hardness with increasing natural aging time. It could be reasoned that, unlike in the transverse direction, heat transfer in the longitudinal direction would be faster, as 
the heat generated during USW could easily flow away from the NZ along the length of the samples.

\subsection{Fatigue behavior and failure mode}

Figure 6.10 illustrates S-N curves of USWed Al6111-HSLA steel joints made at a welding energy of $1000 \mathrm{~J}$ and $2000 \mathrm{~J}$ and tested at room temperature, $\mathrm{R}=0.2$ and a frequency of $50 \mathrm{~Hz}$. The maximum cyclic load $P_{\max }$ was applied from $0.5 \mathrm{kN}$ to $3.5 \mathrm{kN}$ with an interval of $0.5 \mathrm{kN}$. The results showed that at all loading levels, fatigue life of the welded joints made at a welding energy of $2000 \mathrm{~J}$ was higher than that at $1000 \mathrm{~J}$, which was consistent with the tensile test results (Figure 6.5).

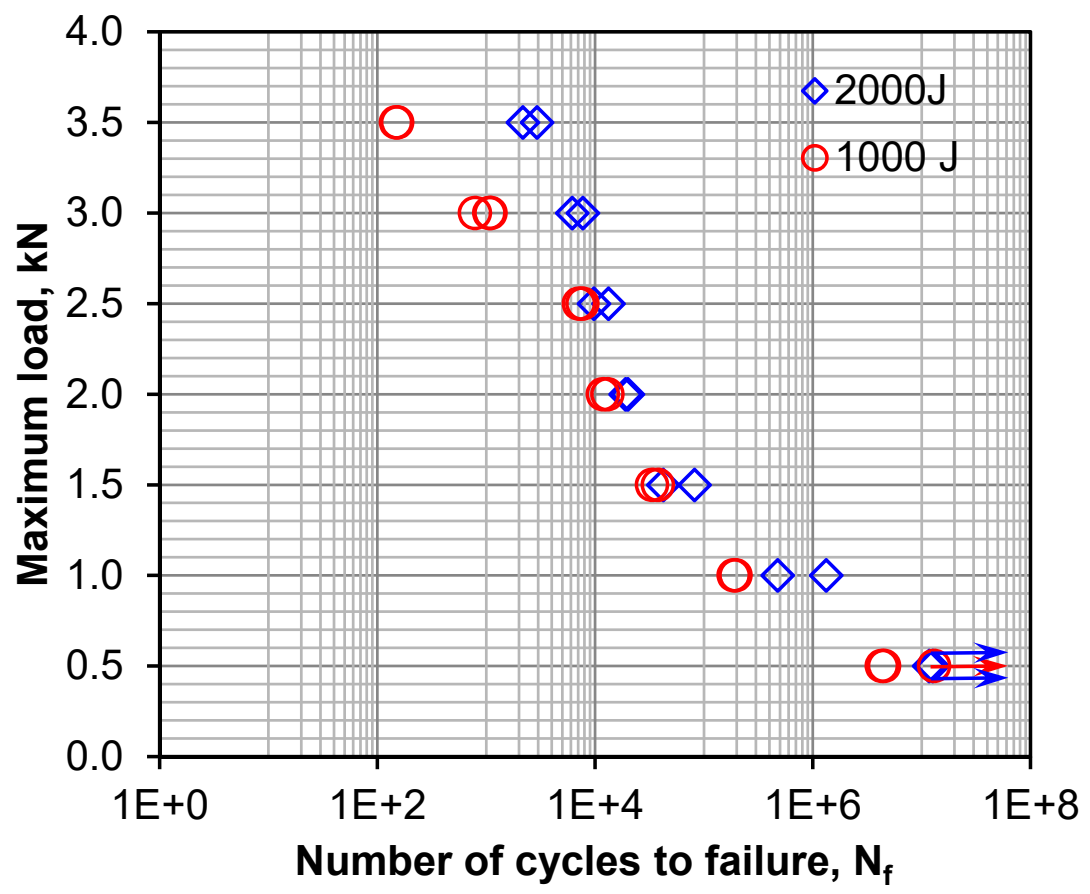

Figure 6.10: S-N curves of the USWed Al-HSLA steel joints tested at room temperature, $R=0.2$, and a frequency of $50 \mathrm{~Hz}$. 
Fatigue limit for the welded joints made at the optimum energy of $2000 \mathrm{~J}$ was $0.5 \mathrm{kN}$. The difference in fatigue life between $1000 \mathrm{~J}$ and $2000 \mathrm{~J}$ welding energy samples could be explained with their failure modes. Figure 6.11 shows the typical macroscopic images of failed fatigue samples at $1 \mathrm{kN}, 2 \mathrm{kN}$, and $3 \mathrm{kN}$ for the joints made at a welding energy of $1000 \mathrm{~J}$ and $2000 \mathrm{~J}$. Two main failure modes were observed, namely: (1) interfacial failure as shown in Figure 6.11(b, c, f) and (2) transverse through thickness (TTT) failure as shown in Figure 6.11(a, d, e). TTT mode of failure could also be further divided into two sub-modes: failure from nugget edge (Figure $6.11 \mathrm{a}, \mathrm{e}$ ), and failure in base metal (i.e., about 2-2.5 $\mathrm{mm}$ away from the nugget edge, Figure 6.11d). The interfacial failure occurred at the low cycle fatigue regime $\left(P_{\max } \geq 2\right.$ $\mathrm{kN})$, while TTT failure occurred at the high cycle fatigue regime $\left(P_{\max }<2 \mathrm{kN}\right)$.
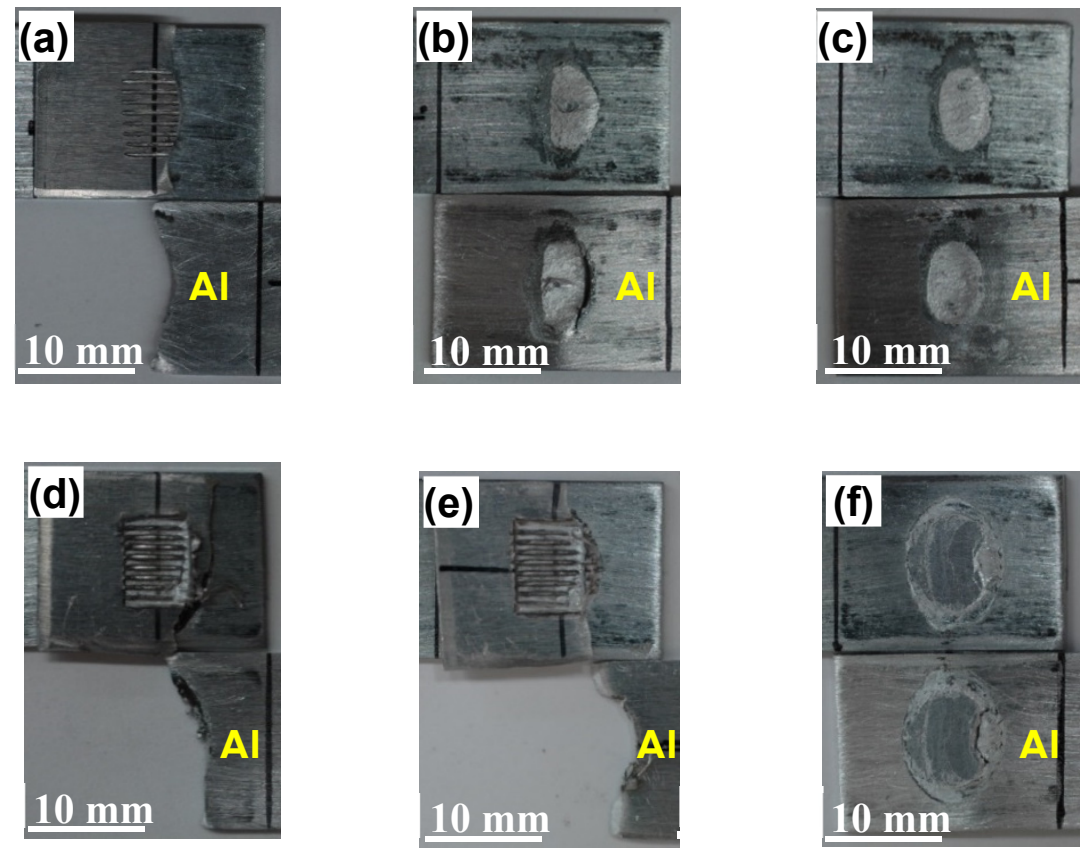

Figure 6.11: Macroscopic images offatigue failed samples made and tested at (a) $1000 \mathrm{~J}-1 \mathrm{kN}$, (b) $1000 \mathrm{~J}-2 \mathrm{kN}$, (c) $1000 \mathrm{~J}-3 \mathrm{kN}$, (d) $2000 \mathrm{~J}-1 \mathrm{kN}$, (e) $2000 \mathrm{~J}-2 \mathrm{kN}$, and (f) $2000 \mathrm{~J}-3 \mathrm{kN}$. 
In the high $P_{\max }$ load condition, interfacial failure was observed to be a progressive shearing process, which was a result of plastic deformation related to high cyclic stress amplitude applied. In this case the interfacial bonding strength was a predominant factor. Since the joint strength of $2000 \mathrm{~J}$ welding energy was higher than that of $1000 \mathrm{~J}$, its fatigue resistance was thus expected to be higher, corroborating the longer fatigue life of the samples made at a welding energy of $2000 \mathrm{~J}$ (Figure 6.10). In the low $P_{\max }$ load condition, the applied stress was low enough to be elastic [169], leading to failure by yielding at the nugget edge, which was the region of stress concentration as tri-axial stresses at the edge could reach the maximum value of normal stress plus the stress arising from bending moment [157]. It was reported that at a lower level of stress amplitude, factors like surface conditions, residual stresses, localized stress concentration, surface protective coating, severe weld concavity and zinc inclusions were detrimental to fatigue life [170]. In the present case, the localized stress concentration at the nugget edge was the predominant factor resulting in nugget edge failure. During USW, higher welding energy levels led to a higher temperature, resulting in softer $\mathrm{Al}$ sheet that experienced a greater extent of bending deformation at nugget edge due to the outward flow of the material under the sonotrode tool indentation. This produced a small micro-level crack tip at the notch of two sheets as indicated in [171]. This micro-level crack caused a stress concentration effect during cyclic loading which allowed the cracks to grow in the transverse direction of $\mathrm{Al}$ alloy sheet. Similar results were obtained during USW of Mg-Mg joint [81] and RSW of DP600 dual phase steel [157]. The failure away from the edge could be attributed to the brazing effect of Al- $\mathrm{Zn}$ eutectoid/eutectic structure and solidified Zn, as described earlier. This brazing effect provided additional strengthening as if the notch has moved $\sim 2-2.5 \mathrm{~mm}$ away from the nugget edge. This was clear for the $2000 \mathrm{~J}$ sample since the actual bonding area was larger than that at $1000 \mathrm{~J}$ as 
observed in Figure 6.11(f) compared to Figure 6.11(c); hence the bonding area due to the brazing effect actually extended up to a distance of 2-2.5 $\mathrm{mm}$.

To further clarify this point, Figure 6.12 shows a schematic diagram of the longitudinal crosssection and top view of the nugget. BC and AD show the bonding area for the $1000 \mathrm{~J}$ and 2000 $\mathrm{J}$ samples, respectively. $\mathrm{AB}$ and $\mathrm{CD}$ indicate the extended bonding region for the $2000 \mathrm{~J}$ sample due to brazing by squeezed-out Al-Zn eutectoid/eutectic and Zn. Lines GH and IJ from the top view correspond to point $\mathrm{A}$ and $\mathrm{B}$.
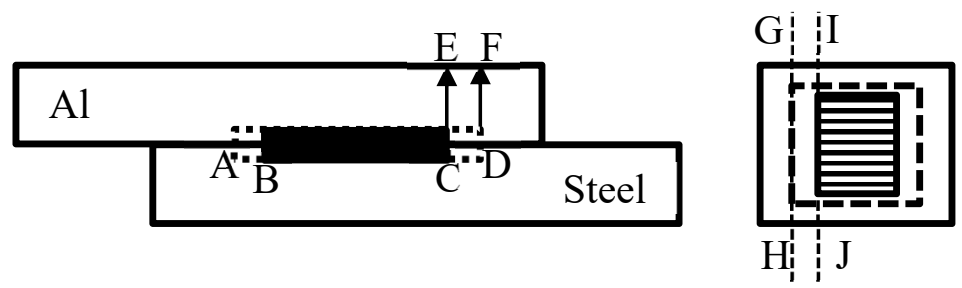

Figure 6.12: Schematic diagrams of (a) side (cross-section) view and (b) top view showing a comparison of bonding areas at a welding energy of $1000 \mathrm{~J}$ and $2000 \mathrm{~J}$, respectively.

Figure 6.13 shows the cyclic stress amplitude vs the number of reversal to failure $\left(2 \mathrm{~N}_{\mathrm{f}}\right)$ on a $\log -\log$ scale for the USWed A16111-HSLA steel joint at a welding energy of $1000 \mathrm{~J}$ and 2000 J. Basquin equation was used to calculate fatigue strength coefficient and fatigue strength exponent in both conditions in relation to both failure modes. Since $1 \times 10^{7}$ cycles are normally considered as a benchmark for a conditional fatigue limit, samples which passed this benchmark were considered to have an infinite fatigue life and therefore, are not included in the curve fitting. The fatigue strength coefficient for interfacial shear failure mode at $2000 \mathrm{~J}$ (199 MPa) was higher than that at $1000 \mathrm{~J}(68 \mathrm{MPa})$, which was in agreement with their static strength. However, fatigue strength coefficient for base metal normal failure mode at $2000 \mathrm{~J}$ (117 MPa) was lower than that at $1000 \mathrm{~J}(192 \mathrm{MPa})$, which could be attributed to the higher stress 
concentration in the higher energy condition. It is well known that the lower the value of fatigue strength exponent, the longer the fatigue life. Since $2000 \mathrm{~J}$ samples show a lower value of fatigue strength exponent compared to $1000 \mathrm{~J}$ samples, it has a longer fatigue life as seen from Figure 6.10, which is expected due to their higher static strength.

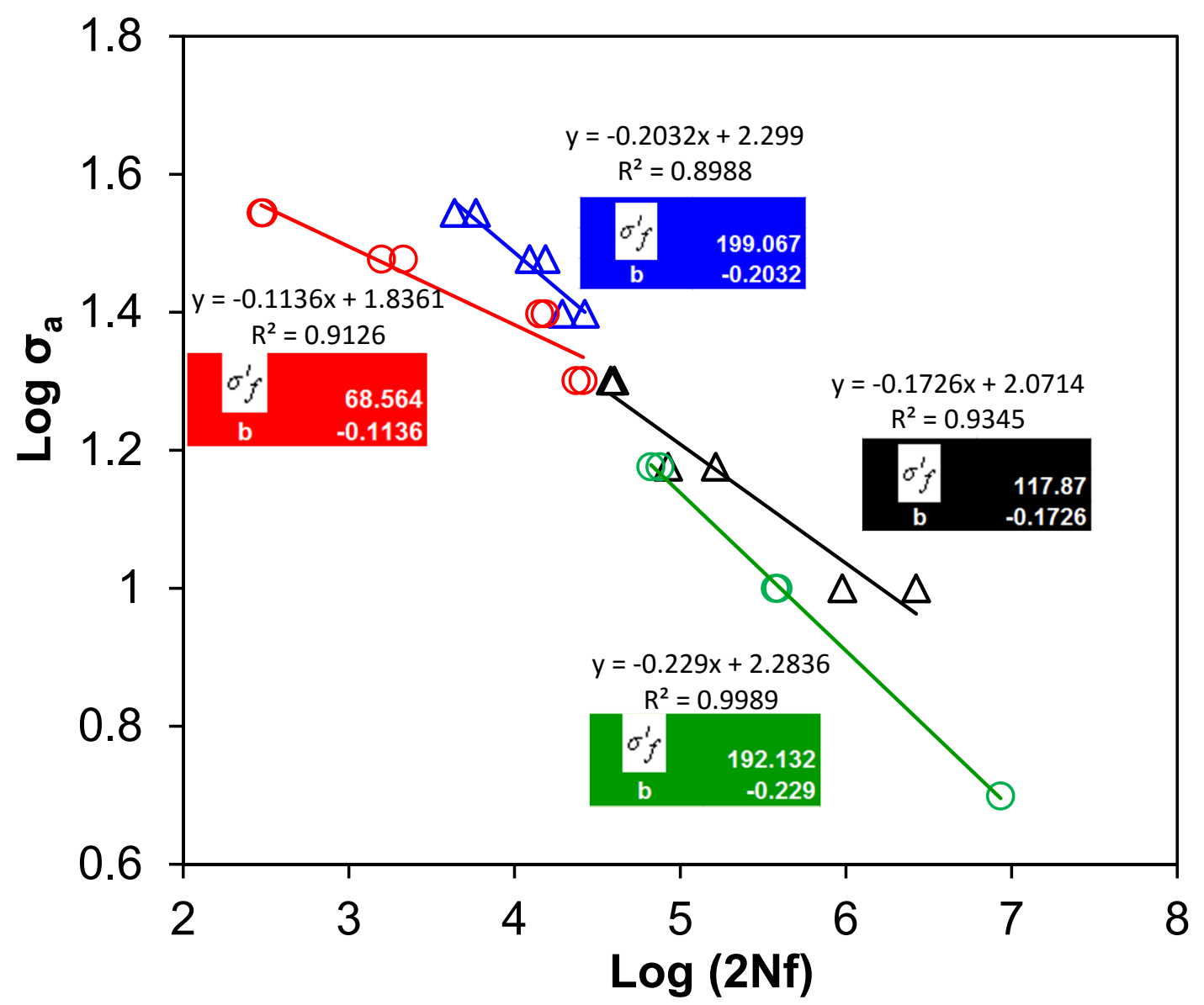

Figure 6.13: Stress amplitude vs. the number of reversals to failure (2Nf) in the double-log scale for the USWed Al-HSLA steel joint at a welding energy of $1000 \mathrm{~J}$ and $2000 \mathrm{~J}$.

\subsection{Fatigue fractography}

Figure 6.14 shows an overall view of fatigue fracture surface of Al base metal, along with higher magnification images of crack initiation, propagation, and fast propagation regions for USWed 
A16111-HSLA steel joint at a welding energy of $2000 \mathrm{~J}$ and tested at a low load condition of $P_{\max }=1 \mathrm{kN}$. It is seen from Figure 6.14(b) and (c) that the crack initiated at the inner edge of the $\mathrm{Al}$ sheet and propagated perpendicular to the loading direction and penetrated through the thickness of the sheet towards the outer surface. This was expected as discussed earlier, bending deformation during welding resulted in the formation of micro-crack at inner notch surface of the joints on the $\mathrm{Al}$ side. This is also schematically shown in Figure 6.12, where the crack initiated at $\mathrm{D}$ and it propagated towards $\mathrm{F}$ in the $2000 \mathrm{~J}-1 \mathrm{kN}$ fatigue test condition, while crack initiated at $\mathrm{C}$ and propagated towards $\mathrm{E}$ in the $1000 \mathrm{~J}-1 \mathrm{kN}$ fatigue test condition. Fatigue crack propagation was characterized by the formation of fatigue striations, which were nearly perpendicular to the propagation direction, as shown in Figure 6.14(d) and (e). A large crack propagation region could be seen between regions Figure 6.14(b) to (e), indicating that most of the fatigue life was spent in the crack propagation as also observed by others [170,172], while the fast propagation region e was quite small (Figure 6.1(a) and (e)). This result was consistent with that reported in [173], where in the case of lower loads the crack would have to grow longer before the applied stress intensity factor reached fracture toughness of the material, resulting in the most fatigue life spent in the crack propagation phase.

Figure 6.15 shows the SEM images of interfacially failed fatigue sample fracture surface on both $\mathrm{Al}$ and steel sides of USWed Al6111-HSLA steel joint made at a welding energy of 2000 $\mathrm{J}$ and tested at a higher cyclic load condition of $P_{\max }=2.5 \mathrm{kN}$. A crack at the nugget edge of Al fracture surface is clearly visible. While the stress concentration at the edge induced crack initiation and propagation along the nugget circumference, due to the high shear deformation at the interface the nugget still failed interfacially before the crack could propagate throughout the circumference. 

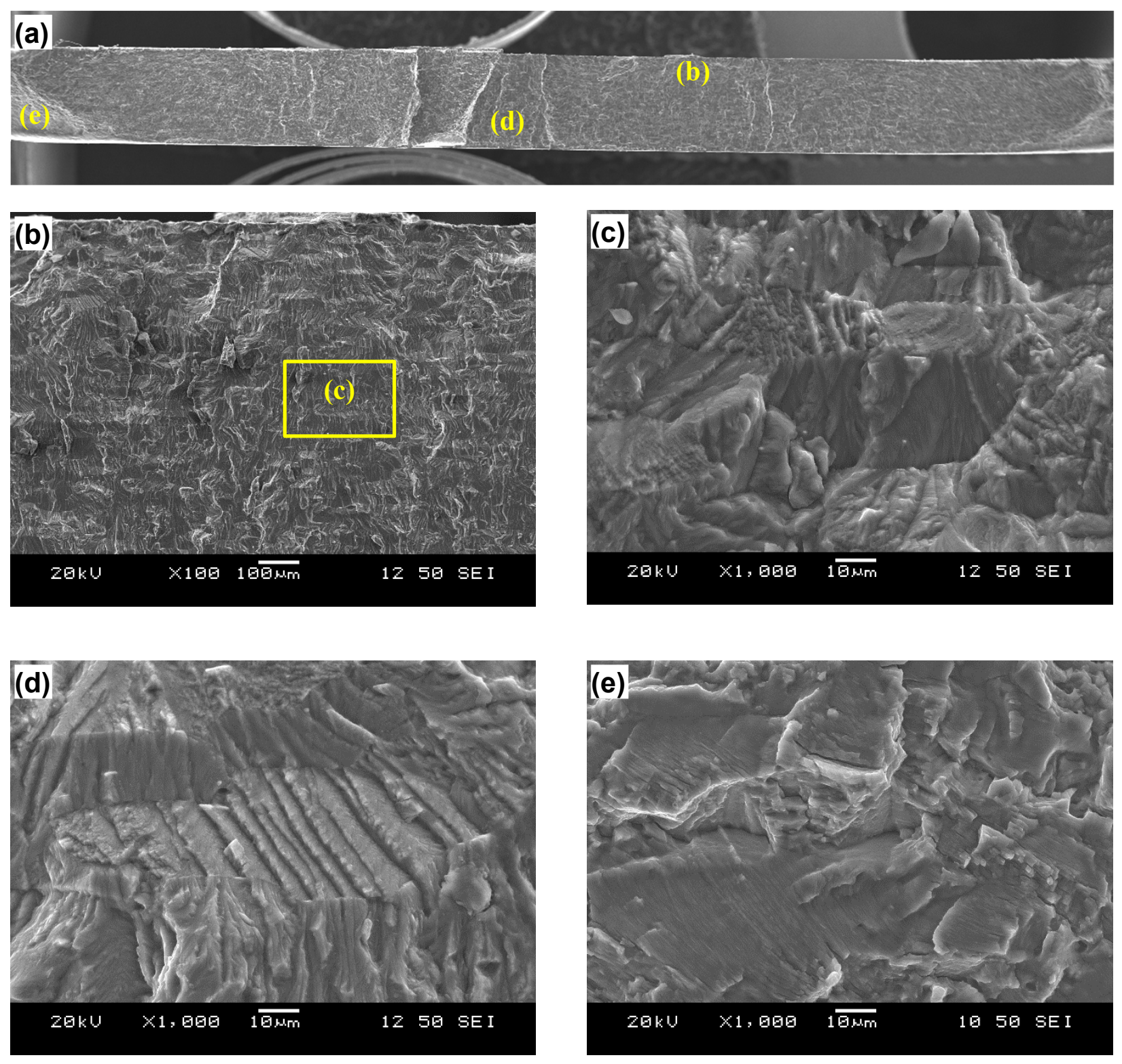

Figure 6.14: Typical SEM images showing Al base metal failed fatigue fracture surface of USWed Al6111-HSLA steel joint made at a welding energy of $2000 \mathrm{~J}$ and tested at a maximum cyclic load of $P_{\max }=1 \mathrm{kN}$. (a) Overall view, (b) crack initiation area, (c) magnified image of (b), (d) magnified image of a crack propagation area, and (e) magnified image of fast crack propagation area.

It was likely that the specimen failed initially at the nugget edge, but interfacial failure eventually occurred. Since the sample was under a high cyclic loading, after fracture a concavity 
was observed to be present as the center part of the nugget was raised up [55]. Figure 6.15(b) shows fracture surface on the steel side, where the edge crack was not observed due to the higher strength of steel. Upon a close examination, a selected region in Figure 6.15(a) on the Al side was magnified as shown in Figure 6.15(c) and the subsequent EDS analyses were performed.
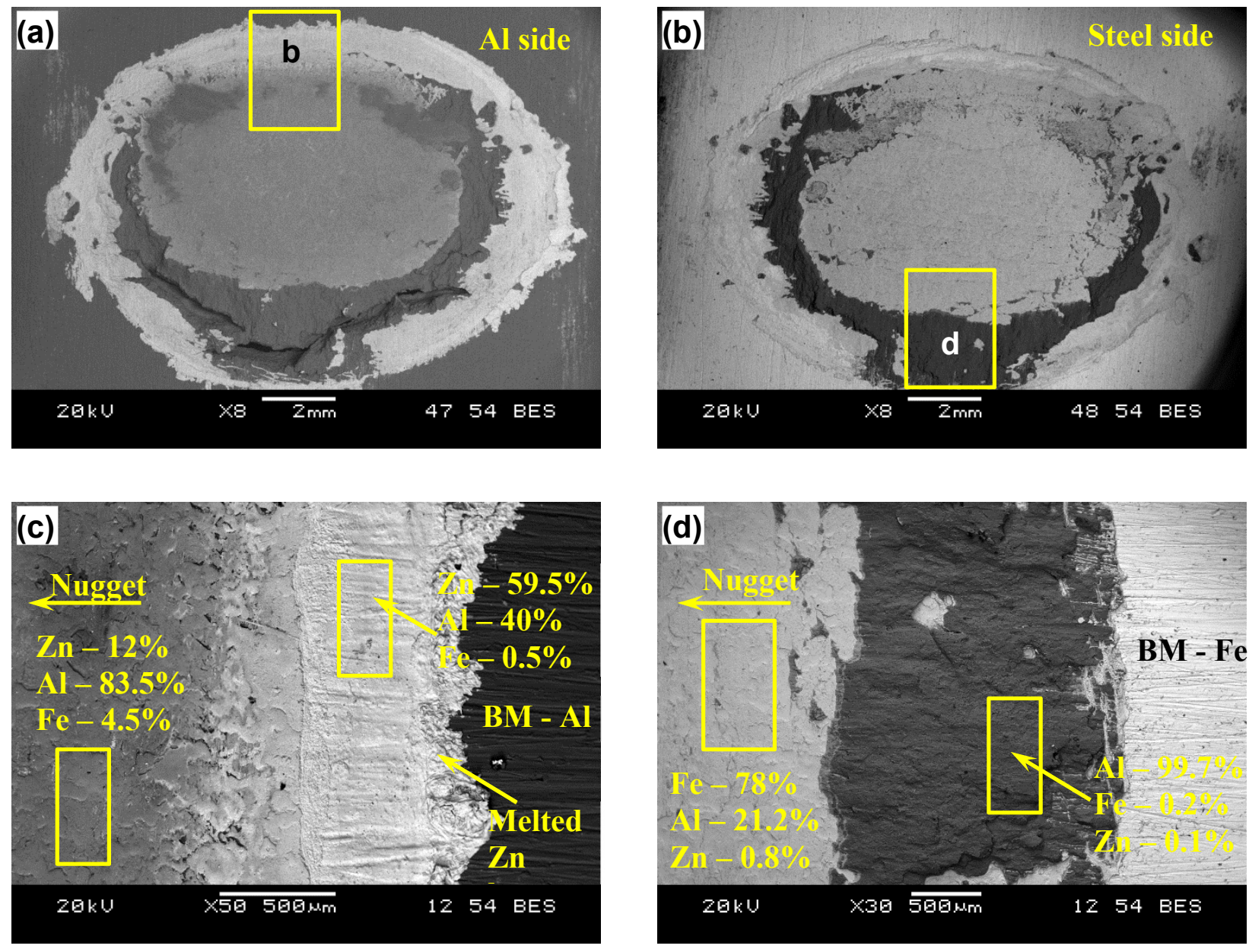

Figure 6.15: Typical SEM images showing interfacial failed fatigue fracture surface of USWed Al6111-HSLA steel made at a welding energy of $2000 \mathrm{~J}$ and tested at a maximum cyclic load of $P_{\max }=2.5 \mathrm{kN}$. (a) Overall view of Al fracture surface, (b) overall view of the steel fracture surface, (c) magnified and $90^{\circ}$ clockwise rotated image of nugget edge in (a), and (d) magnified and $90^{\circ}$ anticlockwise rotated image of the nugget edge in (b) (composition in at.\%). 
It was revealed that the white band surrounding the nugget had a composition (at. \%): 59.5\% $\mathrm{Zn}, 40 \% \mathrm{Al}$, and $0.5 \% \mathrm{Fe}$, which was close to $\mathrm{Al}-\mathrm{Zn}$ eutectoid composition. A thin band of pure zinc could also be seen outside the nugget edge, as marked in Figure 6.15(c). These observations reiterated the earlier discussion regarding the brazing effect of squeezed-out Al-Zn liquid and molten zinc during welding. The nugget region showed a composition (at. \%): 12\% Zn, 83.5\% $\mathrm{Al}$, and $4.5 \% \mathrm{Fe}$, which was Al-rich phase as also observed during microstructure analysis (Fig. 1(d)). Fig. 15(d) shows a higher magnification image of the region showed in a box in Fig. 15(b), and a similar analysis was performed on the steel side. EDS analysis revealed that the dark region had a composition (at. \%): $99.7 \% \mathrm{Al}, 0.2 \% \mathrm{Fe}$, and $0.1 \% \mathrm{Zn}$, indicating that it consisted mainly of Al. Furthermore, the nugget region showed a composition (at. \%): 78\% Fe, 21.2\% Al, and $0.8 \% \mathrm{Zn}$, which had base $\mathrm{Fe}$ with $\mathrm{Al}$ particles on the surface. Hence, it can be concluded that the interfacial failure occurred partially in the bonded layer at the interface, and partially from Al base metal beyond the bonded layer.

\subsection{Summary}

The USW of Al6111-T4 alloy to galvanized HSLA steel has been explored and the interface microstructure, tensile lap shear strength and fatigue properties of the dissimilar welded joints have been characterized. The following conclusions can be drawn:

1. Accelerated diffusion at the joint interface during USW of Al6111 to galvanized HSLA steel resulted in the formation of an interface diffusion layer consisting mainly of Al- $\mathrm{Zn}$ eutectoid/eutectic phase. This Al-Zn eutectoid/eutectic along with some melted $\mathrm{Zn}$ was 
squeezed out due to the shear movement under clamping pressure and then solidified around the nugget edge to create a brazing effect at a welding energy of $\geq 1500 \mathrm{~J}$.

2. The distinct flow pattern of $\mathrm{Zn}$ penetration into $\mathrm{Al}$ was observed mostly in the region of nugget edge due to excess $\mathrm{Zn}$ diffusion along the high angle grain boundaries of $\mathrm{Al}$ alloy.

3. EDS line scan and XRD analyses revealed a very thin $(2 \sim 3 \mu \mathrm{m})$ intermetallic layer of FeAl3 at the joint interface for the samples welded at a high welding energy of $\geq 2000$ J. Due to its thinness no detrimental effect of the intermetallic layer on the joint strength was observed.

4. Some extent of softening in the $\mathrm{NZ}$ on the $\mathrm{Al}$ side was observed in the transverse direction (vibration direction) due to the slower heat transfer in air, which was however quickly recovered due to natural aging of Al6111-T4 alloy. No softening in the longitudinal direction (perpendicular to vibration direction) was observed due to faster heat transfer in the sample length direction.

5. Tensile lap shear strength increased with increasing welding energy, peaked at about $4.3 \mathrm{kN}$ at a welding energy of $2000 \mathrm{~J}$, and then decreased with a further increase in the welding energy. The initial increase of strength with welding energy was due to the formation of an increasingly stronger bond at weld interface and its decrease at the higher energy conditions was related to the change of failure mode.

6. Three failure modes were observed, namely: (i) interfacial failure ( $\leq 1500 \mathrm{~J})$ due to a low bonding strength, (ii) failure at some distance $(2 \sim 2.5 \mathrm{~mm})$ away from the nugget edge $(2000 \mathrm{~J})$ due to the extra strength imparted by the brazing effect of $\mathrm{Al}-\mathrm{Zn}$ eutectoid/eutectic and $\mathrm{Zn}$ around the nugget edge, and (iii) nugget edge failure $(\geq 2500$ J) due to a higher stress concentration arising from the sonotrode tip penetration along 
with the bending of $\mathrm{Al}$ base metal whose effective sheet thickness and load-carrying capacity were subsequently reduced at the higher welding energy.

7. The samples welded at an optimum condition of $2000 \mathrm{~J}$ showed a longer fatigue life than those welded at a welding energy of $1000 \mathrm{~J}$ at all cyclic load levels. Interfacial failure occurred at higher load levels, while TTT fracture happened at lower load levels. The cyclic load at which the failure mode changed from the TTT fracture to the interfacial failure increased with increasing welding energy.

In this study, it is seen how USW process has potential to join dissimilar Al alloy to HSLA steel and achieve strength higher than those achieve by other joining technique. It has been reported that $\mathrm{Mg}-\mathrm{Cu}$ bimetals are widely used in the electronic and electrical industries, electrical appliances, machinery and automotive industries. The research and application of $\mathrm{Mg}-\mathrm{Cu}$ bimetals have been extended from navigation and military fields to civil products of additional high value such as an automobile, computer and communication equipment [9]. These applications involve welding and joining of two dissimilar materials: $\mathrm{Cu}$ and $\mathrm{Mg}$ alloy. As mentioned in literature review there few studies on $\mathrm{Mg}$-to-Cu joints using diffusion bonding and TIG welding. However, as identified in chapter 5 and 6 , USW has greater potential for dissimilar joining. Therefore, Chapter 7 discussed the feasibility of joining AZ31 Mg alloy to copper using USW technique. 


\section{Chapter 7. Ultrasonic Spot Welding of Magnesium Alloy-to-Copper**}

The objective of the proposed research was to study the feasibility of joining AZ31B-H24 Mg alloy to copper and understand diffusion kinetics at the joint interface and to identify the effect of welding energy on the interface diffusion layer and strength of the joints. High-power ultrasonic spot welding (USW) was used to join AZ31B magnesium alloy-to-copper at different welding energy levels, focusing on the interfacial microstructure and strength of the dissimilar joints. The analysis was carried out by studying interface temperature profile, microstructural changes, microhardness, tensile lap shear strength and fracture surface at varying level of welding energy.

\subsection{Microstructure characterization}

SEM micrographs of the interface of the USWed Cu-to-AZ31B-H24 Mg alloy joint with increasing welding energy are shown in Figure 7.1. At a welding energy of $1000 \mathrm{~J}$, a very thin and discontinuous diffusion layer was observed (Figure 7.1(a)), which represented the onset of the diffusion process. This suggested that the diffusion at the joint interface was non-uniform, due to the generation of non-uniform frictional heat arising from the contacts at some asperities on the initially uneven/roughened faying surfaces. Obviously, the initially touched asperities during the high-frequency rubbing would accumulate more heat, leading to "hot spots" having higher temperatures. With increasing welding energy to $1500 \mathrm{~J}$, continuous but non-uniform

\footnotetext{
** This chapter is based on the following publications of the author:

A. Macwan and D.L. Chen, "Microstructure and mechanical properties of ultrasonic spot welded copper-tomagnesium alloy joints”, Materials and Design, 84, 2014, 261-269.
} 
interface diffusion layer with a thickness change from $\sim 2.5 \mu \mathrm{m}$ to $\sim 10 \mu \mathrm{m}$ formed due to a higher interface temperature. The thickness of interface diffusion layer increased with a further increase in the welding energy and a maximum thickness of $\sim 200 \mu \mathrm{m}$ was observed at a welding energy of $2500 \mathrm{~J}$.
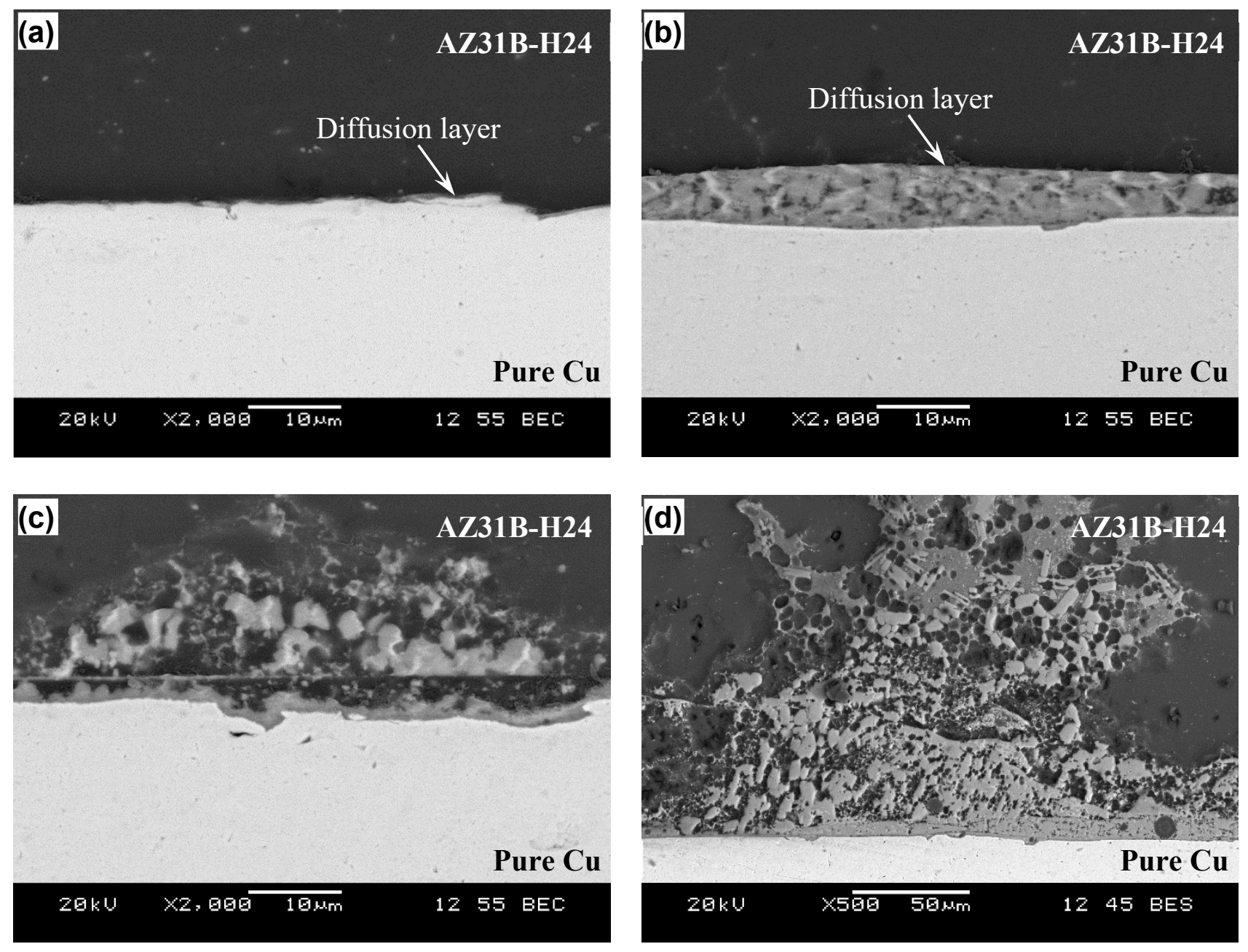

Figure 7.1: Typical SEM images are showing the joint interface of the USWed Cu-to-AZ31H24 joint at a welding energy of (a) $1000 \mathrm{~J}$, (b) $1500 \mathrm{~J}$, (c) $2000 \mathrm{~J}$, and (d) $2500 \mathrm{~J}$.

Despite very short welding times during USW (0.25-1.25 s), the diffusion layer thickness was significantly larger than that observed during diffusion bonding of $\mathrm{Cu}-\mathrm{Mg}(\sim 100 \mu \mathrm{m}$ in $50 \mathrm{~min})$ 
$[113,114]$ and TIG welding $(\sim 150 \mu \mathrm{m})[115]$. This was ascribed to enhanced dynamic diffusion at the joint interface caused by a high concentration of deformation-induced vacancies [174176], which were generated at the high strain rates being estimated to be about 240 to $1140 \mathrm{~s}^{-1}$ when the welding energy increased from 500 to $2500 \mathrm{~J}$ [80], as well as the subsequent microcracking in the brittle reaction layer $[52,177]$. It was reported that the presence of such deformation-induced vacancies resulted in melting point depression and reduced the temperature for eutectic reaction [126].

During USW Mg and Cu interdiffusion occurs at the weld interface, however it is of interest to observe that the interface diffusion layer formed on the $\mathrm{Mg}$ side, rather than the $\mathrm{Cu}$ side, as seen from Figure 7.1(a)-(d). It was due to several reasons. First, $\mathrm{Cu}$ has a much higher melting point $\left(1085^{\circ} \mathrm{C}\right)$ than $\mathrm{Mg}$ alloy $\left(\sim 650^{\circ} \mathrm{C}\right)$, with a dynamic $\mathrm{Mg}-\mathrm{Mg}_{2} \mathrm{Cu}$ eutectic temperature being below the equilibrium eutectic temperature of $485^{\circ} \mathrm{C}$ depending on the vacancy concentration. This means that $\mathrm{Cu}$ was still hard enough even though $\mathrm{Mg}$ alloy sheet became soft with some possible discrete melting spots at high welding energy levels. Panteli et al. [52] also observed that IMC sub-layer melted and re-solidified during ultrasonic welding of $\mathrm{Al}$ to $\mathrm{Mg}$ joined at a welding time of $1.26 \mathrm{~s}$. Second, the frictional heat generated during the mutual rubbing of the faying surfaces during USW would mainly stay on the Mg side which would lead to a somewhat higher temperature than that on the $\mathrm{Cu}$ side. Since the heat transfer on the $\mathrm{Cu}$ side is much faster due to its much higher thermal conductivity $(388 \mathrm{~W} / \mathrm{m} \cdot \mathrm{K})$ compared with AZ31B Mg alloy (96 $\mathrm{W} / \mathrm{m} \cdot \mathrm{K})$ and its much lower specific heat capacity $(385 \mathrm{~J} / \mathrm{kg} \cdot \mathrm{K})$ versus $\mathrm{Mg}$ alloy $(1024 \mathrm{~J} / \mathrm{kg} \cdot \mathrm{K})$ [123]. As a result, the interface diffusion layer could only form on the much softer $\mathrm{Mg}$ side. 


\subsubsection{Weld interface temperature}

The temperature generated at the joint interface due to rubbing, and severe plastic deformation plays an important role in the enhanced diffusion during USW of Cu-to-AZ31B alloy. Typical temperature profiles and peak temperatures at the center of the nugget versus welding energy are shown in Figure 7.2(a) and (b), respectively. It was observed that temperature initially rose rapidly with a heating rate of up to $\sim 1370^{\circ} \mathrm{C} / \mathrm{s}$, reached a maximum temperature, and then

decreased. The cooling rates were also high due to higher thermal conductivity, especially in $\mathrm{Cu}$. This confirmed a shorter thermal cycle during USW compared to FSSW. From Figure 7.2(b), it is seen that with increasing welding energy from $1000 \mathrm{~J}$ to $2500 \mathrm{~J}$ the peak temperature increased from 418 to $482^{\circ} \mathrm{C}$. As mentioned above, these temperatures might be slightly lower due to thermal lag, difficulty in ensuring accurate thermocouple position, and machined a groove in the bottom sheet. Nevertheless, the obtained temperature was high enough to cause a significant loss in the strength of Mg alloys, e.g., the yield stress decreased from $230 \mathrm{MPa}$ at room temperature to $4 \mathrm{MPa}$ at $400^{\circ} \mathrm{C}[178]$. Furthermore, this temperature was very close to the equilibrium $\mathrm{Mg}-\mathrm{Mg}_{2} \mathrm{Cu}$ eutectic temperature of $485^{\circ} \mathrm{C}$. Thus localized eutectic melting would be expected, considering the phenomenon of the melting point depression mentioned above. The localized eutectic liquid would, in turn, decrease the friction or viscosity of the plasticized material flow, and therefore, little frictional heating could be further generated at a welding energy of above $1500 \mathrm{~J}$, thus leading to a plateau-like characteristic (Figure 7.2(b)). 

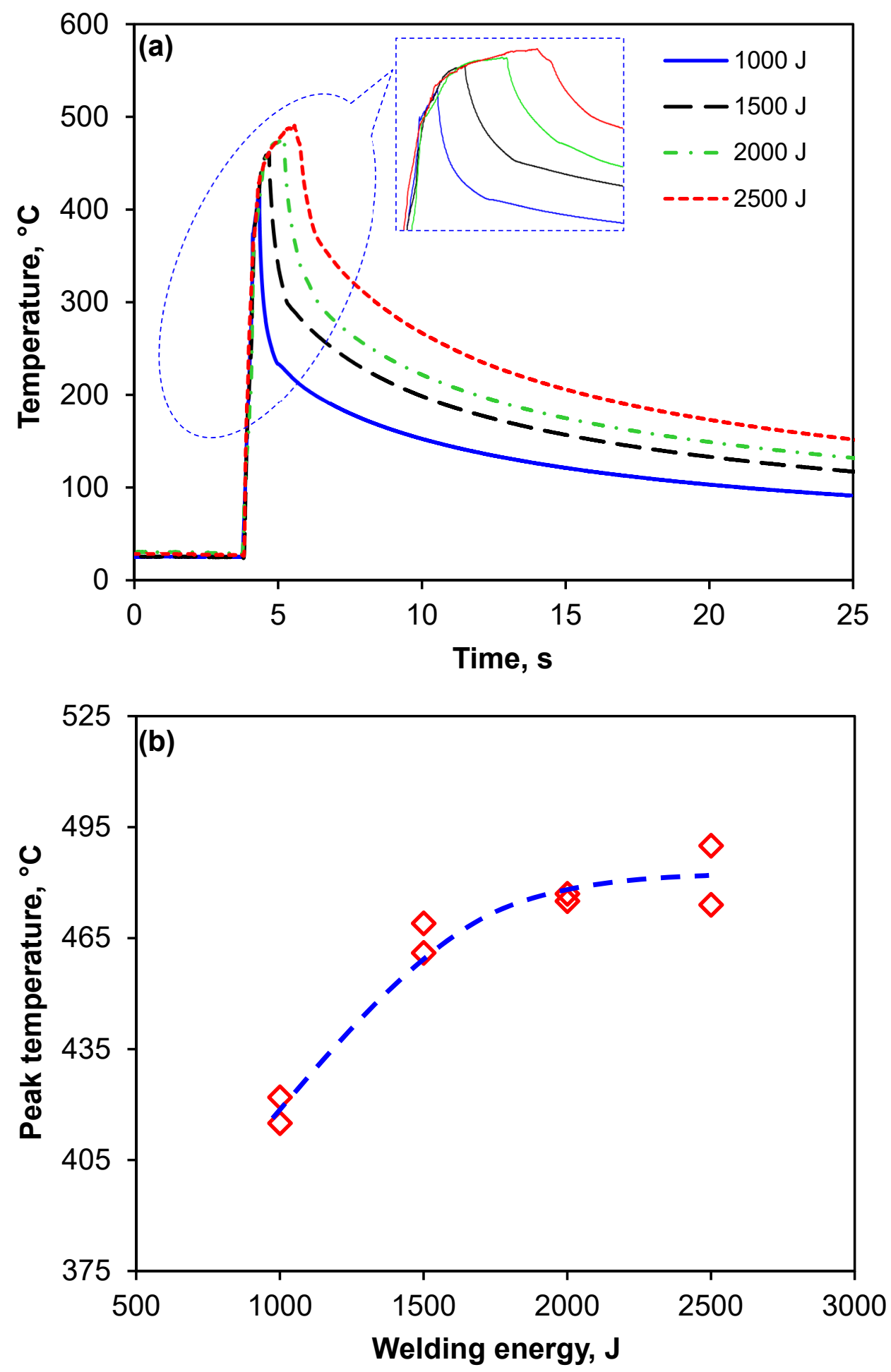

Figure 7.2: (a) Joint interface temperature profiles and (b) peak temperatures, measured at the center of the nugget during USW at a welding energy of $1000 \mathrm{~J}, 1500 \mathrm{~J}, 2000 \mathrm{~J}$ and $2500 \mathrm{~J}$. 


\subsubsection{Energy-dispersive X-ray spectroscopy analysis}

Figure 7.3 shows typical results of EDS line scan at a welding energy of $1000 \mathrm{~J}, 1500 \mathrm{~J}$ and $2000 \mathrm{~J}$, respectively. As discussed earlier, the concentration profile also indicated an increasing thickness of interface diffusion layer with increasing welding energy. The concentration profile of $\mathrm{Mg}$ and $\mathrm{Cu}$ elements across the diffusion layer in Figure 7.3(b), (d) and (f) showed the presence of $\mathrm{Mg}$ and $\mathrm{Cu}$ without $\mathrm{Al}$ and $\mathrm{Zn}$. It is seen that there were dark and white spots on the gray background of the interface diffusion layer as shown in Figure 7.3(c) and (e). The point analysis in Figure 7.3(c) showed a stoichiometric proportion of $\mathrm{Mg}$ to $\mathrm{Cu}$ elements in the interface diffusion layer was close to 2:1, indicating the presence of $\mathrm{Mg}_{2} \mathrm{Cu}$ compound. By referring to the $\mathrm{Cu}-\mathrm{Mg}$ binary phase diagram [179], the diffusion layer should consist of a eutectic structure of $\mathrm{Mg}$ and $\mathrm{Mg}_{2} \mathrm{Cu}$ phase via a eutectic reaction $\left(\mathrm{L} \rightarrow \mathrm{Mg}+\mathrm{Mg}_{2} \mathrm{Cu}\right.$ ), with dark spots being $\mathrm{Mg}$, the gray background being $\mathrm{Mg}_{2} \mathrm{Cu}$, and white spots being $\mathrm{Cu}$ solid solution. Similarly, Hong et al. [180] observed that only $\mathrm{Mg}_{2} \mathrm{Cu}$, rather than $\mathrm{MgCu}_{2}$, formed in a rapid cooling process. The possible diffusion reaction at the interface would be [181],

$$
2 \mathrm{Mg}+4 \mathrm{Cu} \rightarrow \mathrm{Mg}_{2} \mathrm{Cu}+3 \mathrm{Cu} \text {. }
$$

Figure 7.3(e) and (f) showed the presence of porosity on the interface diffusion layer possibly formed during the cooling process. This indicates probably localized melting at the interface during USW. To further validate the analysis above, XRD on the tensile fracture surfaces of both $\mathrm{Cu}$-side and $\mathrm{Mg}$-side was used to verify phases present in the interface diffusion layer. 

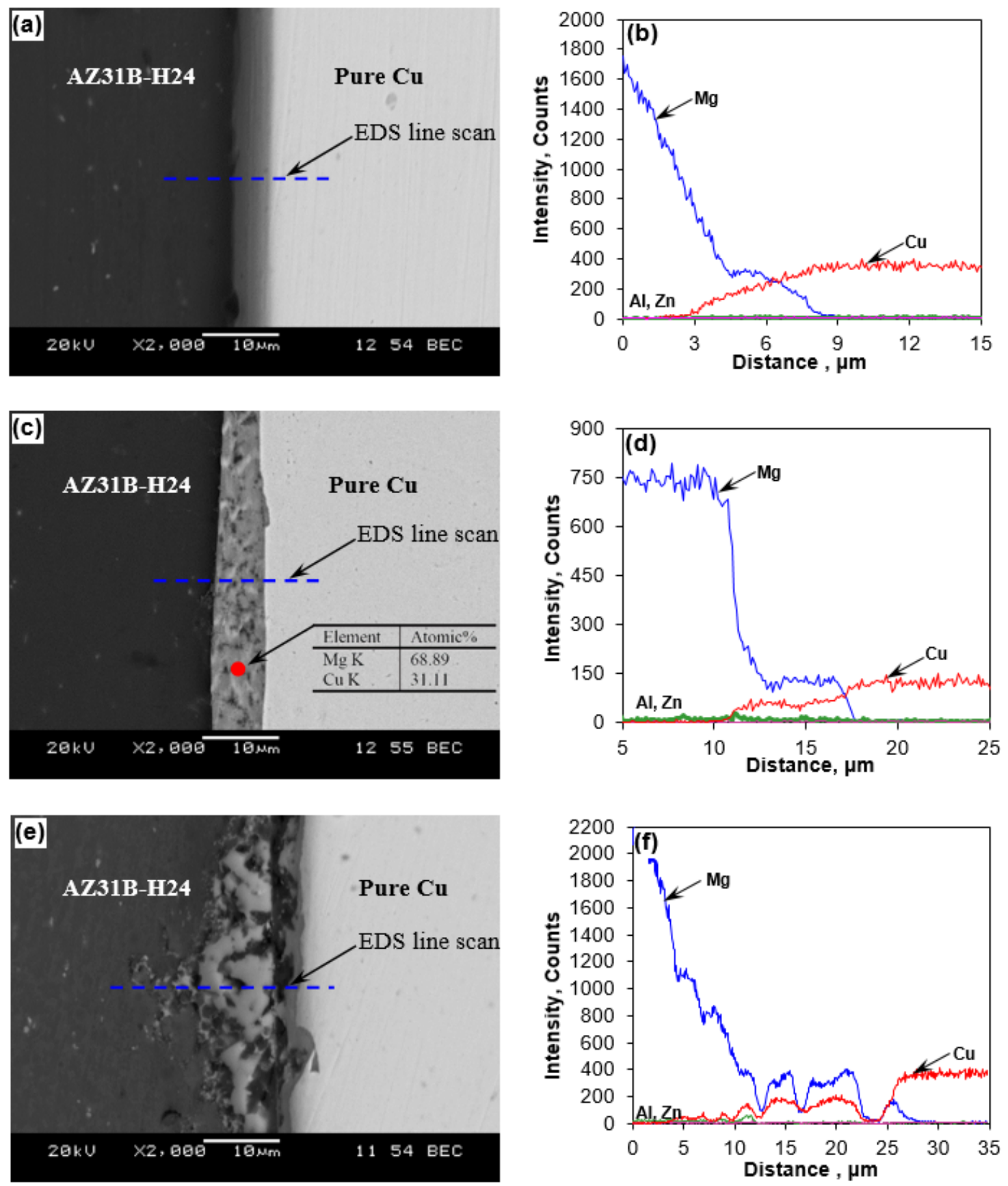

Figure 7.3: (a), (c) and (e) SEM micrographs showing the positions of EDS line scan, and (b), (d) and (f) the results of EDS line scan at a welding energy of $1000 \mathrm{~J}, 1500 \mathrm{~J}$ and $2000 \mathrm{~J}$, respectively.

\subsubsection{X-ray diffraction phase identification}


Figure 7.4 shows XRD spectra obtained from the fracture surface of tensile failed samples on the $\mathrm{Mg}$ side, and $\mathrm{Cu}$ side joined at a welding energy of $1000 \mathrm{~J}, 1500 \mathrm{~J}, 2000 \mathrm{~J}$, and $2500 \mathrm{~J}$, respectively. It is seen that multiple peaks of $\mathrm{Mg}_{2} \mathrm{Cu}$ along with $\mathrm{Mg}$ on the $\mathrm{Mg}$ side, while multiple peaks of $\mathrm{Cu}, \mathrm{Mg}$ and $\mathrm{Mg}_{2} \mathrm{Cu}$ on the $\mathrm{Cu}$ side in all conditions. Furthermore, relatively fewer peaks of $\mathrm{Mg}_{2} \mathrm{Cu}$ were observed at a welding energy of $1000 \mathrm{~J}$ due to lesser diffusion in this condition, which gave rise to a thinner interface diffusion layer. The XRD result confirmed that the interface diffusion layer contained eutectic of $\mathrm{Mg}_{2} \mathrm{Cu}$ and $\mathrm{Mg}$ solid solution, which is in agreement with the above EDS results. However, only single $\mathrm{Cu}$ peaks were identified on $\mathrm{Mg}$ side, indicating the only marginally small amount of $\mathrm{Cu}$ present in the interface diffusion layer.

\subsubsection{Diffusion pattern}

At higher welding energy levels (2000 J and $2500 \mathrm{~J})$, it is of special interest to observe distinctive diffusion patterns, as shown in Figure 7.1(c), 7.1(d), 7.5(a) and 7.5(b), where Figure 7.5(b) shows more details of the boxed area in Figure 7.5(a). A number of such patterns were observed with varying depths into Mg alloy at the "hot spots" along the joint interface. The three colors representing $\mathrm{Mg}$ (dark), $\mathrm{Mg}_{2} \mathrm{Cu}$ (gray) and $\mathrm{Cu}$ solid solution (white) were indicated in Figure 7.5(b) by arrows A, B, and C, respectively. A possible formation mechanism of these unique patterns could be understood in the following four stages as schematically illustrated inFigure 7.5(c). In the first stage interdiffusion between $\mathrm{Mg}$ and $\mathrm{Cu}$ atoms occurred preferably along grain boundaries due to higher diffusion rates. 

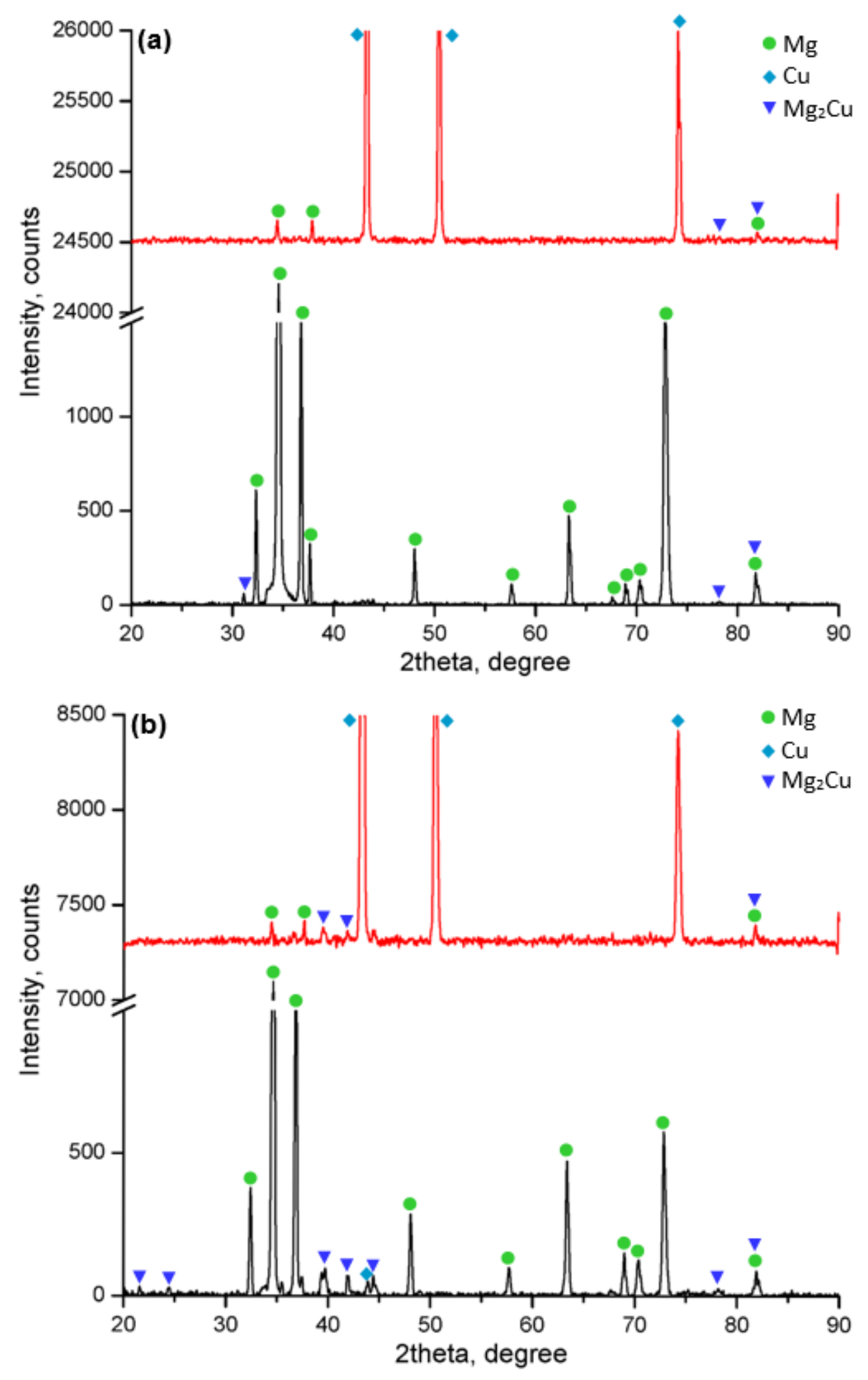

Figure 7.4: XRD patterns obtained on both matching surfaces of $M g$ side and $\mathrm{Cu}$ side after the lap shear tensile test of samples joined at a welding energy of (a) $1000 \mathrm{~J}$, (b) $1500 \mathrm{~J}$, (c) 2000 $J$, and (d) $2500 \mathrm{~J}$. 

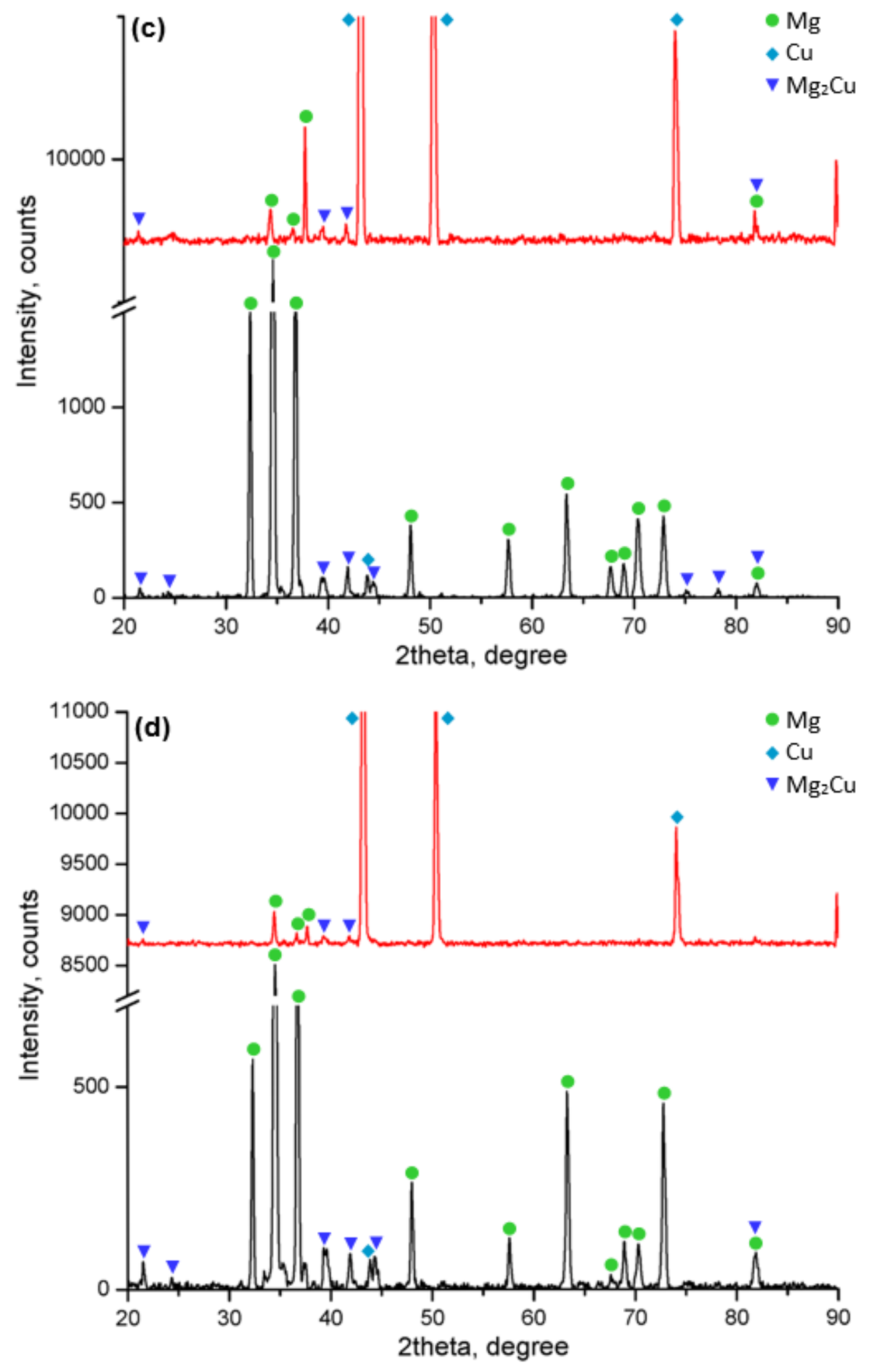

Figure 7.4: XRD patterns obtained on both matching surfaces of $M g$ side and Cu side after the lap shear tensile test of samples joined at a welding energy of (a) $1000 \mathrm{~J}$, (b) $1500 \mathrm{~J}$, (c) 2000 $J$, and (d) $2500 \mathrm{~J}$ (repeat). 

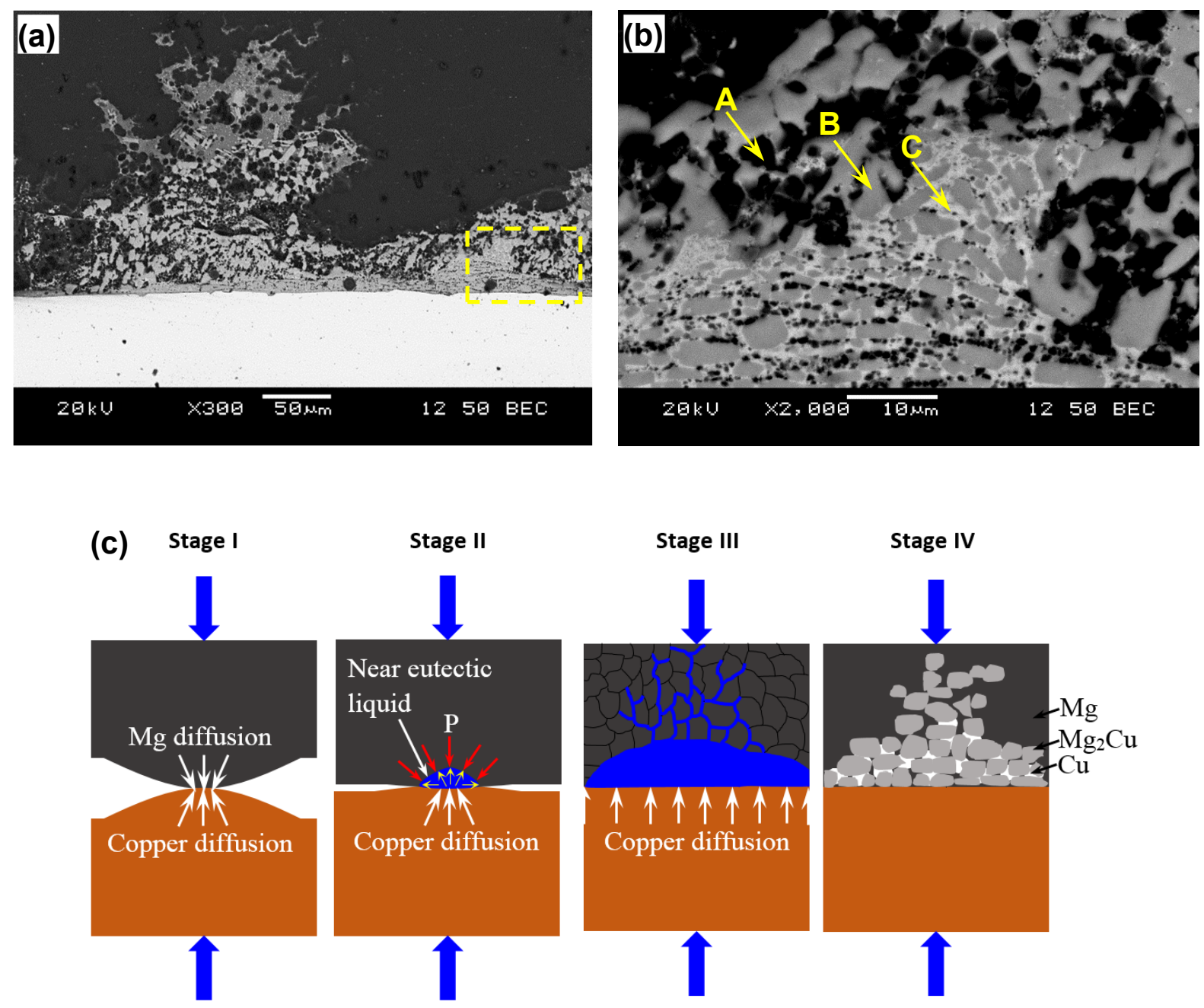

Figure 7.5: (a) SEM micrograph of an outburst-like pattern of diffusion layer at the interface of $2500 \mathrm{~J}$ welding energy sample, (b) a view of the boxed region in (a) at a higher magnification, and (c) schematic diagram showing the formation of outburst-like patterns in four stages.

This process was expedited with rapidly-increasing temperature (Figure 7.2(a)) and vacancies in $\mathrm{Mg}$ due to its relatively low melting point and ultrahigh-frequency $(20 \mathrm{kHz})$ dynamic rubbing. This, along with the smaller radius of $\mathrm{Cu}$ atoms $(0.128 \mathrm{~nm}$ vs. $0.160 \mathrm{~nm}$ for $\mathrm{Mg})$, facilitated and accelerated $\mathrm{Cu}$ atoms diffusing into $\mathrm{Mg}$ side. As the interface iemperature essentially reaching the $\mathrm{Mg}-\mathrm{Mg}_{2} \mathrm{Cu}$ eutectic temperature at a welding energy of $2500 \mathrm{~J}$ (Figure 7.2(b)), localized liquid spots (or hot spots) with a composition of about $14.5 \mathrm{at} \% \mathrm{Cu}$ based on the $\mathrm{Mg}$-Cu phase diagram would develop in the second stage, and then expand to a certain degree. The melting 
process was anticipated from the grain boundary towards the grain interior. If a Mg grain was relatively large, the center region of the grain might be left due to a short welding time (insufficient for melting). For the majority of matter in nature (with some exceptions, e.g., water) the volume of the liquid state is usually larger than its solid state since individual atoms or molecules have more energy and are more active, leading to the thermal expansion and creating an internal pressure. This inner pressure was further enhanced by a better sealing around the softened hot spots and the slight clamping pressure applied during USW. On the other hand, the border/cap surrounding the near-eutectic liquid became increasingly softer, and some highangle grain boundaries along the border became increasingly weaker at high temperatures. Then in the third stage, when the internal pressure at the localized melting spot containing a small amount of near-eutectic liquid with excess $\mathrm{Cu}$ reached a critical value, corresponding to the strength of the surrounding high-angle grain boundaries, the inner liquid would burst out or quickly penetrate into Mg mainly along some grain boundaries to form distinctive outburst-like patterns. In the subsequent cooling (stage IV), the outburst liquid became $\mathrm{Mg}+\mathrm{Mg}_{2} \mathrm{Cu}$ eutectic together with some $\mathrm{Cu}$ solid solution.

\subsection{Vickers microhardness}

Figure 7.6 shows a characteristic microhardness profile of the dissimilar joint of the USWed AZ31-H24 Mg alloy and $\mathrm{Cu}$, which was measured diagonally across samples joined at a welding energy of $2000 \mathrm{~J}$ and $2500 \mathrm{~J}$. It should be noted that the thickness of interface diffusion layer was very small in low welding energy conditions (1000 J and $1500 \mathrm{~J}$ ), and it was difficult to locate indent on the interface diffusion layer. Hence, higher welding energy conditions with 
a thicker diffusion layer were selected for the microhardness tests. It is seen that the microhardness decreased slightly with increasing energy input on the Mg side while no change occurred on the $\mathrm{Cu}$ side. It can be reasoned that as the heat input increased with increasing welding energy, the increase in temperature resulted in grain growth, causing a decrease in hardness based on the Hall-Petch type relationship which was observed in an AZ31B-H24 Mg alloy after friction stir welding or processing $[121,122]$. The unchanged microhardness on the $\mathrm{Cu}$ side with increasing welding energy was because the interface temperature during joining may not have reached the recrystallization temperature of $\mathrm{Cu}$. Another reason was related to a short welding time of $1 \mathrm{~s}$ and $1.25 \mathrm{~s}$, which was not long enough to result in the occurrence of dynamic recrystallization of $\mathrm{Cu}$. Similar results were also reported in the dissimilar welding of Al-Cu joints [116,182].

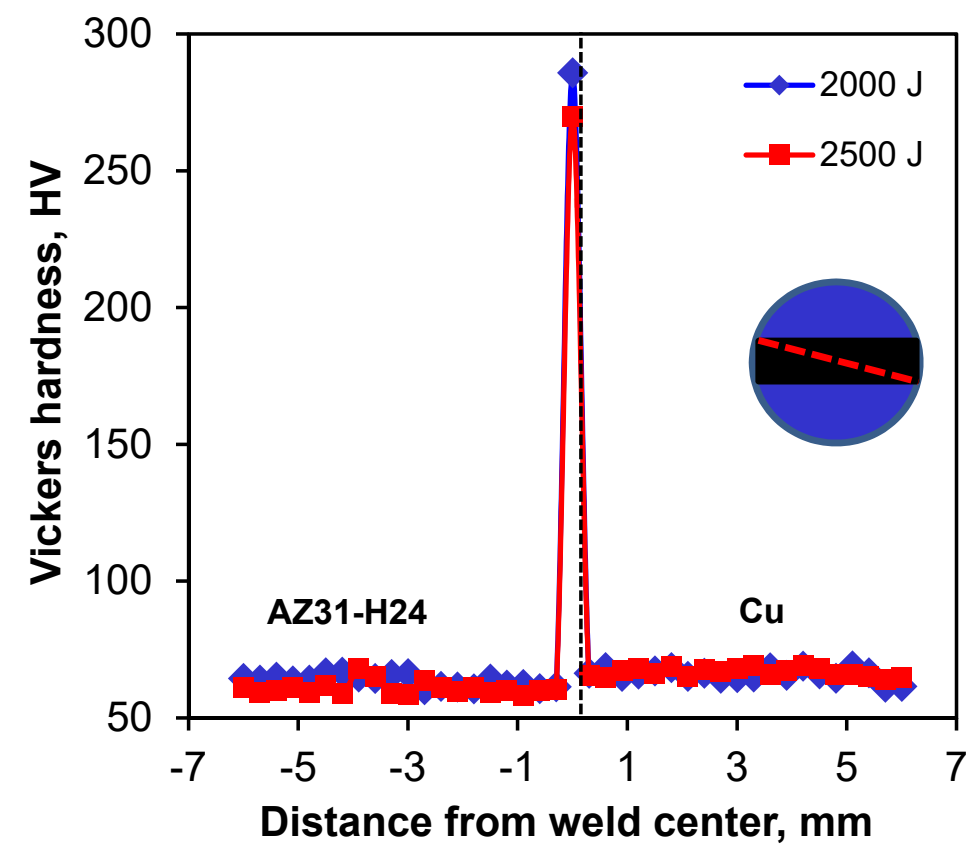

Figure 7.6: Microhardness profile diagonally measured across the joint interface for the samples joined at a welding energy of $2000 \mathrm{~J}$ and $2500 \mathrm{~J}$. 
The microhardness at the joint interface was much higher $(278 \pm 11 \mathrm{HV})$ compared to $\mathrm{Mg}(62 \pm 2$ $\mathrm{HV})$ and $\mathrm{Cu}(66 \pm 2 \mathrm{HV})$ base metals owing to the presence of $\mathrm{Mg}_{2} \mathrm{Cu}$ in the interface diffusion layer. It should be noted that a mean value of three indentations along the interlayer was plotted in Figure 7.6 for better accuracy. The measured hardness value at the interface was somewhat lower than the reported value of $\mathrm{Mg}_{2} \mathrm{Cu}$ [112], due to the presence of a eutectic structure of $\mathrm{Mg}_{2} \mathrm{Cu}$ and $\mathrm{Mg}$ in the interface diffusion layer.

\subsection{Tensile lap shear strength}

The tensile lap shear strength was plotted against welding energy (or time) at a constant power of $2000 \mathrm{~W}$ and constant clamping pressure of 0.4 MPa as shown in Figure 7.7(a). The tensile lap shear strength increased with increasing welding energy up to $1500 \mathrm{~J}$, where it reached its maximum average value of $53 \mathrm{MPa}$ (calculated as the maximum tensile lap shear load divided by the sonotrode area of $8 \times 5 \mathrm{~mm}^{2}$ ), and decreased after that, with a further increase in the welding energy. At a low welding energy of $500 \mathrm{~J}$ and $1000 \mathrm{~J}$, the interface diffusion was limited, and the interface diffusion layer was discontinuous and thin. Since the interface temperature was low, the flowability of metal was limited yet the yield strength of the base material remained high, which led to an incomplete coalescence of the bonding surfaces [116] and therefore resulted in inferior joint strength. At a welding energy of $1500 \mathrm{~J}$, adequate diffusion resulted in the formation of the continuous diffusion layer (Figure 7.1(b)). Though the $\mathrm{Mg}_{2} \mathrm{Cu}$ increased brittleness, the presence of $\mathrm{Mg}$ in the eutectic structure and retained $\mathrm{Cu}$ in the diffusion layer increased plasticity and bonding strength. Also, the plastic deformation of the surface asperities led to an intimate contact, which balanced the embrittlement due to the 
presence of the IMC $\mathrm{Mg}_{2} \mathrm{Cu}$ phase. It follows that the shear strength naturally improved and attained its average maximum value of $53 \mathrm{MPa}$ at $1500 \mathrm{~J}$. As the welding energy further increased to $2000 \mathrm{~J}$ and $2500 \mathrm{~J}$, the higher interface temperature and larger vacancy concentration led to "outburst"-like patterns (Figures 7.1(c), 7.1(d), and 7.5). The occurrence of such "outburst" spots along the interface would deteriorate the coalescence of faying surfaces, thus diminishing the tensile lap shear strength when the welding energy exceeded $1500 \mathrm{~J}$. Also, it was likely that the thicker diffusion layer at higher welding energy levels would have higher internal stresses generated during the rapid cooling after welding (Figure 7.2(a)). This would also result in a decrease in the tensile lap shear strength. It was identified that the maximum tensile lap shear strength in the present study (53 MPa) was higher than that of TIG welded Mg$\mathrm{Cu}$ joints without interlayer (23 $\mathrm{MPa}$ ), and was comparable to the strength achieved using diffusion bonding ( $66 \mathrm{MPa})$, while the welding time was considerably shorter $(0.75 \mathrm{~s})$ compared to that of diffusion bonding (15-20 min) and TIG welding [34,115]. However, it should be noted that there were different sample geometry as well as different alloys of $\mathrm{Mg}$ and $\mathrm{Cu}$ with different thickness of the sheets, which could have an effect on the strength of the joints. Therefore, further studies are required to validate the above comparison. Figure 7.7(b) shows the total failure energy (determined by the integration of a tensile lap shear load displacement curve) was plotted against welding energy. It showed a similar trend with an average maximum total failure energy of $6.1 \mathrm{~J}$ at a welding energy of $1500 \mathrm{~J}$. It was reported that failure energy has a stronger correlation with fracture mode than peak load in the lap shear tensile tests [45]. In the present study, since all the sample failed in the same mode of interfacial failure, this variation could be attributed to the plasticity of the interface layer. As discussed earlier, the plasticity and 
bonding strength were the maximum at $1500 \mathrm{~J}$ due to the presence of a uniform eutectic interface layer, and therefore, the total failure energy was also the highest in this condition.
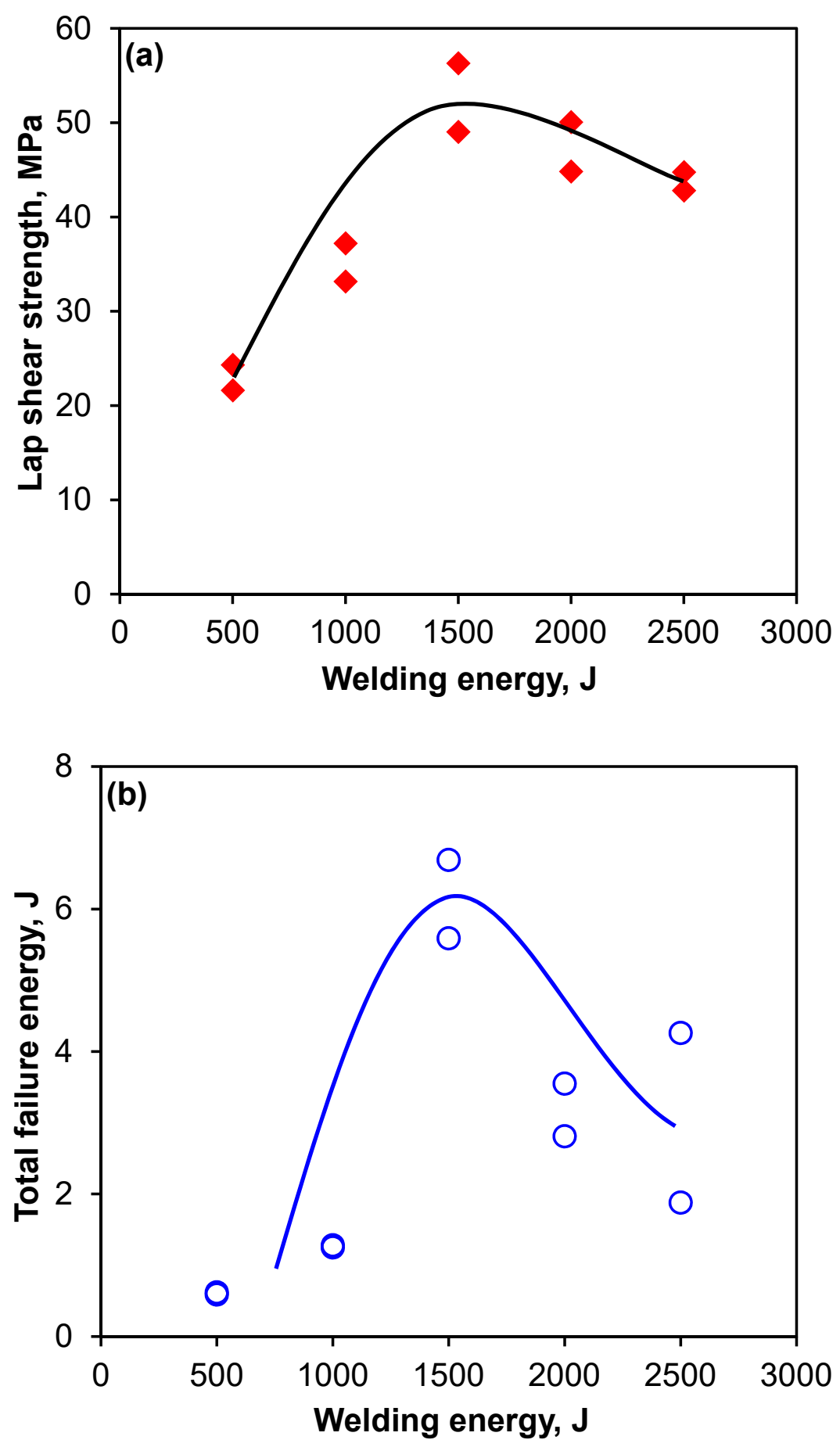

Figure 7.7: (a) Tensile lap shear strength and (b) total failure energy, as a function of welding energy at a constant power of $2000 \mathrm{~W}$ and a clamping pressure of $0.4 \mathrm{MPa}$. 


\subsection{Fractography}

The samples joined at different welding energy levels were all failed in an interface fracture mode. Considering its maximum tensile lap shear strength, the sample joined at a welding energy of $1500 \mathrm{~J}$ was examined using SEM. Figure 7.8(a) and (b) show the SEM images of the overall fracture surface on the $\mathrm{Mg}$ side and $\mathrm{Cu}$ side, respectively. Both images showed the squeezed-out eutectic liquid at the edge of the nugget, confirming the localized melting during USW, as discussed earlier. Vertical pressure lines were observed in Figure 7.8(a). These lines were created by the sonotrode tip teeth of the ultrasonic spot welder, which were evenly grooved to grasp the top and bottom base metal sheets before the vibration process. The nine parallel teeth on the sonotrode tip created a peak-and-valley impression, which indicated that the lines on the interface were also caused by the non-uniform pressure that created a relatively stronger bond and increased friction in those particular areas. Although some were faint, there were approximately nine lines on the fracture surfaces, corresponding to the number of the sonotrode tip teeth. Figure 7.8(c) and (d) show higher magnification images of areas boxed in Figure 7.8(a) and (b), respectively. The horizontal dashed lines in Figure 7.8(c) and (d) indicate the path across which EDS line scans were performed. It is seen from Figure 7.8(e) and (f) that $\mathrm{Cu}$ along with $\mathrm{Mg}_{2} \mathrm{Cu}$ on the $\mathrm{Mg}$ side and $\mathrm{Mg}$ along with $\mathrm{Mg}_{2} \mathrm{Cu}$ phase on the $\mathrm{Cu}$ side were visible, corresponding well to the XRD results shown in Figure 7.5. This indicated that the failure during the tensile lap shear testing occurred within the eutectic structure of the interface diffusion interlayer formed during USW, often referred to as cohesive failure [158]. 

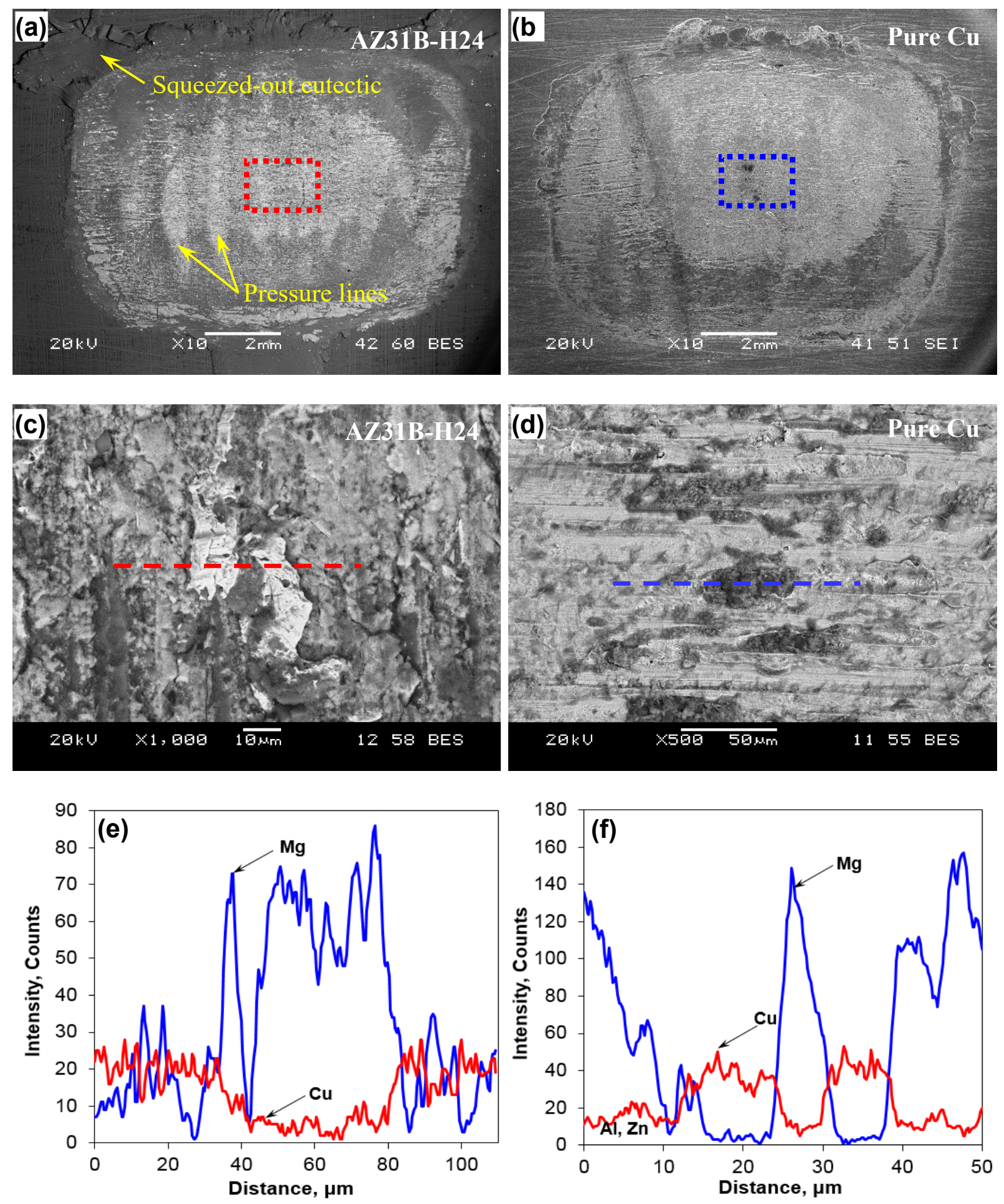

Figure 7.8: SEM images of fracture surfaces joined at a welding energy of $1500 \mathrm{~J}$, (a) overall view on the Mg side, (b) overall view on the Cu side, (c) Mg side at a higher magnification, (d) $C u$ side at a higher magnification, (e) EDS line scan on the fracture surface of $M g$ side, and (f) EDS line scan on the fracture surface of $\mathrm{Cu}$ side. 


\subsection{Summary}

The USW of Cu-to-AZ31B-H24 Mg alloy was conducted at varying welding energy levels along with the measurement of welding temperature profiles and the evaluation of interface microstructure and tensile lap shear strength of the joints. The following conclusions can be drawn:

1) Accelerated diffusion at the joint interface during USW of Cu-to-Mg alloy resulted in the formation of interface diffusion layer consisting of a eutectic structure of $\mathrm{Mg}$ and $\mathrm{Mg}_{2} \mathrm{Cu}$ with some excess $\mathrm{Cu}$.

2) The interface diffusion layer formed only on the $\mathrm{Mg}$ side due to the big difference in the melting point, thermal conductivity, and heat capacity between two dissimilar metals. The thickness of interface diffusion layer is increased with increasing welding energy due to increasing temperature at the joint interface.

3) A characteristic outburst-like diffusion pattern was observed at high levels of welding energy of 2000 and $2500 \mathrm{~J}$, which was explained in four stages of the formation process.

4) The tensile lap shear strength of the joints first increased with increasing welding energy reached the maximum average value of $53 \mathrm{MPa}$ at a welding energy of $1500 \mathrm{~J}$ and then decreased.

5) During the tensile lap shear tests, the failure of the joints made with the optimum welding condition of $1500 \mathrm{~J}$ and 0.75 seconds occurred in the mode of cohesive failure along the eutectic structure of interface diffusion interlayer. 


\section{Chapter 8. Conclusions and Future Work}

In this work, high power USW has been used to join similar Mg-to-Mg and dissimilar of Mg-

to-Al, Al-to-steel and $\mathrm{Mg}$-to-Cu alloys sheets due to the multi-material combinations in the automotive applications.

\subsection{Conclusions}

Much of the focus of this work was on evaluating the feasibility of joining a new highperformance rare earth containing ZEK100 Mg alloy in similar (ZEK100-to-ZEK100) and dissimilar configurations with automotive grade A15754 alloy sheet (Chapter 4 and Chapter 5). Automotive grade heat treatable A16111 alloy was welded with HSLA steel to study the effect of galvanized zinc coating on the strength of the joints and natural aging on the microhardness (Chapter 6). In addition, the feasibility of joining AZ31-H24 Mg alloy-to-Cu using USW technique was studied (Chapter 7). The major conclusions of this work are highlighted below.

1. Dynamic recrystallization occurred at the weld interface of Mg-to-Mg joints due to the predominant effect of temperature rise and high strain rate.

2. An important relationship between grain size and Zener-Hollomon parameter) was established for ZEK100-ZEK100 similar joints prepared by USW to predict grain size and microhardness in various conditions.

3. The interface diffusion layer in all dissimilar joints grew rapidly due to high diffusivities 
of the materials as a result of high strain rate $\left(\sim 10^{3} \mathrm{~s}^{-1}\right)$ and high temperature $\left(\sim 480^{\circ} \mathrm{C}\right)$ at the weld interface.

4. The interface diffusion layer in the dissimilar joints without interlayer/coating consisted of a eutectic layer containing brittle $\mathrm{IMC} \mathrm{Al}_{12} \mathrm{Mg}_{17}$ in $\mathrm{Mg}$ - $\mathrm{Al}$ joints and $\mathrm{Mg}_{2} \mathrm{Cu}$ in $\mathrm{Mg}$ $\mathrm{Cu}$ joints. The thickness of the interface diffusion layer is increased with increasing welding energy.

5. In all the dissimilar joints the interface diffusion layer formed on the softer material side (Mg side for $\mathrm{Mg}$-to-Al and $\mathrm{Mg}$-to-Cu joints, $\mathrm{Al}$ side for Al-to-steel joints) due to the big difference in the melting point, thermal conductivity, and heat capacity between two dissimilar materials.

6. The superior ductility and formability of ZEK100 Mg alloy resulted in enhanced flowability and coalescence at the weld interface, and therefore ZEK100-to-A15754 dissimilar joints exhibited a higher strength than AZ31-A15754 dissimilar joints even with a tin interlayer.

7. During USW of heat-treatable Al6111-T4 alloy, a certain extent of softening in NZ and slightly outside the NZ (or HAZ) on the Al side was observed in the transverse direction (vibration direction) due to the slower heat transfer in air, which was quickly recovered due to the occurrence of natural aging in the A16111-T4 alloy. However, no softening in the longitudinal direction (perpendicular to the vibration direction) was observed due to fast heat transfer in this direction.

8. The role of the $\mathrm{Zn}$ coating in the dissimilar USWed Al-to-steel joints was to eliminate the formation of brittle IMCs of Al-Fe, which were replaced with Al-Zn eutectic structure. 
9. For all the joints in the present study, the tensile lap shear strength first increased with increasing welding energy, reached the maximum values, and then decreased with a further increase in the welding energy.

10. The optimum welding energy or welding time during similar and dissimilar USW of lightweight alloys with a sheet thickness of 1-2 mm was in the range of $\sim 500 \mathrm{~J}$ to 2000 $\mathrm{J}(\sim 0.25 \mathrm{~s}$ to $1 \mathrm{~s})$.

11. In general, USWed similar and dissimilar joints failed in two distinct failure modes during tensile and fatigue tests: (i) interfacial failure due to low bonding strength at low welding energy levels and (ii) nugget edge or nugget pull out failure due to higher stress concentration due to deeper penetration of sonotrode tip only at higher welding energy levels which led to a reduction of effective sheet thickness.

12. Zn melting, and Al-Zn eutectoid/eutectic structure at the weld interface was observed to be advantageous, as the squeezing-out of the liquid solidified at the nugget edge, strengthening the welded joints via a brazing effect and reducing stress concentration at the nugget edge.

\subsection{Major contributions}

The proposed research will contribute to the development of similar and dissimilar USWed joints of lightweight alloys. One may use the results of this work to determine an appropriate set of welding parameters for USW of lightweight alloys to achieve high reliability and durability of the joints. The main objective of this research is to provide an efficient welding process to the Canadian automotive industry and thereby, help them to achieve the goals of 
increasing usage of ultra-lightweight $\mathrm{Mg}$ and $\mathrm{Al}$ alloys in motor vehicles to increase fuel economy and reduce greenhouse gas emissions. Moreover, it will help enhance the capacity of Canadian manufacturing industry to compete on the global market. This research will also contribute to enhance understanding of the fundamentals of USW process as well as the diffusion and microstructural changes during USW, and mechanical properties of the joints so as to guarantee the safety, reliability and durability of the USWed components.

\subsection{Recommendations for future work}

This work represents progress in the development of USW techniques for joining newly developed Mg alloy, automotive grade Al alloys, and HSLA steel in similar and dissimilar configuration. However, these results lead to several additional questions and areas for continued investigations. Those questions and areas are presented below.

1 The rapid growth of the interface diffusion layer was observed during USW in dissimilar configuration. The enhanced diffusion and IMC layer growth rates could be further investigated.

2 The investigation into the feasibility of using other interlayers/coatings material to improve dissimilar joints strength further.

3 One of the most common failure modes observed during tensile and fatigue tests in the present study for both similar and dissimilar joints is nugget edge or nugget pull out failure. As identified, this was due to a higher stress concentration as a result of as a result of deeper penetration of sonotrode tip at a higher welding energy, leading to a 
reduction of effective sheet thickness. It was also noted that fatigue life of the joints was more sensitive to this stress concentration. Therefore, the reduction or elimination of this stress concentration is required to achieve a higher strength. However, to the author's knowledge there was no study which quantified such stresses at the nugget edge, and therefore, it would be interesting to quantify stresses at the nugget edge by residual stress measurements.

4 It was observed that the reduction in the effective sheet thickness had a detrimental effect on the tensile and fatigue properties of the joints. Since the effective sheet thickens is a function of the actual thickness of the material, it would be interesting to study the effects of sheet thickness of the material being joined on the weld strength.

5 There is no information available in the AWS database regarding the procedure for joining dissimilar materials using USW. One of the important parameters to achieve the optimum strength in spot welding is the recommended distance between two spot welds and from the component edge. These parameters (i.e., the distance between two spot welds and from the component edge) should be established by experimental or analytical or numerical methods. 


\section{References}

[1] A.I. Cooper, Materials chemistry: Cooperative carbon capture, Nature. 519 (2015) 294-295. doi:10.1038/nature14212.

[2] M. Jakob, J.H. Aire, Unburnable fossil-fuel reserves, Nature. 517 (2015) 150. doi:10.1038/517150a.

[3] S. Chu, A. Majumdar, Opportunities and challenges for a sustainable energy future, Nature. 488 (2012) 294-303. doi:10.1038/nature11475.

[4] M. McNutt, Climate Change Impacts, Science. 341 (2013) 435. http://science.sciencemag.org/content/341/6145/435.abstract.

[5] J.F. Nie, Y.M. Zhu, J.Z. Liu, X.Y. Fang, Periodic Segregation of Solute Atoms in Fully Coherent Twin Boundaries, Science. 340 (2013) 957-960. doi:10.1126/science. 1229369 .

[6] T.M. Pollock, Weight loss with magnesium alloys, Science. 328 (2010) 986-987. doi:10.1126/science.1182848.

[7] J. Schmale, D. Shindell, E. von Schneidemesser, I. Chabay, M. Lawrence, Clean up our skies, Nature. 515 (2014) 335-337. doi:10.1038/515335a.

[8] F. Mokdad, D.L. Chen, Strain-controlled low cycle fatigue properties of a rare-earth containing ZEK100 magnesium alloy, Mater. Des. 67 (2015) 436-447. doi:10.1016/j.matdes.2014.11.058.

[9] A. Macwan, X.Q. Jiang, D.L. Chen, Interfacial characterization of dissimilar joints between $\mathrm{Al} / \mathrm{Mg} / \mathrm{Al}$-trilayered clad sheet to high-strength low-alloy steel, JOM. 67 (2015) 1468-1477. doi:10.1007/s11837-015-1466-9. 
[10] F. Mokdad, D.L. Chen, Cyclic deformation and anelastic behavior of ZEK100 magnesium alloy: Effect of strain ratio, Mater. Sci. Eng. A. 640 (2015) 243-258. doi:10.1016/j.msea.2015.05.110.

[11] N. Tahreen, D.F. Zhang, F.S. Pan, X.Q. Jiang, C. Li, D.Y. Li, et al., Characterization of hot deformation behavior of an extruded Mg-Zn-Mn-Y alloy containing LPSO phase, J. Alloys Compd. 644 (2015) 814-823. doi:10.1016/j.jallcom.2015.04.144.

[12] F.A. Mirza, D.L. Chen, D.J. Li, X.Q. Zeng, Low cycle fatigue of a rare-earth containing extruded magnesium alloy, Mater. Sci. Eng. A. 575 (2013) 65-73. doi:10.1016/j.msea.2013.03.041.

[13] J. Bohlen, M.R. Nürnberg, J.W. Senn, D. Letzig, S.R. Agnew, The texture and anisotropy of magnesium-zinc-rare earth alloy sheets, Acta Mater. 55 (2007) 21012112. doi:10.1016/j.actamat.2006.11.013.

[14] S. Zhang, D. Zhao, F.A. Mirza, D.L. Chen, Fatigue of Magnesium Alloys, in: Aerosp. Mater. Handb., CRC Press, 2012: pp. 647-698.

[15] M.C. Zhao, M. Liu, G. Song, A. Atrens, Influence of the $\beta$-phase morphology on the corrosion of the Mg alloy AZ91, Corros. Sci. 50 (2008) 1939-1953. doi:10.1016/j.corsci.2008.04.010.

[16] C. Liu, D.L. Chen, S. Bhole, X. Cao, M. Jahazi, Polishing-assisted galvanic corrosion in the dissimilar friction stir welded joint of AZ31 magnesium alloy to 2024 aluminum alloy, Mater. Charact. 60 (2009) 370-376. doi:10.1016/j.matchar.2008.10.009.

[17] A. Macwan, X.Q. Jiang, C. Li, D.L. Chen, Effect of annealing on interface microstructures and tensile properties of rolled $\mathrm{Al} / \mathrm{Mg} / \mathrm{Al}$ tri-layer clad sheets, Mater. Sci. Eng. A. 587 (2013) 344-351. doi:10.1016/j.msea.2013.09.002. 
[18] R.K. Mishra, A.K. Guptaz, R. Sikand, A.K. Sachdevl, L. Jin, Formability enhancement in hot extruded magnesium alloys, Magnes. Technol. 2011. (2011) 363-366.

[19] J.B. Jordon, J.B. Gibson, M.F. Horstemeyer, H. El Kadiri, J.C. Baird, A.A. Luo, Effect of twinning, slip, and inclusions on the fatigue anisotropy of extrusion-textured AZ61 magnesium alloy, Mater. Sci. Eng. A. 528 (2011) 6860-6871. doi:10.1016/j.msea.2011.05.047.

[20] N. Tahreen, D.F. Zhang, F.S. Pan, X.Q. Jiang, C. Li, D.Y. Li, et al., Influence of yttrium content on phase formation and strain hardening behavior of $\mathrm{Mg}-\mathrm{Zn}-\mathrm{Mn}$ magnesium alloy, J. Alloys Compd. 615 (2014) 424-432. doi:10.1016/j.jallcom.2014.06.211.

[21] J.E. Gray, B. Luan, Protective coatings on magnesium and its alloys - a critical review, J. Alloys Compd. 336 (2002) 88-113. doi:10.1016/S0925-8388(01)01899-0.

[22] M. Yamasaki, N. Hayashi, S. Izumi, Y. Kawamura, Corrosion behavior of rapidly solidified Mg-Zn-rare earth element alloys in $\mathrm{NaCl}$ solution, Corros. Sci. 49 (2007) 255-262. doi:10.1016/j.corsci.2006.05.017.

[23] F.A. Mirza, D.L. Chen, D.J. Li, X.Q. Zeng, Cyclic deformation behavior of a rare-earth containing extruded magnesium alloy: effect of heat treatment, Metall. Mater. Trans. A Phys. Metall. Mater. Sci. 46 (2014) 1168-1187. doi:10.1007/s11661-014-2687-1.

[24] F.A. Mirza, D.L. Chen, D.J. Li, X.Q. Zeng, Low cycle fatigue of an extruded Mg3Nd-0.2Zn-0.5Zr magnesium alloy, Mater. Des. 64 (2014) 63-73. doi:10.1016/j.matdes.2014.07.016.

[25] H.M. Rao, R.I. Rodriguez, J.B. Jordon, M.E. Barkey, Y.B. Guo, H. Badarinarayan, et al., Friction stir spot welding of rare-earth containing ZEK100 magnesium alloy sheets, 
Mater. Des. 56 (2014) 750-754. doi:10.1016/j.matdes.2013.12.034.

[26] X.P. Niu, T. Skszek, M. Fabischek, A. Zak, Low temperature warm forming of magnesium ZEK 100 sheets for automotive applications, in: THERMEC 2013, Trans Tech Publications, 2014: pp. 431-436. doi:10.4028/www.scientific.net/MSF.783786.431.

[27] V.K. Patel, S.D. Bhole, D.L. Chen, Ultrasonic spot welding of aluminum to highstrength low-alloy steel: microstructure, tensile and fatigue properties, Metall. Mater. Trans. A. 45 (2013) 2055-2066. doi:10.1007/s11661-013-2123-y.

[28] M. Baig, A.S. Khan, S.-H. Choi, E. Lee, Effect of manufacturing processes and welding type on quasi-static and dynamic responses of aluminum alloys: experiments and modeling, J. Dyn. Behav. Mater. 1 (2015) 299-314. doi:10.1007/s40870-0150025-3.

[29] X. Cui, S. Wang, S.J. Hu, A method for optimal design of automotive body assembly using multi-material construction, Mater. Des. 29 (2008) 381-387. doi:10.1016/j.matdes.2007.01.024.

[30] A. Jambor, M. Beyer, New cars - new materials, Mater. Des. 18 (1997) 203-209. doi:10.1016/S0261-3069(97)00049-6.

[31] D. Carle, G. Blount, The suitability of aluminium as an alternative material for car bodies, Mater. Des. 20 (1999) 267-272. doi:10.1016/S0261-3069(99)00003-5.

[32] A.H. Panteli, P. Prangnell, Friction joining of aluminium-to-magnesium for lightweight automotive applications, University of Manchester, 2012. https://books.google.ca/books?id=hPtBmwEACAAJ.

[33] L. Berger, M. Lesemann, C. Sahr, S. Hart, R. Taylor, SuperLIGHT-CAR - the multi- 
material car body, in: 7th Eur. LS-DYNA Conf. DYNAmore Gmbh, 2009.

[34] G. Mahendran, V. Balasubramanian, T. Senthilvelan, Developing diffusion bonding windows for joining AZ31B magnesium and copper alloys, Int. J. Adv. Manuf.

Technol. 42 (2009) 689-695. doi:10.1007/s00170-008-1645-8.

[35] L. Rd, Vision for Welding Industry, 2000.

[36] S. Niknejad, L. Liu, M.-Y. Lee, S. Esmaeili, N.Y. Zhou, Resistance spot welding of AZ series magnesium alloys: Effects of aluminum content on microstructure and mechanical properties, Mater. Sci. Eng. A. 618 (2014) 323-334. doi:10.1016/j.msea.2014.08.013.

[37] F. Haddadi, D. Strong, P.B. Prangnell, Effect of zinc coatings on joint properties and interfacial reactions in aluminum to steel ultrasonic spot welding, JOM. 64 (2012) 407413. doi:10.1007/s11837-012-0265-9.

[38] A. Macwan, D.L. Chen, Microstructure and mechanical properties of ultrasonic spot welded copper-to-magnesium alloy joints, Mater. Des. 84 (2015) 261-269. doi:10.1016/j.matdes.2015.06.104.

[39] R. Borrisutthekul, Y. Miyashita, Y. Mutoh, Dissimilar material laser welding between magnesium alloy AZ31B and aluminum alloy A5052-O, Sci. Technol. Adv. Mater. 6 (2005) 199-204. doi:10.1016/j.stam.2004.11.014.

[40] V.K. Patel, S.D. Bhole, D.L. Chen, Characterization of ultrasonic spot welded joints of Mg-to-galvanized and ungalvanized steel with a tin interlayer, J. Mater. Process. Technol. 214 (2014) 811-817. doi:10.1016/j.jmatprotec.2013.11.028.

[41] V.K. Patel, S.D. Bhole, D.L. Chen, Microstructure and mechanical properties of dissimilar welded $\mathrm{Mg}-\mathrm{Al}$ joints by ultrasonic spot welding technique, Sci. Technol. 
Weld. Join. 17 (2012) 202-206. doi:10.1179/1362171811Y.0000000094.

[42] B.S. Naik, D.L. Chen, X. Cao, P. Wanjara, Microstructure and fatigue properties of a friction stir lap welded magnesium alloy, Metall. Mater. Trans. A Phys. Metall. Mater. Sci. 44 (2013) 3732-3746. doi:10.1007/s11661-013-1728-5.

[43] P.B. Prangnell, D. Bakavos, Novel approaches to friction spot welding thin aluminium automotive sheet, in: THERMEC 2009, Trans Tech Publications, 2010: pp. 1237-1242. doi:10.4028/www.scientific.net/MSF.638-642.1237.

[44] A. Macwan, D.L. Chen, Ultrasonic spot welding of a rare-earth containing ZEK100 magnesium alloy: Effect of welding energy, Metall. Mater. Trans. A. 47 (2016) 16861697. doi:10.1007/s11661-016-3355-4.

[45] D. Bakavos, P.B. Prangnell, Mechanisms of joint and microstructure formation in high power ultrasonic spot welding 6111 aluminium automotive sheet, Mater. Sci. Eng. A. 527 (2010) 6320-6334. doi:10.1016/j.msea.2010.06.038.

[46] P. Prangnell, F. Haddadi, Y.C. Chen, Ultrasonic spot welding of aluminium to steel for automotive applications - microstructure and optimisation, Mater. Sci. Technol. 27 (2011) 617-624. doi:10.1179/026708310X520484.

[47] V.K. Patel, S.D. Bhole, D.L. Chen, Improving weld strength of magnesium to aluminium dissimilar joints via tin interlayer during ultrasonic spot welding, Sci. Technol. Weld. Join. 17 (2012) 342-347. doi:10.1179/1362171812Y.0000000013.

[48] V.K. Patel, S.D. Bhole, D.L. Chen, Friction stir spot and ultrasonic spot welding of dissimilar magnesium-to-aluminum alloys, in: Proc. 24th CANCAM, Saskatoon, Saskatchewan, Canada, 2013: pp. 6-9.

[49] A. Macwan, V.K. Patel, X.Q. Jiang, C. Li, S.D. Bhole, D.L. Chen, Ultrasonic spot 
welding of Al/Mg/Al tri-layered clad sheets, Mater. Des. 62 (2014) 344-351.

[50] M.P. Matheny, K.F. Graff, Power Ultrasonics, Elsevier, 2015. doi:10.1016/B978-178242-028-6.00011-9.

[51] V.K. Patel, S.D. Bhole, D.L. Chen, Influence of ultrasonic spot welding on microstructure in a magnesium alloy, Scr. Mater. 65 (2011) 911-914. doi:10.1016/j.scriptamat.2011.08.009.

[52] A. Panteli, J.D. Robson, I. Brough, P.B. Prangnell, The effect of high strain rate deformation on intermetallic reaction during ultrasonic welding aluminium to magnesium, Mater. Sci. Eng. A. 556 (2012) 31-42. doi:10.1016/j.msea.2012.06.055.

[53] A. Panteli, Y.C. Chen, D. Strong, X. Zhang, P.B. Prangnell, Optimization of aluminium-to-magnesium ultrasonic spot welding, Jom. 64 (2012) 414-420. doi:10.1007/s11837-012-0268-6.

[54] E. de Vries, Mechanics and mechanisms of ultrasonic metal welding, The Ohio State University, 2004.

[55] K. Graff, A History of Ultrasonics, 1982. doi:10.1109/FREQ.2004.1418421.

[56] N. Ahmed, New developments in advanced welding, CRC Press, 2005. https://books.google.ca/books?id=phXpCVWLqZsC.

[57] E. Hetrick, R. Jahn, L. Reatherford, S. Ward, D. Wilkosz, J. Skogsmo, et al., Ultrasonic spot welding: A new tool for aluminum joining, Weld. J. (Miami, Fla). 84 (2005) 2630. http://www.scopus.com/inward/record.url?eid=2-s2.013444263898\&partnerID=40\&md5=817f96e50b589d64792e6f832fc2fdf6.

[58] Z.S. Al-Sarraf, A study of ultrasonic metal welding, University of Glasgow, 2013.

[59] S. Lin, Study on the multifrequency Langevin ultrasonic transducer, Ultrasonics. 33 
(1995) 445-448. doi:10.1016/0041-624X(95)00051-4.

[60] M. Bloss, K. Graff, Ultrasonic metal welding of advanced alloys: the weldability of stainless steel, titanium, and nickel-based superalloys, Proc. 8th Int. Conf. Trends Weld. Res. (2009) 348-353. doi:10.1361/cp2008twr348.

[61] M. Matheny, Ultrasonic metal welding foils to tabs for lithium-ion battery cells, Batter. Power Prod. Technol. Mag. 16 (2012) 1-15.

[62] S. Matsuoka, H. Imai, Direct welding of different metals used ultrasonic vibration, J. Mater. Process. Technol. 209 (2009) 954-960. doi:10.1016/j.jmatprotec.2008.03.006.

[63] L.P. Connor, R.L. O’Brien, A.W. Society, Welding Handbook: Welding processes, American Welding Society, 1991. https://books.google.ca/books?id=YOhGAQAAIAAJ.

[64] X.D. Cheng, X.C. Li, Investigation of heat generation in ultrasonic metal welding using micro sensor arrays, J. Micromechanics Microengineering. 17 (2007) 273-282. doi:10.1088/0960-1317/17/2/013.

[65] A Primer - Ultrasonic Metal Welding, West Chester, PA 19380, n.d.

[66] R. Jahn, R. Cooper, D. Wilkosz, The effect of anvil geometry and welding energy on microstructures in ultrasonic spot welds of AA6111-T4, Metall. Mater. Trans. A Phys. Metall. Mater. Sci. 38 (2007) 570-583. doi:10.1007/s11661-006-9087-0.

[67] J. Peng, S. Fukumoto, L. Brown, N. Zhou, Image analysis of electrode degradation in resistance spot welding of aluminium, Sci. Technol. Weld. Join. 9 (2004) 331-336. doi:10.1179/136217104225012256.

[68] S.D. Meshram, G. Madhusudhan Reddy, Friction welding of AA6061 to AISI 4340 using silver interlayer, Def. Technol. 11 (2015) 292-298. doi:10.1016/j.dt.2015.05.007. 
[69] L. Xu, L. Wang, Y.-C. Chen, J.D. Robson, P.B. Prangnell, Effect of interfacial reaction on the mechanical performance of steel to aluminum dissimilar ultrasonic spot welds, Metall. Mater. Trans. A. 47 (2015) 334-346. doi:10.1007/s11661-015-3179-7.

[70] H.P.C. Daniels, Ultrasonic welding, Ultrasonics. 3 (1965) 190-196. doi:10.1016/0041$624 X(65) 90169-1$.

[71] G. Harman, J. Albers, The ultrasonic welding mechanism as applied to aluminum-and gold-wire bonding in microelectronics, IEEE Trans. Parts, Hybrids, Packag. 13 (1977) 406-412. doi:10.1109/TPHP.1977.1135225.

[72] I. Lum, J.P. Jung, Y. Zhou, Bonding mechanism in ultrasonic gold ball bonds on copper substrate, Metall. Mater. Trans. A. 36 (n.d.) 1279-1286. doi:10.1007/s11661005-0220-2.

[73] J.E. Krzanowski, A transmission electron microscopy study of ultrasonic wire bonding, Proceedings., 39th Electron. Components Conf. 13 (1989) 176-181. doi:10.1109/ECC.1989.77788.

[74] Y.R. Jeng, J.H. Horng, A microcontact approach for ultrasonic wire bonding in microelectronics, J. Tribol. 123 (2001) 725. doi:10.1115/1.1352744.

[75] Y. Gao, C. Doumanidis, Mechanical analysis of ultrasonic bonding for rapid prototyping, J. Manuf. Sci. Eng. Asme. 124 (2002) 426-434. doi:10.1115/1.1459082.

[76] C.Y. Kong, R.C. Soar, P.M. Dickens, Characterisation of aluminium alloy 6061 for the ultrasonic consolidation process, Mater. Sci. Eng. A. 363 (2003) 99-106. doi:10.1016/S0921-5093(03)00590-2.

[77] G.D. Janaki Ram, Y. Yang, B.E. Stucker, Effect of process parameters on bond formation during ultrasonic consolidation of aluminum alloy 3003, J. Manuf. Syst. 25 
(2006) 221-238. doi:10.1016/S0278-6125(07)80011-2.

[78] Y. Yang, G.D.J. Ram, B.E. Stucker, An analytical energy model for metal foil deposition in ultrasonic consolidation, Rapid Prototyp. J. 16 (2010) 20-28. doi:10.1108/13552541011011668.

[79] A. Macwan, D.L. Chen, Similar and Dissimilar Ultrasonic Spot Welding of A RareEarth Containing ZEK100 Magnesium Alloy, in: A. Singh, M. Solanki, V. Manuel, N.R. Neelameggham (Eds.), Magnes. Technol. 2016, John Wiley \& Sons, Inc., 2016: pp. 109-113. doi:10.1002/9781119274803.ch23.

[80] V.K. Patel, S.D. Bhole, D.L. Chen, Influence of ultrasonic spot welding on microstructure in a magnesium alloy, Scr. Mater. 65 (2011) 911-914. doi:10.1016/j.scriptamat.2011.08.009.

[81] V.K. Patel, S.D. Bhole, D.L. Chen, Fatigue life estimation of ultrasonic spot welded Mg alloy joints, Mater. Des. 62 (2014) 124-132. doi:10.1016/j.matdes.2014.05.008.

[82] V.K. Patel, S.D. Bhole, D.L. Chen, Ultrasonic spot welded AZ31 magnesium alloy: Microstructure, texture, and lap shear strength, Mater. Sci. Eng. A. 569 (2013) 78-85. doi:10.1016/j.msea.2013.01.042.

[83] S.M. Allameh, C. Mercer, D. Popoola, W.O. Soboyejo, Microstructural characterization of ultrasonically welded aluminum, J. Eng. Mater. Technol. 127 (2005) 65. doi:10.1115/1.1836792.

[84] C.I. Chang, C.J. Lee, J.C. Huang, Relationship between grain size and Zener-Holloman parameter during friction stir processing in AZ31 Mg alloys, Scr. Mater. 51 (2004) 509-514. doi:10.1016/j.scriptamat.2004.05.043.

[85] C. Zener, H.J. H, Effect of strain rate upon plastic flow of steel, J. Appl. Phys. 15 
(1944) 22.

[86] Z. Yu, H. Choo, Z. Feng, S.C. Vogel, Influence of thermo-mechanical parameters on texture and tensile behavior of friction stir processed Mg alloy, Scr. Mater. 63 (2010) 1112-1115. doi:10.1016/j.scriptamat.2010.08.016.

[87] P.J. Bates, J. MacDonald, V. Sidiropoulos, M. Kontopoulou, Comparison of experimental and analytical vibration welding meltdown-time profiles for nylon 66 and polypropylene, Polym. Eng. Sci. 45 (2005) 789-797. doi:10.1002/pen.20333.

[88] C.J. Nonhof, G. a Luiten, Estimates for process conditions during the ultrasonic welding of thermoplastics, Polym. Eng. Sci. 36 (1996) 1177-1183. doi:Doi 10.1002/Pen.10511.

[89] R. V. Barsukov, S. V. Levin, I.I. Savin, The method of indirect determination of oscillations amplitude of high-power ultrasonic transducers, Int. Work. Tutorials Electron Devices Mater. EDM - Proc. 2 (2002) 39-41. doi:10.1109/SREDM.2002.1024382.

[90] R.I. Rodriguez, J.B. Jordon, H.M. Rao, H. Badarinarayan, W. Yuan, H. El Kadiri, et al., Microstructure, texture, and mechanical properties of friction stir spot welded rareearth containing ZEK100 magnesium alloy sheets, Mater. Sci. Eng. A. 618 (2014) $637-$ 644. doi:10.1016/j.msea.2014.09.010.

[91] M. Harooni, B. Carlson, R. Kovacevic, D. Street, Effect of process parameters on the weld quality in laser welding of AZ31B magnesium alloy in lap joint configuration, (2012) 509-519.

[92] P. Liu, Y. Li, H. Geng, J. Wang, Microstructure characteristics in TIG welded joint of $\mathrm{Mg} / \mathrm{Al}$ dissimilar materials, Mater. Lett. 61 (2007) 1288-1291. 
doi:10.1016/j.matlet.2006.07.010.

[93] J.L. Murray, The Al-Mg (Aluminum-Magnesium) system, Bull. Alloy Phase Diagrams. 3 (n.d.) 60-74. doi:10.1007/BF02873413.

[94] E. Hajjari, M. Divandari, S.H. Razavi, S.M. Emami, T. Homma, S. Kamado, Dissimilar joining of $\mathrm{Al} / \mathrm{Mg}$ light metals by compound casting process, J. Mater. Sci. 46 (2011) 6491-6499. doi:10.1007/s10853-011-5595-4.

[95] L. Liu, D. Ren, F. Liu, A review of dissimilar welding techniques for magnesium alloys to aluminum alloys, Materials (Basel). 7 (2014) 3735-3757. doi:10.3390/ma7053735.

[96] J. Robson, A. Panteli, P.B. Prangnell, Modelling intermetallic phase formation in dissimilar metal ultrasonic welding of aluminium and magnesium alloys, Sci. Technol. Weld. Join. 17 (2012) 447-453. doi:10.1179/1362171812Y.0000000032.

[97] H. Das, S.S. Jana, T.K. Pal, A. De, Numerical and experimental investigation on friction stir lap welding of aluminium to steel, Sci. Technol. Weld. Join. 19 (2014) 6975. doi:10.1179/1362171813Y.0000000166.

[98] R. Rana, C. Lahaye, R.K. Ray, Overview of lightweight ferrous materials: strategies and promises, JOM. 66 (2014) 1734-1746. doi:10.1007/s11837-014-1126-5.

[99] A.C. Lilly, S.C. Deevi, Z.P. Gibbs, Electrical properties of iron aluminides, Mater. Sci. Eng. A. 258 (1998) 42-49. doi:10.1016/S0921-5093(98)00915-0.

[100] F. Haddadi, Joint performance and interface reactions in dissimilar aluminium to steel ultrasonic spot welding, The University of Manchester, 2012.

[101] F. Haddadi, F. Abu-Farha, Microstructural and mechanical performance of aluminium to steel high power ultrasonic spot welding, J. Mater. Process. Technol. 225 (2015) 
262-274. doi:10.1016/j.jmatprotec.2015.06.019.

[102] S. Chen, J. Huang, K. Ma, H. Zhang, X. Zhao, Influence of a Ni-foil interlayer on Fe/Al dissimilar joint by laser penetration welding, Mater. Lett. 79 (2012) 296-299. doi:10.1016/j.matlet.2012.03.073.

[103] P. Xue, B.L. Xiao, Z.Y. Ma, Effect of interfacial microstructure evolution on mechanical properties and fracture behavior of friction stir-welded Al-Cu joints, Metall. Mater. Trans. A. 46 (2015) 3091-3103. doi:10.1007/s11661-015-2909-1.

[104] C. Maldonado, A. Medina-Flores, L. Béjar, I. Mejía, T.H. North, Nanoparticle and intermetallic formation in dissimilar friction welds produced with silver interlayers, Microsc. Microanal. null (2004) 568-569. doi:10.1017/S1431927604884253.

[105] K. Ueda, T. Ogura, S. Nishiuchi, K. Miyamoto, T. Nanbu, A. Hirose, Effects of Znbased alloys coating on mechanical properties and interfacial microstructures of steel/aluminum alloy dissimilar metals joints using resistance spot welding, Mater. Trans. 52 (2011) 967-973. doi:10.2320/matertrans.L-MZ201108.

[106] Y.C. Chen, T. Komazaki, Y.G. Kim, T. Tsumura, K. Nakata, Interface microstructure study of friction stir lap joint of AC4C cast aluminum alloy and zinc-coated steel, Mater. Chem. Phys. 111 (2008) 375-380. doi:10.1016/j.matchemphys.2008.04.038.

[107] Y.C. Chen, D. Bakavos, A. Gholinia, P.B. Prangnell, HAZ development and accelerated post-weld natural ageing in ultrasonic spot welding aluminium 6111-T4 automotive sheet, Acta Mater. 60 (2012) 2816-2828. doi:10.1016/j.actamat.2012.01.047.

[108] H. Kasai, Y. Morisada, H. Fujii, Dissimilar FSW of immiscible materials: Steel/magnesium, Mater. Sci. Eng. A. 624 (2015) 250-255. 
doi:10.1016/j.msea.2014.11.060.

[109] W.M. Elthalabawy, T.I. Khan, Eutectic bonding of austenitic stainless steel 316L to magnesium alloy AZ31 using copper interlayer, Int. J. Adv. Manuf. Technol. 55 (2011) 235-241. doi:10.1007/s00170-010-3026-3.

[110] X.J. Yuan, G.M. Sheng, J. Luo, J. Li, Microstructural characteristics of joint region during diffusion-brazing of magnesium alloy and stainless steel using pure copper interlayer, Trans. Nonferrous Met. Soc. China (English Ed. 23 (2013) 599-604. doi:10.1016/S1003-6326(13)62505-4.

[111] D. Ren, L. Liu, Interface microstructure and mechanical properties of arc spot welding Mg-steel dissimilar joint with Cu interlayer, Mater. Des. 59 (2014) 369-376. doi:10.1016/j.matdes.2014.03.006.

[112] J. Zhang, Q. Shen, G. Luo, Y. Wang, M. Li, L. Zhang, Microstructural characterization of the $\mathrm{Mg} / \mathrm{Cu} / \mathrm{Al}$ diffusion bonded joint, J. Phys. Conf. Ser. 419 (2013) 12021. http://stacks.iop.org/1742-6596/419/i=1/a=012021.

[113] L.F. Hu, F.M. Wang, S.P. Chen, Q. Sen Meng, Effect of current on the interfacial structures of the dissimilar metals diffusion bonding, in: Mater. Process. Technol. ICAMMP2011, Trans Tech Publications, 2012: pp. 1423-1427. doi:10.4028/www.scientific.net/AMR.418-420.1423.

[114] G. Mahendran, V. Balasubramanian, T. Senthilvelan, Influences of diffusion bonding process parameters on bond characteristics of $\mathrm{Mg}$-Cu dissimilar joints, Trans.

Nonferrous Met. Soc. China. 20 (2010) 997-1005. doi:10.1016/S1003-6326(09)60248$\mathrm{X}$.

[115] L. Liming, W. Shengxi, Z. Limin, Study on the dissimilar magnesium alloy and copper 
lap joint by TIG welding, Mater. Sci. Eng. A. 476 (2008) 206-209.

doi:10.1016/j.msea.2007.04.089.

[116] R. Balasundaram, V.K. Patel, S.D. Bhole, D.L. Chen, Effect of zinc interlayer on ultrasonic spot welded aluminum-to-copper joints, Mater. Sci. Eng. A. 607 (2014) 277286. doi:10.1016/j.msea.2014.03.135.

[117] A. Macwan, D.L. Chen, Ultrasonic spot welding of rare-earth containing ZEK100 magnesium alloy to 5754 aluminum alloy, Mater. Sci. Eng. A. 666 (2016) 139-148. doi:10.1016/j.msea.2016.04.060.

[118] C.Y. Zhang, D.L. Chen, A.A. Luo, Joining 5754 automotive aluminum alloy 2-mmthick sheets using ultrasonic spot welding, Weld. J. 93 (2014) 131-138.

[119] C.Q. Zhang, J.D. Robson, O. Ciuca, P.B. Prangnell, Microstructural characterization and mechanical properties of high power ultrasonic spot welded aluminum alloy AA6111-TiAl6V4 dissimilar joints, Mater. Charact. 97 (2014) 83-91. doi:10.1016/j.matchar.2014.09.001.

[120] Y. Bin He, Q.L. Pan, Q. Chen, Z.Y. Zhang, X.Y. Liu, W. Bin Li, Modeling of strain hardening and dynamic recrystallization of ZK60 magnesium alloy during hot deformation, Trans. Nonferrous Met. Soc. China (English Ed. 22 (2012) 246-254. doi:10.1016/S1003-6326(11)61167-9.

[121] N. Afrin, D.L. Chen, X. Cao, M. Jahazi, Microstructure and tensile properties of friction stir welded AZ31B magnesium alloy, Mater. Sci. Eng. A. 472 (2008) 179-186. doi:10.1016/j.msea.2007.03.018.

[122] M. Fairman, N. Afrin, D.L. Chen, X. Cao, M. Jahazi, Microstructural evaluation of friction stir processed \{AZ31B-H24\} magnesium alloy, Can. Metall. Q. 46 (2007) 425- 
432. doi:10.1179/cmq.2007.46.4.425.

[123] W.D. Callister, D.G. Rethwisch, Materials Science and Engineering: An Introduction, John Wiley \& Sons, Incorporated, 2012. https://books.google.ca/books?id=6cwpkgEACAAJ.

[124] N.F. Kazakov, Diffusion Bonding of Materials, Pergamon Press Canada Ltd., Ontario, 1985. doi:10.1016/B978-0-08-032550-7.50006-0.

[125] J.C. Tan, M.J. Tan, Dynamic continuous recrystallization characteristics in two stage deformation of Mg-3Al-1Zn alloy sheet, Mater. Sci. Eng. A. 339 (2003) 124-132. doi:10.1016/S0921-5093(02)00096-5.

[126] I.E. Gunduz, T. Ando, E. Shattuck, P.Y. Wong, C.C. Doumanidis, Enhanced diffusion and phase transformations during ultrasonic welding of zinc and aluminum, Scr. Mater. 52 (2005) 939-943. doi:10.1016/j.scriptamat.2004.12.015.

[127] M.R. Sriraman, S.S. Babu, M. Short, Bonding characteristics during very high power ultrasonic additive manufacturing of copper, Scr. Mater. 62 (2010) 560-563. doi:10.1016/j.scriptamat.2009.12.040.

[128] U. Andrade, M.A. Meyers, K.S. Vecchio, A.H. Chokshi, Dynamic recrystallization in high-strain, high-strain-rate plastic deformation of copper, Acta Metall. Mater. 42 (1994) 3183-3195. doi:10.1016/0956-7151(94)90417-0.

[129] G.E. Dieter, Mechanical Fundamentals, in: Mech. Metall. - SI Metr. Ed., 1988: pp. 1119.

[130] S.L. Semiatin, J.J. Jonas, Formability and Workability of Metals: Plastic Instability and Flow Localization, American Society for Metals, 1984. https://books.google.ca/books?id=OdJRAAAAMAAJ. 
[131] N. Tateishi, T.H. North, N. tateishi, t. h. north, (n.d.).

[132] P. Pawlow, The dependency of the melting point on the surface energy of a solid body, Z. Phys. Chem. 65 (1909) 545-548.

[133] S. Elangovan, S. Semeer, K. Prakasan, Temperature and stress distribution in ultrasonic metal welding-An FEA-based study, J. Mater. Process. Technol. 209 (2009) 11431150. doi:10.1016/j.jmatprotec.2008.03.032.

[134] H.J. Frost, M.F. Ashby, Deformation-mechanism maps: The plasticity and creep of metals and ceramics, Oxford, Pergamon Press. (1982) 175. doi:10.1016/03783804(84)90015-9.

[135] S.M. Fatemi-Varzaneh, A. Zarei-Hanzaki, H. Beladi, Dynamic recrystallization in AZ31 magnesium alloy, Mater. Sci. Eng. A. 456 (2007) 52-57. doi:10.1016/j.msea.2006.11.095.

[136] M.R. Barnett, Quenched and annealed microstructures of hot worked magnesium AZ31 uniaxial compression ND constraint, Mater. Trans. 44 (2003) 571-577. doi:10.2320/matertrans.44.571.

[137] K. Kubota, M. Mabuchi, K. Higashi, Review Processing and mechanical properties of fine-grained magnesium alloys, J. Mater. Sci. 34 (1999) 2255-2262. doi:10.1023/A:1004561205627.

[138] A.G. Beer, Evolution of hot working stress and microstructure of Mg-3Al-1Zn, Deakin University, 2004.

[139] Z. Yu, H. Choo, Influence of twinning on the grain refinement during high-temperature deformation in a magnesium alloy, Scr. Mater. 64 (2011) 434-437. doi:10.1016/j.scriptamat.2010.11.009. 
[140] B.S. Naik, D.L. Chen, X. Cao, P. Wanjara, Texture development in a friction stir lapwelded AZ31B magnesium alloy, Metall. Mater. Trans. A. 45 (2014) 4333-4349. doi:10.1007/s11661-014-2372-4.

[141] C. Zhang, L. Li, A coupled thermal-mechanical analysis of ultrasonic bonding mechanism, Metall. Mater. Trans. B Process Metall. Mater. Process. Sci. 40 (2009) 196-207. doi:10.1007/s11663-008-9224-9.

[142] D.R. Milner, G.W. Rowe, Fundamentals of solid phase welding, Metall. Rev. 7 (1962) $433-480$.

[143] Y. Chino, K. Sassa, A. Kamiya, M. Mabuchi, Enhanced formability at elevated temperature of a cross-rolled magnesium alloy sheet, Mater. Sci. Eng. A. 441 (2006) 349-356. doi:10.1016/j.msea.2006.08.038.

[144] A.G. Truog, Bond improvement of Al/Cu joints created by very high power ultrasonic additive manufacturing, The Ohio State University, 2012. http://rave.ohiolink.edu/etdc/view?acc_num=osu1337885605.

[145] T.H. Youssef, R.A. Essawi, Effect of working temperature on young's modulus of electrolytic copper, Czechoslov. J. Phys. B. 29 (n.d.) 1266-1270. doi:10.1007/BF01590447.

[146] J. Koike, Y. Sato, D. Ando, Origin of the anomalous $\{1012\}$ twinning during tensile deformation of mg alloy sheet, Mater. Trans. 49 (2008) 2792-2800. doi:10.2320/matertrans.MRA2008283.

[147] D. Sarker, D.L. Chen, Dependence of compressive deformation on pre-strain and loading direction in an extruded magnesium alloy: Texture, twinning and de-twinning, Mater. Sci. Eng. A. 596 (2014) 134-144. doi:10.1016/j.msea.2013.12.038. 
[148] D. Sarker, J. Friedman, D.L. Chen, Twin growth and texture evolution in an extruded AM30 magnesium alloy during compression, J. Mater. Sci. Technol. 30 (2014) 884887. doi:10.1016/j.jmst.2014.06.011.

[149] S.H. Chowdhury, D.L. Chen, S.D. Bhole, X. Cao, P. Wanjara, Lap shear strength and fatigue life of friction stir spot welded AZ31 magnesium and 5754 aluminum alloys, Mater. Sci. Eng. A. 556 (2012) 500-509. doi:10.1016/j.msea.2012.07.019.

[150] S.H. Chowdhury, D.L. Chen, S.D. Bhole, X. Cao, P. Wanjara, Lap shear strength and fatigue behavior of friction stir spot welded dissimilar magnesium-to-aluminum joints with adhesive, Mater. Sci. Eng. A. 562 (2013) 53-60. doi:10.1016/j.msea.2012.11.039.

[151] M. Boba, M.J. Worswick, R. Mishra, J. Carter, Formability of AZ31B and ZEK100 magnesium alloy sheets at elevated temperatures, Mg2012 9th Int. Conf. Magnes. Alloy. Their Appl. (2012) 397-402.

[152] F. Hayat, The effects of the welding current on heat input, nugget geometry, and the mechanical and fractural properties of resistance spot welding on $\mathrm{Mg} / \mathrm{Al}$ dissimilar materials, Mater. Des. 32 (2011) 2476-2484. doi:10.1016/j.matdes.2010.11.015.

[153] Y.S. Sato, A. Shiota, H. Kokawa, K. Okamoto, Q. Yang, C. Kim, Effect of interfacial microstructure on lap shear strength of friction stir spot weld of aluminium alloy to magnesium alloy, Sci. Technol. Weld. Join. 15 (2010) 319-324. doi:10.1179/136217109X12568132624208.

[154] D.H. Choi, B.W. Ahn, C.Y. Lee, Y.M. Yeon, K. Song, S.B. Jung, Formation of intermetallic compounds in $\mathrm{Al}$ and $\mathrm{Mg}$ alloy interface during friction stir spot welding, Intermetallics. 19 (2011) 125-130. doi:10.1016/j.intermet.2010.08.030.

[155] X.J. Wang, T.K. Guo, Z.K. Zhang, P.C. Wang, J.P. Shi, Y.L. Wu, et al., Dissimilar 
friction stir spot welding without key hole between AZ31B magnesium alloy and 5052 aluminum alloy, in: Adv. Mater. Mater. Process., Trans Tech Publications, 2013: pp. 2320-2325. doi:10.4028/www.scientific.net/AMR.652-654.2320.

[156] H.M. Rao, W. Yuan, H. Badarinarayan, Effect of process parameters on mechanical properties of friction stir spot welded magnesium to aluminum alloys, Mater. Des. 66 (2015) 235-245. doi:10.1016/j.matdes.2014.10.065.

[157] C. Ma, D.L. Chen, S.D. Bhole, G. Boudreau, A. Lee, E. Biro, Microstructure and fracture characteristics of spot-welded DP600 steel, Mater. Sci. Eng. A. 485 (2008) 334-346. doi:10.1016/j.msea.2007.08.010.

[158] W. Xu, L. Liu, Y. Zhou, H. Mori, D.L. Chen, Tensile and fatigue properties of weldbonded and adhesive-bonded magnesium alloy joints, Mater. Sci. Eng. A. 563 (2013) 125-132. doi:10.1016/j.msea.2012.11.049.

[159] J. Roesler, H. Harders, M. Baeker, Mechanical Behaviour of Engineering Materials: Metals, Ceramics, Polymers, and Composites, Springer Berlin Heidelberg, 2007. https://books.google.ca/books?id=37o0MAEACAAJ.

[160] J.L. Murray, The Al-Zn (Aluminum-Zinc) system, Bull. Alloy Phase Diagrams. 4 (n.d.) 55-73. doi:10.1007/BF02880321.

[161] F. Haddadi, Rapid intermetallic growth under high strain rate deformation during high power ultrasonic spot welding of aluminium to steel, Mater. Des. 66 (2015) 459-472. doi:10.1016/j.matdes.2014.07.001.

[162] J.E. Hilliard, B.L. Averbach, M. Cohen, Self and interdiffusion in aluminum-zinc alloys, Acta Metall. 7 (1959) 86-92. doi:10.1016/0001-6160(59)90113-0.

[163] J.S. Dohie, J.R. Cahoon, W.F. Caley, The grain-boundary diffusion of Zn in $\alpha-F e$, J. 
Phase Equilibria Diffus. 28 (2007) 322-327. doi:10.1007/s11669-007-9093-y.

[164] E. Fereiduni, M. Movahedi, A.H. Kokabi, Aluminum/steel joints made by an alternative friction stir spot welding process, J. Mater. Process. Technol. 224 (2015) 110. doi:10.1016/j.jmatprotec.2015.04.028.

[165] J.M. Piccini, H.G. Svoboda, Effect of pin length on Friction Stir Spot Welding (FSSW) of dissimilar Aluminum-steel joints, Procedia Mater. Sci. 9 (2015) 504-513. doi:10.1016/j.mspro.2015.05.023.

[166] W. Zhang, D. Sun, L. Han, Y. Li, Optimised design of electrode morphology for novel dissimilar resistance spot welding of aluminium alloy and galvanised high strength steel, Mater. Des. 85 (2015) 461-470. doi:10.1016/j.matdes.2015.07.025.

[167] G. Figner, R. Vallant, T. Weinberger, H. Schrottner, H. Pasic, N. Enzinger, Friction stir spot welds between aluminium and steel automotive sheets: influence of welding parameters on mechanical properties and microstructure, Weld. World. 53 (2009) R13R23. doi:10.1016/j.msea.2008.05.025.

[168] P. Xue, B.L. Xiao, D.R. Ni, Z.Y. Ma, Enhanced mechanical properties of friction stir welded dissimilar Al-Cu joint by intermetallic compounds, Mater. Sci. Eng. A. 527 (2010) 5723-5727. doi:10.1016/j.msea.2010.05.061.

[169] F.C. Campbell, Elements of Metallurgy and Engineering Alloys, ASM International, 2008. https://books.google.ca/books?id=6VdROgeQ5M8C.

[170] W. Xu, D. Westerbaan, S.S. Nayak, D.L. Chen, F. Goodwin, E. Biro, et al., Microstructure and fatigue performance of single and multiple linear fiber laser welded DP980 dual-phase steel, Mater. Sci. Eng. A. 553 (2012) 51-58. doi:10.1016/j.msea.2012.05.091. 
[171] T.J. Franklin, J. Pan, M. Santella, T.-Y. Pan, Fatigue behavior of dissimilar ultrasonic spot welds in lap-shear specimens of magnesium and steel sheets, SAE Int. J. Mater. Manuf. 4 (2011) 581-588.

[172] J.F. Cooper, R.A. Smith, The measurement of fatigue cracks at spot-welds, Int. J. Fatigue. 7 (1985) 137-140. doi:http://dx.doi.org/10.1016/0142-1123(85)90023-4.

[173] G.E. Totten, Fatigue Crack Propagation, Adv. Mater. Process. 166 (2008) 39-41.

[174] M. Militzer, W.P. Sun, J.J. Jonas, Modelling the effect of deformation-induced vacancies on segregation and precipitation, Acta Metall. Mater. 42 (1994) 133-141. doi:10.1016/0956-7151(94)90056-6.

[175] M.J. Zehetbauer, G. Steiner, E. Schafler, A. V. Korznikov, E. Korznikova, Deformation induced vacancies with severe plastic deformation: measurements and modelling, Mater. Sci. Forum. 503-504 (2006) 57-64. doi:10.4028/www.scientific.net/MSF.503-504.57.

[176] K.L. Murty, K. Detemple, O. Kanert, J.T.M. Dehosson, In-situ nuclear magnetic resonance investigation of strain, temperature, and strain-rate variations of deformation-induced vacancy concentration in aluminum, Metall. Mater. Trans. A. 29 (n.d.) 153-159. doi:10.1007/s11661-998-0168-0.

[177] R.W. Richards, R.D. Jones, P.D. Clements, H. Clarke, Metallurgy of continuous hot dip aluminising, Int. Mater. Rev. 39 (1994) 191-212. doi:http://dx.doi.org/10.1179/imr.1994.39.5.191.

[178] A. Jäger, P. Lukáč, V. Gärtnerová, J. Bohlen, K.U. Kainer, Tensile properties of hot rolled AZ31 Mg alloy sheets at elevated temperatures, J. Alloys Compd. 378 (2004) 184-187. doi:10.1016/j.jallcom.2003.11.173. 
[179] H. Okamoto, Cu-Mg (copper-magnesium), J. Phase Equilibria. 13 (n.d.) 213-214. doi:10.1007/BF02667494.

[180] J.W. Hong, H.S. Kang, W.Y. Yoon, S.M. Lee, Microstructural characterization of droplet emulsified Mg60Cu30Y10 powders, Mater. Sci. Eng. A. 449-451 (2007) 727732. doi:10.1016/j.msea.2006.02.382.

[181] B. Arcot, C. Cabral, J.M.E. Harper, S.P. Murarka, Intermetallic reactions between copper and magnesium as an adhesion / barrier layer, in: Symp. G - Mater. Reliab. Issues Microelectron., 1991: pp. 231-237.

[182] J. Yang, B. Cao, Investigation of resistance heat assisted ultrasonic welding of 6061 aluminum alloys to pure copper, Mater. Des. 74 (2015) 19-24. doi:10.1016/j.matdes.2015.02.028. 